\title{
Basic leucine zipper and W2 domain- containing protein 2 (BZW2): A novel cardiac WNT component
}

\author{
Doctoral Thesis \\ In partial fulfillment of the requirements for the degree \\ "Doctor rerum naturalium (Dr. rer. nat.)" \\ in the Molecular Medicine Study Program \\ at the Georg-August University Göttingen
}

Submitted by
Elena Chebbok

Born in

Moscow, Russia

Göttingen, September 2015 


\title{
Members of the Thesis Committee:
}

Supervisor

\author{
Dr. Laura C Zelarayán \\ Institute of Pharmacology \\ University Medical Center Göttingen \\ Georg-August-University Göttingen
}

Second member of the thesis committee

Prof. Dr. Viacheslav Nikolaev

Department of Cardiology and Pneumology

University Medical Center Göttingen

Georg-August-University Göttingen

Third member of the thesis committee

Prof. Dr. Steven Johnsen

Translational Cancer Research

University Medical Center Göttingen

Georg-August-University Göttingen

Date of Disputation: $\quad 1^{\text {st }}$ December 2015 


\section{AFFIDAVIT}

Here I declare that my doctoral thesis entitled "Basic leucine zipper and W2 domain-containing protein 2 (BZW2): A novel cardiac WNT component" has been written independently with no other sources and aids than quoted.

Elena Chebbok

Göttingen, September 2015 
Posters

- $\quad$ Pavlova E, Noack C, Zafiriou MP, Zimmermann WH \& Zelarayán LC (2014). Molecular characterization of the Basic leucine zipper and W2 domain-containing protein 2 (BZW2): a novel WNT component with a potential role in cardiogenesis and cardiac remodeling. The 80th Annual Meeting of the German Society for Experimental and Clinical Pharmacology and Toxicology (DGPT), Hannover, Germany.

- $\quad$ Pavlova E, Noack C, Zafiriou MP, Zimmermann WH \& Zelarayán LC (2014). Molecular characterization of the Basic leucine zipper and W2 domain-containing protein 2 (BZW2): a novel WNT component with a potential role in cardiogenesis and cardiac remodeling. The 12th Dutch-German Joint Meeting of the Molecular Cardiology Working Groups (DGJM), Groningen, Netherlands.

- $\quad$ Pavlova E, Noack C, Zafiriou MP, Zimmermann WH \& Zelarayán LC (2013). Molecular characterization of the Basic leucine zipper and W2 domain-containing protein 2 (BZW2): a novel WNT component with a potential role in cardiogenesis and cardiac remodeling. 2013 - Herbsttagung und Jahrestagung der Arbeitsgruppe Rhythmologie, Basic-Science-Meeting, Dresden, Germany.

\section{Publications}

- Zafiriou MP, Noack C, Unsöld B, Didie M, Pavlova E, Fischer HJ, Reichardt HM, Bergmann MW, El-Armouche A, Zimmermann WH, Zelarayan LC. Erythropoietin responsive cardiomyogenic cells contribute to heart repair post myocardial infarction. Stem Cells. 2014 Sep;32(9):2480-91. doi: 10.1002/stem.1741.

- $\quad$ Renger A, Zafiriou MP, Noack C, Pavlova E, Becker A, Sharkova K, Bergmann MW, El-Armouche A, Zimmermann WH, Zelarayán LC. The four and a half LIMdomain 2 controls early cardiac cell commitment and expansion via regulating $\beta$ catenin-dependent transcription. Stem Cells. 2013 May;31(5):928-40. doi: 10.1002/stem.1332.

- Noack C, Zafiriou MP, Schaeffer HJ, Renger A, Pavlova E, Dietz R, Zimmermann WH, Bergmann MW, Zelarayán LC. Krueppel-like factor 15 regulates $W n t / \beta$-catenin transcription and controls cardiac progenitor cell fate in the postnatal heart. EMBO Mol Med. 2012 Sep;4(9):992-1007. doi: 10.1002/emmm.201101043. Epub 2012 Jul 5 


\section{Table of Contents}

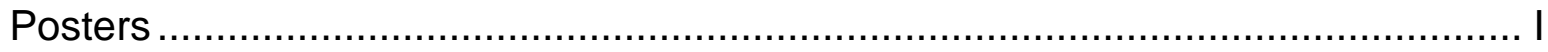

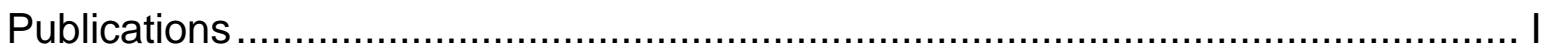

List of Figures ................................................................................................ VI

List of Tables ..................................................................................................... IX

Acknowledgements ........................................................................................ X

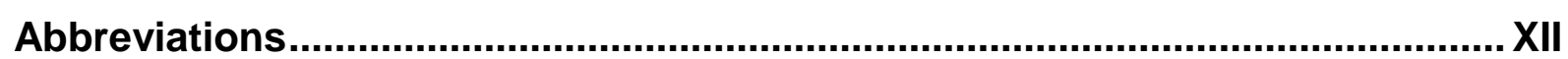

Summary .........................................................................................................XVII

Zusammenfassung .................................................................................. XVIII

1. Introduction .................................................................................................... 1

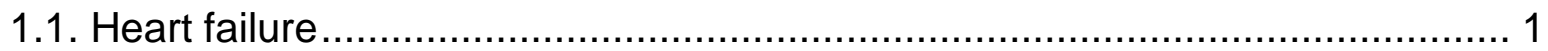

1.1.1. Pathological cardiac remodelling and current therapies ......................... 1

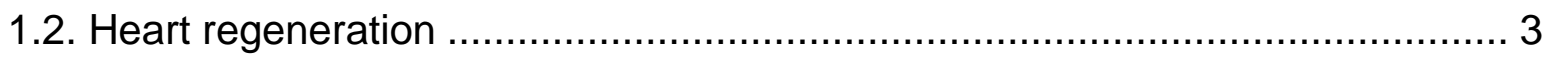

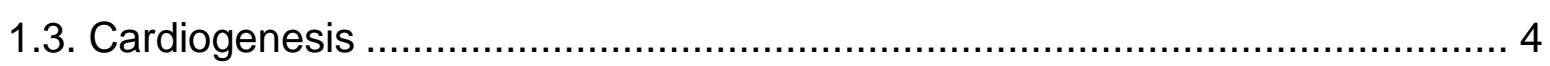

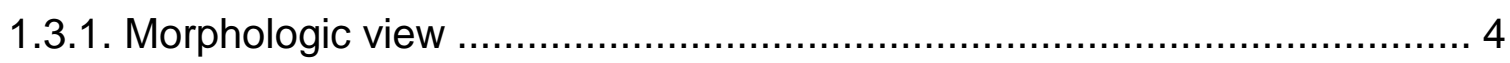

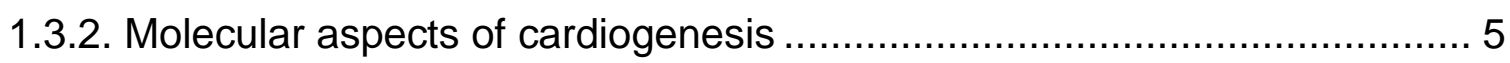

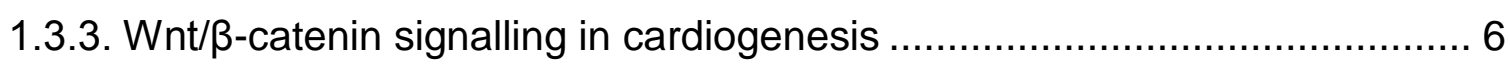

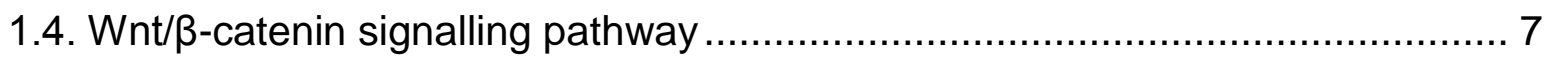

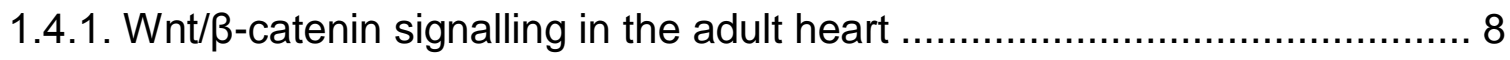

1.4.2. Cardiac specific regulation of the $\mathrm{Wnt} / \beta$-catenin signalling .................... 9

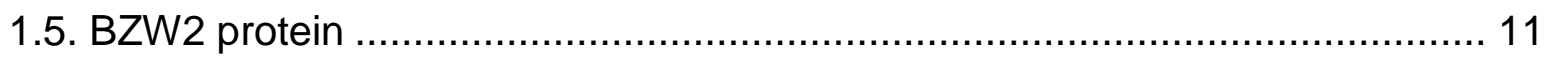

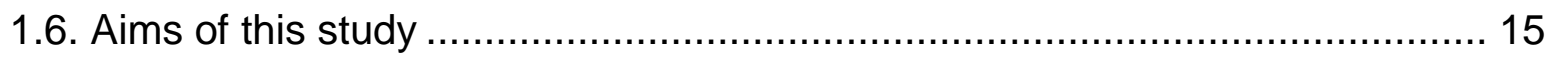

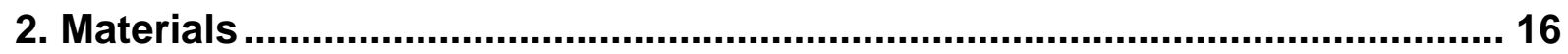

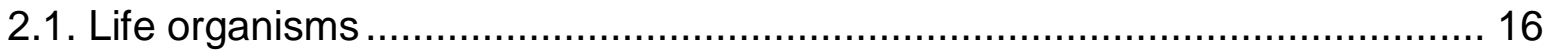

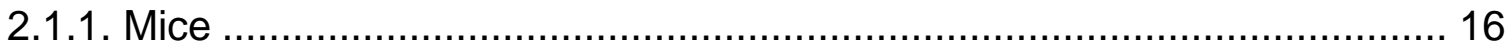

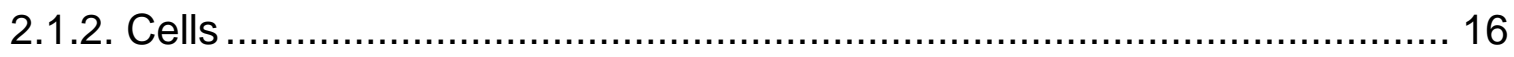

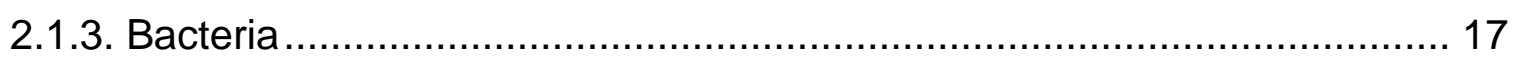

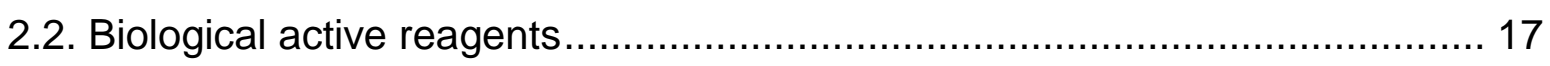

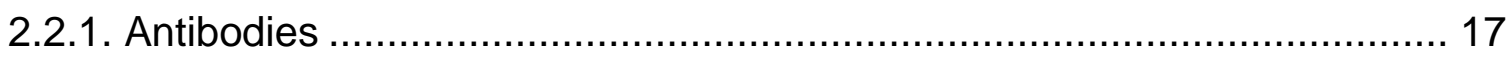


2.2.2. Enzymes and supplemented buffers ............................................... 18

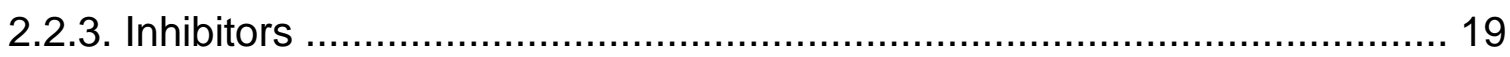

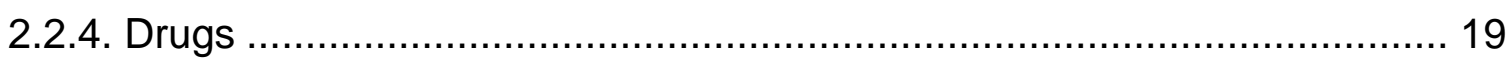

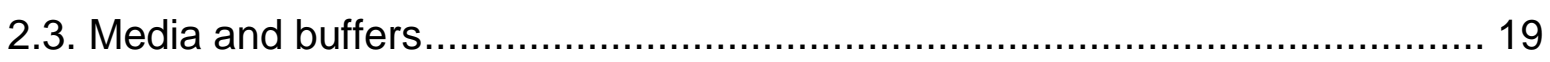

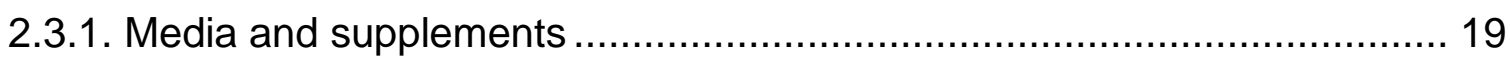

2.3.2. Buffers and compositions ................................................................ 21

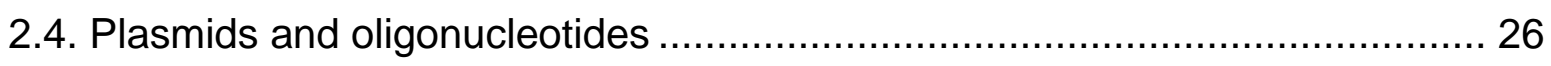

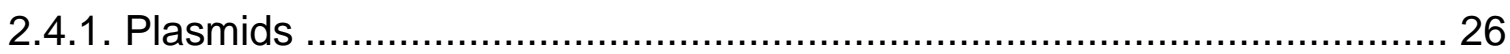

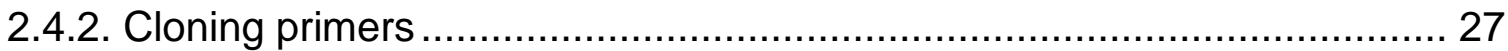

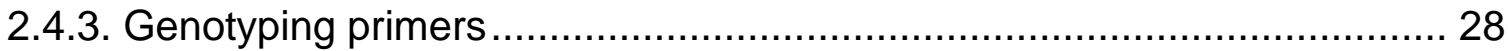

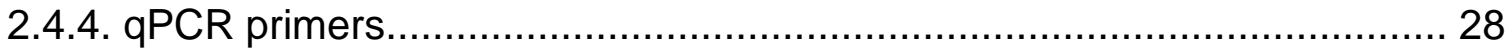

2.5. Other chemicals and consumables …................................................... 30

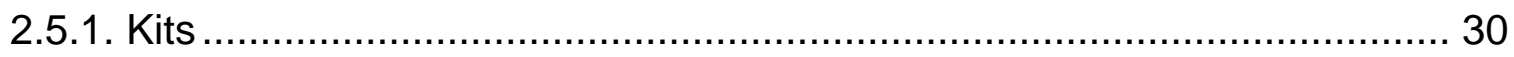

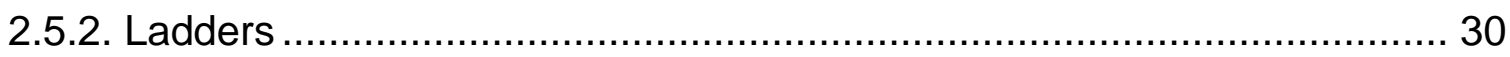

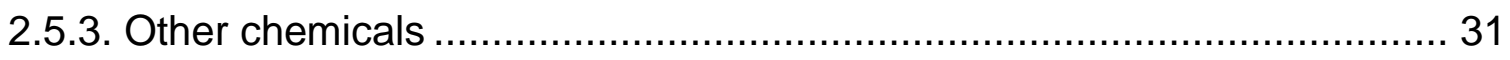

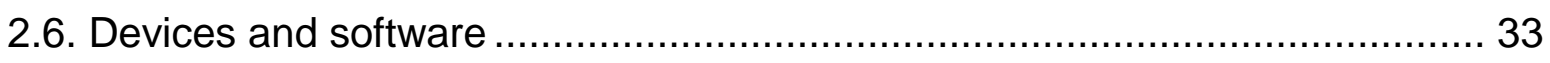

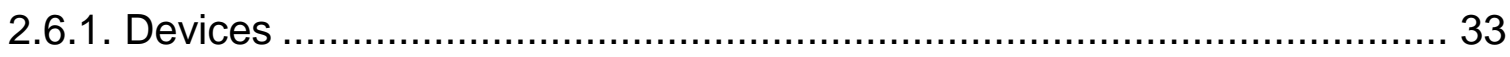

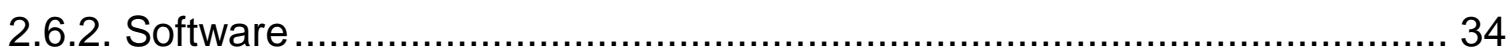

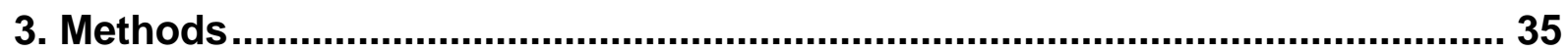

3.1. Molecular biological methods .............................................................. 35

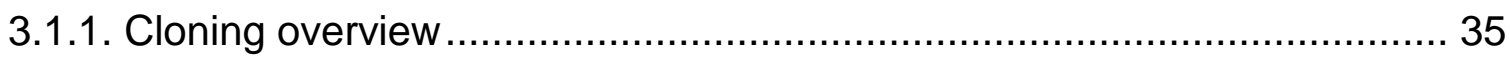

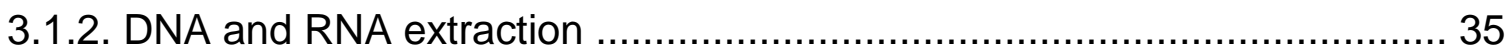

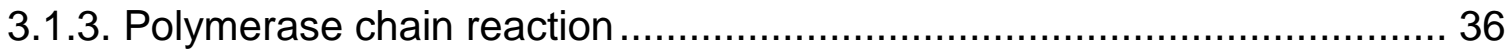

3.1.4. Enzymatic digestion, dephosphorylation and ligation of DNA ................. 36

3.1.5. DNA transformation into Escherichia coli ............................................ 36

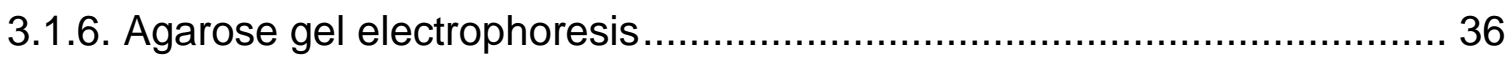

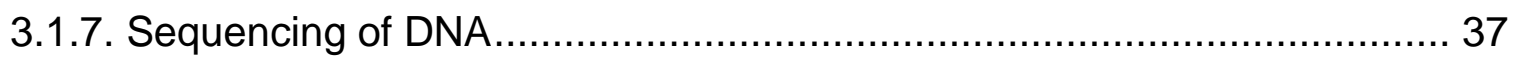

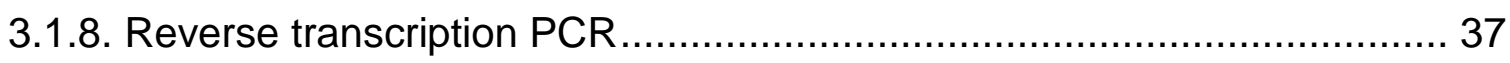




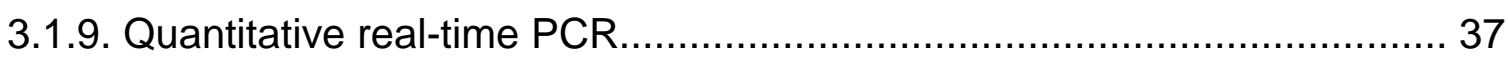

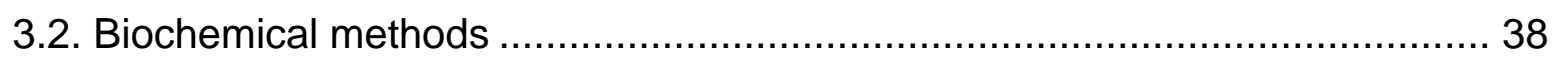

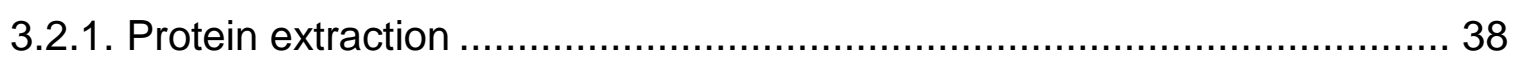

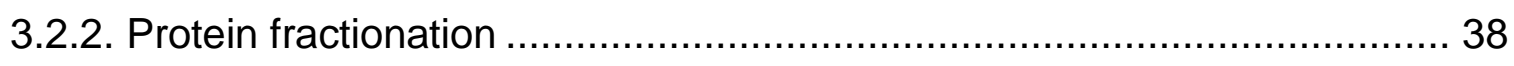

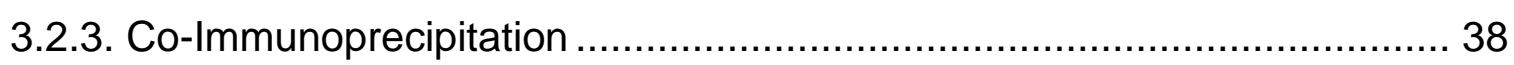

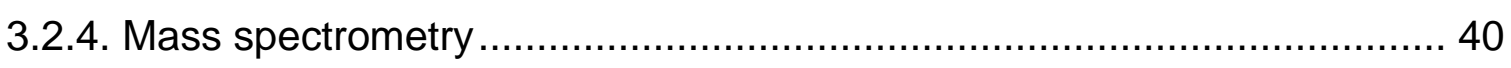

3.2.5. Sodium dodecyl sulfate polyacrylamide gel electrophoresis ................... 40

3.2.6. Western blot assay ............................................................................ 41

3.2.7. Luciferase reporter assay .................................................................. 41

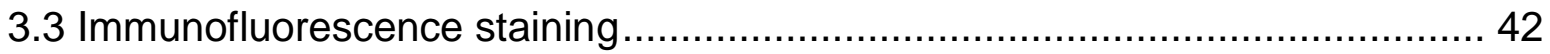

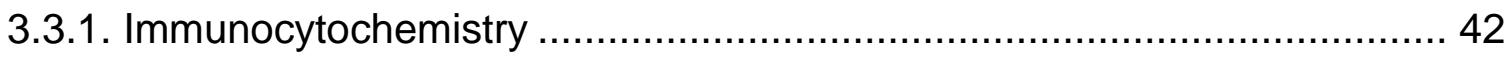

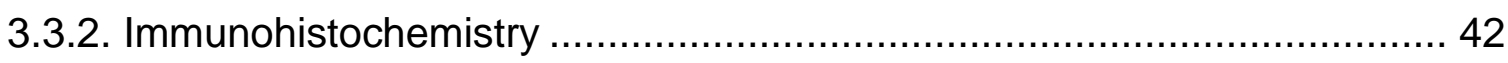

3.4. Cell work

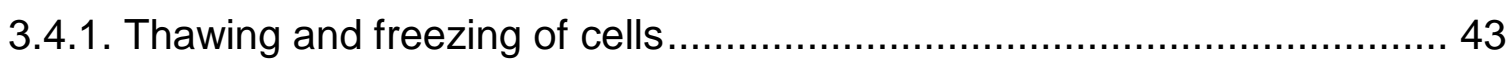

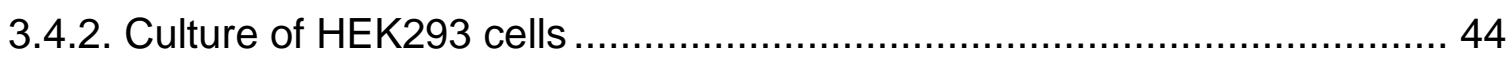

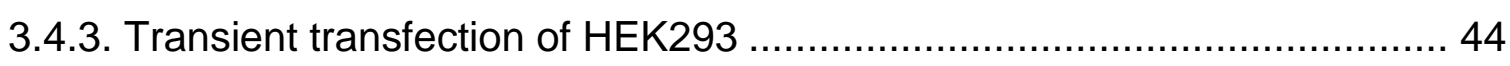

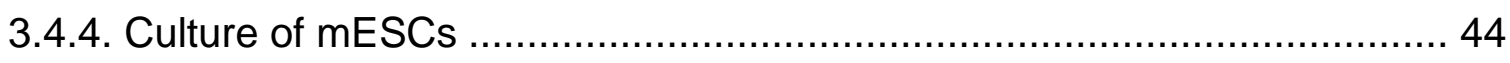

3.4.5. Generation of transgenic mESC line ...................................................... 45

3.4.6. Differentiation of mESCs to cardiomyocytes ......................................... 46

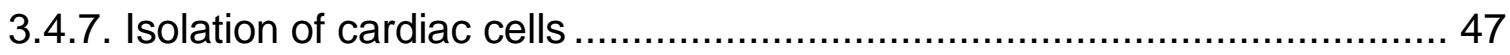

3.5. Mice

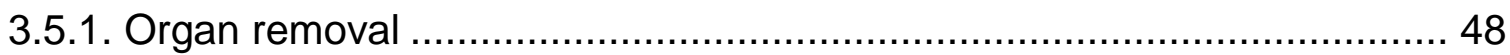

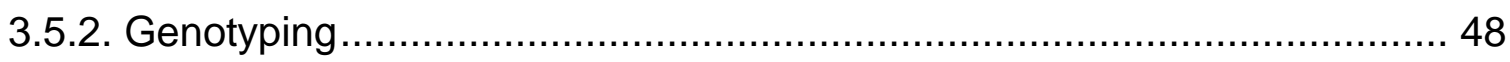

3.5.3. Transverse aortic constriction (TAC) operations .................................... 49

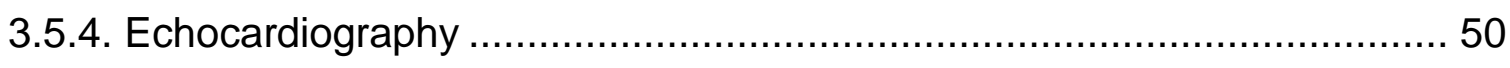

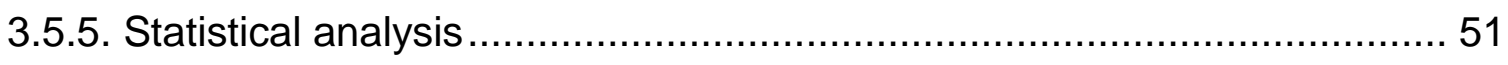

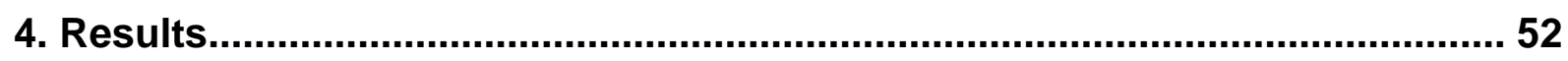

4.1. Molecular characterization of BZW2 ………...................................... 52 
4.1.1. Validation of BZW2 interaction with $\beta$-catenin and KLF15 52

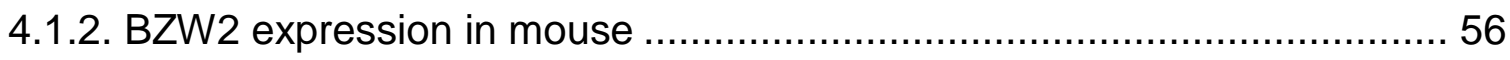

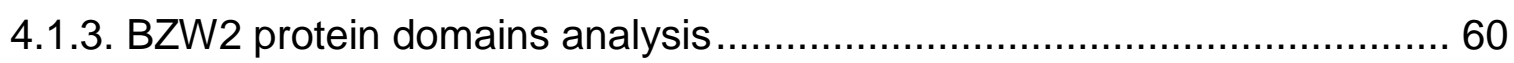

4.2. Investigation of $B Z W 2$ role in the $\mathrm{Wnt} / \mathrm{\beta}$-catenin signaling ............................ 62

4.2.1. BZW2 expression upon upregulation of the $\mathrm{Wnt} / \beta$-catenin signalling in vivo 62

4.2.2. BZW2 role in the $\mathrm{Wnt} / \beta$-catenin signalling as a downstream target gene 64

4.2.3. BZW2 role in the $\mathrm{Wnt} / \beta$-catenin signalling as a co-regulator.................... 65

4.3. Investigation of BZW2 role in the normal heart homeostasis....................... 72

4.4. Investigation of BZW2 role in stress-induced cardiac remodelling ................ 76

4.4.1. BZW2 expression in cardiac disease …………................................ 76

4.4.2. Transverse aortic constriction (TAC) in Bzw2 KI mice ....................... 77

4.5. Investigation of BZW2 role in in vitro cardiogenesis ................................. 80

4.5.1. Generation of BZW2 gain-of-function in murine embryonic stem cells

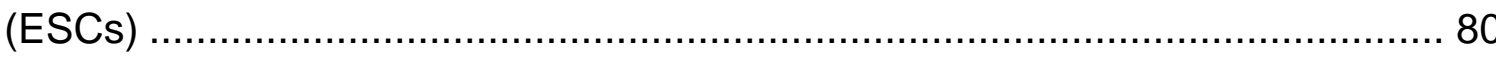

4.5.2. BZW2 role in the ESCs differentiation to cardiomyocytes ....................... 83

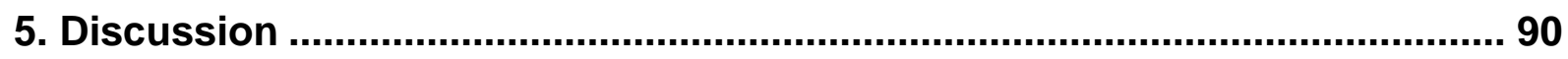

5.1. BZW2 is associated with the $\mathrm{Wnt} / \beta$-catenin signalling components ............... 91

5.2. Different BZW2 protein domains are responsible for a dynamic cellular

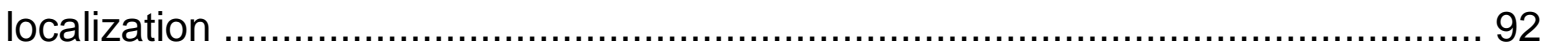

5.3. Bzw2 is highly expressed during cardiogenesis and in the adult heart.......... 92

5.4. BZW2 is a cardiac specific factor of the $W n t / \beta$-catenin signalling ................. 93

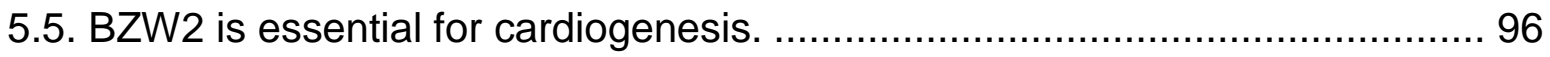

5.6. BZW2 is important for normal homeostasis and stress-induced response in

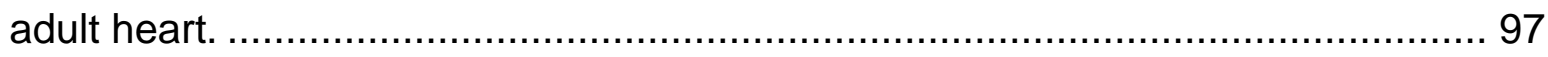

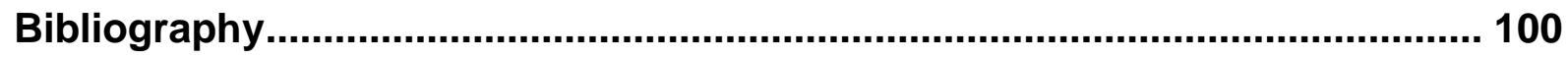

Apendix 


\section{List of Figures}

Figure 1: Four morphological stages of the cardiogenesis in mouse. 5

Figure 2: Schematic representation of time specific regulatory role of the $\mathrm{Wnt} / \beta$ catenin signaling pathway during cardiogenesis.

Figure 3: Schematic view of $\mathrm{Wnt} / \mathrm{\beta}$-catenin signaling. 8

Figure 4: Klf15 KO mice and Klf15 expression in different organs. 10

Figure 5: Alignment of the BZW2 protein in different organisms. 12

Figure 6: Schematic view of human / murine Bzw2 transcript. 13

Figure 7: Amino acid sequence of murine BZW2. 14

Figure 8: The workflow of the differentiation experiments. 47

Figure 9: Transverse aortic constriction (TAC) in mice. 49

Figure 10: Echocardiography analysis 50

Figure 11: Validation of BZW2 interaction with $\beta$-catenin and KLF15. 53

Figure 12: BZW2 interaction with $\beta$-catenin analyzed by mass spectrometry. 53

Figure 13: Co-localization analysis of BZW2 with $\beta$-catenin and KLF15. 54

Figure 14: BZW2 localization in cell compartments. 55

Figure 15: BZW2 protein expression in different murine organs 56

Figure 16: BZW2 expression in selected cardiac cell types. 57

Figure 17: Bzw2 mRNA expression during cardiac development in mice. 58

Figure 18: Bzw2 mRNA expression in the mouse embryo 59

Figure 19: Validation of BZW2 truncated forms for domain analysis. 60

Figure 20: BZW2 protein domains analysis 61 
Figure 21: BZW2 expression in KIf15 knock-out (KO) mice under upregulation of the $\mathrm{Wnt} / \beta$-catenin signaling. 62

Figure 22: BZW2 expression in cardiac specific $\beta$-catenin gain-of-function mice. .... 63

Figure 23: BZW2 expression in cardiac specific $\beta$-catenin loss-of-function mice 64

Figure 24: Luciferase reporter assay indicating BZW2 role in the $\mathrm{Wnt} / \beta$-catenin signaling as a target gene. 65

Figure 25: BZW2 role in the Wnt/ß-catenin signaling as a co-regulator. 66

Figure 26: Bzw2 KI transgenic mouse model with a conditional potential. 67

Figure 27: Validation of BZW2 expression in BzW2 KI mice. 68

Figure 28: BZW2 truncated protein is expressed in the heart of homozygous BzW2 KI mice. 69

Figure 29: $\beta$-catenin is upregulated in the heart of homozygous Bzw2 KI mice. ...... 70

Figure 30: $\beta$-catenin expression analyses in Bzw2 KI mice. 71

Figure 31: Echocardiography analysis of Bzw2 KI mice. 74

Figure 32: Echocardiography analysis in aged Bzw2 KI mice. 76

Figure 33: BZW2 expression in cardiac disease. 77

Figure 34: Echocardiography analysis in TAC operated Bzw2 KI mice. 79

Figure 35: Hypertrophy marker in TAC operated Bzw2 KI mice. 80

Figure 36: Analysis of Bzw2 expression in murine ESCs during differentiation to cardiomyocytes.

Figure 37: Validation of CMV-Flag-Bzw2 construct integration in genomic DNA of ESCs. 82

Figure 38: BZW2 expression analyses of ESC clones. 83

Figure 39: Differentiation of BZW2 gain-of-function ESCs to cardiomyocytes. 84 
Figure 40: BZW2 role in early cardiac differentiation.

Figure 41: Differentiation efficiency of BZW2 overexpressing ESCs. 86

Figure 42: Expressing analysis of BZW2 overexpressing ESCs at differentiation days 0 and 4 . 88

Figure 43: The Wnt/ß-catenin cascade in BZW2 overexpressing ESCs. 89 


\section{List of Tables}

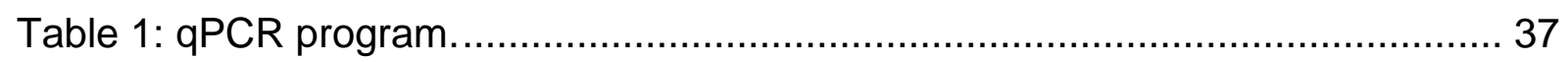

Table 2: Seeding HEK293 cell number..................................................... 44

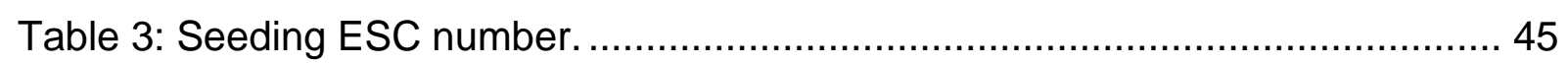

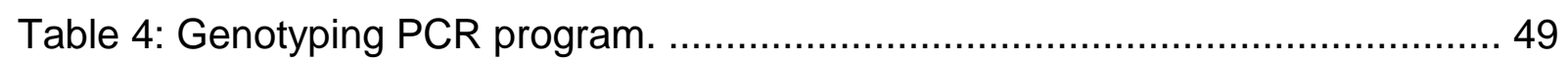




\section{Acknowledgements}

Working for the last four years in the Institute of Pharmacology I learned a lot; not only related to science, but life as well. I met many nice people and made new friends. I thank the God for this experience.

I am most grateful to my supervisor, my thesis committee member and my examination referee Dr. Laura C Zelarayán. You supported and helped me in all possible situations. You always had cool ideas and led this project in the right direction. You had time for me; not only for work, but also for personal support. In these four years you were my supervisor, my friend and my older sister. Thank you very much for your patience with me.

A huge gratitude I express for my colleagues and friends Dr. Claudia Noack and Dr. Maria-Patapia Zafeiriou. Thank you very much for your help, support and advices regarding work as well as personal matters. Thank you for being there for me in bad and good.

I am also very grateful to our group, the old and new members: Eric Schoger, Franziska S Rathjens, Katja Raum, Kerstin Sahlmann, Lavanya lyer, Monique Wölfer, Romina D'Almeida and Vanessa Dusend. Thank you for the nice, friendly and cheerful atmosphere, for your helpfulness at the work and for a lot of fun. It was a great time with you.

Big thanks I express to the head of our institute Prof. Wolfram-Hubertus Zimmermann.

Especially I thank my thesis committee members Prof. Steven Johnsen, Prof. Susanne Lutz and Prof. Viacheslav Nikolaev for their helpful advices for this project. Moreover, I thank to Dr. Katrin Streckfuß-Bömeke and Prof. Thomas Meyer for the willingness to be my examination referees. 
For their advices in stem cell work I specially thank Elif Levent, Mei Ling Chang Liao, Satish Galla and Sumon Sur.

For TAC operations, echography measurements and echography analyses I thank the SFB 1002 service unit, especially Beate Knocke, Marcel Zoremba, Roland Blume and Sabrina Wollborn,

For helping with paraffin tissue embedding I thank Ines Müller. For the endless mice genotyping I thank Ursula Leonhardt and Daniela Liebig-Wolter.

I am grateful to Dr. Karl Toischer and Prof. Gerd Hasenfuß for human heart tissue samples and to Dr. Simon Lämmle and Prof. Ali El-Armouche for angiotensin II treated mice samples.

For coordination, helpfulness and a nice atmosphere during our molecular medicine retreats I thank our coordinator Dr. Meskauskas.

I will miss a lot my colleagues and friends from the Institute of Pharmacology. Thank you for so many funny and happy moments that we had together.

A deep gratitude I express to my family, and especially to my husband Mohammed Chebbok. Thank you so much for your endless patience, your support and your love and that you went through this time with me! 


\section{Abbreviations}

\begin{tabular}{|c|c|}
\hline$A$ & Alanine \\
\hline ACE & Angiotensin-converting-enzyme \\
\hline Ang & Angiotensin \\
\hline ANP & Atrial natriuretic peptide \\
\hline APC & Adenomatosis polyposis coli \\
\hline ATF & Activating transcription factor \\
\hline AWTh & Anterior wall thickness \\
\hline B6 & Black 6 mice (C75BL/6N) \\
\hline BMP & Bone morphogenetic protein \\
\hline BNP & Brain natriuretic peptide \\
\hline Bry & Brachyury \\
\hline BSA & Bovine serum albumin \\
\hline BTrCP & $\begin{array}{l}\beta \text {-transducin repeat containing E3 } \\
\text { ubiquitin protein ligase }\end{array}$ \\
\hline BW & Body weight \\
\hline bZIP & Basic leucine zipper domain \\
\hline $\mathrm{BZW}$ & $\begin{array}{l}\text { Basic leucine zipper and W2 domains } \\
\text { containing protein }\end{array}$ \\
\hline $\mathrm{C}$ & Cysteine \\
\hline cDNA & Complementary DNA \\
\hline CDS & Coding sequence \\
\hline CK & Casein kinase \\
\hline CMV & Cytomegalovirus \\
\hline CO-IP & co-Immunoprecipitation \\
\hline CPCs & Cardiac progenitor cells \\
\hline CRE & Cyclization recombination \\
\hline CREB & cAMP response element-binding protein \\
\hline $\mathrm{D}$ & Aspartic acid \\
\hline DKK & Dickkopf-related protein \\
\hline DMSO & Dimethyl sulfoxide \\
\hline DNA & Deoxyribonucleic acid \\
\hline
\end{tabular}




\begin{tabular}{ll} 
dNTP & Deoxynucleoside triphosphate \\
\hline DPR & Dapper \\
\hline DSP & $\begin{array}{l}\text { Dithiobis(succinimidyl propionate) / } \\
\text { Lomant's Reagent }\end{array}$ \\
\hline DVL & Dishevelled \\
\hline E & Glutamic acid \\
\hline EBs & Embryoid bodies \\
\hline EF & Ejection fraction \\
\hline EGR & Early growth response protein \\
\hline eIF & Eukaryotic initiation factor \\
\hline ESC & Embryonic stem cells \\
\hline E. coli & Escherichia coli \\
\hline F & Phenylalanine \\
\hline FAS & Fraction area shortening \\
\hline FBs & Cardiac fibroblasts \\
\hline FGF & Fibroblast growth factor \\
\hline FHF & First heart field \\
\hline FLK & Fetal liver kinase \\
\hline FZ & Frizzled \\
\hline G & Glycine \\
\hline GAPDH & Glyceraldehyde 3-phosphate \\
\hline GSK & dehydrogenase \\
\hline H & Glycogen synthase kinase \\
\hline HAND & Histidine \\
\hline HE & Heart- and neural crest derivatives- \\
\hline HEK & expressed protein \\
\hline HO & Heterozygous \\
\hline HRP & Human embryonic kidney \\
\hline Horsoleucine \\
\hline Horseradish peroxidase \\
\hline
\end{tabular}




\begin{tabular}{ll} 
IF & Immunofluorescence \\
\hline IgG & Immunoglobulin G \\
\hline iPSCs & Immunoprecipitation \\
\hline ISL & Induced pluripotent stem cells \\
\hline K & LIM-homeo-domain transcription factor \\
\hline KI & Lysine \\
\hline KLF & Knock-in \\
\hline KO & Krueppel-like factor \\
\hline L & Knock-out \\
\hline LA & Leucine \\
\hline LC-MS/MS & Left atrium \\
\hline LEF & Nanoflow liquid chromatography tandem \\
\hline LRP & mass spectrometry \\
\hline LV & Lymphoid enhancing factor \\
\hline M & Lipoprotein receptor-related protein \\
\hline MEF & Left ventricle \\
\hline MEFs & Methionine \\
\hline mESCs & Myocyte enhancer factor \\
\hline MESP & Murine embryonic fibroblasts \\
\hline MHC & Murine embryonic stem cells \\
\hline Ml & Mesoderm posterior homolog \\
\hline MLC & Myosin heavy chain \\
\hline $\mathrm{mRNA}$ & Myocardium infarction \\
\hline $\mathrm{N}$ & Myosin light chain \\
\hline $\mathrm{NF-KB}$ & Messenger RNA \\
\hline $\mathrm{NKX}$ & Asparagine \\
\hline $\mathrm{NLS}$ & Nuclear factor 'kappa-light-chain- \\
\hline $\mathrm{NP}-40$ & enhancer' of activated B-cells \\
\hline OCT & NK2 transcription factor related \\
\hline Noctamer binding transcription factor \\
\hline
\end{tabular}




\begin{tabular}{ll} 
P & Proline \\
\hline PC12 & Pheochromocytoma cells \\
\hline PBS & Phosphate-buffered saline \\
\hline PCR & Polymerase chain reaction \\
\hline PP & Protein phosphatase \\
\hline PVDF & Polyvinylidene fluoride \\
\hline qPCR & Quantitative PCR \\
\hline R & Arginine \\
\hline RA & Right atria \\
\hline RAAS & Renin-angiotensin-aldosterone-system \\
\hline RNA & Ribonucleic acid \\
\hline RRL & Rabbit reticulocyte lysate \\
\hline RT & Room temperature \\
\hline RT-PCR & Reverse transcription PCR \\
\hline RV & Right ventricle \\
\hline S & Serine \\
\hline Sca-1 & Stem cells antigen-1 \\
\hline SDS-PAGE & Sodium dodecyl sulfate polyacrylamide \\
\hline Ser & gel electrophoresis \\
\hline sFRP & Serine \\
\hline Sham & Secreted frizzled-related protein \\
\hline SHF & Surgical intervention \\
\hline SMAD & Threonine \\
\hline SOX & The TAt heart field \\
\hline SRF & Sma and Mad related protein \\
\hline SV40 & SRY-related HNG-box \\
\hline T & Serum response factor \\
\hline TAC & Simian-virus \\
\hline TBP & Threonine \\
\hline TBX & Transverse aortic constriction \\
\hline TCF & Throtein \\
\hline & \\
\hline
\end{tabular}




\begin{tabular}{ll} 
TK & Thymidine kinase \\
\hline TPT & Tumor protein, translationally-controlled \\
\hline TropT & Cardiac Troponin T \\
\hline V & Valine \\
\hline W & Tryptophan \\
\hline WB & Western blot \\
\hline WT & Wild type \\
\hline Y & Tyrosine \\
\hline ZIP & Leucine zipper domain
\end{tabular}

Abbreviations of Units were done according to the International System of Units. 


\section{Summary}

Tight regulation of the $\mathrm{Wnt} / \mathrm{\beta}$-catenin pathway is crucial not only at all stages of embryonic cardiac development but also for maintaining normal adult heart homeostasis. Indeed, activation of the $\mathrm{Wnt} / \beta$-catenin signaling is associated with pathological heart remodeling. A better understanding of the fine tuning of the Wnt-off and -on -states in the progression of cardiac failure is attractive to identify potential targets for blocking pathological remodeling and/or activating endogenous tissue regeneration. This work focused on the identification of a tissue specific regulator of this cascade in the heart, which remains elusive.

Previous data in the group identified the basic leucine zipper and W2 domains containing protein (BZW) 2 as a $\beta$-catenin and KLF15 cardiac interaction partner. The role of BZW2 in Wnt signaling in cardiogenesis and adult cardiac homeostasis was specifically addressed in this study. Analysis of the BZW2 protein showed that the putative ZIP and bZIP containing domain is important for nuclear localization, suggesting its role in the nucleus. BZW2 expression was found prominent in the adult heart but also during cardiac embryogenesis. Low BZW2 expression was required for effective cardiac mesoderm formation as found by abrogation of cardiomyocytes formation upon BZW2 overexpression in an in vitro cardiogenesis model. However, BZW2 expression was not crucial for embryogenesis, which could be based on compensatory function of related proteins. Interestingly, BZW2 was necessary to maintain normal cardiac function and during stress induced response. Regarding the Wnt/ $\beta$-catenin signaling, although BZW2 did not significantly induce inhibition of the Wnt transcriptional activity in vitro, the lack of BZW2 resulted in de novo synthesis of $\beta$-catenin specifically in the adult heart tissue in vivo. Moreover, BZW2 was found to be regulated downstream of the $\mathrm{Wnt} / \mathrm{\beta}$-catenin signaling suggesting its role as a regulatory feedback factor in vivo.

In summary, this study identified a novel heart tissue component of the $\mathrm{Wnt} / \mathrm{\beta}$-catenin pathway with a new level of regulation and demonstrated its relevance to maintain normal heart homeostasis. Given the ubiquitous expression and multiple functions of $\beta$-catenin, tissue specific modulation under pathological conditions may provide new therapeutic approaches. 


\section{Zusammenfassung}

Die Regulation des $W n t / \beta$-catenin Signalwegs ist nicht nur entscheidend für alle Stadien der kardialen Entwicklung, sondern auch für die Homöostase im adulten Herzen. Tatsächlich ist die Aktivierung des Wnt/ $\beta$-catenin Signalwegs mit dem pathologischen Herz-Remodeling assoziiert. Ein besseres Verständnis der Regulation des Wnt/ $\beta$-catenin Signalwegs bei Herzinsuffizienz könnte die Identifikation potentieller Faktoren zum Blockieren des pathologischen HerzRemodelings und/oder das Aktivieren der endogenen Regeneration ermöglichen. Diese Arbeit konzentriert sich auf die Identifikation von gewebespezifischen Regulatoren des Wnt/ $\beta$-catenin Signalwegs im Herzen.

Frühere Arbeiten unserer Gruppe identifizierten basic leucine zipper and W2 domains containing protein (BZW) 2 als einen kardialen Interaktionspartner von $\beta$-catenin und KLF15. Die Rolle von BZW2 im Wnt/ $\beta$-catenin Signalweg bei der Kardiogenese und der Homöostase des adulten Herzens war das Thema dieser Studie. Eine Analyse des BZW2-Proteins zeigte, dass die mutmaßliche ZIP und bZIP umfassende Domäne wichtig für die nukleare Lokalisation ist. Die Expression von BZW2 hat sich als bedeutsam im adulten Herzen, aber auch während der embryonalen Kardiogenese erwiesen. Eine niedrige BZW2-Expression ist für die effektive Bildung des kardialen Mesoderms notwendig, denn es kam unter BZW2-Überexpression zu einem Abbruch der Kardiomyozytenbildung in einem Modell der in vitro Kardiogenese. Dennoch war die BZW2-Expression nicht entscheidend für die Embryogenese, was auf eine kompensatorische Funktion verwandter Proteine hindeuten könnte. Interessanterweise war BZW2 für den Erhalt der normalen Herzfunktion und während der Reaktion auf Stress notwendig. Obwohl BZW2 die Wnt-Transkriptionsaktivität in vitro nicht signifikant inhibiert hat, resultierte das Fehlen von BZW2 in de novo Synthese von $\beta$-catenin spezifisch im adulten Herzgewebe in vivo. Außerdem wurde BZW2 selbst durch den Wnt/B-catenin Signalweg reguliert, was auf seine Rolle als regulatorischer Rückkopplungsfaktor in vivo hindeutet.

Zusammenfassend identifizierte diese Arbeit einen neuen herzgewebespezifischen Faktor des Wnt/ $\beta$-catenin Signalwegs auf einer neuen Regulationsebene und demonstrierte seine Relevanz für die normale Herzhomöostase. Angesichts der ubiquitären Expression und der vielfältigen Funktionen von $\beta$-catenin könnte die gewebespezifische Modulation neue Therapieoptionen darstellen. 


\section{Introduction}

\subsection{Heart failure}

Insufficient pump function of the heart as found in heart failure condition is one of the most common causes of death affecting over 23 million people worldwide. ${ }^{1}$ In Germany heart failure is on the $3^{\text {rd }}$ place of death causes. ${ }^{2}$ Beside congenital cardiomyopathies, the main risk factors for heart failure are obesity, diabetes, dyslipidemia, hypertension, infections, alcoholism and tobacco among others. ${ }^{3}$

The main problem is that upon injury the absence of a robust regenerative response results in muscle loss and contractile decay, which ultimately leads to a failing heart. ${ }^{4}$ Currently, available pharmacological treatments are delaying but not preventing the onset of heart failure. Upon stress the heart undergoes tissue remodeling, which is a biological adaptation process of the failing heart. A common feature of the hemodynamically or metabolically stressed heart is a switch towards "fetal" metabolism and re-expression/elevation of fetal genes. They include genes encoding proteins involved in signaling pathways (NF-KB, SRF, SMADs, EGR1 or CREB, FZ, Axin, WNT) and cardiac transcription factors (MEF2, GATA4, NKX2.5, HAND, TBX5), some of them (SMADs, CREB, FZ, WNT, MEF2, GATA4, NKX2.5, HAND, TBX5) are involved in embryonic heart development. ${ }^{5-9}$ However, the pathophysiological relevance of this re-expression in diseases progression remains still unclear.

\subsubsection{Pathological cardiac remodelling and current therapies}

Before reaching the heart failure stage, the heart undergoes a process of remodeling, a compensatory response, which initially intends to maintain the pump function. However, long-term activation of this remodeling upon sustained stimulus contributes to progressive deterioration and culminates in heart failure. Morphologically, pathological cardiac remodeling involves cardiac myocytes growth and death, vascular remodeling, fibrosis and inflammation, which lead to change in the heart geometry namely less elliptical and more spherical. ${ }^{10}$

The stress-induced compensatory response involves mechanical changes leading to increase in myocardial fiber length and an increase in the force of contraction, up to a certain point. This is accompanied by a series of neuroendocrine regulation in 
response to the damaged muscle and impaired function due to the tendency of the cardiac output to decrease. Neuroendocrine adaptation includes activation of sympathetic nervous system and renin-angiotensin-aldosterone-system (RAAS, a hormonal system regulating blood pressure and fluid balance), both of them trying to restore and maintain cardiac output and blood pressure. These long-term compensation mechanisms become counterproductive, the heart dilates, wall stress increases and the heart muscle becomes weak. This is vicious cycle, which progresses to heart failure.

As mentioned above activation of embryonic pathways are suggested to play an important early role in the process of heart remodelling. Because the elucidation of these pathways may help to develop novel pharmacological strategies to support myocardial regeneration, many of the cardiac-restricted factors originally characterized within a purely developmental context are now becoming significant in translational cardiac research. ${ }^{6,11}$

Currently established therapies delay the progression of heart failure symptoms but do not prevent the development of end stage heart failure. They are mainly aiming to stop the vicious cycle at different point such as targeting the RAAS system with ACEinhibitors; ameliorating the sympathetic nervous system response by $\beta$-adrenergic receptor blockers; or decreasing volume by reduction of preload and afterload with Diuretics. Cardiac glycosides (digitalis) are used in acute heart failure to increase contractility and decrease heart rate by increasing intracellular calcium. Ultimately, in heart failure progression surgical and technical therapies are used, up to heart transplantation when pharmacological treatments failed. ${ }^{12}$ It is evident, that all these therapies cannot prevent the progression of heart muscle decay and/or reverse damage. Therefore, new therapeutic approaches under investigation try to focus on prevention of heart failure progression by either blocking cellular deterioration or enhancing the hearts own regeneration. The latter can be achieved by stimulation of resident cell sources (cardiac progenitor differentiation and cardiomyocytes proliferation) or direct cellular reprogramming of cardiac fibroblasts. ${ }^{13-15}$ Other promising approaches under investigation are cell transplantation (ESCs/iPSCs, cardiac progenitors and cardiomyocytes) and tissue engineering. ${ }^{16,17}$ For blocking cellular deterioration, it is imperative to get insight into the molecular mechanisms responsible for maintaining normal cardiac homeostasis. This study focused on such 
a signaling, namely the Wnt pathway, whose tight regulation is essential for maintaining normal heart function.

\subsection{Heart regeneration}

The traditional view of the heart as a terminally differentiated organ without any capacity for cardiomyocyte renewal has been challenged in the last years in several studies. $^{18-21}$ Current evidences suggest that the mammalian heart possesses a capacity for repair through cardiomyocyte de-differentiation followed by proliferation and re-differentiation or endogenous cardiac progenitor cells (CPCs) activation or maybe a combination of both ${ }^{13,19-22}$. However, these mechanisms are insufficient to replace severely damaged myocardium under regular pathological circumstances. Taking advantage of the integration of ${ }^{14} \mathrm{C}$ (generated by nuclear bomb tests during the Cold War) into DNA it was shown that adult human heart possess a cardiomyocytes renewal rate of $1 \%$ per year at the age of 20 and $0.3 \%$ at the age of 75 in the normal heart homeostasis. ${ }^{20,23}$ Moreover, by combining two different pulsechase approaches in mice it has been demonstrated that cardiomyocytes genesis is dominantly by division of pre-existing cardiomyocytes during normal aging, a process that increases by four-fold adjacent to areas of myocardial injury ${ }^{21}$ although cardiomyocytes derived from CPCs accounted for a $20 \%$ of the new formed cardiomyocytes. Another study demonstrated full regeneration of injured hearts in 1day old mice characterized by cardiomyocytes proliferation with minimal hypertrophy or fibrosis. This regenerative capacity was lost in murine heart by 7 days of age. ${ }^{24}$ Further approaches using embryonic stem cells (ESCs) for transplantation of functional cardiomyocytes in animal models have begun to show promising results. ${ }^{17}$ Multiple studies have demonstrated engraftment of mouse ESC-derived cardiomyocytes to improve contractile function when transplanted to rodent. ${ }^{25}$ Understanding the mechanisms regulating cardiomyocyte generation and participating in the process of heart remodelling will be the basis not only for designing new therapeutic targets enhancing/blocking the heart's own mechanisms but also for optimization of cardiomyocyte derivation from stem cells for applications in studies of fundamental heart muscle biology, drug discovery, and potentially also cell-based heart repair. ${ }^{26}$ 


\subsection{Cardiogenesis}

\subsubsection{Morphologic view}

The vertebrate heart is the first organ that becomes functional during embryogenesis. Cardiac precursor cells are found before gastrulation bilaterally distributed in the posterior epiblast directly adjacent to the primitive streak. Additionally, cardiac precursors are found in the upper third of the primitive streak under Hensen's node (in mouse embryonic post coitum day E4.5). The mesoderm is built during gastrulation by cell migration from primitive streak between ectoderm and endoderm. After specification the pre-cardiac mesoderm migrates from the primitive streak in an anterolateral direction. These cells will form the heart-forming fields on either side of the primitive streak in endocardial tubes (E5.5-6.0). Cell specification may occur when the cells are organized in the heart fields. Prospective heart cells with a cranial position will form anterior structures of the tubular heart, while more caudally localized cells will form posterior structures. Then, two endocardial tubes migrate anterior-medial and subsequently fuse at the anterior ends to the first distinct cardiac structure, the cardiac crescent (E6.5-7.5) (Figure 1A). First heart field (FHF) progenitor cells (caudal crescent) start to differentiate. The cardiac crescent forms the beating, linear heart tube (Figure 1B). Second heart field (SHF) progenitors gradually migrate into the linear heart tube and differentiate (E8.0). After rightward looping of the linear heart tube (E8.5) cardiac neural crest cells contribute to the heart, which already shows defined four-chamber morphology (E10.5) (Figure 1C). At E14.5, the heart shows four fully separated chambers (FHF differentiates to the left ventricle and SHF to the right ventricle and a large portion of the atria) and the outflow tract (differentiated from SHF) connected to the pulmonary trunk and the dorsal aorta (Figure 1D). ${ }^{27-31}$ 

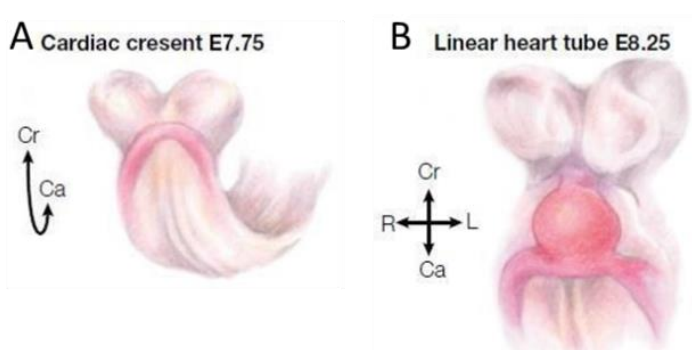

C Looping heart E10.5

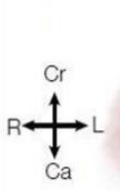

Remodelling heart E12.5

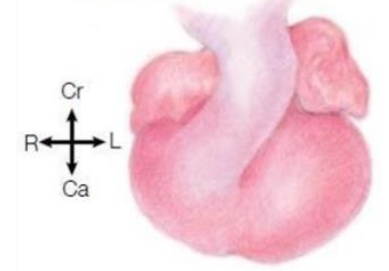

Figure 1: Four morphological stages of the cardiogenesis in mouse.

$\mathrm{Cr}=$ cranial; $\mathrm{Ca}=$ caudal; $\mathrm{R}=$ right $\mathrm{L}=$ left. $\mathbf{A}$ The cardiac crescent (here shown at $\mathrm{E7.75}$ ) is the first distinct cardiac structure and is built at E6.5-7.5 by anterior-medial migration of two endocardial tubes and theirs subsequently fusion at the anterior ends. FHF cells start to differentiate. B At E8.0 the cardiac crescent forms the beating, linear heart tube (here shown at E8.25) by FHF cells differentiation and SHF cells migration and differentiation. C After rightward looping, cardiac neural crest and proepicardial cells contribute to the heart, which already shows defined four-chamber morphology (E10.5). FHF cells differentiate mainly to the left and right ventricles. SHF cells differentiate into outflow tract, the right ventricle and a large portion of the atria. D At E14.5 (here shown at E12.5) the heart shows four nearly fully separated chambers and the outflow tract connected to the pulmonary trunk and the dorsal aorta.

(Adapted from Harvey RP, review, 2010) 32 $^{32}$

\subsubsection{Molecular aspects of cardiogenesis}

Mesoderm induction, an evolutionary conserved process, is the first step before cardiogenesis and is regulated by numerous conserved signaling pathways (Nodal, BMP, Wnt, FGF). ${ }^{31,33}{ }^{34}$ During ingression of mesoderm cells through the primitive streak Wnt/B-catenin signaling activation induces Brachyury (Bry) expression and leads to mesoderm progenitors $\left(\mathrm{BRY}^{+}\right)$formation. ${ }^{31,35}$ Inactivation of $\mathrm{Wnt} / \beta$-catenin signaling and activation of non-canonical Wnt signaling lead to induction of primordial cardiovascular progenitors $\left(\mathrm{BRY}^{+} / \mathrm{FLK1} 1^{+}\right) .{ }^{36-38}$ At this step, endoderm provides mesoderm with inductive signals, the growth factors including BMPs, FGFs, and Wnt proteins. $^{39,} 40$ The following cardiogenic mesoderm specification occurs upon downregulation of Bry and activation of mesoderm posterior (MESP) 1 expression by eomesodermin. ${ }^{37}, 38$ Because of their cranial position in the cardiac crescent, FHF progenitors are exposed to cytokines of the $\mathrm{BMP}^{41}$ and $\mathrm{FGF}^{42}$ families as well as to inhibitors of the Wnt/ $\beta$-catenin pathway ${ }^{43-45}$, resulting in cardiac differentiation marked by expression of key regulators NKX2.5, GATA-4 and TBX5. ${ }^{31,46}$ Cardiomyocytes commitment is evident by expression of myosin light chain (MLC) $2 a$ and sarcomeric myosin heavy chain (MHC) expression. ${ }^{47} \mathrm{SHF}$ cells remain in a proliferative, 
undifferentiated progenitor state in the cardiac crescent and are marked by LIMhomeo-domain transcription factor 1 (ISL-1). ${ }^{48,}{ }^{49}$ ISL-1 expression is dependent on Wnt/ $\beta$-catenin signaling ${ }^{50,51}$ and is required for SHF cells survival, proliferation and migration into the heart tube. ${ }^{31}$ When SHF cells reach the heart tube, ISL-1 expression decreases and differentiation takes place. ${ }^{52}$

\subsubsection{Wnt/ß-catenin signalling in cardiogenesis}

$W n t / \beta$-catenin signaling pathway is essential for cardiogenesis. It regulates heart development in a multiphasic manner beginning with mesoderm formation through all developmental steps up to the formed heart. ${ }^{31,36}$

It was shown that $\beta$-catenin knock-out mice fail to generate mesoderm. ${ }^{53}$ Moreover, early inhibition of the $\mathrm{Wnt} / \mathrm{\beta}$-catenin signaling blocks expression of mesodermspecific marker genes in murine ESCs. It results in a loss of MESP1 and downregulation of FLK1 expression. ${ }^{54}$ It was shown that the Bry promotor includes TCF binding site, suggesting that mesoderm formation depends on $\mathrm{Wnt} / \beta$-catenin signaling using Bry expression. ${ }^{55,56}$ These data together indicate that $\mathrm{Wnt} / \beta$-catenin activation is essential for mesoderm formation ${ }^{36}$ (Figure 2). Furthermore, cardiogenic mesoderm formation from mesodermal precursors (process of the cardiac specification) depends on the $\mathrm{Wnt} / \beta$-catenin inactivation ${ }^{36}$ (Figure 2). It was shown that $\mathrm{Wnt} / \beta$-catenin signaling supports the expansion of committed cardiac progenitor cells. ${ }^{36,57}$ Mice expressing stabilized $\beta$-catenin display enlarged ventricles, more cells and upregulated Cyclin D2. Mice with a depleting $\beta$-catenin function display smaller ventricles and reduced proliferation. ${ }^{57}$ All these data together indicate that $\mathrm{Wnt} / \beta$ catenin signaling promotes cell proliferation in cardiogenesis ${ }^{36}$ (Figure 2).

Addition of Wnt3a decreased differentiation of ESC-derived cardiomyocyte during embryo body (EB) differentiation ${ }^{58,59}$ as well as ISL- $1^{+}$CPCs differentiation ${ }^{60}$. Overexpression of stabilized $\beta$-catenin in ISL- $1^{+}$CPCs results in a downregulation of several important cardiac genes at E9.0 in mouse. ${ }^{61}$ These data together indicate that $\mathrm{Wnt} / \beta$-catenin signaling inhibits terminal differentiation of cardiomyocytes ${ }^{36}$ (Figure 2). 


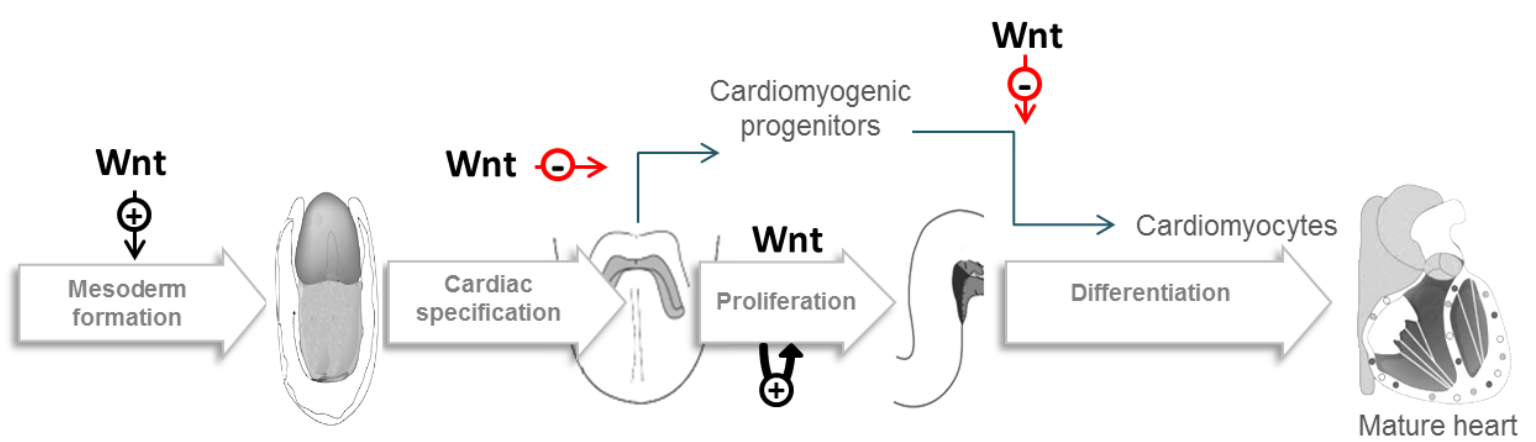

Figure 2: Schematic representation of time specific regulatory role of the $\mathrm{Wnt} / \beta$-catenin signaling pathway during cardiogenesis.

Wnt/ $\beta$-catenin signaling needs to be active during mesoderm formation and proliferation but inactive during cardiac specification. Inactive $\mathrm{Wnt} / \beta$-catenin signaling leads to terminal cardiomyocytes differentiation. Information collected from Ueno S et al., 2007 ${ }^{58}$; Naito AT et al., 2006 ${ }^{59}$; Qyang $Y$ et al., $2007^{60}$; Gessert S \& Kühl M, $2010^{36}$.

\subsection{Wnt/ $\beta$-catenin signaling pathway}

Transduction of the Wnt signal involves complex protein-protein interactions with regulatory inputs at many distinct levels including membrane receptors, cytoplasmic and nuclear protein complexes. In absence of Wnt, $\beta$-catenin, the key transduction protein of the $\mathrm{Wnt} / \beta$-catenin signaling, is sequestered in a destruction protein complex and the pathway is inactive (Figure 3A). The complex includes Axin2, adenomatosis polyposis coli (APC), protein phosphatase (PP) 2a, glycogen synthase kinase (GSK) $3 \beta$ and casein kinase (CK) $1 \alpha$. CK1 $1 \alpha$ phosphorylates $\beta$-catenin at Ser45, which is followed by phosphorylation at Ser33, Ser37 and Thr41 by GSK3 $\beta$. The phosphorylation sites are recognized by the beta-transducin repeat containing E3 ubiquitin protein ligase ( $\beta \mathrm{TrCP})$ and $\beta$-catenin is ubiquitinated and targeted to proteasome for degradation. In the presence of Wnt, it binds to the Frizzled (FZ) receptor and the co-receptor lipoprotein receptor-related protein (LRP) 5/6, which becomes phosphorylated and activated (Figure 3B). The destruction complex and phosphoprotein Dishevelled (DVL) are sequestered to the plasma membrane becoming inactive. Axin2 binds to the cytoplasmatic tail of LRP-5/6 and becomes dephosphorylated. DVL binds to $\mathrm{FZ}$, becomes activated by phosphorylation and inhibits GSK3 $\beta$ activity. Thus $\beta$-catenin cannot be phosphorylated and degraded, accumulates in cytosol and becomes translocated into the nucleus. In nucleus, after a certain level of $\beta$-catenin is reached, it binds to T-cell factor / lymphoid enhancing factor (TCF/LEF) transcription factors, displacing the bound repressors and activating 
the cascade. Interaction of further specific co-factors activates the $\mathrm{Wnt} / \mathrm{\beta}$-catenin signaling target gene transcription. The $W n t / \beta$-catenin signaling is inhibited extracellularly by binding of Dickkopf-related protein (DKK) 1 to LRP-5/6 or by binding of secreted frizzled-related protein (sFRP) to Wnt or to FZ. Intracellular inhibition occurs by a negative feedback loop mechanism, when target genes are a part of the destruction complex, like Axin2, or when they block gene transcription in nucleus by binding to TCF/LEF. ${ }^{62-67}$

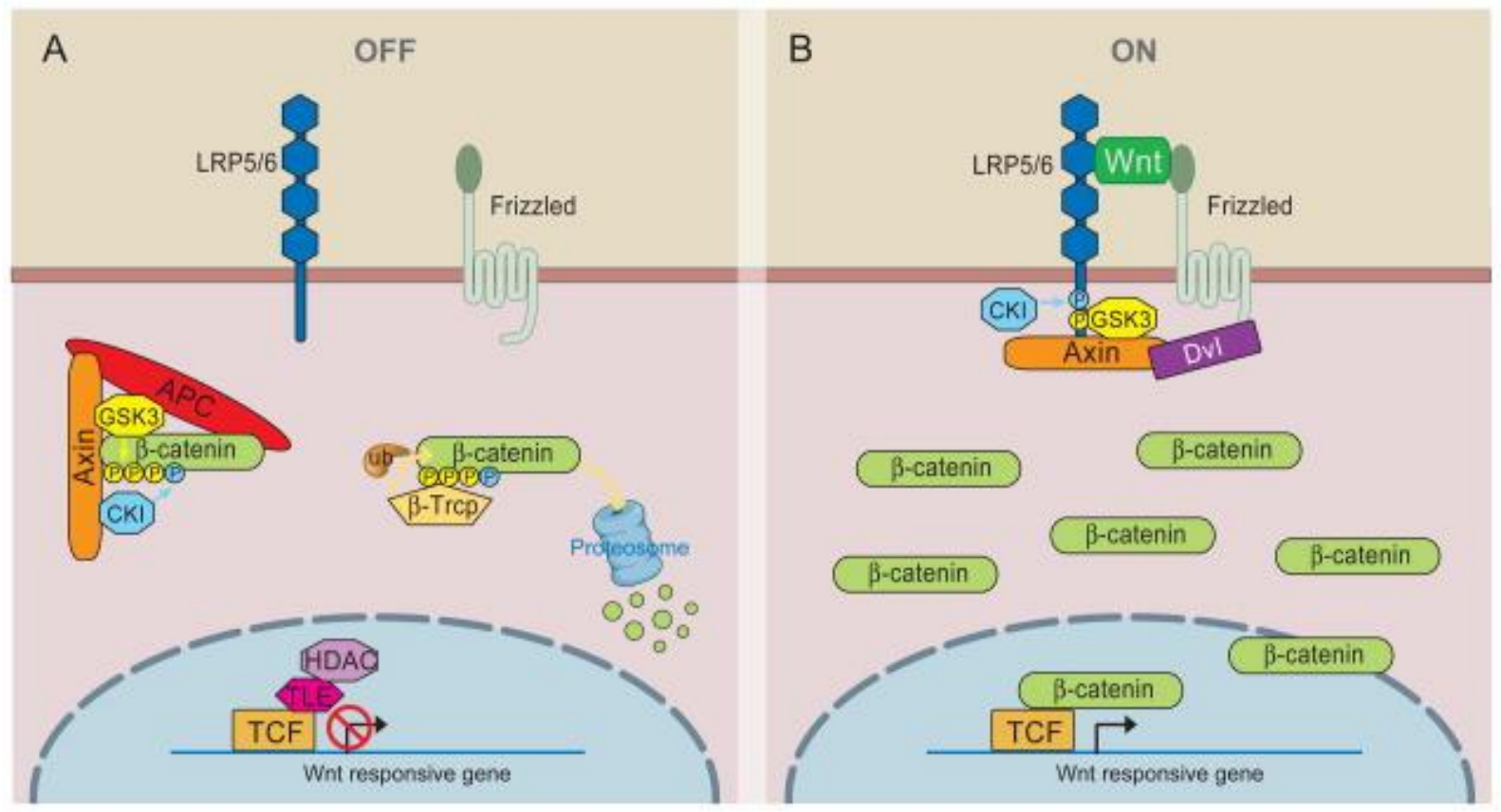

Figure 3: Schematic view of Wnt/ $\beta$-catenin signaling.

A When $W n t / \beta$-catenin signaling is inactive the key protein $\beta$-catenin is bound by destruction protein complex, including APC, PP2A, GSK3 and CK1 $\alpha$. $\beta$-catenin becomes phosphorylated by GSK3 and CK1 $\alpha$ and targeted to the proteasome for degradation. B In the presence of Wnt the signaling becomes activated. The destruction complex and DVL are sequestered to the plasma membrane. DVL inhibits GSK3 and $\beta$-catenin accumulates in cytosol and subsequently in the nucleus where it binds to TCF/LEF and activates gene transcription.

(MacDonald BT et al., 2009) ${ }^{62}$

\subsubsection{Wnt/ß-catenin signaling in the adult heart}

The role of Wnt in cardiogenesis is very well described; however its role in adult heart homeostasis is not completely understood. In normal adult cardiomyocytes the activity of the $\mathrm{Wnt} / \beta$-catenin signaling is low. ${ }^{68}$ However, $\mathrm{Wnt} / \beta$-catenin signaling is activated in the whole heart in response to cardiac injury in adult mammals and several evidences showed important roles in hypertrophy and cardiac remodeling. ${ }^{69}$ 
Although the current studies are controversial regarding the role of $\mathrm{Wnt} / \mathrm{\beta}$-catenin signaling in heart failure, there are consistent evidences showing upregulation of components of the $\mathrm{Wnt} / \beta$-catenin signaling in different cardiac injury models. In hypertrophic hearts FZ as well as $\beta$-catenin were found to be upregulated. ${ }^{70,71}$ DVL-1 was found to be upregulated in TAC operated rat hearts as wells as in post-ischemic hearts. $^{72,73}$ Moreover, Axin2 and Dapper1 (DPR1, Wnt signaling antagonist via DVL degradation) were found upregulated in post-ischemic hearts. ${ }^{74-76}$ Regulatory response seems to depend on injury model and the level at which the signaling cascade is modified. To investigate the role of $\beta$-catenin in adult heart under diseased conditions, several studies used transgenic mouse lines with cardiac specific inducible deletion as well as stabilization of $\beta$-catenin. Depletion of $\beta$-catenin depending on $\alpha-M h c$ promoter in the adult heart leads to a significant preserved left ventricle function and survival four week after infarction. ${ }^{77}$ In unstressed heart prolonged $\beta$-catenin stabilization led to impaired cardiac function. ${ }^{78}$ Moreover, $\beta$ catenin stabilization led to an abrogated compensatory hypertrophic response to Ang II treatment ${ }^{79}$ and after $\mathrm{TAC}^{80}$. In contrast, in other studies $\beta$-catenin stabilization was described to be required for cardiac hypertrophy. ${ }^{71,80,81}$ Mice expressing a nondegradable form of $\beta$-catenin in MIc2v expressing cells developed cardiac hypertrophy followed by dilated cardiomyopathy with increased mortality ${ }^{81}$ Altogether these studies reflect the importance of a tight $\mathrm{Wnt} / \beta$-catenin signaling regulation in the adult heart. However, the molecular mechanisms determining context-specific regulation and responses of the ubiquitous $\mathrm{Wnt} / \beta$-catenin pathway in adult heart cells remain largely unknown. Understanding of the fine tuning of the Wnt-off/-on state is essential to prevent heart progression and to maintain/preserve normal cardiac function.

\subsubsection{Cardiac specific regulation of the $\mathrm{Wnt} / \beta$-catenin signalling}

Based on the conservation of the pathway and its relevance in the process of cardiogenesis, the $\mathrm{Wnt} / \beta$-catenin signaling offers a suitable target for tissue regeneration. Thus, understanding the mechanisms of $\mathrm{Wnt} / \beta$-catenin regulation in heart failure offers the potential to develop new therapeutic approaches. However, the knowledge of a tissue specific regulation of this ubiquitously expressed pathway is currently missing. Previous work in our group reported a novel level of regulation in the $\mathrm{Wnt} / \beta$-catenin signaling namely the Krueppel-like factor (KLF) 15, which inhibits 
Wnt/ $\beta$-catenin transcriptional activity and controls CPC fate in the postnatal heart. ${ }^{78}$ In line with its inhibitory role, a global Klf15 functional knock-out mouse showed upregulation of Wnt/ $\beta$-catenin transcriptional activity as demonstrated by $T c f 7 / 2$ and $c-M y c$ upregulation specifically in heart tissue (Figure 4A; Noack $C$ et al., unpublished), although Klf15 is highly expressed in other organs beside the heart (Figure 4B; Noack $\mathrm{C}$ et al., unpublished). This indicates the requirement of additional tissue specific co-factors for this regulation.
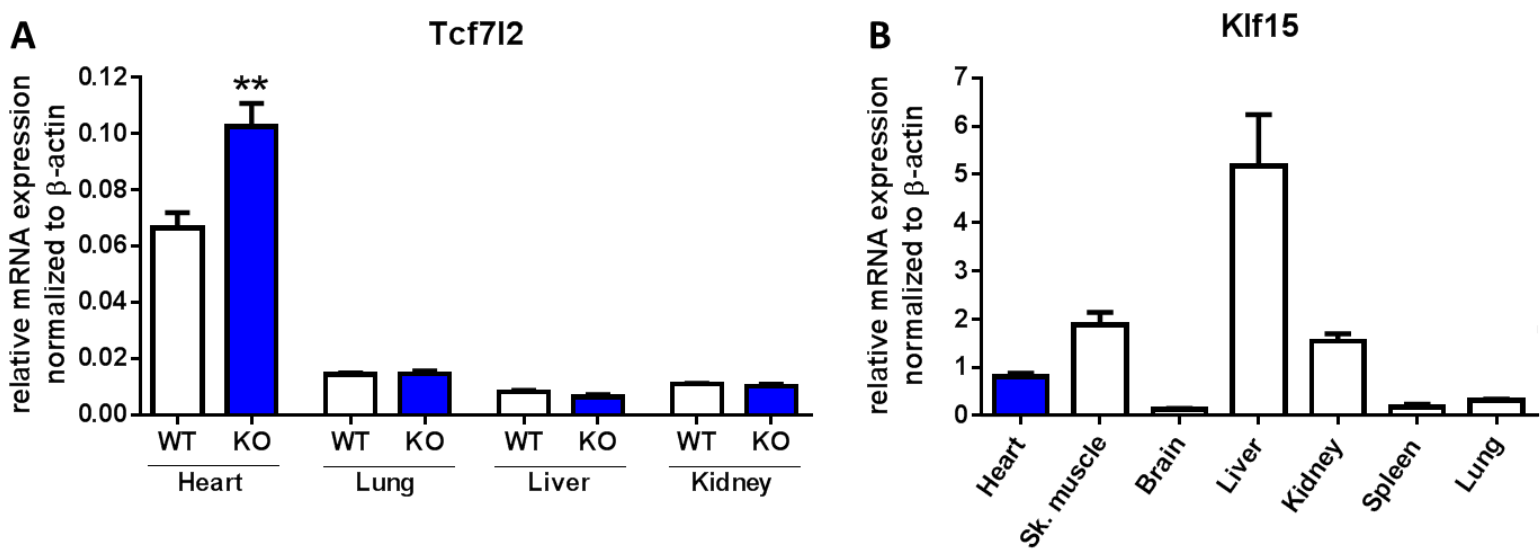

Figure 4: KIf15 KO mice and KIf15 expression in different organs.

A Tcf7l2 mRNA expression normalized to $\beta$-actin in different organs of Klf15 knock-out (KO) mice (heart, lung, liver and kidney; $n=5 /$ group, Student's $t$-test, ${ }^{* *} \mathrm{p}<0.001$ ) analyzed by $\mathrm{qPCR}$ showing cardiac specific Wnt/B-catenin signaling upregulation in Klf15 KO mice. B Klf15 mRNA expression normalized to $\beta$-actin in different murine organs (heart, skeletal muscle, brain, liver, kidney, spleen and lung; $n=5$ ) analyzed by qPCR showing that KIf15 is not predominantly expressed in the heart (Noack $C$ et al., unpublished).

In order to identify such factors, a yeast-2-hybrid screen was performed using a human cardiac library (kindly provided by Norbert Frey, University Kiel) and $\beta$-catenin as well as KLF15 as prey proteins. Only six proteins were found to bind both $\beta$ catenin and KLF15, among which basic leucine zipper and W2 domains containing protein (BZW) 2 was found (Renger $A$ et al., unpublished). The putative nuclear localization of BZW2 and data showing high expression in the adult rat heart ${ }^{82-85}$ prompted us to select this candidate for further investigation among the others. 


\subsection{BZW2 protein}

BZW2 is an evolutionary highly conserved protein as appreciated in Figure 5, which shows the comparison of its peptidic sequence among Homo sapiens, Mus musculus, Gallus gallus, Xenopus tropicanis, Danio rerio and Drosophila melanogaster, however nothing is known about its function in the heart. BZW2 belongs to the BZW protein family consists of BZW2 and homologue BZW1. Via Northern blot analysis it was shown that Bzw2 mRNA is predominantly expressed in the adult rat heart in comparison to brain, spleen, lung, liver, skeletal muscle, kidney and testis. Bzw2 RNA is highly expressed during rat brain development (E12.0-20.0) and rapidly decreases after birth (postnatal day P2), which allows concluding that BZW2 should have a role in neurogenesis. The local specific RNA expression in the adult rat brain (especially in cerebellum) was demonstrated via in situ hybridization. ${ }^{82}$ In another study BZW2 was shown to bind to eukaryotic initiation factors (elF) 2 and 3 in HeLa cells in vitro. Furthermore BZW2 inhibits protein synthesis in rabbit reticulocyte lysate (RRL) system, an in vitro system testing expression activity. Interestingly BZW2 seems to increase translation of activating transcription factor (ATF) $4^{86}$, which is crucial for osteoblast differentiation ${ }^{87}$. Overexpression of a Bzw2transcript in HeLa cells showed cytosolic localization. ${ }^{86}$ Furthermore, upregulation of Bzw2 was detected in different human lymphomas via microarray. ${ }^{88}$ To best of my knowledge no data are available showing the role of BZW2 in cardiac cells. 


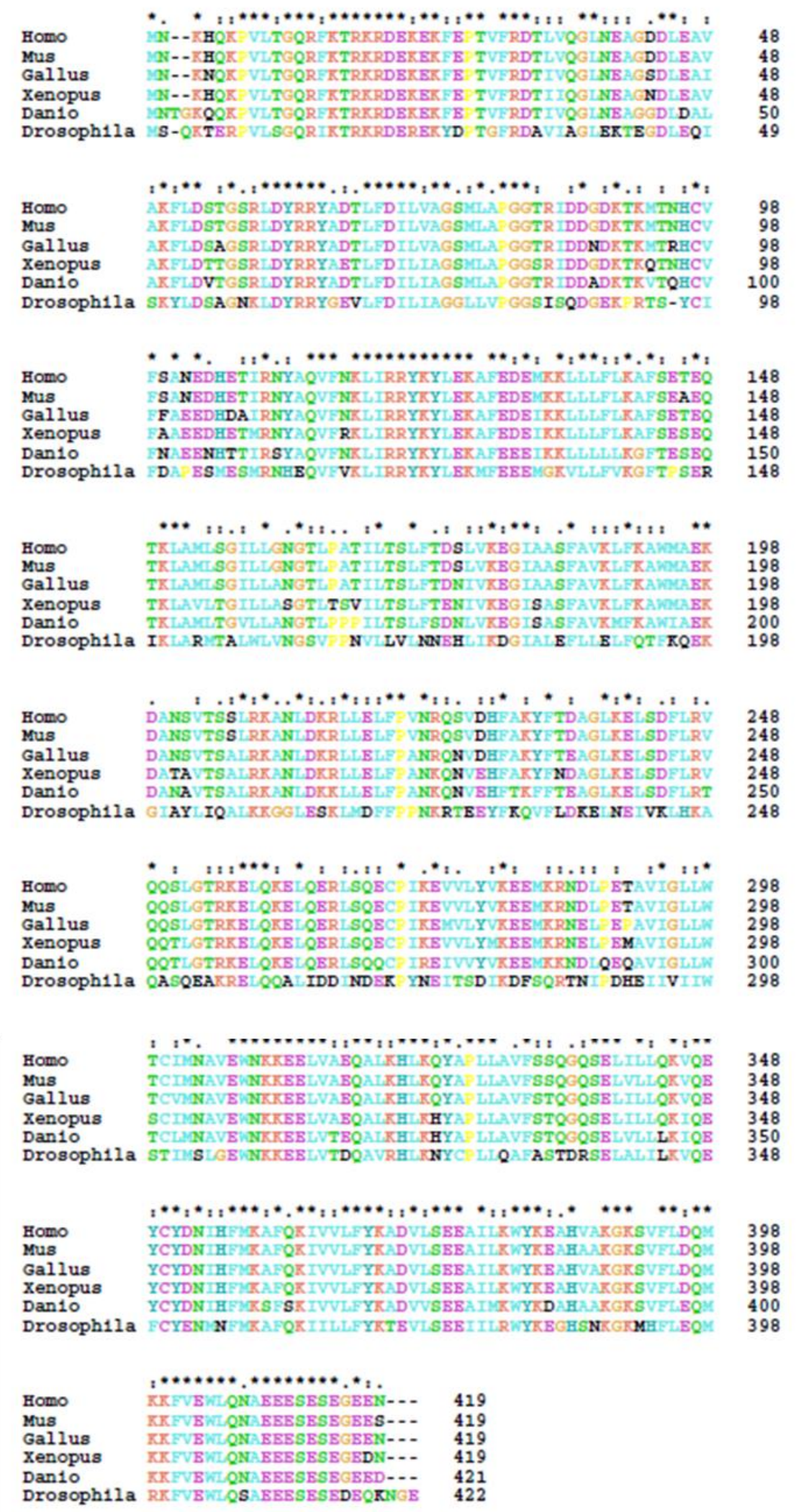

Figure 5: Alignment of the BZW2 protein in different organisms.

BZW2 protein in Homo sapiens (NP_001153239.1), Mus musculus (NP_080116.2), Gallus gallus (NP_001006358.2), Xenopus tropicanis (XP_002933339.1), Danio rerio (NP_957212.1) and Drosophila melanogaster (NP_730958.1). Color code for amino acids: non-polar/hydrophobic (light blue), polar/hydrophilic (green), basic (red), acidic (magenta) and others (yellow, orange, blue). 
Structurally Bzw2 transcript includes 12 exons (Figure 6). The transcription starts in exon 2 and ends in exon 12. BZW2 protein is $48 \mathrm{kDa}$ in size and includes an $\mathrm{N}$ terminal basic leucine zipper domain (bZIP) and a C-terminal W2 domain.

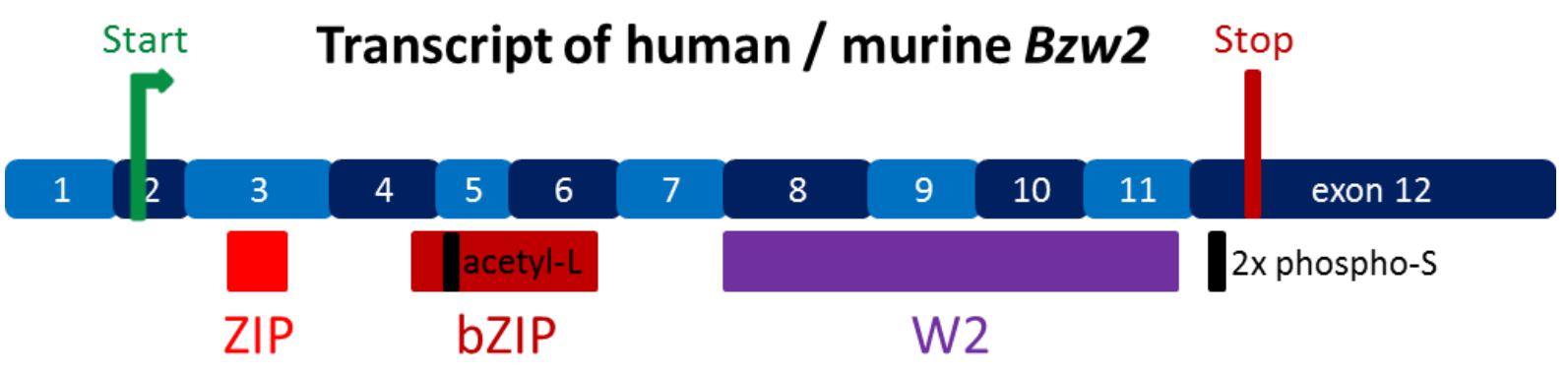

Figure 6: Schematic view of human / murine Bzw2 transcript.

The transcript includes 12 exons. The coding sequence (CDS) starts in exon 2 and ends in exon 12. The putative ZIP domain is coded by exon 3 . The following putative bZIP domain is coded by exons 46 and includes an N6-acetyllysine. The W2 domain is coded by exons 8-11 and is following by two phosphoserines.

C-terminal W2 domain is typical for translation initiation factors. It contains two aromatic/acidic residue-rich regions, which are important for mediating protein-protein interactions. ${ }^{89,} 90$ In BZW2 protein the W2 domain is coded by exons 8-11 (NCBI, NP_001153239.1, NM_001159767.1). The bZIP domain is typical for transcription factors. It consists of a basic region mediating sequence specific DNA binding properties and the leucine zipper requiring holding of two DNA binding regions together. $^{84}$ The basic region of the bZIP domain is described to include the conserved sequence "asparagine $(\mathrm{N})-\mathrm{x} 7$ - arginine $(\mathrm{R})$ / lysine $(\mathrm{K})$ "84 or " $\mathrm{N}-\mathrm{x} 9-$ $\mathrm{R} / \mathrm{K}^{\prime 83}$ and to consist of approximately 16 amino residues. Exactly 9 amino acids in C-terminal direction starts the leucine zipper region of the bZIP domain. It consists of a repetition of leucine $(L)$ or other hydrophobic amino acids (isoleucine $(I)$, valine $(V)$, phenylalanine $(F)$ or methionine $(M)$ ) at every seventh position and forms $\alpha$-helices. ${ }^{84}$ Human and murine BZW2 proteins include a nearly identical 74 amino acids long construct in the N-terminus coding by exons 4-6: "histidine $(H) 105-\mathrm{N} 110-\mathrm{x} 9-$ R120" (as basic region) - x8 - "F129 - x6 - L136 - x6 - F143 - x7 - L151 - x6 L158 - x5 - L164 - x7 - L172 - x5 - V178" as ZIP region (Figure 6 and Figure 7). Here is important to mention that not all hydrophobic amino acids, in the leucine zipper region of the putative bZIP domain, are found on the exactly seventh position in BZW2. Furthermore analysis of the human and murine BZW2 protein sequences 
revealed an $\mathrm{N}$-terminal region suitable to the leucine zipper domain (ZIP). Similar to the bZIP domain, the ZIP domain is typical for transcription factors and is important for DNA binding. It forms alpha helix by a periodic repetition of leucine $(L)$ residues at every seventh position over a distance covering 4-8 helical turns ${ }^{85}$ In the human and murine BZW2 proteins this suitable region ("L38 - L45 - L52 - L59") is coded by exon 3 (Figure 6 and Figure 7). Moreover by similarity an N6-acetyllysine (K117) located in the putative bZIP domain was identified, as well as two C-terminal phosphoserines (S412, S414) (NCBI, NP_001153239.1) (Figure 6 and Figure 7). Thus, BZW2 possesses characteristic typical of an scafold protein placed in a complex, which remains to be investigated.

MNKHQKPVLTGQRFKTRKRDEKEKFEPTVFRDTLVQG

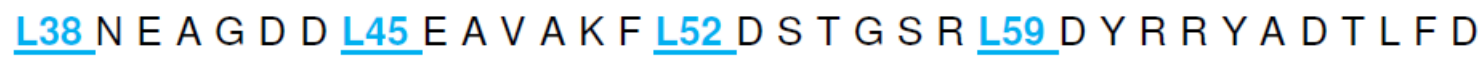
I L V A G S M A P G G TRIDDGDKTKMTNHCV F S A E D $\underline{\mathrm{H} 105}$ E

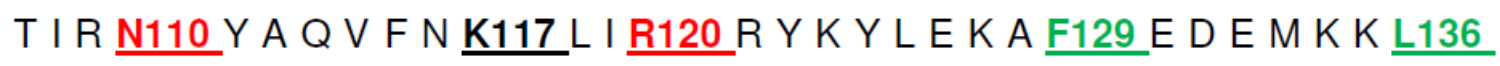

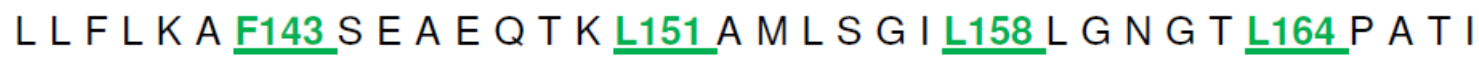
L T S L172 F T D L L 1 178 K E G I A A S F A V K LF K A W M A E K D A N S VTSSLRKANLDKRLLELFPVNRQSVDHFAKYFTDAGLK ELSDFLRVQQSLGTRKELQKELQERLSQECPIKEVVLY VKEEMKRNDLPETAVIGLLWTCIMNAVEWNKKEELVA EQA LKHLKQYAPLLAVFSSQGQSELVLLQKVQEYCYD NIHFMKAFQKIVVLFYKADVLSEEAILKWYKEAHAAKG

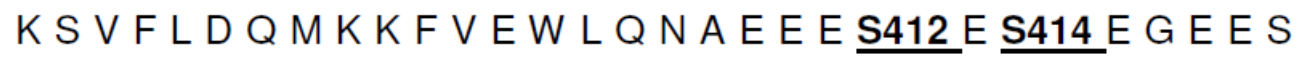

Figure 7: Amino acid sequence of murine BZW2.

The putative ZIP domain is shown in blue (L38 - L45 - L52 - L59). The following putative bZIP domain includes an N6-acetyllysine (K117). It consists of a basic region, shown in red (H105 - N110 $x 9-R 120)$ and a leucine zipper region, shown in green (F129 - x6 - L136 - x6 - F143 - x7 - L151 $x 6-L 158-x 5-L 164-x 7-L 172-x 5-V 178)$. In the C terminus two phosphoserines (S412, S414) are located. 


\subsection{Aims of this study}

The current knowledge demonstrates: (1) that $\mathrm{Wnt} / \beta$-catenin signaling is an essential dynamically regulated player in the developing cardiovascular system; (2) that activation occurs during adaptation of the cardiovascular system in response to injury and (3) that downregulation of $\beta$-catenin is associated with improved cardiac remodeling post-injury. Given the ubiquitous expression and multiple functions of $\beta$ catenin, the identification of cell- and context-specific regulators of the pathways is essential for pharmacological manipulation of the cascade. Based on this knowledge, this work aimed to characterize cardiac specific $\mathrm{Wnt} / \beta$-catenin components with a potential role on modulation of Wnt-context-dependent biological responses in the heart. This study specifically test the hypothesis that BZW2 is a novel cardiac $\mathrm{Wnt} / \mathrm{\beta}$ catenin signaling member, and that is important for processed of cardiogenesis and in adult cardiac homeostasis. 


\section{Materials}

2.1. Life organisms

\subsubsection{Mice}

\begin{tabular}{ll} 
Mice & Genetic Modification \\
\hline NMRI & Albino \\
\hline C75BL/6N & Wild type \\
\hline Bzw2 KI & $\begin{array}{l}\text { Knock-in: causes "first knock-out"; } \\
\text { insert upstream of exon 4 of Bzw2 } \\
\text { gene leads to expression } \\
\text { interruption, resulting in truncated }\end{array}$
\end{tabular}

Source

Animal facility UMG

Charles River

BZW2 protein

\begin{tabular}{|c|c|c|}
\hline KIf15 KO & $\begin{array}{l}\text { Knock-out: exon } 2 \text { of } K I f 15 \text { gene is } \\
\text { replaced by a non-functional LacZ } \\
\text { cassette }\end{array}$ & $\begin{array}{l}\text { W. Birchmeier, Berlin; } \\
\text { Noack C et al., 2012 }\end{array}$ \\
\hline $\begin{array}{l}\alpha M h c- \\
\text { MerCreMer/ } \\
\beta-C a t^{\Delta e \times 3}\end{array}$ & $\begin{array}{l}\text { Inducible cardiac specific } \\
\text { stabilization of } \beta \text {-catenin }\end{array}$ & Noack C et al., $2012^{78}$ \\
\hline $\begin{array}{l}\alpha M h c- \\
\text { MerCreMer/ } \\
\beta-C a t^{\Delta \times 22-6}\end{array}$ & $\begin{array}{l}\text { Inducible cardiac specific } \\
\beta \text {-catenin knock-down }\end{array}$ & $\begin{array}{l}\text { own breading from } \alpha M h c- \\
\text { MerCreMer }^{91} \text { (J. D. Molkentin, } \\
\text { Cincinnati) and } \beta-C a t^{A e \times 2-6} \\
\text { (The Jackson Laboratory) }\end{array}$ \\
\hline
\end{tabular}

2.1.2. Cells

UC DAVIS KOMPRepository

Knockout mouse project own breading from $a M h c-$

MerCreMer ${ }^{91}$ (J. D. Molkentin,

(The Jackson Laboratory)
Source

ATCC, CRL-1573
Cell line

HEK293
Genetic background

human embryonic kidney cells, including Adenovirus 5 DNA $^{92}$
ESC- $\alpha-M H C-\quad$ Double transgenic $\alpha-M H C-G F P / \alpha-$
GFP/a-MHC- MHC-Neomycin resistance cassette
NeoR sequence (NeoR) murine ESCs; DBA background; hygromycin resistant

Cell line
HEK293
ESC- - MHC-
GFP/a-MHC-
NeoR

\author{
A. M. Becker \\ (L. J. Field's Lab, \\ Indianapolis) ${ }^{26,93}$
}

MEFs

NMRI

own production 


\begin{tabular}{|c|c|c|}
\hline $\begin{array}{l}\text { Puromycin } \\
\text { resistant MEFs }\end{array}$ & $\begin{array}{l}\text { Puromycin resistant; C57BL/6 } \\
\text { background }\end{array}$ & $\begin{array}{l}\text { Stem cell technologies, } \\
\text { Cat } \# 000325\end{array}$ \\
\hline $\begin{array}{l}\text { ESC-FLAG- } \\
\text { BZW2 }\end{array}$ & $\begin{array}{l}\text { Transgenic murine ESCs expressing } \\
\text { Flag-BZW2 generated from ESC- } \alpha- \\
\text { MHC-GFP/a-MHC-NeoR }\end{array}$ & own generation \\
\hline
\end{tabular}

2.1.3. Bacteria

\begin{tabular}{|c|c|c|}
\hline Species & Type & Source \\
\hline E. coli & NEB 10-beta & NEB \\
\hline E. coli & XL10-Gold ${ }^{\circledR}$ Ultracompetent Cells & Stratagene \\
\hline
\end{tabular}

2.2. Biological active reagents

2.2.1. Antibodies

\begin{tabular}{|c|c|c|c|c|c|}
\hline \multirow{2}{*}{ Primary antibody } & \multirow{2}{*}{ Species } & \multirow{2}{*}{ Manufact. } & \multicolumn{3}{|c|}{ Dilution/Amount } \\
\hline & & & WB & IF & IP \\
\hline anti- $\beta$-Catenin & mouse & Zymed & $1: 1000$ & & \\
\hline anti- $\beta$-Catenin, clone 14 & mouse & $\begin{array}{l}\text { BD } \\
\text { Biosiences }\end{array}$ & & $1: 100$ & - \\
\hline anti-BZW2, HPA022813 & rabbit & Sigma & $1: 1000$ & - & $1 \mu \mathrm{g}$ \\
\hline anti-BZW2, Q91VK1 & rabbit & $\begin{array}{l}\text { Thermo } \\
\text { scientific }\end{array}$ & - & $1: 100$ & - \\
\hline $\begin{array}{l}\text { anti-Caspase } 3, \mathrm{H} 277 \\
\text { (against procaspase-3) }\end{array}$ & rabbit & Santa Cruz & $1: 1000$ & - & - \\
\hline anti-FLAG, monoclonal & rabbit & Sigma & & $1: 100$ & - \\
\hline anti-FLAG M2, monoclonal & mouse & Sigma & $1: 1000$ & - & $1 \mu \mathrm{g}$ \\
\hline $\begin{array}{l}\text { anti-FLAG M2, } \\
\text { HRP conjugated }\end{array}$ & mouse & Sigma & $1: 1000$ & - & - \\
\hline anti-GAPDH & mouse & $\begin{array}{l}\text { Zytomed } \\
\text { Systems }\end{array}$ & $1: 50000$ & - & - \\
\hline
\end{tabular}




\begin{tabular}{|c|c|c|c|c|c|}
\hline anti-HA & mouse & Sigma & - & $1: 100$ & - \\
\hline $\begin{array}{l}\text { anti-HA, HRP conjugated, } \\
\text { clone HA7 }\end{array}$ & mouse & Sigma & $1: 1000$ & - & - \\
\hline anti-Lamin A/C & goat & Santa Cruz & $1: 200$ & - & - \\
\hline anti-Tpt1, clone 2C4 & mouse & Sigma & $1: 1000$ & - & - \\
\hline $\begin{array}{l}\text { anti-Cardiac Troponin T, } \\
\text { clone 3D6 }\end{array}$ & mouse & Abcam & - & $1: 100$ & - \\
\hline normal mouse $\lg \mathrm{G}_{1}$ & mouse & Santa Cruz & - & $1: 200$ & $1 \mu \mathrm{g}$ \\
\hline normal rabbit lgG & rabbit & Santa Cruz & - & $1: 200$ & $1 \mu \mathrm{g}$ \\
\hline
\end{tabular}

\begin{tabular}{|c|c|c|c|c|}
\hline \multirow{2}{*}{ Secondary antibody } & \multirow{2}{*}{ Species } & \multirow{2}{*}{ Manufacturer } & \multicolumn{2}{|c|}{ Dilution/Amount } \\
\hline & & & WB & IF \\
\hline anti-mouse-Alexa Fluor 488 & goat & Invitrogen & - & $1: 200$ \\
\hline anti-rabbit-Alexa Fluor 594 & goat & Invitrogen & - & $1: 200$ \\
\hline $\begin{array}{l}\text { anti-goat-lgG, } \\
\text { HRP conjugated }\end{array}$ & rabbit & Dako & $1: 5000$ & - \\
\hline $\begin{array}{l}\text { anti-mouse-lgG, } \\
\text { HRP conjugated }\end{array}$ & rabbit & Dako & $1: 10000$ & - \\
\hline $\begin{array}{l}\text { anti-rabbit-lgG, } \\
\text { HRP conjugated }\end{array}$ & goat & Dako & $1: 5000$ & - \\
\hline
\end{tabular}

2.2.2. Enzymes and supplemented buffers

Enzymes

Fast AP Thermosensitive Alkaline Phosphatase $1 \mathrm{U} / \mu \mathrm{L}+10 \times$ reaction buffer for $A P$

Fast Digest Enzymes + 10x Fast Digest buffer / Fast Digest Green buffer

GoTaq® qPCR MasterMix 2x + CXR Reference Dye

M-MLV RT 5× Buffer + M-MLV Reverse Transcriptase 200 $\mathrm{U} / \mu \mathrm{L}$

\section{Manufacturer}

Thermo Scientific

Thermo Scientific

Promega

Promega 
Phusion DNA Polymerase $2 \mathrm{U} / \mu \mathrm{L}+5 \times$ Phusion HF buffer Thermo Scientific

T4 DNA Ligase $5 \mathrm{U} / \mu \mathrm{L}+10 \times$ T4 DNA Ligase buffer Thermo Scientific

Trypsin EDTA $0.05 \%$ / 0.25\%

Gibco

Trypsin $2.5 \%$

Gibco

2.2.3. Inhibitors

\begin{tabular}{lll} 
Inhibitor & Dilution & Manufacturer \\
\hline $\begin{array}{l}\text { PhosSTOP Phosphatase Inhibitor } \\
\text { Cocktail }\end{array}$ & $\begin{array}{l}1 \text { tablet } / 1 \mathrm{ml} \mathrm{H}_{2} \mathrm{O} \\
(10 \times)\end{array}$ & Roche \\
\hline $\begin{array}{l}\text { Protease Inhibitor Cocktail, Complete } \\
\text { Mini EDTA free }\end{array}$ & $\begin{array}{l}1 \text { tablet } / 1.5 \mathrm{ml} \mathrm{H}_{2} \mathrm{O} \\
(10 \times)\end{array}$ & Roche
\end{tabular}

2.2.4. Drugs

\begin{tabular}{l} 
Drug \\
\hline Forene \\
\hline Novaminsulfon-ratiopharm ${ }^{\circledR} 500$ \\
\hline Tamoxifen \\
2.3. Media and buffers
\end{tabular}

Manufacturer

Abbvie

Ratiopharm

Sigma-Aldrich

2.3.1. Media and supplements

\section{Supplement}

\begin{tabular}{l} 
Adenosine \\
L(+)-Ascorbic acid \\
\hline Cytidine \\
\hline DMEM (+ Glucose, - Pyruvate), \#61965-059
\end{tabular}

Manufacturer

Sigma

AppliChem

Sigma

Gibco 
DMEM (+ Glucose, + L-Glutamine, + HEPES, - Pyruvate), \#42430-082

Gibco

Fetal bovine serum (FBS), \#10270-106

Gibco

L-Glutamin (200 mM, 100x), \#25030-123

Gibco

Guanosine

Sigma

Iscove-Medium, \#F0465

Biochrom

Leukemia inhibitory factor (LIF, 107 U/ml, ESGRO) \#ESG1107

Millipore

2-Mercaptoethanol (50 mM), \#31350010

Gibco

Non-essential amino acids solution (100x), \#11140-068

Gibco

PBS (- Ca, - Mg), \#14190-169

Gibco

Puromycin 10 mg/ml, \#A11138-03

Gibco

Penicillin-Streptomycin (100x), \#15140-122

Gibco

Sodium pyruvate (100 mM), \#11360-039

Gibco

Thymidine

Sigma

Uridine

Sigma

\begin{tabular}{lll} 
Medium & \multicolumn{1}{l}{ Ingredient } & Volume \\
\hline HEK293 medium & \multicolumn{1}{l}{ DMEM } & $450 \mathrm{ml}$ \\
\cline { 2 - 3 } & FBS & $50 \mathrm{ml}$ \\
\hline \multirow{2}{*}{ PEF medium } & DMEM & $5 \mathrm{ml}$ \\
\cline { 2 - 3 } & FBS & $500 \mathrm{ml}$ \\
\cline { 2 - 3 } & Penicillin-Streptomycin & $50 \mathrm{ml}$ \\
\cline { 2 - 3 } & Non-essential amino acids & $5.5 \mathrm{ml}$ \\
\hline mESC medium & DMEM & $5.5 \mathrm{ml}$ \\
\cline { 2 - 3 } & FBS & $500 \mathrm{ml}$ \\
\cline { 2 - 3 } & Penicillin-Streptomycin & $92 \mathrm{ml}$ \\
\hline
\end{tabular}




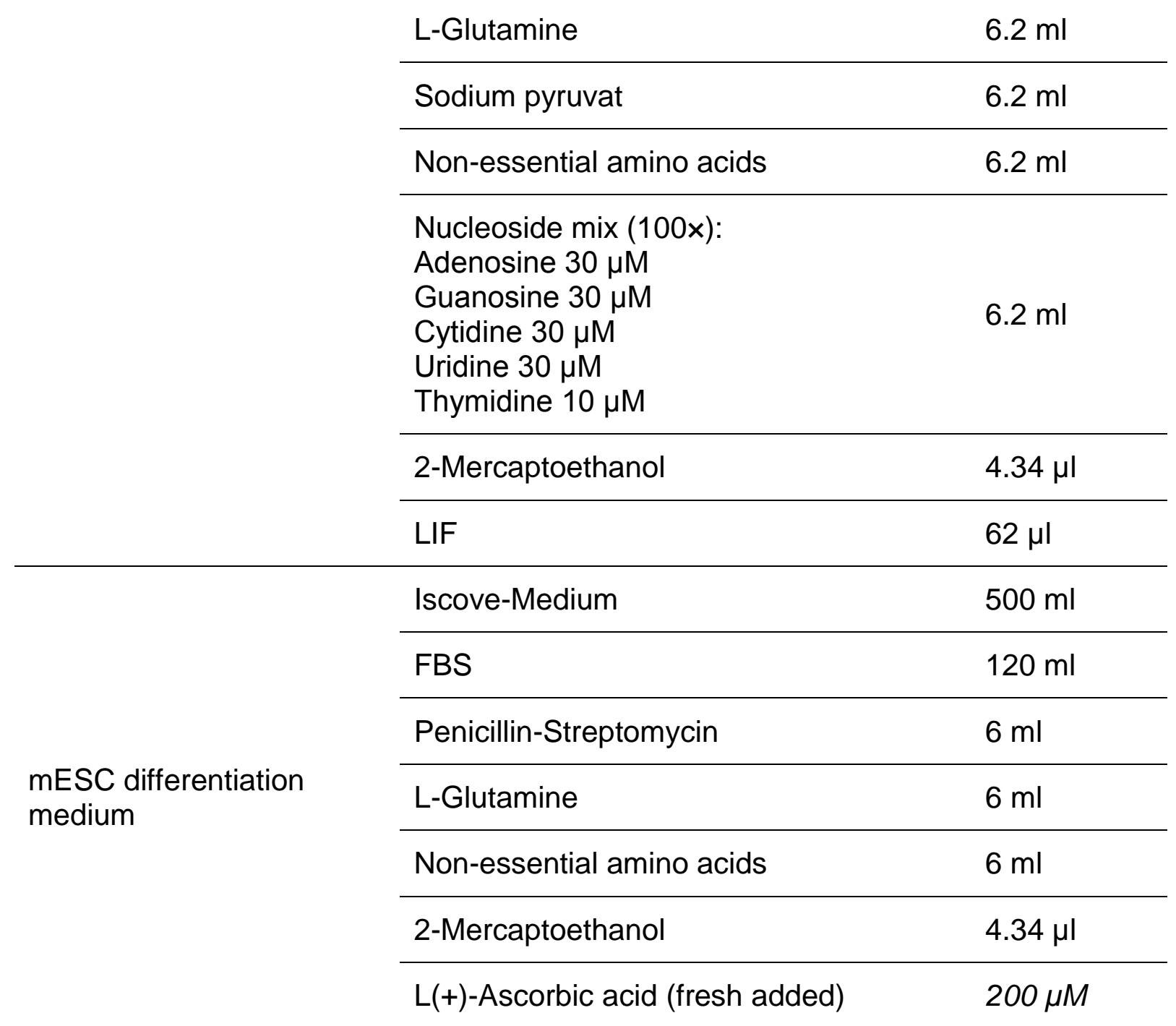

2.3.2. Buffers and compositions

Protein immunoprecipitation

\begin{tabular}{lll} 
Buffer & \multicolumn{1}{l}{ Ingredient } & Amount/Volume \\
\hline HEPES & $596 \mathrm{mg}$ \\
\hline $\mathrm{NaCl}$ & $438 \mathrm{mg}$ \\
\cline { 2 - 3 } IP-lysis buffer & EDTA $\mathrm{mM} \mathrm{MCl}_{2}$ & $7 \mathrm{mg}$ \\
\hline Triton-X 100 & $14.6 \mathrm{mg}$ \\
\hline glycerol & $0.5 \mathrm{ml}$ \\
\hline
\end{tabular}


$\rightarrow$ Fill to $50 \mathrm{ml}$ with $\mathrm{ddH}_{2} \mathrm{O}(\mathrm{pH} 7.5)$

\begin{tabular}{lll}
\hline & IP-lysis buffer & $750 \mu \mathrm{l}$ \\
\cline { 2 - 3 } $\begin{array}{l}\text { IP-lysis buffer } \\
+ \text { inhibitors }\end{array}$ & Proteinase inhibitor (10x) & $150 \mu \mathrm{l}$ \\
\cline { 2 - 3 } & Phosphatase inhibitor (10x) & $100 \mu \mathrm{l}$
\end{tabular}

$\underline{\text { Cell lysis }}$

\begin{tabular}{|c|c|c|}
\hline Buffer & Ingredient & Amount/Volume \\
\hline \multirow{8}{*}{ Bäuerle buffer } & HEPES & $2.38 \mathrm{~g}$ \\
\hline & $\mathrm{NaCl}$ & $10.2 \mathrm{~g}$ \\
\hline & Glycerol & $100 \mathrm{ml}$ \\
\hline & $\mathrm{MgCl}_{2}$ & $102 \mathrm{~g}$ \\
\hline & EDTA & $93 \mathrm{mg}$ \\
\hline & EGTA & $19 \mathrm{mg}$ \\
\hline & NP-40 & $5 \mathrm{ml}$ \\
\hline & $\rightarrow$ Fill to $500 \mathrm{ml}$ with $\mathrm{ddH}_{2} \mathrm{O}$ & \\
\hline \multirow{3}{*}{ Lysis buffer } & Bäuerle buffer & $750 \mu \mathrm{l}$ \\
\hline & Proteinase inhibitor $(10 x)$ & $150 \mu \mathrm{l}$ \\
\hline & Phosphatase inhibitor $(10 x)$ & $100 \mu l$ \\
\hline \multirow{7}{*}{ Hypertonic buffer } & HEPES & $2,98 \mathrm{~g}$ \\
\hline & $\mathrm{KCl}$ & $0,93 \mathrm{~g}$ \\
\hline & $\mathrm{NaCl}$ & $4,38 \mathrm{~g}$ \\
\hline & EDTA & $0,009 \mathrm{~g}$ \\
\hline & DTT & $0,039 \mathrm{~g}$ \\
\hline & Glycerol & $25 \mathrm{ml}$ \\
\hline & $\rightarrow$ Fill to $250 \mathrm{ml}$ with $\mathrm{ddH}_{2} \mathrm{O}$ & \\
\hline \multirow{2}{*}{ Hypotonic buffer } & HEPES & $0,596 \mathrm{~g}$ \\
\hline & $\mathrm{KCl}$ & $0,186 \mathrm{~g}$ \\
\hline
\end{tabular}




\begin{tabular}{ll}
$\mathrm{MgCl}_{2}$ & $0,102 \mathrm{~g}$ \\
\hline EDTA & $0,009 \mathrm{~g}$ \\
\hline DTT & $0,039 \mathrm{~g}$ \\
\hline
\end{tabular}

$\rightarrow$ Fill to $250 \mathrm{ml}$ with $\mathrm{ddH}_{2} \mathrm{O}$

Polyacrylamide gel electrophoresis

\begin{tabular}{|c|c|c|}
\hline Buffer & Ingredient & Amount/Volume \\
\hline \multirow{6}{*}{ Laemmli buffer } & Tris $\mathrm{HCl}, \mathrm{pH} 6.8$ & $2 \mathrm{ml}$ \\
\hline & Bromphenol blue $0.5 \%$ & $0.5 \mathrm{ml}$ \\
\hline & SDS & $0.8 \mathrm{~g}$ \\
\hline & Glycerin $100 \%$ & $1 \mathrm{ml}$ \\
\hline & $\beta$-Mercaptoethanol & $1 \mathrm{ml}$ \\
\hline & $\rightarrow$ Fill to $10 \mathrm{ml}$ with $\mathrm{ddH}_{2} \mathrm{O}$ & \\
\hline \multirow{6}{*}{ Separating gel $(12 \%, 2 x)$} & $\mathrm{dd}_{2} \mathrm{O}$ & $3.3 \mathrm{ml}$ \\
\hline & Acrylamide $30 \%$ & $4.0 \mathrm{ml}$ \\
\hline & Tris $1.5 \mathrm{M}, \mathrm{pH} 8.8$ & $2.5 \mathrm{ml}$ \\
\hline & SDS $10 \%$ & $0.1 \mathrm{ml}$ \\
\hline & APS $10 \%$ & $0.1 \mathrm{ml}$ \\
\hline & TEMED & $0.004 \mathrm{ml}$ \\
\hline \multirow{6}{*}{ Stacking gel $(6 \%, 2 \times)$} & $\mathrm{dd}_{2} \mathrm{O}$ & $2.8 \mathrm{ml}$ \\
\hline & Acrylamide $30 \%$ & $0.85 \mathrm{ml}$ \\
\hline & Tris $0.5 \mathrm{M}, \mathrm{pH} 6.8$ & $1.25 \mathrm{ml}$ \\
\hline & SDS 10\% & $0.05 \mathrm{ml}$ \\
\hline & APS $10 \%$ & $0.05 \mathrm{ml}$ \\
\hline & TEMED & $0.005 \mathrm{ml}$ \\
\hline \multirow{2}{*}{ Running buffer (10x) } & Tris base & $30.3 \mathrm{~g}$ \\
\hline & Glycine & $144 \mathrm{~g}$ \\
\hline
\end{tabular}


$\rightarrow$ Fill to 1 I with $\mathrm{ddd}_{2} \mathrm{O}$

$\underline{\text { Western blot }}$

\begin{tabular}{|c|c|c|}
\hline Buffer & Ingredient & Amount/volume \\
\hline \multirow{2}{*}{ Blocking solution } & Milk, non-fatty dried & $5 \%$ \\
\hline & $\rightarrow$ Dissolved in TBST & \\
\hline \multirow{4}{*}{ Transfer buffer $(10 x)$} & Tris base & $75.6 \mathrm{~g}$ \\
\hline & Glycine & $74.4 \mathrm{~g}$ \\
\hline & SDS & $15 \mathrm{~g}$ \\
\hline & $\rightarrow$ Fill to 1 I with $\mathrm{ddd}_{2} \mathrm{O}$ & \\
\hline \multirow{3}{*}{$\begin{array}{l}\text { Transfer buffer + } \\
\text { Methanol }\end{array}$} & Transfer buffer (10x) & $10 \mathrm{ml}$ \\
\hline & Methanol & $20 \mathrm{ml}$ \\
\hline & $\rightarrow$ Fill to $100 \mathrm{ml}$ with $\mathrm{dd}_{2} \mathrm{O}$ & \\
\hline \multirow{3}{*}{ TBST } & Tris/HCl 1 M, pH 7.6 & $20 \mathrm{ml}$ \\
\hline & $\mathrm{NaCl} 5 \mathrm{M}$ & $33 \mathrm{ml}$ \\
\hline & Tween-20 & $1 \mathrm{ml}$ \\
\hline
\end{tabular}

$\rightarrow$ Fill to 1 I with $\mathrm{ddd}_{2} \mathrm{O}$

$\underline{\text { Cardiac cells isolation }}$

Buffer

10x Perfusion Buffer $\mathrm{pH} 7.4$
Ingredient

Amount/Volume

\begin{tabular}{ll}
$\mathrm{NaCl}$ & $70.3 \mathrm{~g}$ \\
\hline $\mathrm{KCl}$ & $11 \mathrm{~g}$ \\
\hline $\mathrm{KH}_{2} \mathrm{PO}_{4}$ & $0.82 \mathrm{~g}$ \\
\hline $\mathrm{Na}_{2} \mathrm{HPO}_{4} \times 2 \mathrm{H}_{2} \mathrm{O}$ & $1.1 \mathrm{~g}$ \\
\hline $\mathrm{Mg}_{2} \mathrm{SO}_{4} \times 7 \mathrm{H}_{2} \mathrm{O}$ & $3 \mathrm{~g}$ \\
\hline HEPES & $23.83 \mathrm{~g}$
\end{tabular}


$\rightarrow$ Fill to $1 \mathrm{I}$ with dd $\mathrm{H}_{2} \mathrm{O}$

\begin{tabular}{|c|c|c|}
\hline \multirow{6}{*}{$1 \times$ Perfusion Buffer } & $\mathrm{NaHCO}_{3}$ & $0.195 \mathrm{~g}$ \\
\hline & Taurin & $1.875 \mathrm{~g}$ \\
\hline & BDM & $0.5 \mathrm{~g}$ \\
\hline & Glucose & $0.5 \mathrm{~g}$ \\
\hline & $10 \times$ Perfusion Buffer & $50 \mathrm{ml}$ \\
\hline & $\rightarrow$ Fill to $0.5 \mathrm{ml}$ with $\mathrm{ddH}_{2} \mathrm{O}$ & \\
\hline \multirow{3}{*}{ Digestion Buffer } & $\begin{array}{l}\text { Collagenase from Clostridium } \\
\text { histolyticum }\end{array}$ & $0.1 \mathrm{~g}$ \\
\hline & $100 \mu \mathrm{M} \mathrm{CaCl}_{2}$ & $6.25 \mu \mathrm{l}$ \\
\hline & $\rightarrow$ Fill to $50 \mathrm{ml}$ with $1 \times$ Perfusic & \\
\hline \multirow[b]{2}{*}{ Stopping Buffer } & FBS & $5 \mathrm{ml}$ \\
\hline & $100 \mu \mathrm{M} \mathrm{CaCl}{ }_{2}$ & $6.25 \mu \mathrm{l}$ \\
\hline
\end{tabular}

$\rightarrow$ Fill to $50 \mathrm{ml}$ with $1 \times$ Perfusion Buffer

Immunofluorescence staining

\begin{tabular}{lll} 
Buffer & Ingredient & Percentage \\
\hline \multirow{3}{*}{ Buffer A } & BSA & $0.2 \%$ \\
\cline { 2 - 3 } & $\rightarrow$ Dissolved in PBS & $0.3 \%$ \\
\hline Buffer B & BSA & $5 \%$ \\
\cline { 2 - 3 } & Triton X 100 & $0.1 \%$ \\
\cline { 2 - 3 } & $\rightarrow$ Dissolved in PBS & $2 \%$ \\
\hline Buffer C & BSA & $0.1 \%$ \\
\cline { 2 - 3 } & Triton X 100 & $2 \%$ \\
\cline { 2 - 3 } & $\rightarrow$ Dissolved in PBS
\end{tabular}

$\rightarrow$ Dissolved in PBS 
Other buffers

\begin{tabular}{lll} 
Buffer & Ingredient & Amount \\
\hline & Tris base & $242,2 \mathrm{~g}$ \\
\cline { 2 - 3 } TAE buffer (50x) & EDTA & $18,6 \mathrm{~g}$ \\
\cline { 2 - 3 } & Acetic acid & $57,1 \mathrm{~g}$
\end{tabular}

2.4. Plasmids and oligonucleotides

2.4.1. Plasmids

\begin{tabular}{|c|c|c|}
\hline Plasmid & Insert & Source \\
\hline pcDNA3.1+-Flag-KIf15-Neo & $\begin{array}{l}\text { cloning source for } \\
\text { pcDNA3. } 1^{+}-\text {Flag-Neo }\end{array}$ & $\begin{array}{l}\text { Noack C et al., } \\
2012^{78}\end{array}$ \\
\hline pcDNA3.1+-Flag-Bzw2-Neo & $\begin{array}{l}\text { full length transcript of murine } \\
\text { Bzw2, neomycin resistance }\end{array}$ & own cloning \\
\hline pcDNA3.1 $1^{+}-$Flag-Bzw2- $\Delta C$ & $\begin{array}{l}\mathrm{N} \text { terminus of murine } B z w 2 \text {, } \\
\text { neomycin resistance }\end{array}$ & own cloning \\
\hline pcDNA3.1 $1^{+}-$Flag-Bzw2- $\Delta N$ & $\begin{array}{l}\mathrm{C} \text { terminus of murine } B z w 2 \text {, } \\
\text { neomycin resistance }\end{array}$ & own cloning \\
\hline pcDNA3.1+-Flag-Bzw2-Hygro & $\begin{array}{l}\text { murine } B z w 2, \text { hygromycin } \\
\text { resistance }\end{array}$ & own cloning \\
\hline pcDNA3.1 $1^{+}$-Flag-Bzw2-Puro & $\begin{array}{l}\text { murine } B z w 2 \text {, puromycin } \\
\text { resistance }\end{array}$ & own cloning \\
\hline $\begin{array}{l}\text { pcDNA3. } 1^{+}-\text {Flag-Bzw2-Puro- } \\
\text { Orange }\end{array}$ & $\begin{array}{l}\text { murine } B z w 2 \text {, puromycin } \\
\text { resistance, mOrange cassette }\end{array}$ & own cloning \\
\hline pcDNA3.1 $1^{+}-H A-K I f 15$ & human KIf15, HA-tag & $\begin{array}{l}\text { Noack C et al., } \\
2012^{78}\end{array}$ \\
\hline pcDNA3.1 $1^{+}-\beta-C a t-c-M y c$ & murine $\beta$-catenin, c-myc-Tag & $\begin{array}{l}\text { Noack C et al., } \\
2012^{78}\end{array}$ \\
\hline$p c D N A 3.1^{+}-$Flag- $\beta-C a t-\Delta N$ & $\begin{array}{l}\text { murine } \beta \text {-catenin without exon } \\
\text { 3, FLAG-tag }\end{array}$ & $\begin{array}{l}\text { Noack C et al., } \\
2012^{78}\end{array}$ \\
\hline$p C S 2^{+}-T C F 4 E-H A$ & human Tcf4, isoform 2, HA-tag & Prof. A. Hecht \\
\hline
\end{tabular}




\begin{tabular}{|c|c|c|}
\hline pcDNA3.1 $1^{+}$ & negative control & Invitrogen \\
\hline pTOPflash & $\begin{array}{l}\beta \text {-Catenin/TCF dependent } \\
\text { luciferase-reporter }\end{array}$ & Upstate \\
\hline pFOPflash & negative control for pTOPflash & Upstate \\
\hline$p R L-C M V$ & Renilla luciferase-reporter & Promega \\
\hline pGL4.10-Bzw2-promoter & $\begin{array}{l}\text { putative Bzw2 promoter } \\
\text { dependent luciferase-reporter }\end{array}$ & own cloning \\
\hline$p G L 4.10$ & $\begin{array}{l}\text { negative control for } p G L 4.10 \text { - } \\
\text { Bzw2-promoter }\end{array}$ & Promega \\
\hline
\end{tabular}

\subsubsection{Cloning primers}

Oligonucleotides were designed manually or using "Primer3web" version 4.0.0. freeware (http://primer3.ut.ee/) and synthetized by Eurofins Genomics.

\begin{tabular}{|c|c|c|}
\hline Primer & Sequence $\left(5^{\prime} \rightarrow 3^{\prime}\right)$ & Characteristics \\
\hline Notl-Bzw2-fwd & TTGCGGCCGCTGAATAAGCAT & $\begin{array}{l}\text { Notl, ATG was } \\
\text { replaced by CTG }\end{array}$ \\
\hline Bzw2-Xbal-rev3 & GGGTCTAGATTAGCTTTCTTCG & Xbal \\
\hline$\Delta \mathrm{C}-\mathrm{Bzw} 2-\mathrm{fwd}$ & AAAAGCGGCCGCTGAATAAGCATC & $\begin{array}{l}\text { Notl, ATG was } \\
\text { replaced by CTG }\end{array}$ \\
\hline$\Delta \mathrm{C}-\mathrm{Bzw} 2-\mathrm{rev}$ & $\begin{array}{l}\text { TGGTCTAGAGGTTATCGGAGAAAGT } \\
\text { CC }\end{array}$ & Xbal, stop codon \\
\hline$\Delta N-B z w 2-f w d$ & AAAGCGGCCGCGAGTCCAGCAGT & Notl \\
\hline$\Delta N-B z w 2-r e v$ & GCCCTCTAGATTAGCTTTCTTCGCC & Xbal, stop codon \\
\hline Avrll-Puro-fwd & CTTCCTAGGTAGCCCAAGCTTA & Avrll \\
\hline Puro-BstZ17I-rev & GGAGTATACGTTGTTCCAGACG & BstZ17I \\
\hline BstZ17I-IRES-fwd & CCCGTATACCCCTTCTTGACGAGTT & BstZ17I \\
\hline Orange-BstZ17I-rev & AAAGTATACAATCGCTCTAGAGCGG & BstZ17I \\
\hline mBZW2prom-fwd & $\begin{array}{l}\text { AACGGTACCTCTTTTCCAACCCAGTG } \\
\text { TCC }\end{array}$ & Kpnl \\
\hline
\end{tabular}


mBZW2prom-rev

TTTGCTAGCGTACATGGTCAACCCCA ACC

Nhel

2.4.3. Genotyping primers

\begin{tabular}{|c|c|c|c|}
\hline & Primer & Sequence $\left(5^{\prime} \rightarrow 3^{\prime}\right)$ & $\begin{array}{l}\text { Fragment } \\
\text { size [bp] }\end{array}$ \\
\hline \multirow{3}{*}{$\begin{array}{l}\text { Bzw2 } \\
\mathrm{Kl} \\
\text { mice }\end{array}$} & Bzw2-F & TAACGTGGTTGACACCACAGTTGG & \multirow{3}{*}{$\begin{array}{c}\text { KI: } 560 \\
\text { WT: } 326\end{array}$} \\
\hline & Bzw2-Neo-F & GGGATCTCATGCTGGAGTTCTTCG & \\
\hline & Bzw2-ttR & TTATTCACAGTGGCACTTCTGCTGC & \\
\hline \multirow{2}{*}{$\begin{array}{l}\text { ESC- } \\
\text { FLAG- } \\
\text { BZW2 }\end{array}$} & $\begin{array}{l}\text { CMV-mBzw2 } 2^{\text {ex3-4 }}- \\
\text { fwd }\end{array}$ & GCGTGTACGGTGGGAGGTCTATATA & \multirow{2}{*}{425} \\
\hline & $\begin{array}{l}\text { CMV-mBzw2 } \\
\text { rev }\end{array}$ & GTTCCTCCAGGGGCAAGCATACT & \\
\hline
\end{tabular}

2.4.4. qPCR primers

\begin{tabular}{|c|c|c|c|}
\hline Gene & & Sequence $\left(5^{\prime} \rightarrow 3^{\prime}\right)$ & $\begin{array}{l}\text { Fragment } \\
\text { size [bp] }\end{array}$ \\
\hline \multirow{2}{*}{ murine $\beta$-actin } & fwd & CACACCCGCCACCAGTTC & \multirow{2}{*}{164} \\
\hline & rev & СССАТТСССАССАТСАСАСС & \\
\hline \multirow{2}{*}{$\begin{array}{l}\text { murine Anp } \\
\text { (Nppa) }\end{array}$} & fwd & САTCACCCTGGGCTTCTTCCT & \multirow{2}{*}{405} \\
\hline & rev & TGGGCTCCAATCCTGTCAATC & \\
\hline \multirow{2}{*}{ murine axin2 } & fwd & AGCCGCCATAGTC & \multirow{2}{*}{145} \\
\hline & rev & GGTCCTCTTCATAGC & \\
\hline \multirow{2}{*}{ murine Bmp4 } & fwd & TGGGGAGGAGGAGGAGGAAGAG & \multirow{2}{*}{173} \\
\hline & rev & GGATGCTGCTGAGGTTGAAGAGG & \\
\hline \multirow{2}{*}{$\begin{array}{l}\text { murine Bnp } \\
\text { (Nppb) }\end{array}$} & fwd & AAGTCCTAGCCAGTCTCCAGAGC & \multirow{2}{*}{268} \\
\hline & rev & CTTCAGTGCGTTACAGCCCAAAC & \\
\hline murine Bry & fwd & CCGGTGCTGAAGGTAAATGT & 274 \\
\hline
\end{tabular}




\begin{tabular}{|c|c|c|c|}
\hline & rev & CCTCCATTGAGCTTGTTGGT & \\
\hline \multirow{2}{*}{ murine Bzw2 } & fwd & TGAAGGAGCTGTCGGACTTT & \multirow{2}{*}{228} \\
\hline & rev & CAACCAGCTCCTCCTTCTTG & \\
\hline \multirow{2}{*}{$\begin{array}{l}\text { murine Ctnnb } \\
\text { ( } \beta \text {-catenin) }\end{array}$} & fwd & ACTGCTGGGACTCTG & \multirow{2}{*}{130} \\
\hline & rev & TGATGGCGTAGAACAG & \\
\hline \multirow{2}{*}{ CMV-mBzw2 $2^{e x 3-4}$} & fwd & GCGTGTACGGTGGGAGGTCTATATA & \multirow{2}{*}{425} \\
\hline & rev & GTTCCTCCAGGGGCAAGCATACT & \\
\hline \multirow{2}{*}{ murine c-Myc } & fwd & TTCTATCACCAGCAACAG & \multirow{2}{*}{132} \\
\hline & rev & ATAGGATGGAGAGCAGAG & \\
\hline \multirow{2}{*}{ murine Gapdh } & fwd & ATGTTCCAGTATGACTCCACTCACG & \multirow{2}{*}{171} \\
\hline & rev & GAAGACACCAGTAGACTCCACGACA & \\
\hline \multirow{2}{*}{ murine Mesp1 } & fwd & GGTAGCGGACAGCGGCAGAG & \multirow{2}{*}{102} \\
\hline & rev & CACGGATGGCGGCAAGAAGC & \\
\hline \multirow{2}{*}{ murine Oct4 } & fwd & GCTTCAGACTTCGCCTCCTCACC & \multirow{2}{*}{191} \\
\hline & rev & GCCATCCCTCCGCAGAACTCG & \\
\hline \multirow{2}{*}{ murine Sox17 } & fwd & CTCGGGGATGTAAAGGTGAA & \multirow{2}{*}{229} \\
\hline & rev & GCTTCTCTGCCAAGGTCAAC & \\
\hline \multirow{2}{*}{ murine Tbp } & fwd & CCAGAACAACAGCCTTCCACC & \multirow{2}{*}{322} \\
\hline & rev & CAACGGTGCAGTGGTCAGAGT & \\
\hline \multirow{2}{*}{$\begin{array}{l}\text { murine Tcf7l2 } \\
\text { (Tcf4) }\end{array}$} & fwd & AACGGAACAGACAGTATAATGG & \multirow{2}{*}{147} \\
\hline & rev & CACAGGAGTTGAAGGATTGG & \\
\hline \multirow{2}{*}{ murine Tpt1 } & fwd & AAAAACAATGCCACCACTCC & \multirow{2}{*}{224} \\
\hline & rev & GTTGCTCTCCTGGACTACCG & \\
\hline
\end{tabular}


2.5. Other chemicals and consumables

2.5.1. Kits

\begin{tabular}{|c|c|}
\hline Kit & Manufacturer \\
\hline Mouse ES Cell Nucleofector ${ }^{\circledR}$ Kit & Lonza \\
\hline Dual-Luciferase ${ }^{\circledR}$ Reporter Assay & Promega \\
\hline NucleoBond ${ }^{\circledR}$ Xtra Maxi & \multirow{6}{*}{ Macherey-Nagel } \\
\hline NucleoSpin ${ }^{\circledR}$ Gel and PCR Clean-up & \\
\hline NucleoSpin ${ }^{\circledR}$ Plasmid (NoLid) & \\
\hline NucleoSpin ${ }^{\circledR}$ RNA & \\
\hline NucleoSpin ${ }^{\circledR}$ RNA Midi & \\
\hline NucleoSpin ${ }^{\circledR}$ Tissue & \\
\hline REDExtract-N-Amp Tissue PCR Kit & Sigma-Aldrich \\
\hline
\end{tabular}

2.5.2. Ladders

Ladder

Manufacturer

GeneRuler 1 kb DNA Ladder

GeneRuler 100 bp DNA Ladder

MassRuler DNA Ladder Mix

Thermo Scientific

6x Loading Dye

Spectra Multicolor Broad Range Protein Ladder

Thermo Scientific 
2.5.3. Other chemicals

Substance

\begin{tabular}{|c|c|}
\hline Acetic acid $100 \%$ & Merck \\
\hline Acrylamide $30 \%$ & AppliChem \\
\hline Agarose UltraPure ${ }^{T M}$ & AppliChem \\
\hline Ammonium persulfate (APS) & Life technologies \\
\hline Ampicillin & AppliChem \\
\hline 2,3-BDM & Sigma Aldrich \\
\hline Bromophenol blue & AppliChem \\
\hline BSA (bovine serum albumin) & Sigma-Aldrich \\
\hline Bradford reagent, Rothi-Quant & Roth \\
\hline Calcium chloride & Roth \\
\hline Chemoluminescence reagent (Femto Lucent) & G Biosciences \\
\hline Collagen & Internal production \\
\hline DAPI/Antifade solution & $\begin{array}{l}\text { Chemicon } \\
\text { International }\end{array}$ \\
\hline DMSO & Thermo Scientific \\
\hline DSP & Thermo Scientific \\
\hline dNTP PCR Nucleotide-Mix (10 mM) & Promega \\
\hline DTT 100mM & Promega \\
\hline EDTA & AppliChem \\
\hline EGTA & AppliChem \\
\hline Ethanol & Carl Roth \\
\hline Ethidium bromide & Sigma \\
\hline Gelatine & Sigma-Aldrich \\
\hline Glucose & Roth \\
\hline Glycerol & Gerbu \\
\hline
\end{tabular}




\begin{tabular}{|c|c|}
\hline Glycine & AppliChem \\
\hline HEPES, ultrapure & Carl Roth \\
\hline Roti@-Histofix $4 \%$ & Carl Roth \\
\hline Hoechst & Life technologies \\
\hline LB Agar / LB Medium & AppliChem \\
\hline Magnesium chloride & AppliChem \\
\hline$\beta$-Mercaptoethanol & AppliChem \\
\hline Methanol & Carl Roth \\
\hline Milk, non-fatty dried & Carl Roth \\
\hline Moviol $^{\circledR}$ & Carl Roth \\
\hline NP-40 & Sigma \\
\hline Poly-L-lysine & Sigma \\
\hline Ponceau S & AppliChem \\
\hline Potassium chloride & Carl Roth \\
\hline 2-Propanol & AppliChem \\
\hline Protein G Sepharose 4 Fast Flow & GE Healthcare \\
\hline SDS (Sodiumdodecylsulfat) & AppliChem \\
\hline Sodium chloride & Carl Roth \\
\hline TEMED (N,N,N`,N`-Tetramethylethylendiamin) & AppliChem \\
\hline Toluene & Roth \\
\hline TransFectin & Bio Rad \\
\hline Tris Base, ultrapure & Carl Roth \\
\hline Tris-hydrochloride & Carl Roth \\
\hline TritonX-100 & AppliChem \\
\hline TurboFect & Thermo Scientific \\
\hline Tween-20 & Sigma-Aldrich \\
\hline
\end{tabular}


2.6. Devices and software

2.6.1. Devices

Device

7900 HT Fast Real-Time PCR System

Beckman J2-21 Floor Model Centrifuge

CASY cell counter Model TT

Centrifuge $5417 \mathrm{C} / \mathrm{R}$

Electrophoresis chamber PerfectBlue ${ }^{\mathrm{TM}}$ Maxi L

Electroporator Nucleofector ${ }^{\mathrm{TM}} 2 \mathrm{~b}$ Device

FlexStation 3 Multi-Mode Microplate Reader

Fully Automated Rotary Microtome Leica RM2255

GelDoc $^{\text {TM }}$ XR Imaging System

Heated Paraffin Embedding Module Leica EG1150 H

Heraguard ${ }^{\mathrm{TM}} \mathrm{ECO}$ Clean bench

Incubation Hood Certomat ${ }^{\circledR}$ HK for Orbital Shaker

Ismatec REGLO ISM834 Digital 4-Ch Var-Speed Pump

Low Voltage Power Supply Power Pack P25

Luminometer GLOMAX ${ }^{\text {TM }} 96$ Microplate

Microscope Axio Imager M2

Microscope Axiovert 200

Microscope Leica M80

Microscope LSM 710

Microscope Stemi 2000 Stereo

SteREO Lumar V12 with Microinjection

MIR-153 Refrigerated Incubator
Manufacturer

Applied Biosystems

Beckman

Roche Innovatis AG

Eppendorf

Peqlab

Lonza

Molecular Devices

Leica-Biosystems

BioRad

Leica-Biosystems

Thermo Scientific

B.Braun Biotech

International

Ismatec

Biometra

Promega

Carl Zeiss

Carl Zeiss

Leica

Carl Zeiss

Carl Zeiss

Carl Zeiss

Sanyo 


\begin{tabular}{ll} 
Orbital Shaker Certomat $^{\circledR} \mathrm{U}$ & $\begin{array}{l}\text { B.Braun Biotech } \\
\text { International }\end{array}$ \\
\hline Spectrophotometer NanoDrop 1000 & Peqlab \\
\hline T Gradient Thermocycler & Biometra \\
\hline Thermomixer Compact & Eppendorf \\
\hline TissueLyser II & Quiagen \\
\hline UV Transilluminators Tl1 & Biometra \\
\hline Veriti $^{\circledR}$ 96-Well Thermal Cycler & Applied Biosystems \\
\hline VersaDoc $^{\text {TM }}$ Imaging System & BioRad
\end{tabular}

\subsubsection{Software}

\begin{tabular}{ll} 
Software & Manufacturer \\
\hline AxioVision & Carl Zeiss \\
\hline Gentle V1.9.4 & Magnus Manske, Köln \\
\hline GLOWMAX 1.9.2 & Promega \\
\hline GraphPad Prism 4 & GraphPad Software \\
\hline Image Lab & Bio Rad \\
\hline ND-1000 V3.8.1 & NanoDrop Technologies \\
\hline SDS 2.4 & Applied Biosystems \\
\hline Soft Max Pro5.4 & Molecular Devices \\
\hline Quantity One 4.6.7 & Bio Rad \\
\hline VisiView Version 2.1.1 & Visitron Systems GmbH \\
\hline ZEN 2011 (blue version) & Carl Zeiss
\end{tabular}




\section{Methods}

3.1. Molecular biological methods

\subsubsection{Cloning overview}

pcDNA3.1 $1^{+}$-flag-Bzw2-Neo: Complementary DNA (cDNA) synthetized from extracted RNA from murine cardiac tissue by reverse transcription was used to generate Bzw2 transcript including restriction digestion sites via PCR. The Bzw2 transcript was cloned into pcDNA3.1 $1^{+}$-flag-Klf15-Neo plasmid replacing Klf15 transcript.

pcDNA3.1 $1^{+}$-Flag-Bzw2- $\triangle C / \Delta N$ : Flag-tagged truncated forms of Bzw2 transcript were synthetized using pcDNA3.1 $1^{+}$-flag-Bzw2-Neo plasmid.

pcDNA3.1 $1^{+}$-Flag-Bzw2-Hygro: Bzw2 expressing plasmids with different resistance cassettes were generated. Hygromycin resistance cassette was cut from $p L V X-T e t-$ On Advanced vector and cloned into pcDNA3.1 $1^{+}$-flag-Bzw2-Neo vector replacing neomycin resistance cassette.

pcDNA3.1 $1^{+}$-Flag-Bzw2-Puro: Puromycin resistance cassette including restriction sites was synthetized using $p L V X$-Tight-Puro vector via PCR and cloned into pcDNA3.1 $1^{+}$Flag-Bzw2-Hygro plasmid replacing hygromycin resistance cassette.

pcDNA3.1 $1^{+}$-Flag-Bzw2-Puro-Orange: IRES-mOrange cassette including restriction site was synthetized using $p B S K$-aMHC-NIOIL plasmid and cloned into pcDNA3.1 $1^{+}$Flag-Bzw2-Puro plasmid downstream of puromycin resistance cassette. This cloning step was done to simplify positive clones screening. However expression of the mOrange fluorescent protein chromophore did not work.

pGL4.10-Bzw2-promoter: A putative Bzw2 promoter region (a sequences 1745 bp upstream the Bzw2 start codon including $3 \mathrm{TCF} / \mathrm{LEF}$ putative consensus sequences) including restriction digestion sites was synthetized from genomic DNA extracted from murine tissue and cloned into the multiple cloning site of $p G L 4.10$ vector generating $p G L 4.10-B z w 2-p r o m o t e r$ plasmid.

\subsubsection{DNA and RNA extraction}

Genomic DNA, RNA and plasmid DNA were extracted from murine and human tissue and cells using commercial Macherey-Nagel kits accordingly manufacturer's instruction. Quantification was done using NanoDrop photometer. 


\subsubsection{Polymerase chain reaction}

Polymerase chain reaction (PCR) was used to amplify and modify specific DNA sequences for cloning. Therefore, specific modified primers were designed. The copy accuracy was ensured by the proof reading function of Phusion polymerase (Thermo Scientific). Amounts of enzyme, primers, dNTPs and DNA as well as PCR program were taken accordingly manufacturer's instruction. "Tm calculator" freeware from New England Biolabs or gradient PCR were used to identify the optimal annealing temperature. Extension time was taken 1 min per $1 \mathrm{~kb}$ DNA.

\subsubsection{Enzymatic digestion, dephosphorylation and ligation of DNA}

Enzymatic digestion (FastDigest enzymes from Thermo Scientific) was used to test plasmids as well as to generate appropriate binding sites in target DNA and in vectors for further ligation. Dephosphorylation (Fast AP Thermosensitive Alkaline Phosphatase from Thermo Scientific) avoided re-ligation of vectors. Ligation of vectors (40 ng) with target DNA (1:7 mol ratio) was done using T4 DNA Ligase (from Thermo Scientific). After Ligase inactivation new generated plasmids were transformed into $E$. coli for multiplication. All steps were done accordingly manufacturer's instruction.

\subsubsection{DNA transformation into Escherichia coli}

$50 \mu \mathrm{l}$ of Escherichia coli (E. coli) were thawed on ice. $2 \mu \mathrm{l}$ of inactive ligation reaction or $10 \mathrm{ng}$ of plasmid DNA were mixed to $E$. coli and incubated on ice for $30 \mathrm{~min}$. After heat shock at $42^{\circ} \mathrm{C}$ for $45 \mathrm{~s}$ cells rested on ice for $5 \mathrm{~min}$. Next, $400 \mu \mathrm{l}$ of LB medium were added and cells incubated at $37^{\circ} \mathrm{C}$ for $30 \mathrm{~min}$ at $300 \mathrm{rpm}$. Afterwards cells were plated on LB agarose plates ( $100 \mu \mathrm{g} / \mathrm{ml}$ ampicillin).

\subsubsection{Agarose gel electrophoresis}

Agarose gel electrophoresis was used for visualization and separation of DNA fragments, using TAE buffer and agarose gel consisting of $0.5-2 \%$ agarose and $0.001 \%$ ethidium bromide. 


\subsubsection{Sequencing of DNA}

DNA sequencing was done by Sequence Laboratory Göttingen using standard primers (T7 / CMV-fwd / BGH-rev / M13-rev for pcDNA3. $1^{+}$and RV3 for $p G L 4.10$ ) or cloning primers.

\subsubsection{Reverse transcription PCR}

For RNA expression analysis CDNA was synthesized by reverse transcription PCR (RT-PCR) using 0.4-1 $\mu \mathrm{g}$ mRNA, $500 \mu \mathrm{g}$ oligo-dT as primers, $10 \mathrm{pmol}$ dNTPs (from Promega), M-MLV 5X Reaction Buffer and 100 units of RNA-dependent DNA polymerase Moloney Murine Leukemia Virus Reverse Transcriptase (M-MLV RT from Promega) in $20 \mu$ total volume. Negative RT (no enzyme) was used as control for genomic DNA contamination. The method was done accordingly manufacturer's instruction.

\subsubsection{Quantitative real-time PCR}

Quantitative real-time PCR (qPCR) allows quantification of RNA expression in tissue and cells using CDNA as template for polymerase chain reaction. SYBR Green ${ }^{\mathrm{TM}}$ dye intercalates into double-stranded DNA with each cycle. Using the standard curve of gene of interest with known concentration $\left(10^{3}-10^{8}\right.$ molecules/ $\mu$ l) the quantity of expressed RNA of interest can be evaluated. qPCR was done using GoTaq® qPCR MasterMix (from Promega) in 7900 HT Fast Real-Time PCR System (from Applied Biosystems) according to the PCR program below (Table 1) and was analyzed by SDS2.4 software (Applied Biosystems). cDNA was used in 1:1 - 1:10 dilutions depending on mRNA amount.

Table 1: qPCR program.

\begin{tabular}{|l|c|c|c|}
\hline \multicolumn{1}{|c|}{ Cycle step } & Temp. & Time & Cycles \\
\hline & $50^{\circ} \mathrm{C}$ & $2 \mathrm{~min}$ & \multirow{2}{*}{$1 \times$} \\
\cline { 1 - 3 } Initial denaturation & $95^{\circ} \mathrm{C}$ & $10 \mathrm{~min}$ & \\
\hline Denaturation & $95^{\circ} \mathrm{C}$ & $15 \mathrm{sec}$ & \multirow{2}{*}{$40 \times$} \\
\hline Annealing & $55 / 60^{\circ} \mathrm{C}$ & $1 \mathrm{~min}$ & \multirow{2}{*}{$1 \times$} \\
\cline { 1 - 3 } Extension & $95^{\circ} \mathrm{C}$ & $15 \mathrm{sec}$ & \\
\cline { 1 - 3 } Final extension & $60^{\circ} \mathrm{C}$ & $15 \mathrm{sec}$ & \multirow{2}{*}{$1 \times$} \\
\cline { 1 - 3 } Inactivation & $95^{\circ} \mathrm{C}$ & $15 \mathrm{sec}$ & \\
\hline
\end{tabular}




\subsection{Biochemical methods}

\subsubsection{Protein extraction}

For protein extraction, tissue or cells were first washed with PBS, subsequently 0.3-1 $\mathrm{ml}$ of protein lysis buffer was added. All steps were done on ice. Cells were scrapped from the surface, placed in Eppendorf tubes and mixed by pipetting up and down. Alternatively, tissue was placed in $2 \mathrm{ml}$ Eppendorf tubes with protein lysis buffer and metal beads and further disrupted and homogenized for $1.5 \mathrm{~min}$ at $30 \mathrm{~Hz}$ by TissueLyser (Qiagen). Next, the lysates were centrifuged at $1000 \times \mathrm{g}$ for $20 \mathrm{~min}$ at $4^{\circ} \mathrm{C}$. The supernatants were taken and protein concentration was quantified by

Bradford assay using bovine serum albumin (BSA) as a standard curve. Protein lysates were stored at $-20^{\circ} \mathrm{C}$.

\subsubsection{Protein fractionation}

Protein separation in cytosolic and nuclear fractions was done using hyper- and hypotonic buffers. The lysis of tissue and cells was done as described in 3.2.1 till the centrifugation step, using $0.3-1 \mathrm{ml}$ of the Hypotonic buffer instead of the lysis buffer. The protein lysates from tissue were placed in new $1.5 \mathrm{ml}$ tubes without beads. After incubation on ice for $15 \mathrm{~min}$, pre-diluted nonoxinol 40 (10\% NP-40) was added to the final concentration of $1 \%$ for tissue and $0.1 \%$ for cells. Lysates were vortexed and incubated for $5 \mathrm{~min}$ on ice and centrifuged at $4,000 \mathrm{rpm}$ for $5 \mathrm{~min}$ at $4^{\circ} \mathrm{C}$. The supernatant with the cytosolic protein fraction was taken and frozen for storage at $20^{\circ} \mathrm{C}$. The rest supernatant was completely removed from the pellet with the nuclear fraction. The pellet was dissolved in $0.3 \mathrm{ml}$ of the Hypertonic buffer and incubated for 25 min on ice. Next, NP-40 was added to the final concentration of $1 \%$ for tissue and $0.1 \%$ for cells. Lysates were vortexed and incubated for $10 \mathrm{~min}$ on ice and centrifuged at $13,000 \mathrm{rpm}$ for $5 \mathrm{~min}$ at $4^{\circ} \mathrm{C}$. The supernatant with the nuclear protein fraction was taken and frozen for storage at $-20^{\circ} \mathrm{C}$.

\subsubsection{Co-Immunoprecipitation}

Co-Immunoprecipitation (co-IP) was used to test an interaction between two proteins, where one of the proteins was immunoprecipitated from protein lysate bound on its 
interacting partners. The precipitate was subsequently analyzed by Western blot assay or mass spectrometry regarding the interactor of interest. Co-IP was prepared in vivo with BZW2 as precipitated protein and $\beta$-catenin as a potential interactor which was subsequently detected by Western blot assay. For in vitro co-IP FlagBzw2 construct was co-transfected with HA-KIf15 into human embryonic kidney cells (HEK293). BZW2 was immunoprecipitated using antibodies against FLAG-tag and KLF15 was detected by Western blot assay using antibodies against HA-tag. Appropriated immunoglobulin $\mathrm{G}(\mathrm{IgG})$ instead of antibody of interest served as a negative control. Co-IP was always done from fresh isolated protein lysates.

\subsubsection{Co-IP in vivo}

Murine heart was isolated, washed with PBS and cut in $\sim 2 \mathrm{~mm}$ small pieces. To crosslink interacting proteins tissue was placed into a $2 \mathrm{ml}$ tube and incubated for 30 min at room temperature (RT) in $2 \mathrm{mM}$ DSP/PBS (Lomant's Reagent from Thermo Scientific) which was pre-dissolved in DMSO accordingly manufacturer's instruction. Next, tissue was washed with PBS and after adding IP-lysis buffer grinded with mortar and pestle. Lysate was centrifuged at $100 \times \mathrm{g}$ for $10 \mathrm{~min}$ at $4^{\circ} \mathrm{C}$. After collecting the supernatant, centrifugation and collecting were repeated. Lysate was never vortexed! Finally, the protein concentration was measured. To avoid unspecific precipitation, lysate was pre-cleaned with sepharose beads (Protein G Sepharose 4 Fast Flow from GE Healthcare). For that, after washing 3 times in PBS, $100 \mu$ l beads were added to $1-4 \mu \mathrm{g}$ of protein (total, including negative control portion) in a $1.5 \mathrm{ml}$ tube. The lysate with beads was filled with PBS to $\sim \mathrm{ml}$ and was incubated for $1 \mathrm{~h}$ at $4^{\circ} \mathrm{C}$ by rotation. To remove beads, lysate was centrifuged at $100 \times \mathrm{g}$ for $1 \mathrm{~min}$ at $4^{\circ} \mathrm{C}$. The lysate was collected and separated in 2 equal parts. $1 \mu \mathrm{g}$ of rabbit-anti-BZW2 antibody (from Sigma Aldrich) as well as $1 \mu \mathrm{g}$ rabbit-lgG (from Santa Cruz) as a negative control were added to one lysate part. The protein-antibody mix was incubated over night at $4^{\circ} \mathrm{C}$ by rotation. Next, pre-washed $50 \mu \mathrm{l}$ sepharose beads were added to each condition. The protein-antibody-beads mix was incubated for 1.5 $\mathrm{h}$ at $4^{\circ} \mathrm{C}$ by rotation. Finally sepharose beads were carefully washed 3 times in PBS by centrifugation at $100 \times \mathrm{g}$ for $1 \mathrm{~min}$. To elute proteins from beads, PBS was completely removed and beads were incubated in $40 \mu \mathrm{l}$ of $4 \times$ Laemmli buffer per condition for $5 \mathrm{~min}$ at $95^{\circ} \mathrm{C}$. After it cooled down it was centrifuged for $1 \mathrm{~min}$ at 1000 
$\times \mathrm{g}$ and $30 \mu \mathrm{l}$ of each eluate were collected. The eluate was stored at $-20^{\circ} \mathrm{C}$ for further analysis.

\subsubsection{Co-IP in vitro}

HEK293 cells were co-transfected with plasmid expressing FLAG-BZW2 and plasmid expressing HA-KLF15 (transfection protocol see 3.4.3.). After 2 days in culture cells were washed with PBS and lysed by adding $1 \mathrm{ml}$ of IP-lysis buffer per $10 \mathrm{~cm}$ dish plate and collected by scrapping. The lysate was carefully pipetted up and down and centrifuged at $100 \times \mathrm{g}$ for $20 \mathrm{~min}$ at $4^{\circ} \mathrm{C}$. The protein concentration was measured by Bradford assay. Apart from the used antibodies, same procedure, as written above in 3.2.3.1., was used from this step on. Here immunoprecipitation was done using mouse-anti-FLAG antibody (Sigma) and mouse-IgG (Santa Cruz) for negative control.

\subsubsection{Mass spectrometry}

Nanoflow liquid chromatography tandem mass spectrometry (LC-MS/MS) was done at the Proteomics Facility of the UMG (Head: Prof. H. Urlaub / Dr. C. Lenz). Shortly, BZW2 protein enriched by IP from murine heart tissue using rabbit-anti-BZW2 antibody and rabbit-lgG as a negative control (see 3.2.3.1.) was separated by onedimensional PAGE and stained with colloidal Coomassie. Each lane was cut into 23 slices, reduced, alkylated, subjected to digestion with trypsin and analyzed by LCcoupled-MS/MS on an Orbitrap XL mass spectrometer. Affinity co-purified proteins are categorized as specific or non-specific according to the relative abundance of the protein in bait vs. control. Specific interaction partners are significantly more abundant in the purified sample containing the bait than in a control sample (IgG isotype). ${ }^{94,95}$ The resulting MS/MS spectra were searched against the NCBI protein database for protein identification. Analysis was done using the Mascot software (Matrix Science).

3.2.5. Sodium dodecyl sulfate polyacrylamide gel electrophoresis

Sodium dodecyl sulfate polyacrylamide gel electrophoresis (SDS-PAGE) was used to separate proteins from a protein lysate according to their molecular mass. Negatively 
charged SDS binds to proteins and leads to their repulsion of each other. First, quantified and denatured protein lysates $\left(5 \mathrm{~min}\right.$ at $95^{\circ} \mathrm{C}$ in $4 \times$ Laemmli buffer) were loaded on the collecting gel. Collecting was done at $70 \mathrm{~V}$ by constant electric current. The separation started in the following separation gel where smaller proteins migrate faster, so that proteins were separated linear their molecular mass in the gel ( $140 \mathrm{~V}$ by constant electric current).

\subsubsection{Western blot assay}

By Western blot assay (WB) proteins were transferred from the SDS polyacrylamide gel to polyvinylidene fluoride (PVDF) membrane in a vertical electric field at $140 \mathrm{~mA}$ by constant voltage. Proteins stayed on the membrane by hydrophobic polar interactions and were immunodetected using specific antibodies. The specific primary antibodies were either directly bound to the enzyme peroxidase or secondary antibodies were needed. By substrate adding peroxidase reduces hydrogen peroxide, this oxides luminol under formation of chemiluminescence. The chemiluminescence was detected by VersaDoc ${ }^{T M}$ XR Imaging System. The normalized density (analyzed using Quantity One 4.6.7 or Image Lab from BioRad) was compared between different samples.

\subsubsection{Luciferase reporter assay}

Luciferase reporter assay was used for two different aims.

To test for a possible role of BZW2 in the regulation of $\mathrm{Wnt} / \mathrm{\beta}$-catenin signaling activity, TOPflash/FOPflash luciferase reporter assay was used. A TOPflash plasmid (from Upstate) includes luciferase gene driven by a $T K$ promoter containing 3 TCF/LEF binding sites, the target genes of Wnt/ $\beta$-catenin signaling. TOPflash plasmid was co-transfected (transfection protocol see 3.4.3., Page 44) with an empty vector as a control and with a vector including a potential regulator like BZW2 into HEK293 cells. After culturing for 2 days cells were lysed by a passive lysis buffer accordingly manufacturer's instruction (Dual-Luciferase ${ }^{\circledR}$ Reporter Assay from Promega). Measuring of luminescence was done after adding the substrate (luciferin) via GLOMAXTM 96 Microplate luminometer from Promega. As a negative control FOPflash plasmid was used including 3 mutated TCF/LEF binding sites. To consider 
transfection efficiency, Renilla plasmid ( $p R L-C M V$ from Promega) was co-transfected and Renilla luciferase activity was used for normalization.

To test for a possible role of the $\mathrm{Wnt} / \mathrm{\beta}$-catenin signaling in regulation of transcriptional activity of Bzw2, a putative promoter region of Bzw2 (1745 bp upstream from $A T G$ ) including 3 putative TCF/LEF binding sites was cloned into a plasmid for driving a luciferase gene ( $p$ GL4.10 from Promega). The empty plasmid was used as a control. Renilla expressing plasmid was co-transfected and Renilla luciferase activity was used for normalization.

\subsection{Immunofluorescence staining}

\subsubsection{Immunocytochemistry}

Immunofluorescence (IF) staining of cells was used to detected protein expression in cultured cells. Therefore, cells grown on glass cover slips were washed with PBS 3 times for 2 min, fixed with Histofix for $30 \mathrm{~min}$ at RT and washed again with PBS 3 times for 2 min. Next, cells were permeabilized with $0.3 \%$ Triton X-100, $0.2 \%$ BSA in PBS for 10 min at RT and blocked with 5\% BSA, 0.1\% Triton X-100 in PBS for $1 \mathrm{~h}$ at RT. Afterwards, cells were incubated with primary antibodies in $1 \%$ BSA, $0.1 \%$ Triton $\mathrm{X}-100$ in PBS over night at $4^{\circ} \mathrm{C}$. Therefor cover slips with cells were placed on $50 \mu \mathrm{l}$ drops of antibody solution inverted in a dark chamber. Next day, cells were washed with PBS 3 times for 10 min and incubated with the secondary antibodies for $1 \mathrm{~h}$ at $\mathrm{RT}$ in the same way as the primary antibodies. After washing in PBS 3 times for 10 min, cells were incubated with Hoechst solution ( $1 \mu \mathrm{g} / \mu \mathrm{l}$ final concentration) in PBS for $5 \mathrm{~min}$ at RT to stain cell nuclei. Then, cells were washed again 3 times for $5 \mathrm{~min}$ and the cover slips were put on the microscope slides inverted on $20 \mu \mathrm{l}$ drops of Mowiol. Cells were stored at $4^{\circ} \mathrm{C}$ and were observed under fluorescence microscope $24 \mathrm{~h}$ after mounting.

\subsubsection{Immunohistochemistry}

Immunofluorescence (IF) staining of murine tissue was used to detected protein expression in the heart. Murine hearts were isolated, washed in PBS and fixed in Histofix overnight at $4^{\circ} \mathrm{C}$ by rotation. Next, tissue was washed again with PBS and incubated in $70 \%$ ethanol solution at $4^{\circ} \mathrm{C}$ at least for 3 days. Tissue embedding and 
slides cutting were performed by technical assistant Ines Müller. For embedding hearts were dehydrated in a row of ethanol ( $80 \%$ for $30 \mathrm{~min}, 90 \%$ for $30 \mathrm{~min}, 96 \%$ for $1 \mathrm{~h}, 96 \%$ for $30 \mathrm{~min}, 100 \%$ for $1 \mathrm{~h}$ and $100 \%$ for $30 \mathrm{~min}$ of ethanol). After incubation in $1: 1 \mathrm{mixture}$ of ethanol/toluene for $15 \mathrm{~min}, 1 \mathrm{~h}$ incubation in toluene and further incubation for $30 \mathrm{~min}$ in toluene, hearts were embedded overnight in paraffin at $60^{\circ} \mathrm{C}$. Serial $4 \mu \mathrm{m}$ slides were cut and stored for further use at $4^{\circ} \mathrm{C}$.

Preparation of paraffin slides for staining was performed by technical assistant Ines Müller. Paraffin slides were first deparaffinized in xylol / Roti-Histol for $10 \mathrm{~min}$ and rehydrated in an ethanol row twice for each step for 2 min: 100\%, 95\%, 90\%, 80\%, $70 \%$ ethanol. Next, slides were washed in water for $10 \mathrm{~min}$, in PBS for $10 \mathrm{~min}$ and then incubated in $10 \mathrm{mM}$ trisodium citrate, $0.05 \%$ Tween20 buffer $(\mathrm{pH} \mathrm{6})$ in a microwave at $180 \mathrm{~W}$ for $15 \mathrm{~min}$. Afterwards slides were cooled down for $20 \mathrm{~min}$ at RT, washed with PBS for 5 min, blocked in 5\% BSA, 0.1\% Triton X-100 in PBS for 1 $\mathrm{h}$ at $\mathrm{RT}$ in a dark wet chamber and incubated there with primary antibodies in $1 \%$ BSA, $0.1 \%$ Triton $\mathrm{X}-100$ in PBS overnight at $4^{\circ} \mathrm{C}$. On the second day, slides were washed with PBS 3 times for 5 min, incubated with secondary antibodies for $1 \mathrm{~h}$ at RT in a dark wet chamber, washed with PBS 3 times, incubated with DAPI (1:1000) in PBS for $10 \mathrm{~min}$ at RT to stain cell nuclei and washed again 3 times. Afterwards slides were mounted with Mowiol ${ }^{\circledR}$ and air dried. Slides were stored at $4^{\circ} \mathrm{C}$.

\subsection{Cell work}

\subsubsection{Thawing and freezing of cells}

Cells were harvested as explained in 3.4.2. (Page 44) and 3.4.4. (Page 44), counted, centrifuged for $5 \mathrm{~min}$ at $300 \times \mathrm{g}$ and diluted in freezing medium to $1.5 \times 10^{6}$ cells per 1 $\mathrm{ml}$ medium. $1 \mathrm{ml}$ of cells was placed per 1 cryo tube. Tubes were placed in an isopropanol container and were slowly frozen at $-80^{\circ} \mathrm{C}$. After one day cells were placed for storage at $-150^{\circ} \mathrm{C}$ or in liquid nitrogen. For thawing, cells were quickly transferred to appropriate $37^{\circ} \mathrm{C}$-warm medium and platted as described in 3.4.2. and 3.4.4. On the second day medium was changed. 


\subsubsection{Culture of HEK293 cells}

Human embryonic kidney cells (HEK293) were used as a standard in vitro model for validation of protein interaction, protein regulative capacity analysis as well as for characterization of protein localization in cell compartments. Cells were cultured in 10 $\mathrm{ml}$ medium in $\mathrm{T} 75$ flasks at $37^{\circ} \mathrm{C}$ and $5 \% \mathrm{CO}_{2}$. For splitting, medium was removed and cells were incubated with $4 \mathrm{ml} 0.25 \%$ trypsin for $3-5 \mathrm{~min}$ at $37^{\circ} \mathrm{C}$. Digestion was stopped by adding $8 \mathrm{ml}$ of medium. Cells were pipetted up and down for 3-4 times for better cell separation. $2 \mathrm{ml}$ of cells was mixed with $8 \mathrm{ml}$ medium and placed into a new flask. HEK293 cells were splitted two times per week.

\subsubsection{Transient transfection of HEK293}

Cells were harvested as explained in 3.4.2. (Page 44), counted and plated on $1 \%$ collagen pre-coated plates (Table 2). For plating on glass cover slips for a following cell staining, pre-coating was done with poly-L-lysine. Therefore poly-L-lysine was incubated on the glass cover slips at $37^{\circ} \mathrm{C}$ for $2 \mathrm{~min}$, than it was removed and cover slips were air dried. Next day, a transfection mix prepared according to the product manual (Transfectin or Turbofect) was added to the medium of cells. After 4-6 $\mathrm{h}$ medium was changed and cells were cultured for 2 days for the following analysis.

Table 2: Seeding HEK293 cell number.

\begin{tabular}{|c|c|}
\hline Plate format & $\begin{array}{c}\text { Cell number per plate } \\
\text { / well for seeding }\end{array}$ \\
\hline $10 \mathrm{~cm}$ dish & $2.2 \times 10^{6}$ \\
\hline 6-well plate & $3 \times 10^{5}$ \\
\hline 12-well plate & $10^{5}$ \\
\hline 24-well plate & $5 \times 10^{4}$ \\
\hline
\end{tabular}

\subsubsection{Culture of mESCs}

The used murine embryonic stem cell line was published elsewhere. ${ }^{26}$ The cells were isolated in L. J. Field's Lab (Indianapolis) from morula of transgenic mice expressing enhanced green fluorescence protein (EGFP) under control of alpha-myosin heavy chain ( $\alpha-M h c$, a cardiac muscle specific factor) promoter as well as geneticin (G-418) resistance protein under the $\alpha-M h c$ promoter. These characteristics allow selection 
and visualization of cardiomyocytes during differentiation of ESCs. Cells were cultured in $10 \mathrm{ml}$ of ESC-medium at $37^{\circ} \mathrm{C}$ and $5 \% \mathrm{CO}_{2}$ on irradiated, inactivated murine embryonic fibroblasts (MEFs), plated on a $0.1 \%$ gelatin coated $10 \mathrm{~cm}$ dish at least one day before seeding ESCs. For splitting, cells were washed with $5 \mathrm{ml}$ of prewarmed PBS and incubated with $4 \mathrm{ml} 0.25 \%$ trypsin for $3-5 \mathrm{~min}$ at $37^{\circ} \mathrm{C}$. Digestion was stopped by adding $8 \mathrm{ml}$ medium. Cells were pipetted up and down for 3-4 times for better cell separation. $10^{6}$ cells were taken in $10 \mathrm{ml}$ medium and placed into a new $10 \mathrm{~cm}$ dish (Table 3). ESCs cells were splitted every two days; the medium was changed on the day between including washing with PBS.

Table 3: Seeding ESC number.

\begin{tabular}{|c|c|c|}
\hline Plate format & $\begin{array}{c}\text { MEF number per plate } \\
\text { / well for seeding }\end{array}$ & $\begin{array}{c}\text { ESC number per plate } \\
\text { / well for seeding }\end{array}$ \\
\hline $10 \mathrm{~cm}$ dish & $2 \times 10^{6}$ & $1 \times 10^{6}$ \\
\hline 6-well plate & $2.5 \times 10^{5}$ & $1.25 \times 10^{5}$ \\
\hline 12-well plate & $10^{5}$ & $5 \times 10^{4}$ \\
\hline 24-well plate & $5 \times 10^{4}$ & $2.5 \times 10^{4}$ \\
\hline 96-well plate & $2.6 \times 10^{4}$ & uncounted \\
\hline
\end{tabular}

3.4.5. Generation of transgenic mESC line

ESCs were used to analyze gain-of-function of BZW2 during cardiogenesis in vitro. For that, a new transgenic BZW2 overexpressing ESC line was generated. The overexpressing construct ( $p c D N A 3.1^{+}$-Flag-Bzw2-Puro-Orange) included the coding sequence (CDS) of the murine BZW2 transcript tagged by FLAG and driven by a cytomegalovirus (CMV) promoter as well as the puromycin resistance gene driven by a simian-virus (SV40) promoter. Transfection of the construct occurred by a nucleofection using Amaxa® Nucleofector ${ }^{\circledR}$ Technology (from Lonza). The construct was cut from the plasmid by Sall digesting enzyme, separated by agarose gel electrophoresis and extracted from the gel. On the splitting day cells were fed with ESC medium. Four hours later MEFs were removed from the culture by pre-plating. Therefore, cells were collected as described in 3.4.4. (Page 44) and incubated on the same plate for $30 \mathrm{~min}$ at $37^{\circ} \mathrm{C}$. The supernatant was collected and cells were counted. The following protocol was done according to manufacturer's instruction; $1.5 \times 10^{6}$ cells, $2 \mu \mathrm{g}$ of DNA and A-23 program were used. Afterwards transfected cells were plated on a $10 \mathrm{~cm}$ dish. On the second day medium was changed. On the 
third day clones were started to be selected by puromycin $(1 \mu \mathrm{g} / \mathrm{ml}$ final concentration) for 12 days. Next, 96 clones were picked and placed on a 96 -well plate. After medium change and two days of culture clones were separated by trypsinization with $50 \mu \mathrm{l} 0.25 \%$ trypsin, following stop of trypsinization with $100 \mu \mathrm{l}$ medium and pipetting up and down. On the next day 1/4-1/2 cells (depending on the density) per clone were splitted on a new 96-well plate for DNA extraction and 1/4-1/2 on a new 96-well plate with a MEF layer for freezing and storage. On the next day cells for freezing were trypsinized with $25 \mu$ trypsin, stopped with $75 \mu$ ESC medium and mixed with $100 \mu \mathrm{l} \mathrm{ESC}$ medium \& freezing medium in the ration 1:1. $30 \mu \mathrm{l}$ mineral oil were added on top to cover the cells. The plate was sealed with paraffin and put in a Styrofoam box at $-80^{\circ} \mathrm{C}$ for storage. Cells for DNA extraction were washed with PBS. DNA extraction was done with a Macherey-Nagel Kit. The genotyping of clones was done using REDExtract-N-Amp Tissue Kit (from Sigma) accordingly manufacturer's instruction (see 3.5.2., Page 48). $100 \mathrm{ng}$ DNA and 400 $\mathrm{nM}$ of each primer (CMV-mBzw2 ${ }^{\text {ex3-4 }}$-fwd / -rev) were used. After identification of 29 DNA-positive clones, they were plated on a new 96-well plate. Next, they were splitted 1/6-1/2 cells per clone on 24-well plates for further RNA extraction and on a new 96-well plate for further culture. RNA was extracted using a Macherey-Nagel Kit. RNA expressed from the construct as well as the total Bzw2 RNA (including endogenous Bzw2) was analyzed by qPCR. After clone selection cells were seeded on 6-well plates without the MEF layer for subsequent protein extraction and analysis.

\subsubsection{Differentiation of mESCs to cardiomyocytes}

Two identified BZW2 overexpressing ESC clones (\#15, \#34) and untransfected cells (WT) as negative control were used in differentiation experiment. Spontaneous cardiomyocyte differentiation was used (Figure 8 ). On differentiation day 0 cells were plated as described before, washed with PBS and collected in differentiation medium $\left(2.5 \times 10^{4} \mathrm{cells} / \mathrm{ml}\right)$. Next, 200 hanging drops per cell line, each drop $20 \mu \mathrm{l}$, were prepared on the lid of two $15 \mathrm{~cm}$ dishes. $10 \mathrm{ml}$ of PBS per dish prevented drying-out of drops. On differentiation day 3 hanging drops including formed embryoid bodies (EBs) were collected with $10 \mathrm{ml}$ differentiation medium per cell line in low attachment dishes. On differentiation day 5 EBs were plated on gelatin coated plates: 6-well plates for protein analysis, 12 well plates for RNA analysis, 96-well plates for 
monitoring of GFP expression and beating areas. On differentiation day 11 cardiomyocytes selection with G418 (1 mg/ml final concentration) started. Samples for protein analysis were collected on differentiation days 0 and 16, for RNA analysis on days 0, 4, 9 and 16. The size of EBs were measured on day 3 and 5, GFP and beating areas were monitored on differentiation day $7,9,11,13$ and 16 .

\section{Differentiation Experiment}

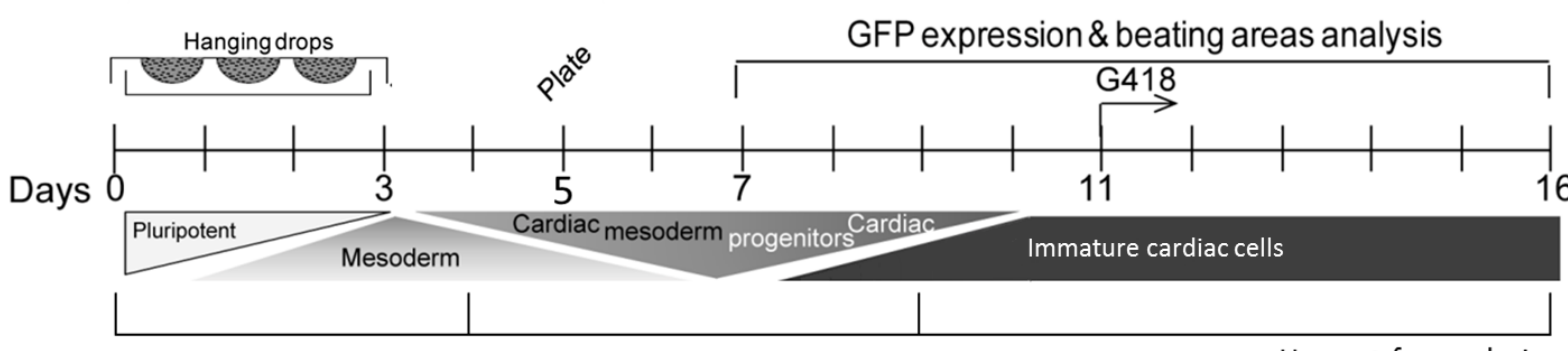

$\underline{\text { Harvest for analysis }}$

Figure 8: The workflow of the differentiation experiments.

The scheme describes the workflow of the differentiation experiments of ESCs to cardiomyocytes (see text above). Modified from Renger A et al., 2013. ${ }^{26}$

\subsubsection{Isolation of cardiac cells}

Cardiomyocytes and cardiac fibroblasts were isolated via Langendorff preparation from murine hearts with the help of Eric Schoger und Sebastian Pasch. The heart was dissected including remaining aorta from sacrificed mice. It was washed in cold PBS, transferred into 1× Perfusion Buffer and placed on a blunt 20G cannula. The heart was fixed on the cannula with yarn on remaining aorta and fixed on the Langendorff apparatus and perfused with Perfusion Buffer for $1 \mathrm{~min}$. The following digestion was performed by perfusion with Digestion Buffer for 9 min at $37^{\circ} \mathrm{C}$. Heart was separated from atria, remaining aorta and cannula and was transferred in the Digestion Buffer. The tissue was minced. After adding of $5 \mathrm{ml}$ Stopping Buffer suspension was re-suspended and collected in a $15 \mathrm{ml}$ reaction tube. It was filled up to a total volume of $10 \mathrm{ml}$ with Stopping Buffer and was set for 2 min to separate cell debris. Supernatant was collected, set for $8 \mathrm{~min}$ and transferred to a new $15 \mathrm{ml}$ collection tube. Remaining pellet was re-suspended in $10 \mathrm{ml}$ Stopping Buffer and set for $8 \mathrm{~min}$, supernatant was collected. Remaining Pellet was re-suspended in $10 \mathrm{ml}$ Stopping Buffer a second time and set for further $8 \mathrm{~min}$, supernatant was collected. Cardiomyocytes containing pellet was shock frozen in liquid nitrogen or immediately 
used for RNA extraction. Supernatant was centrifuged at $300 \times \mathrm{g}$ for 5 min at $4^{\circ} \mathrm{C}$ and removed, while the pellet was collected in $10 \mathrm{ml}$ MEF Medium and pre-plated in a $100 \mathrm{~mm}$ culture dish. After $2 \mathrm{~h}$ medium was changed. After $2 \mathrm{~d}$ medium was changed a second time. On day three, fibroblast medium was removed, fibroblasts were rinsed in PBS and trypsinized. After re-suspension, cells were placed into $15 \mathrm{ml}$ reaction tubes and centrifuged at $300 \times \mathrm{g}$ for $5 \mathrm{~min}$ at $4^{\circ} \mathrm{C}$. Supernatant was removed and pellet was shock frozen or used for RNA extraction.

Cardiac progenitor cells were isolated by Dr. Maria Patapia Zafeiriou as described in Zafiriou MP et al., 2014. ${ }^{96}$

\subsection{Mice}

All mouse experiments were approved by the animal review board LAVES (Niedersächsisches Landesamt für Verbraucherschutz und Lebensmittelsicherheit).

\subsubsection{Organ removal}

Mice were shortly anesthetized by isoflurane inhalation. Cervical dislocation followed directly. The organs were removed, washed in cold PBS and prepared for next steps.

\subsubsection{Genotyping}

Genotyping of mice was done using REDExtract-N-Amp Tissue PCR Kit from tail tips biopsies ( 18 days after birth) accordingly manufacturer's instruction. The used primers were "NeoR-F and Bzw2tt-R" for the Bzw2 KI mice and "Bzw2-F and Bzw2tt$R$ " for the wild type. Per sample to $5 \mu$ of PCR Mix 4 pmol s1-, 4 pmol s2- and $8 \mathrm{pmol}$ as-primer were added. Additionally $2 \mu \mathrm{l}$ genomic DNA from a tail tip, extracted using the same kit, was added and filled to total $10 \mu \mathrm{l}$ with $\mathrm{H}_{2} \mathrm{O}$. PCR program as described in Table 4 was used. Genotyping was done with help of technical assistants Ursula Leonhardt and Daniela Liebig-Wolter. 
Table 4: Genotyping PCR program.

\begin{tabular}{|l|c|c|c|}
\cline { 1 - 3 } \multicolumn{1}{|c|}{ Cycle step } & Temp. & Time & Cycles \\
\hline Initial denaturation & $94^{\circ} \mathrm{C}$ & $300 \mathrm{~s}$ & $1 \times$ \\
\hline Denaturation & $94^{\circ} \mathrm{C}$ & $15 \mathrm{~s}$ & \multirow{2}{*}{$40 \times$} \\
\hline Annealing & $54^{\circ} \mathrm{C}$ & $30 \mathrm{~s}$ & \multirow{2}{*}{$40 \times$} \\
\hline Extension & $72^{\circ} \mathrm{C}$ & $60 \mathrm{~s}$ & \\
\hline Final extension & $72^{\circ} \mathrm{C}$ & $300 \mathrm{~s}$ & $1 \times$ \\
\hline
\end{tabular}

3.5.3. Transverse aortic constriction (TAC) operations

Transverse aortic constriction (TAC) was used as an experimental model for pressure overload-induced cardiac hypertrophy. Constriction of the aorta occurred in the area of the aortic arch between the brachiocephalic artery and the left common carotid artery (Figure 9). Surgical intervention (Sham) served as negative control. Operations were done by Sabrina Wollborn, service unit SFB 1002. Heterozygous mice (20 TAC, 10 Sham) as well as wild type mice (20 TAC, 10 Sham) of mixed gender (1:1) were operated at the age of approximately 14 weeks. The cardiac function was analyzed by echocardiography two weeks before the operation as well as two and four weeks after the operation. Cardiac tissue was collected five weeks after TAC.

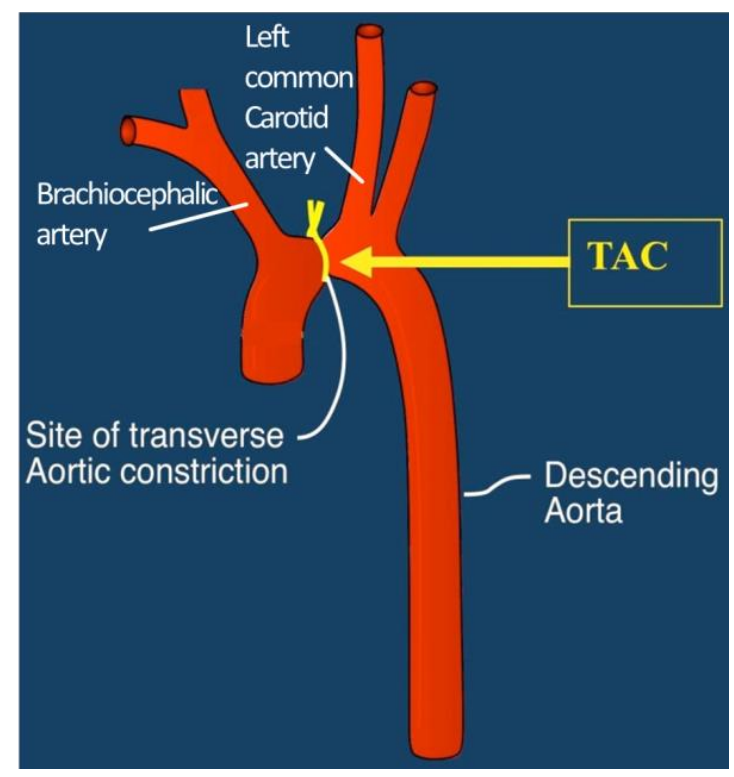

Figure 9: Transverse aortic constriction (TAC) in mice.

Transverse aortic constriction (TAC) between the brachiocephalic artery and the left common carotid artery leads to a pressure overload in the heart in systole, which induces compensated cardiac hypertrophy with the following cardiac dilatation and heart failure.

(Adapted from Washington University School of Medicine in St.Louis, mcpc.wustl.edu/Surgical.html) 


\subsubsection{Echocardiography}

Analysis of cardiac function in mice was done by echocardiography, performed by the service unit SFB 1002. Mice were anesthetized by isoflurane inhalation and ventricular measurements were done using the VisualSonics Vevo 2100 Imaging System equipped with a $45 \mathrm{MHz}$ MS-550D MicroScan transducer by Marcel Zoremba and Roland Blume. Analyses of the raw echocardiography data were done by Beate Knocke. Following parameters were measured in systole (-s) and in diastole (-d), apart from epicardium area (Epi, only in systole): anterior (AWTh) and posterior (PWTh) wall thickness, LV interior length (L) and LV interior area (Area) as shown in Figure 10. Heart weight (HW), fraction area shortening (FAS) and ejection fraction (EF) were calculated using following formulas:

$$
\begin{aligned}
& \mathrm{HW}=1.05 \times 5 / 6 \times \text { Epi-s } \times(\text { L-s }+(\text { AWTh-s }+ \text { PWTh-s }) / 2)-\text { Area-s } \times \text { L-s } \\
& \text { FAS }=(\text { Area-d }- \text { Area-s }) / \text { Area-d } \times 100 \\
& \text { EF }=(\text { Vol- } d-\text { Vol-s }) / \text { Vol-d } \times 100 \\
& \mathrm{Vol}=5 / 6 \times \text { Area } \times \text { L }
\end{aligned}
$$

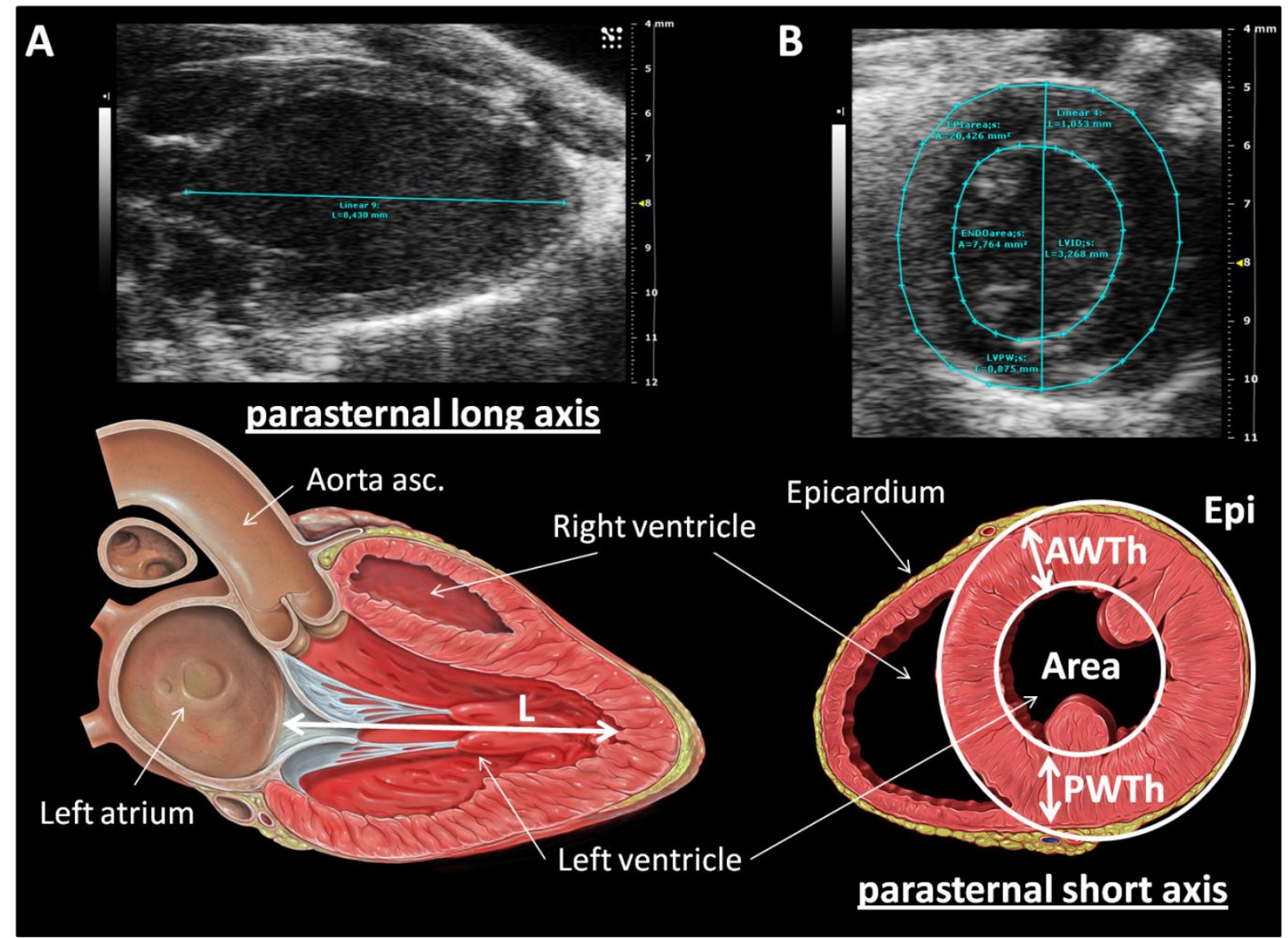

Figure 10: Echocardiography analysis. 
Echocardiography analyses were performed by the service unit SFB 1002. A Parasternal long axis view of the heart, showing LV, RV, LA and aorta ascendens; L: LV interior length. B Parasternal short axis view of the heart, showing LV, RV and epicardium; AWTh: anterior wall thickness; PWTh: posterior wall thickness; Area: LV interior area; Epi: epicardium area.

Schematic images are modified from Patrick J. Lynch, medical illustrator.

\subsubsection{Statistical analysis}

Statistical significance between two groups was analyzed by Student's $t$-test, using GraphPad Prism4 program. P values smaller than 0.05 were taken as significant $\left({ }^{*} p<0.05 ;{ }^{* *} p<0.01 ;{ }^{* *} p<0.001\right)$. Results were shown as arithmetic mean with standard error (SEM). 


\section{Results}

\subsection{Molecular characterization of BZW2}

\subsubsection{Validation of BZW2 interaction with $\beta$-catenin and KLF15}

This work aimed to characterize the role of cardiac specific $\mathrm{Wnt} / \mathrm{\beta}$-catenin components with a potential role on modulation of Wnt-context-dependent biological responses. Specifically, the basic leucine zipper and W2 domains containing protein (BZW) 2 was found to interact with Wnt components such as KLF15 and $\beta$-catenin.

Under the following criteria BZW2 was selected for further analysis in the present study: I) reported high expression in adult rat heart ${ }^{82}$; II) biochemical characteristics (predicted DNA and protein domains) and III) conservation of the protein. Firstly, BZW2 interactions with $\beta$-catenin and KLF15 were validated by means of coimmunoprecipitation (co-IP). Due to the suitability of the antibodies, the interaction of BZW2 and $\beta$-catenin was validated in murine heart tissue. BZW2 was immunoprecipitated using a monoclonal rabbit-anti-BZW2 antibody and $\beta$-catenin was detected by Western blot using a monoclonal mouse-anti- $\beta$-catenin antibody (Figure 11A). Detection of endogenous murine KLF15 was not possible due to unavailable good antibody (several commercial as well as extra produced antibodies were tested). To validate this interaction mouse FLAG-BZW2 and HA-KLF15 were overexpressed in HEK293 cells. FLAG-BZW2 was immunoprecipitated using monoclonal mouse-anti-FLAG antibody and HA-KLF15 was detected by Western blot with anti-HA-HRP antibody (Figure 11B). 
A

murine heart

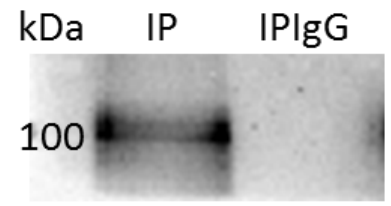

IP: anti-BZW2 / IgG

IB: anti- $\beta$-catenin
B overexpressing HEK293 cells: FLAG-BZW2 + HA-KLF15
$\mathrm{kDa} \quad \mathrm{IP}$
55
IP: anti-FLAG / IgG
IB: anti-HA

IPIgG

$\mathrm{L}$
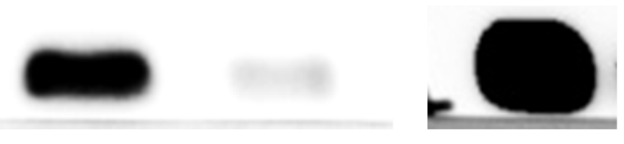

\section{Figure 11: Validation of BZW2 interaction with $\beta$-catenin and KLF15.}

Co-immunoprecipitation (co-IP) experiments validated BZW2 interactions with $\beta$-catenin and KLF15, visualized by Western blot analysis (IP = immunoprecipitation with specific antibody, IPIgG = immunoprecipitation with immunoglobulins as a negative control, $\mathrm{L}=$ lysate as a detection control, IB = immunoblot). A BZW2 was precipitated from adult murine heart tissue using monoclonal rabbit-antiBZW2 antibody. $\beta$-catenin was detected by Western blot using monoclonal mouse-anti- $\beta$-catenin antibody. B FLAG-BZW2 and HA-KLF15 were overexpressed in HEK293 cells. BZW2 was precipitated using monoclonal mouse-anti-FLAG antibody. KLF15 was detected by anti-HA-HRP antibody.

Moreover, mass spectrometry analysis of co-immunoprecipitated BZW2 using mouse heart tissue was carried out at the Proteomic facility (UMG), in which $\beta$-catenin was identified (Figure 12).

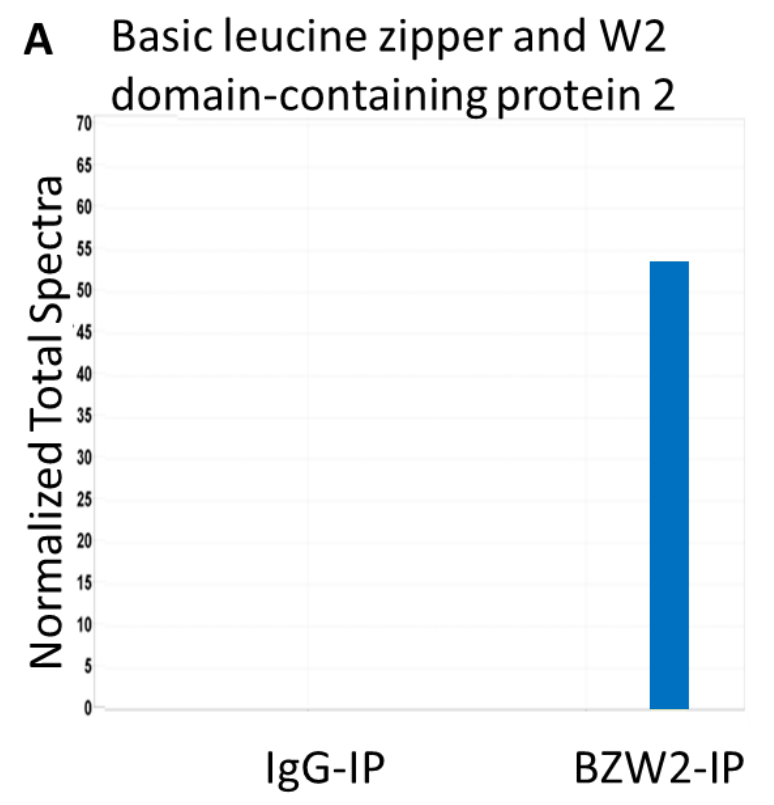

B

Catenin beta-1

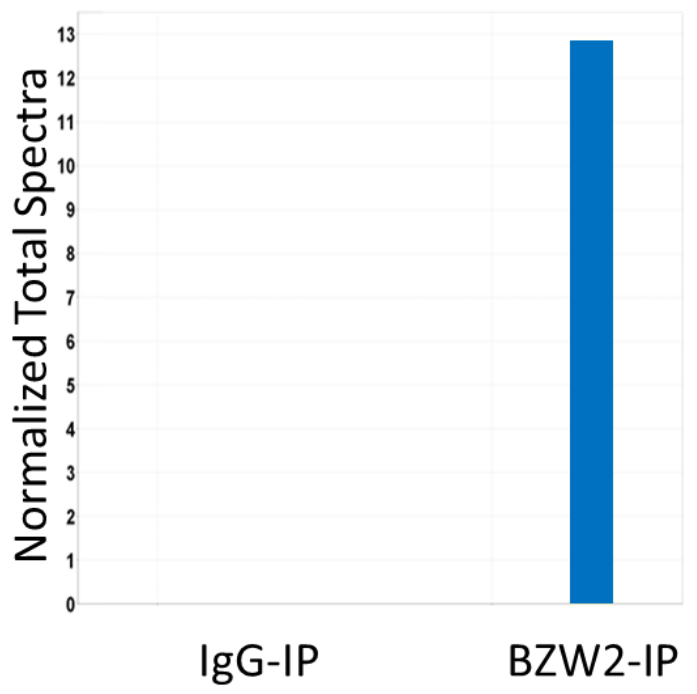

Figure 12: BZW2 interaction with $\beta$-catenin analyzed by mass spectrometry. 
BZW2 protein was enriched from adult murine heart tissue by IP using monoclonal rabbit-anti-BZW2 antibody (and rabbit-lgG as a control) and analyzed for interacting partners by mass spectrometry. Nanoflow liquid chromatography tandem mass spectrometry (LC-MS/MS) was performed at the Proteomics Facility of the UMG (Head: Prof. H. Urlaub / Dr. C. Lenz). The experiment was successfully repeated. A Enrichment of BZW2 was validated by BZW2 detection in the BZW2-IP fraction. B $\beta$-catenin was enriched in BZW2 enriched sample in contrast to IgG control.

Next, to infer about the level of association of BZW2 with the identified proteins, cell localization of BZW2 was investigated by co-immunofluorescence and confocal analysis. FLAG-BZW2 was overexpressed with either $\beta$-catenin or HA-KLF15 in HEK293 cells. Cells were harvested after $48 \mathrm{~h}$ and fixed for staining using above described antibodies. Stained cells were analyzed by confocal microscopy. As expected, $\beta$-catenin was observed at the membrane, in the cytosol and nuclear cell compartments, and KLF15 exclusively in the nucleus (Figure 13). BZW2 was localized at the cytosolic and nuclear compartment. This analysis showed that BZW2 is co-localized in common cellular compartments to $\beta$-catenin and KLF15, namely the cytosol, in which BZW2 was co-localized with $\beta$-catenin, and the nucleus, in which it was co-localized with both $\beta$-catenin and KLF15.
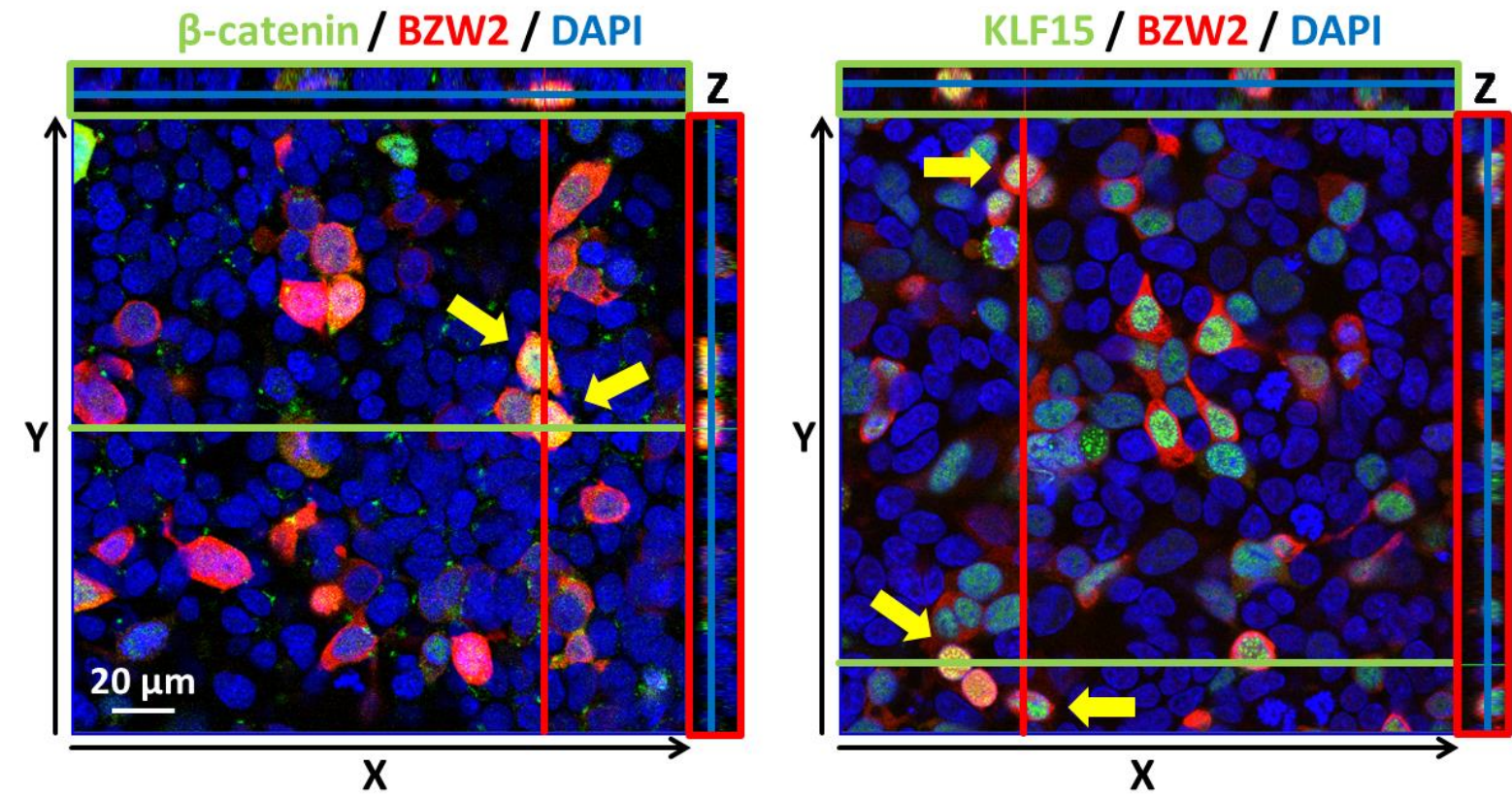

Figure 13: Co-localization analysis of BZW2 with $\beta$-catenin and KLF15.

BZW2 was found in cytosolic and nuclear compartments. FLAG-BZW2 and $\beta$-catenin as well as FLAG-BZW2 and HA-KLF15 were overexpressed in HEK293 cells. After two days of culture cells were fixed and stained with specific antibodies. $\beta$-catenin was detected by mouse-anti- $\beta$-catenin and anti- 
mouse-Alexa Fluor 488 (green) antibodies, KLF15 by mouse-anti-HA and anti-mouse-Alexa Fluor 488 (green) antibodies, BZW2 by rabbit-anti-FLAG and anti-rabbit-Alexa Fluor 594 (red) antibodies. Cell nuclei were stained using DAPI (blue). Cells were analyzed by confocal microscopy using Z-stack. The pictures represent 3-dimensional Z-stack overlays generated from individual photos to ensure analysis of complete cell content including all sections through the cell. In the big box cells are represented 2dimensional in $\mathrm{X}$ - and $\mathrm{Y}$-axes. In small green and red boxes cells are represented in the $3^{\text {rd }}$ dimension: Z-axis. Scale bar: $20 \mu \mathrm{m}$.

To evaluate the biological relevance of this expression, murine heart sections were stained for BZW2 and Troponin T to visualize the endogenous localization of BZW2 in this tissue (Figure 14). Cardiac Tropinin $T$ was used to visualize adult cardiomyocytes. BZW2 was found to be strongly expressed in the nucleus but also found in the cytosol co-localizing with cardiac Tropinin T staining.
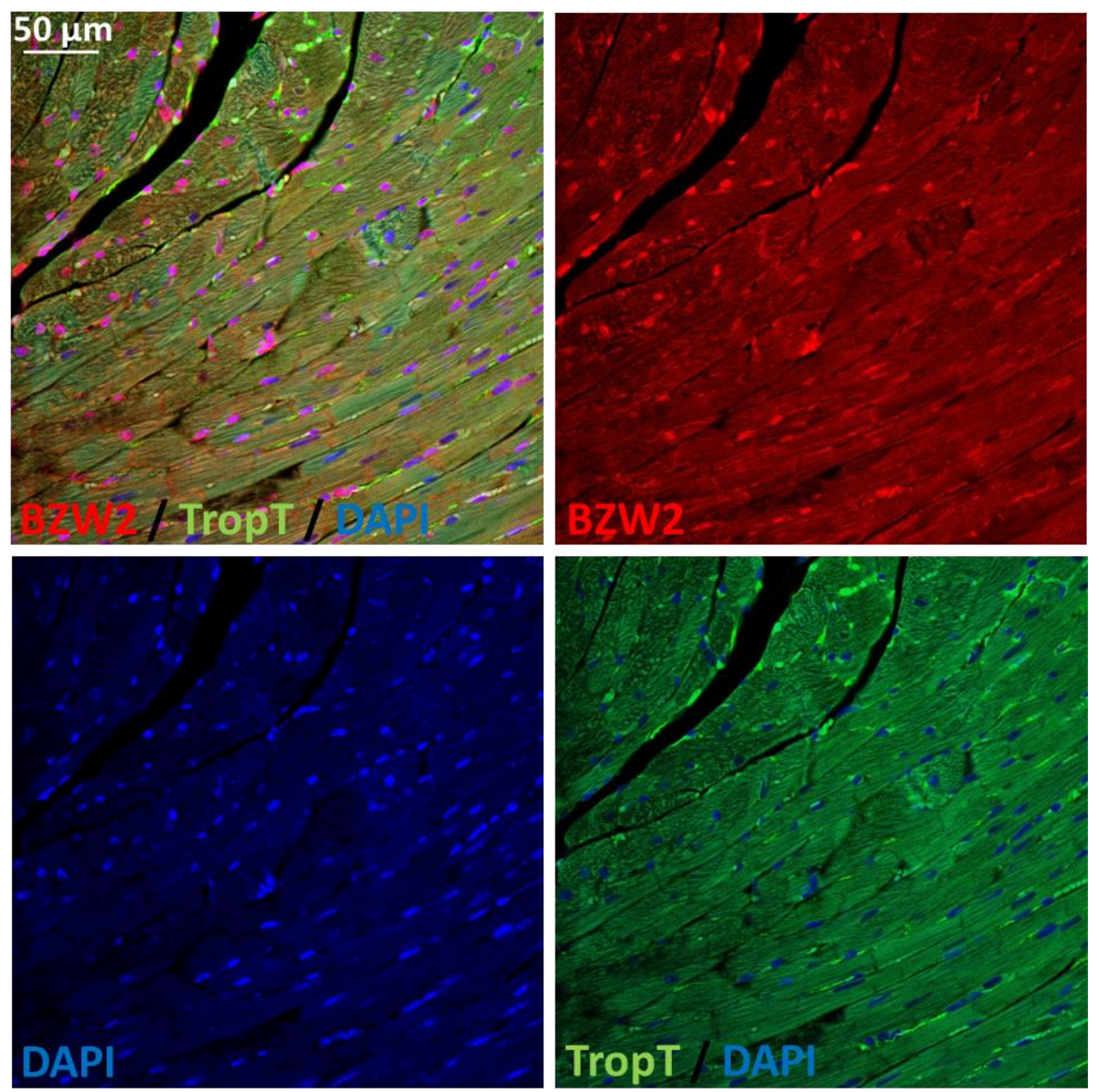

Figure 14: BZW2 localization in cell compartments.

BZW2 expression in heart tissue of adult NMRI mice was analyzed. BZW2 was found in the cytosol as well as in the nucleus. Confocal images were done from immunostained paraffin slides: BZW2 was 
detected using rabbit-anti-BZW2 (Q91VK1) \& anti-rabbit-Alexa Fluor 594 (red) antibodies. Cardiomyocytes were visualized by mouse-anti-troponin $\mathrm{T}$ (TropT) and anti-mouse-Alexa Fluor 488 (green) antibodies, showing cytosolic staining and nuclei by DAPI (blue). Scale bar: $50 \mu \mathrm{m}$.

\subsubsection{BZW2 expression in mouse}

These results encouraged to further investigate the expression of BZW2 and its relevance for heart biology. The hypothesis was tested, that BZW2 is specific expressed in heart tissue. Tissue from different murine organs (heart, spleen, lung, liver, kidney, brain and skeletal muscle) was analyzed for BZW2 protein expression. The organs were collected and protein was extracted for Western blot analysis. BZW2 was observed highly expressed in the heart and skeletal muscle tissue in comparison to spleen, lung, liver, kidney or brain (Figure 15). GAPDH was used as housekeeping protein control for all analyzed organs and compared relative expression. We are aware of the difficulty of an ideal housekeeper expression in such an analysis due to its variability in different tissue.

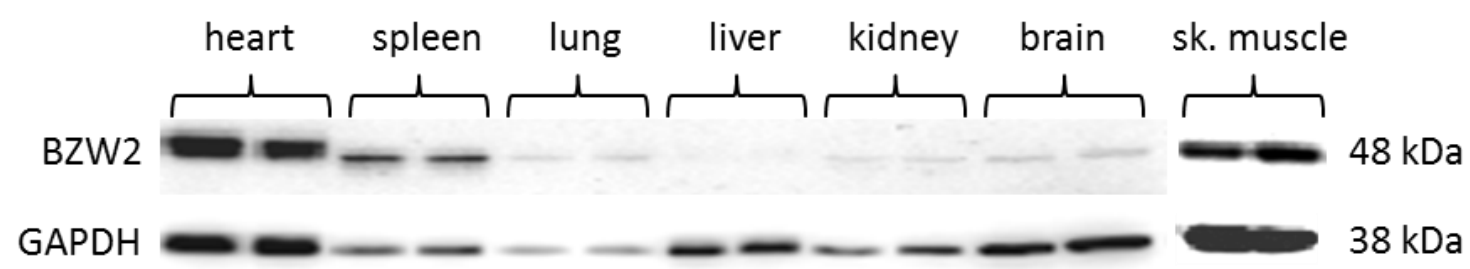

Figure 15: BZW2 protein expression in different murine organs.

Western blot analysis showed high BZW2 expression in the heart and skeletal muscle tissue. Tissue lysate from heart, spleen, lung, liver, kidney, brain and skeletal muscle were analyzed for BZW2 protein expression via Western blot ( $n=2 /$ group). Same amount of total protein was loaded for every sample. BZW2 was detected using rabbit-anti-BZW2 antibody. GAPDH was detected using mouseanti-GAPDH antibody.

This analysis indicated that BZW2 is indeed very high expressed in the heart but also in skeletal muscle, indicating a muscle specific factor under normal organ homeostasis. Moreover, high transcript expression of BZW2 was observed in heart and skeletal muscle human tissue in comparison to trachea, testis, spleen, prostate, ovary, mammary gland, lung, kidney, hippocampus, epidermis, cerebral cortex, cerebellum, aorta, adipose tissue (data not shown, collaboration partner personal communication, David Zhang, Pharmaceutical Division, Roche AG). 
Wnt transcriptional inhibiton mediated by the KLF15 complex was previously observed in CPC, which showed altered cell fate upon KLF15 loss of fuction. To evaluate the possibility that BZW2 forms part of this complex, BZW2 expression was first analyzed in different heart cell types. Cardiomyocytes, cardiac fibroblasts and cardiac progenitors were analyzed. Cardiomyocytes and cardiac fibroblasts were isolated from adult murine hearts via Langendorff perfusion method. For protein analysis fibroblasts were isolated using a collagenase-trypsin-digestion protocol. Cardiac progenitors were isolated with a protocol described by Zafiriou MP et al., $2014{ }^{96}$ Cells were isolated using an antibody against the stem cell marker stem cells antigen (Sca) -1. The purity of the cells was controlled by flow cytometry analysis. Furthermore, GPCR analysis as used to further confirm the nature of the isolated population which indeed showed strong expression of Sca-1 and almost abscent expression of the cardiomyocytes marker cardiac troponin $\mathrm{T}$ (TropT), indicating the undifferenriated nature of this population. ${ }^{96}$ BZW2 was highly expressed in cardiomyocytes and cardiac progenitors compared to cardiac fibroblasts, detected via qPCR and Western blot. The tumor protein, translationally-controlled (TPT) 1 was used as a loading control. ${ }^{97-99}$ These observavtion indicate an important role of BZW2 in CMs and CPC population.

A

Bzw2

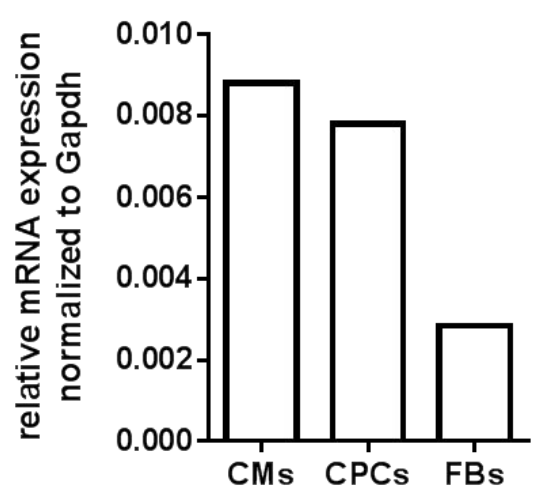

B

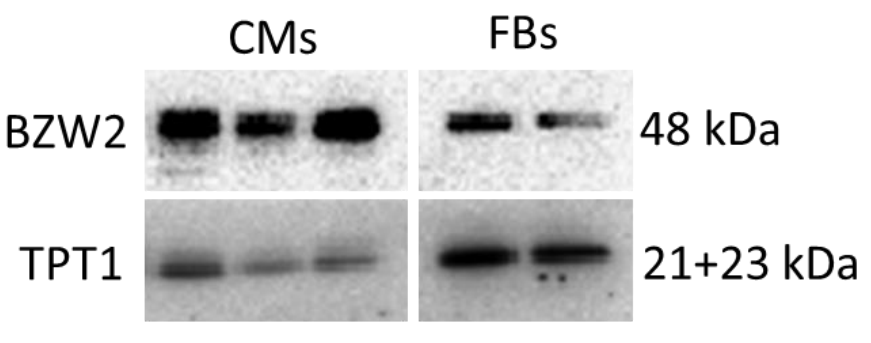

Figure 16: BZW2 expression in selected cardiac cell types.

BZW2 expression was analyzed in cardiomyocytes (CMs), cardiac progenitor cells (CPCs) and cardiac fibroblasts (FBs). A Preliminary results indicated higher Bzw2 mRNA expression in cardiomyocytes and cardiac progenitors compared to fibroblasts ( $n=1 / C M s ; n=2 / C P S ; n=2 / F B s$ ). $B$ In line, Western blot analysis demonstrated higher BZW2 protein expression in cardiomyocytes compared to fibroblasts ( $n=3 / C M s ; n=2 / F B s$ ). Due to the minor amount of isolated CPC, they were not used for 
protein expression analysis. Tumor protein, translationally-controlled (TPT) 1 was detected using mouse-anti-TPT1 antibody for normalization. Cardiomyocytes isolation in this experiment was performed with help of Sebastian Pasch.

The data showed above indicate a role of BZW2 in a mature and undifferentiated cell population. Since the expression of in embryonic development BZW2 was not characterized, we investigate its epxression in the developing heart. To do that, murine cardiac tissue at different developmental stages was collected: cardiac crescent (embryonic post coitum days E7.0-7.5), linear heart tube and looping heart (E8.5 \& E9.5), embryonic hearts (E11.5, E13.5, E15.5 \& E17.5), postnatal hearts (postnatal days P1, P3, P6, P8, P10 \& P13) and adult heart (P60). For the cardiac crescent stage approximately 10 embryos per sample were used, for linear heart tube stage - 5-7 embryos per sample, for looping heart stage and at embryonic day E11.5 - 3-5 embryos. Postnatal and adult hearts were isolated without atria. Analysis by qPCR showed that Bzw2 mRNA was detected throughout heart development and in the postnatal heart. However, it could be observed that the expression was higher during early heart development at embryonic days $8.5 \& 9.5$ as well as in the adult heart (Figure 17). Expression during heart maturation in the early postnatal heart was less prominent.

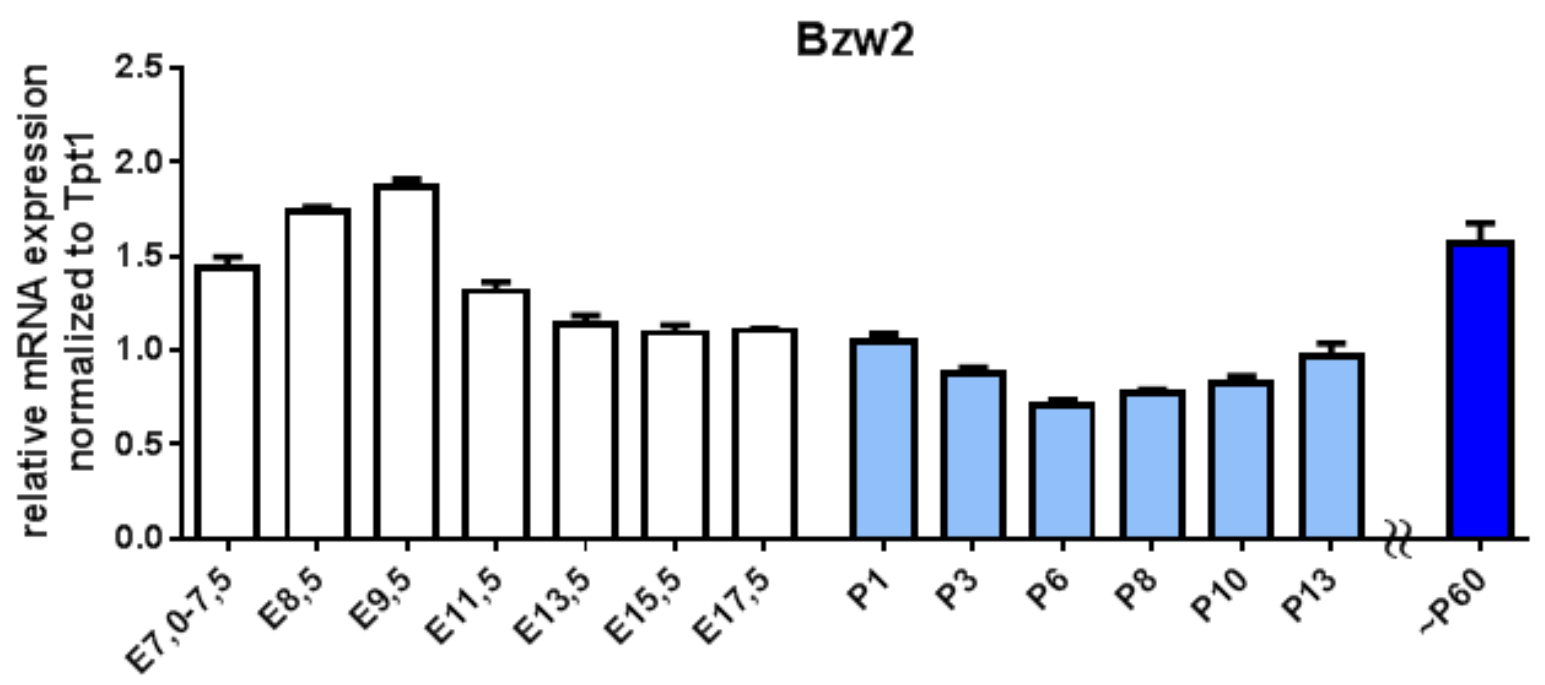

Figure 17: Bzw2 mRNA expression during cardiac development in mice.

Bzw2 mRNA expression was tested in cardiac tissue of MNRI mice at different developing stages (embryonic post coitum day $=\mathrm{E}$; postnatal day $=\mathrm{P}, \mathrm{n}=3$ /group). It was analyzed by $\mathrm{qPCR}$ and normalized to Tpt1 expression. Cardiac tissue was isolated from mice in different developing stages: 
cardiac crescent (E7.0-7.5), linear heart tube and looping heart (E8.5 \& E9.5), embryonic hearts (E11.5, E13.5, E15.5 \& E17.5), postnatal hearts (P1, P3, P6, P8, P10 \& P13) and adult heart (P60). At early stages cardiac tissue from several embryos was pooled together per sample: at E7.0-7.5 approximately 10 embryos, at E8.5 - 5-7 embryos, at E9.5 \& E11.5 - 3-5 embryos were pooled together to one sample. From stage P1 to adulthood, only ventricular tissue was analyzed.

Furthermore, we were interested in the epxression pattern of BZW2 in whole embryo development. Therefore whole mount in situ hybridization was performed to investigate the mRNA Bzw2 expression pattern in the mouse embryo. A selfdesigned sense (S) and antisense (AS) Bzw2 in situ probe was used for mRNA detection in embryos E9.5 and 10.5. Bzw2 was detected not only in the developing heart, but also highly expressed in somites, limbs and branchial arches in E9.5 and in somites, first and second branchial arches, midbrain/hindbrain, dorsal root ganglia as well as fore and hind limbs in E10.5, suggesting a role for BZW2 in development (representative picture in Figure 18).
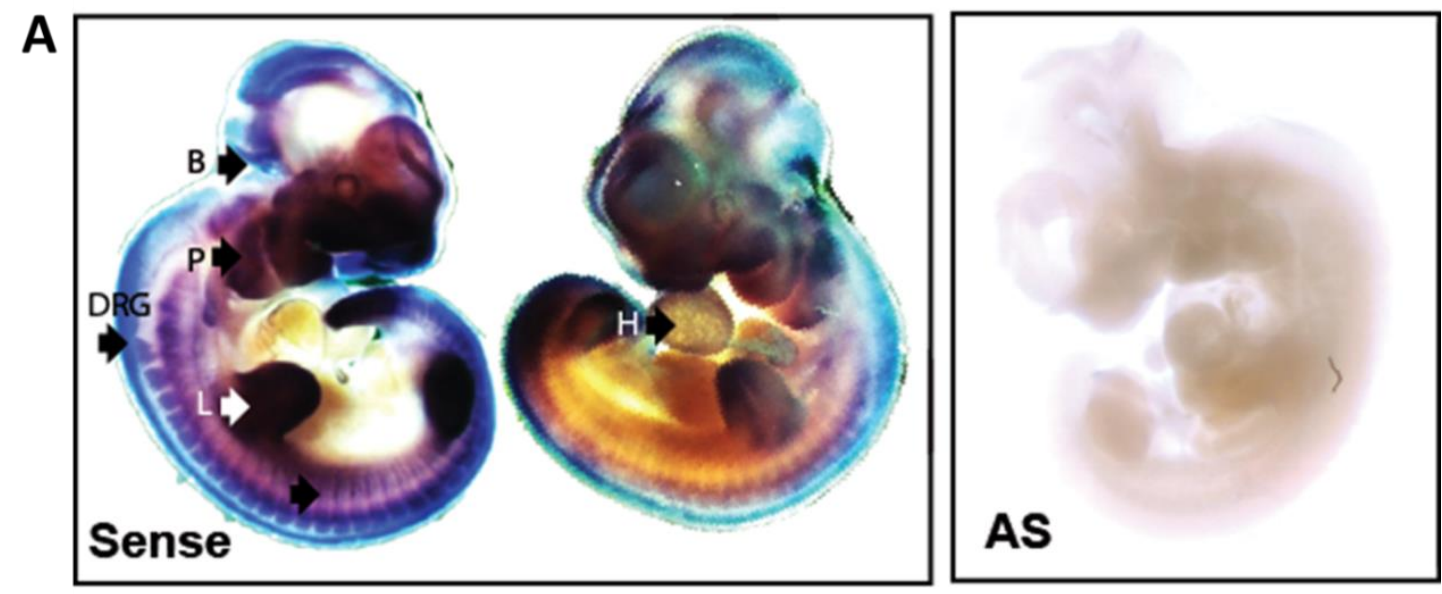

B

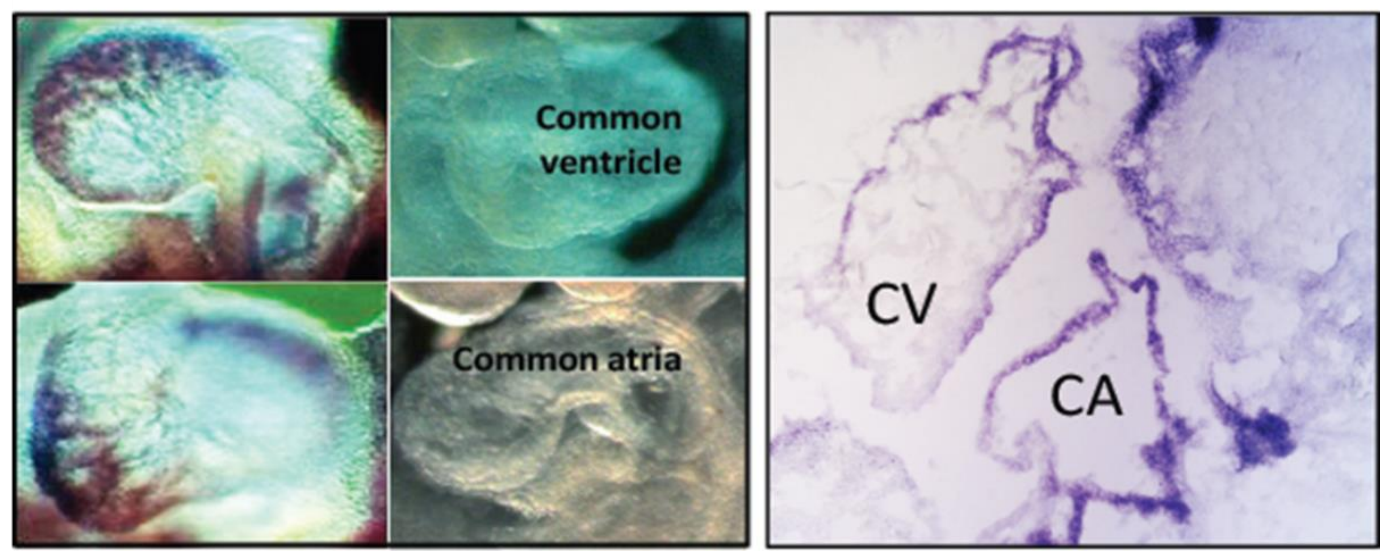

Figure 18: Bzw2 mRNA expression in the mouse embryo.

Whole mount in situ hybridization with sense and antisense (AS) control Bzw2 in situ probe in embryos E9.5 and E10.5. A Arrows indicate the most prominent expression as indicated in the text. B: brain; P: 
pharyngeal pouches; L: limbs; DRG: dorsal root ganglia; H: heart. B Expression in the heart is observed in the common ventricle $(\mathrm{CV})$ and atria $(\mathrm{CA})$. Experiment was performed by Eric Schoger with a modified protocol based on Zelarayán LC et al., 2007. ${ }^{100}$

\subsubsection{BZW2 protein domains analysis}

Localization of BZW2 in different cell compartment was observed suggesting a dynamic transport of BZW2, which may dependent on pathway activation. Therefore, we next investigated the biochemical characteristics of the protein and tested the hypothesis that BZW2 contains a domain necessary for specific cell localization. Two truncated protein forms of BZW2 were designed. In one construct, the $\mathrm{C}$ terminus was deleted including nearly the complete W2 domain $(B z W 2-\Delta C)$. In the second construct the $\mathrm{N}$ terminus was deleted including putative ZIP and bZIP domains $(B z w 2-\Delta N)$ (Figure 19A). These constructs were validated via Western blot analysis from overexpressed HEK293 cells (Figure 19B).

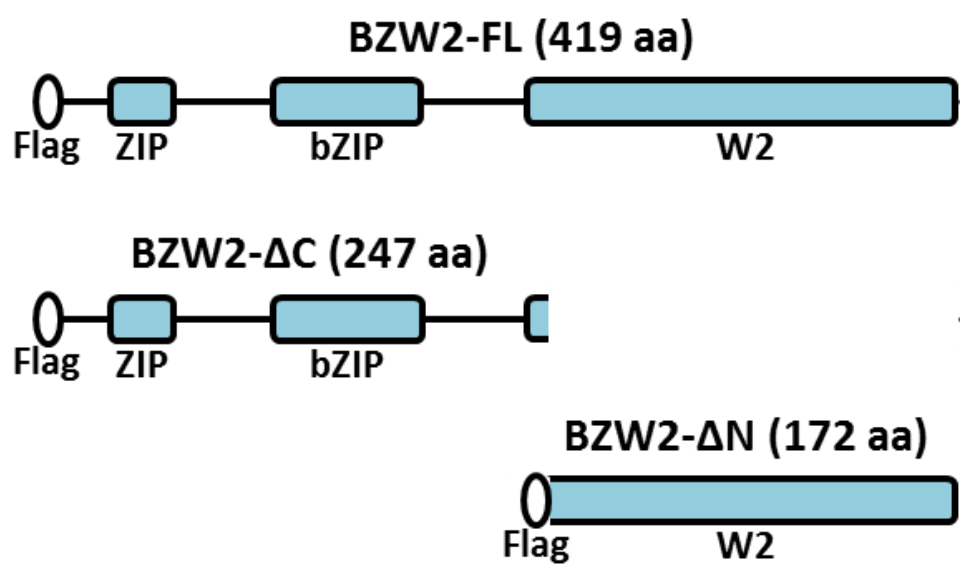

Figure 19: Validation of BZW2 truncated forms for domain analysis.

A Schematic representation of all generated FLAG-tagged constructs. Full length BZW2 (BZW2-FL) includes putative ZIP, bZIP domains and W2 domain. In the $C$ terminus truncated form (BZW2- $\triangle C$ ) nearly the complete $W 2$ domain is deleted. In the $N$ terminus truncated form (BZW2- $\Delta N$ ) putative ZIP and bZIP domains are deleted.

The truncated Bzw2 constructs as well as the full length Bzw2 (Bzw2-FL) were separately transfected into HEK293 cells. Western blot analysis of BZW2 in fractionated cytosolic and nuclear fractions showed that BZW2-FL is located in both, cytosol and nucleus in overexpressed HEK293 cells. Deletion of $\mathrm{C}$ terminus including W2 domain leads to reduction of cytosolic localization. In contrast, deletion of $\mathrm{N}$ 
terminus including putative ZIP and bZIP domains leads to reduction of nucleic localization (Figure 20).

A
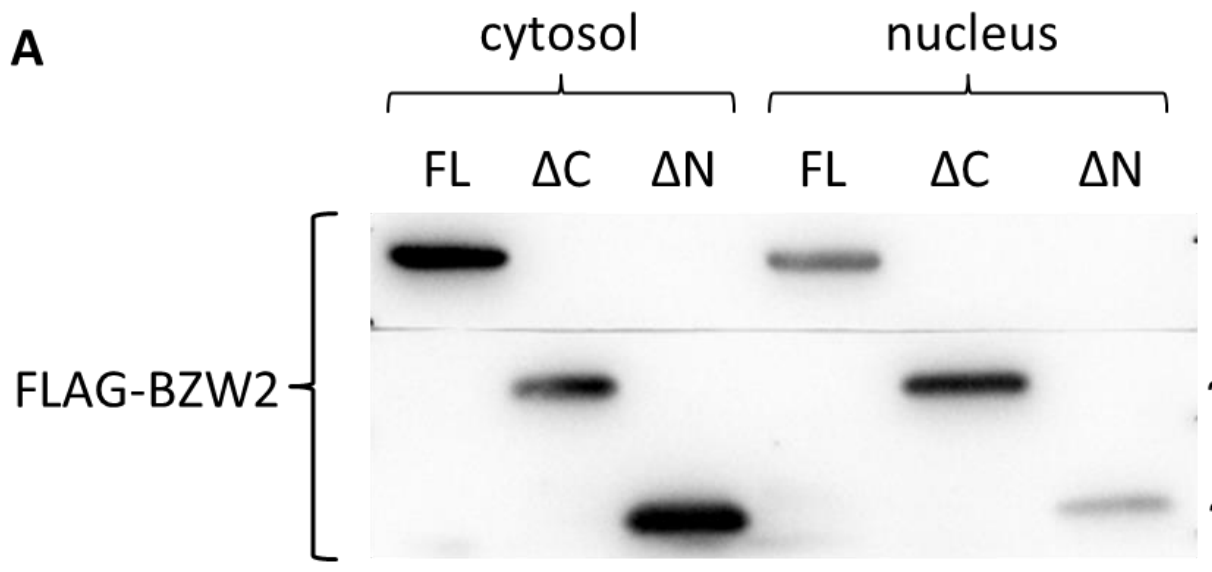

$48 \mathrm{kDa}$

$\operatorname{Lamin} \mathrm{A} / \mathrm{C}$

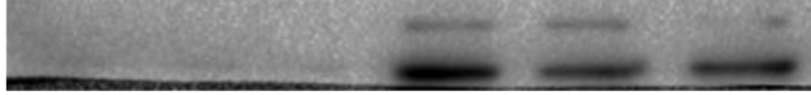

$65+74 \mathrm{kDa}$

Inact. Caspase-3

$32 \mathrm{kDa}$

\section{GAPDH}

$38 \mathrm{kDa}$

B

FLAG

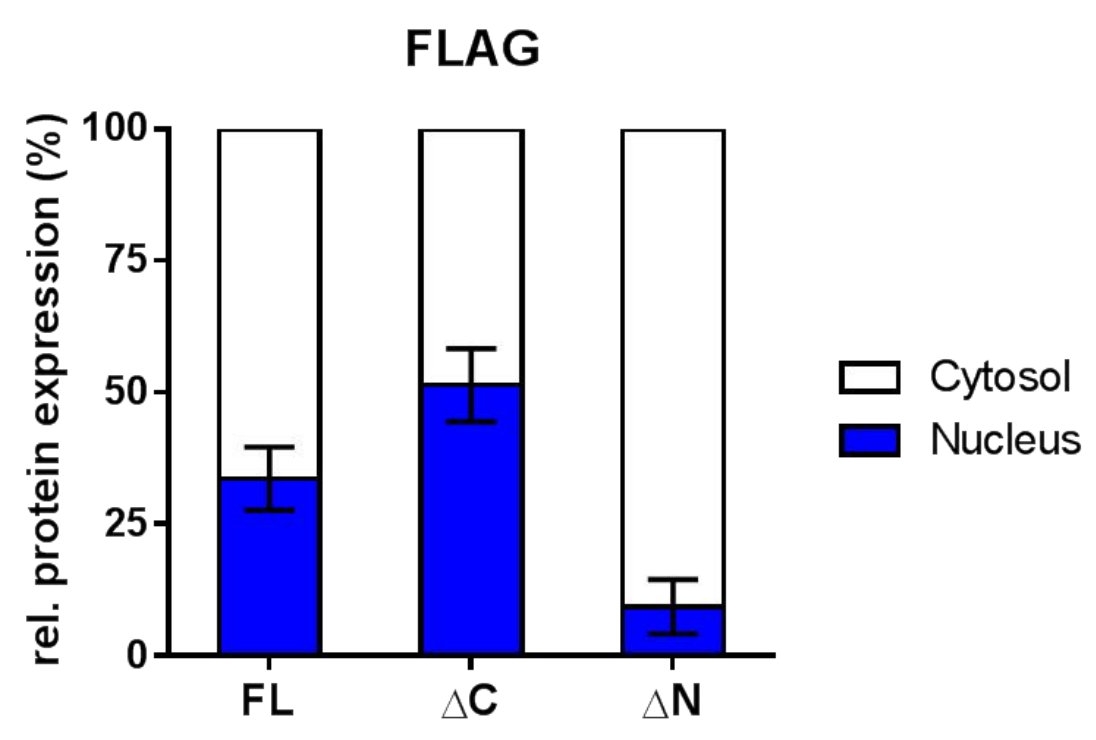

$\sim 28 \mathrm{kDa}$

$\sim 20 \mathrm{kDa}$

(65+74 $\mathrm{kDa}$

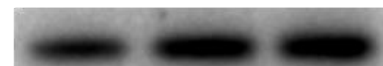

$38 \mathrm{kDa}$

B

Figure 20: BZW2 protein domains analysis.

A BZW2-FL, BZW2- $\Delta$ C and BZW2- $\Delta N$ were each overexpressed in HEK293 cells ( $n=3 /$ group). Protein lysates were separated in cytosolic \& nucleic fractions. BZW2 expression was detected via Western blot using mouse-anti-FLAG antibody. GAPDH (cytosol), lamin $A / C$ (nucleus) and inactive form of caspase 3 (cytosol) were used as controls for separation. B BZW2 expression in cell compartments was normalized to the total BZW2 expression. Full length BZW2 (FL) is localized in both cell 
compartments, predominantly in cytosol. Deletion of $C$ terminus $(\Delta C)$ leads to the reduction of the cytosolic localization, meanwhile deletion of $N$ terminus $(\Delta N)$ leads to the reduction of the nucleic localization.

4.2. Investigation of $B Z W 2$ role in the $W n t / \beta$-catenin signaling

4.2.1. BZW2 expression upon upregulation of the $\mathrm{Wnt} / \beta$-catenin signalling in vivo

The above described experiments demonstrated an assoccitation of BZW2 components of the $\mathrm{Wnt} / \beta$-catnein cascede as well as strongly suggest an important role of BZW2 in signaling adult and developing heart cells. Next, we further investigated its role in the Wnt cascade. We found BZW2 upregulation in mice showing modulation of the $\mathrm{Wnt} / \beta$-catenin cascade. Upregulation of the $\mathrm{Wnt} / \beta$-catenin trasncriptional activity was previosly reported in KIf15 knock-out (KO) mouse heart as demosntrated by Tcf7l2 upregulation (Figure 4, Introduction, Page 10). Expression of Bzw2 was analyzed in heart, lung, liver and kidney from Klf15 knock-out (KO) mice in comparison to wild type $\mathrm{C} 75 \mathrm{BL} / 6 \mathrm{~N}$ control mice. It was found that similar to the Tcf7/2 expression (Figure 4, Page 10) BZW2 expression was higher in Klf15 KO mice specifically in the heart (Figure 21), further supporting the participationof BZW2 in the Wnt cascade.

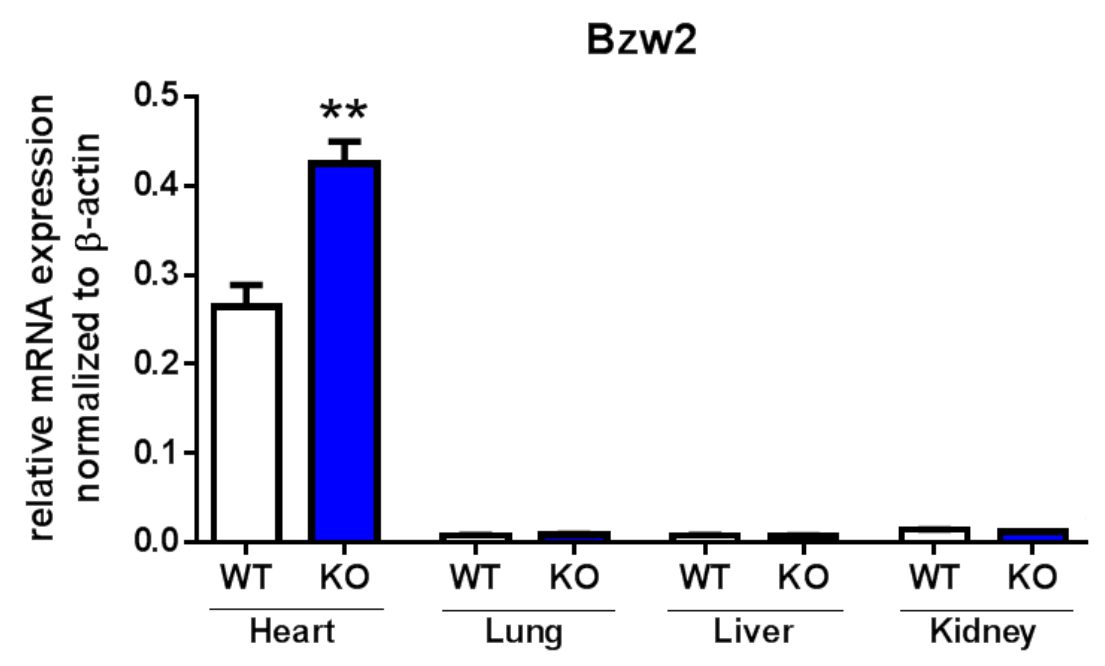

Figure 21: BZW2 expression in KIf15 knock-out (KO) mice under upregulation of the Wnt/ $\mathrm{B}$ catenin signaling. 
BZW2 expression was tested in the heart, lung, liver and kidney of the Klf15 knock-out (KO) mice compared to the wild type mice (WT). BZW2 was upregulated specifically in the heart, despite the global knock-out. Bzw2 mRNA expression was analyzed via qPCR and normalized to $\beta$-actin ( $n=6 /$ group, Student's $t$-test, ${ }^{* *} \mathrm{p}<0.01$ ).

To corroborate the direct relation to the $\mathrm{Wnt} / \beta$-catenin cascade activation, BZW2 expression was analyzed in the heart of mice with an inducible $\alpha$-Mhc specific $\beta$ catenin stabilization $\left(\beta\right.$-catenin $\left.{ }^{\Delta e \times 3}\right)$ resulting in $W n t / \beta$-catenin transcriptional activation. Moreover the heart of mice with an inducible $\alpha$-Mhc specific $\beta$-catenin ( $\beta$ catenin $^{\Delta e \times 2-6}$ ) depletion resulting in reduced $\mathrm{Wnt} / \beta$-catenin activation was analyzed. These double transgenic mice carry a tamoxifen inducible CRE recombinase driven by the $\alpha$-Mhc promoter. $\beta$-catenin locus is flanked by loxP sites either at exons 3 (including phosphorylation amino residues leading to $\beta$-catenin degradation), which results in a gain-of-function or at exons 2-6, resulting in a loss-of-function after recombination induced by Tamoxifen injection. In line with BZW2 expression in KIf15 $\mathrm{KO}$ mice, BZW2 protein expression in the heart of $\beta$-catenin gain-of-function mice was also upregulated in comparison to the wild type mice (Figure 22), indicating cardiac BZW2 upregulation under upregulation of Wnt/ß-catenin transcriptional signaling.
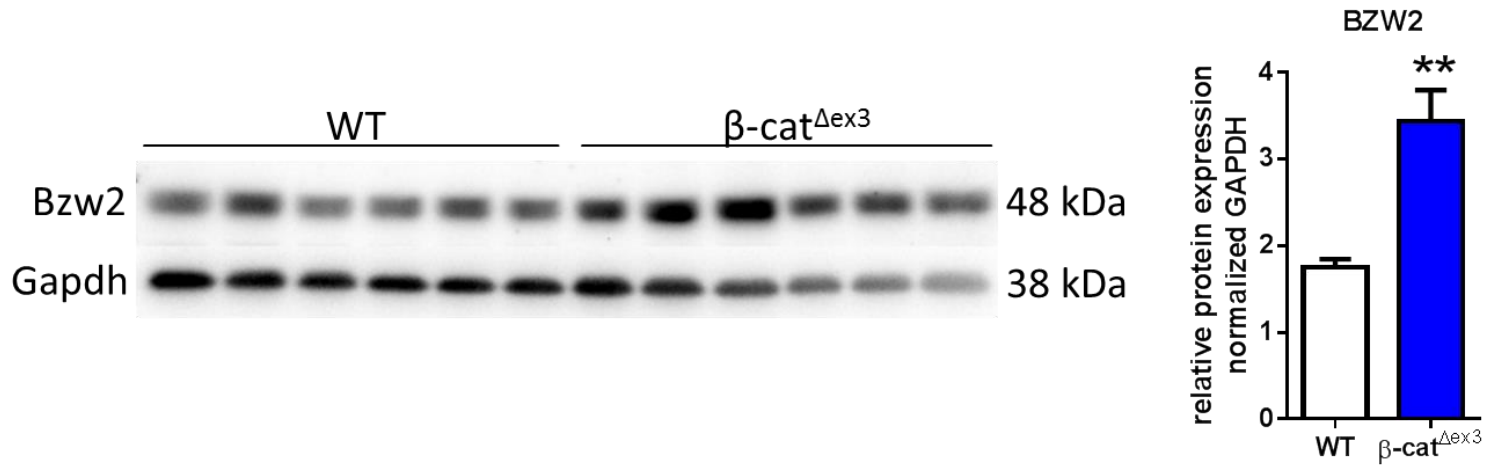

Figure 22: BZW2 expression in cardiac specific $\beta$-catenin gain-of-function mice.

BZW2 expression in the heart of cardiac specific $\beta$-catenin stabilized mice ( $\beta$-cat ${ }^{\Delta e \times 3}$, described above) was analyzed by Western blot and normalized to GAPDH ( $n=6 /$ group). BZW2 protein expression was upregulated in the heart of these mice compared to the wild type (WT). The graph represents analyzed Western blot data (Student's $t$-test, ${ }^{* *} p<0.01$ ). 
Interestingly cardiac BZW2 protein expression under $\beta$-catenin downregulation was not changed compared to the wild type mice (Figure 23). Supporting a role as a negative feedback factor.
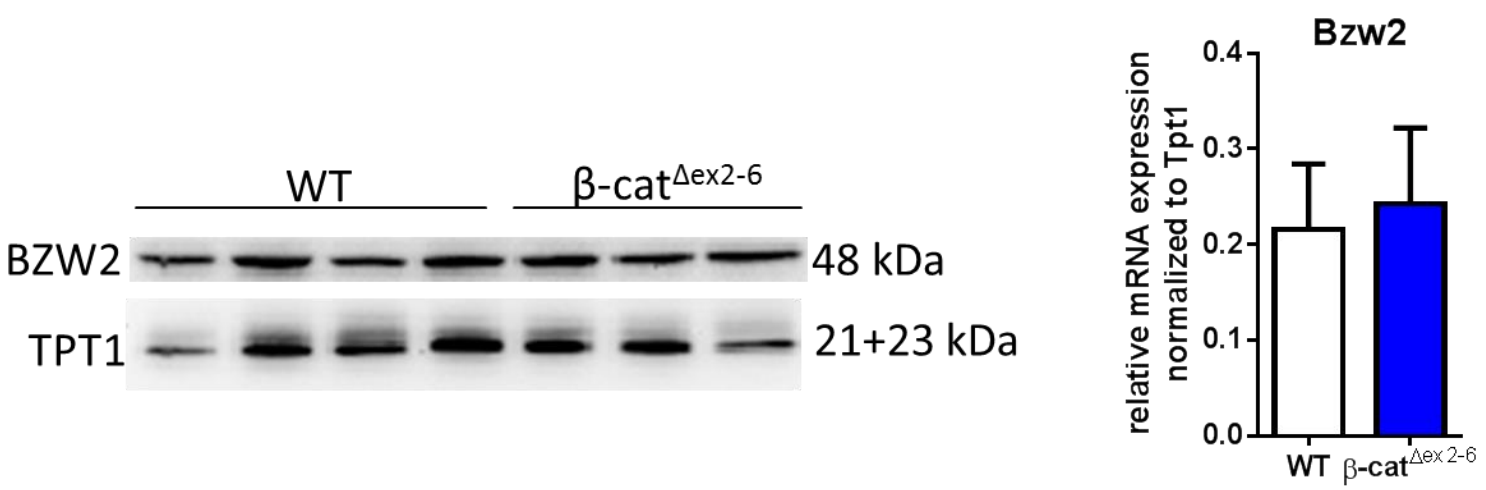

Figure 23: BZW2 expression in cardiac specific $\beta$-catenin loss-of-function mice.

BZW2 expression in the heart of cardiac specific $\beta$-catenin depleted mice $\left(\beta\right.$-cat ${ }^{\text {ex2-6 }}$, described above) was analyzed by Western blot and normalized to TPT1 $(n=3)$. BZW2 protein expression was unchanged in the heart of these mice compared to the wild type (WT). The graph represents analyzed Western blot data.

4.2.2. BZW2 role in the $W n t / \beta$-catenin signalling as a downstream target gene

High expression of BZW2 in mice under upregulation of the $\mathrm{Wnt} / \mathrm{\beta}$-catenin signaling opened another question, namely whether BZW2 itself is regulated by the $\mathrm{Wnt} / \beta$ catenin signaling. An in silico promoter analysis of the 5'-region of the ATG BZW2 codon was performed using online available tools (http://alggen.lsi.upc.es). This identified three TCF/LEF putative consensus sequences 1745 bp upstream the Bzw2 start codon. This fragment was cloned into $p G L 4.10$ vector to drive luciferase gene expression for experimental testing (Figure 24A). Luciferase activity in this experimental set up represents Bzw2 transcriptional activity. Non-modified pGL4.10 vector was used as a negative control (NC). Bzw2-promoter construct was cotransfected with Tcf7l2. Renilla luciferase expressing plasmid was co-transfected for normalization. TCF7L2 overexpression significantly upregulated Bzw2 transcriptional activity (Figure 24B). These data suggest that Bzw2 transcription is regulated by $\mathrm{Wnt} / \beta$-catenin target genes. 


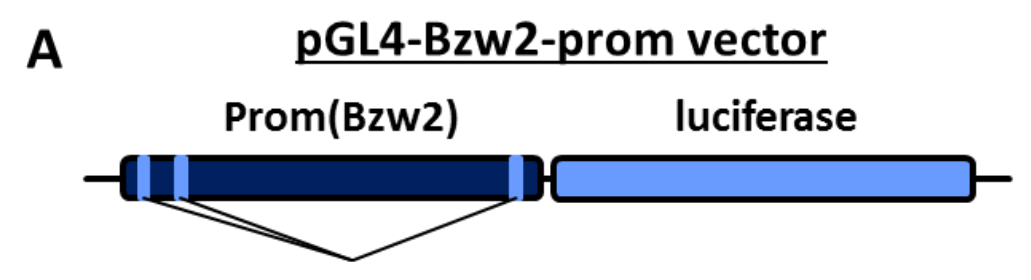

TCF/LEF consensus sequences

B

\section{Bzw2 transcriptional activity}

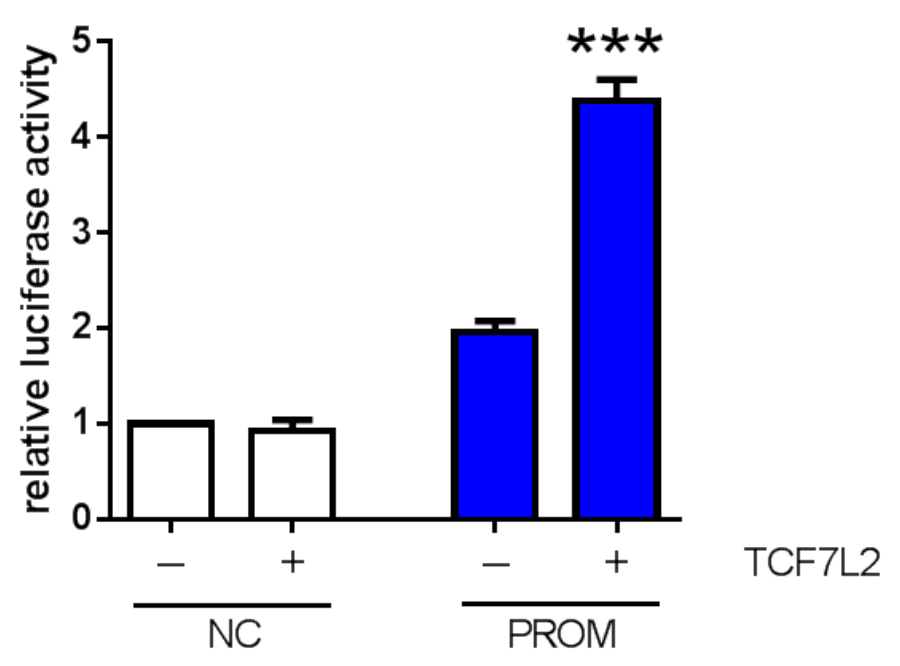

Figure 24: Luciferase reporter assay indicating BZW2 role in the $W n t / \beta$-catenin signaling as a target gene.

A pGL4-Bzw2-prom plasmid includes luciferase gene driven by a sequences 1745 bp upstream the Bzw2 start codon including 3 TCF/LEF putative consensus sequences (a putative Bzw2 promoter). Unmodified pGL4.10 vector (not shown) was used as a negative control for unspecific binding to the vector in all experiments. B Significant increase of Bzw2 transcriptional activity by TCF7L2 in HEK293 cells was detected by dual luciferase assay ( $n=3 /$ group; Student's $t$-test, ${ }^{* * *} p<0.001$ ). Unmodified pGL4.10 vector was used as a negative control (NC).

\subsubsection{BZW2 role in the $\mathrm{Wnt} / \beta$-catenin signalling as a co-regulator}

BZW2 was highly expressed in mice under upregulation but not under downregulation of the Wnt/ $\beta$-catenin signaling. It opened a question whether BZW2 was compensatory upregulated to inhibit the $\mathrm{Wnt} / \beta$-catenin signaling in these mice. To test BZW2 putative regulatory role on the $\mathrm{Wnt} / \beta$-catenin signaling the TOPflash/FOPflash reporter assay was used. TOPflash plasmid includes luciferase gene driven by TK-promoter with three TCF/LEF consensus sequences. FOPflash 
plasmid includes 3 mutated TCF/LEF consensus sequences and was used as a negative control for unspecific binding to the plasmid (Figure 25A). Luciferase activity, detected by measurement of the luminescence produced from luciferin oxidation, represents indirect $\mathrm{Wnt} / \mathrm{\beta}$-catenin signaling transcriptional activity. TOPflash and FOPflash plasmids were single co-transfected into HEK293 cells with BZW2 expressing plasmid or with the empty vector as a negative control. Renilla luciferase expressing plasmid was co-transfected for normalization. By overexpression of BZW2 no significant changes of Wnt/ $\beta$-catenin signaling activity were detected by luminescence changes (Figure 25B).

A

$\underline{\text { TOP vector }}$

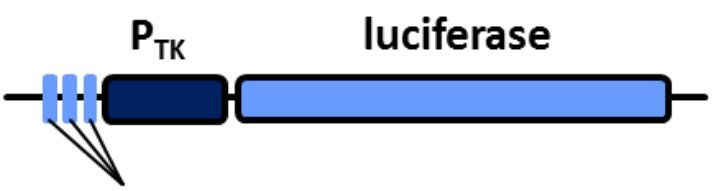

TCF/LEF consensus sequences

B

Wnt signaling activity

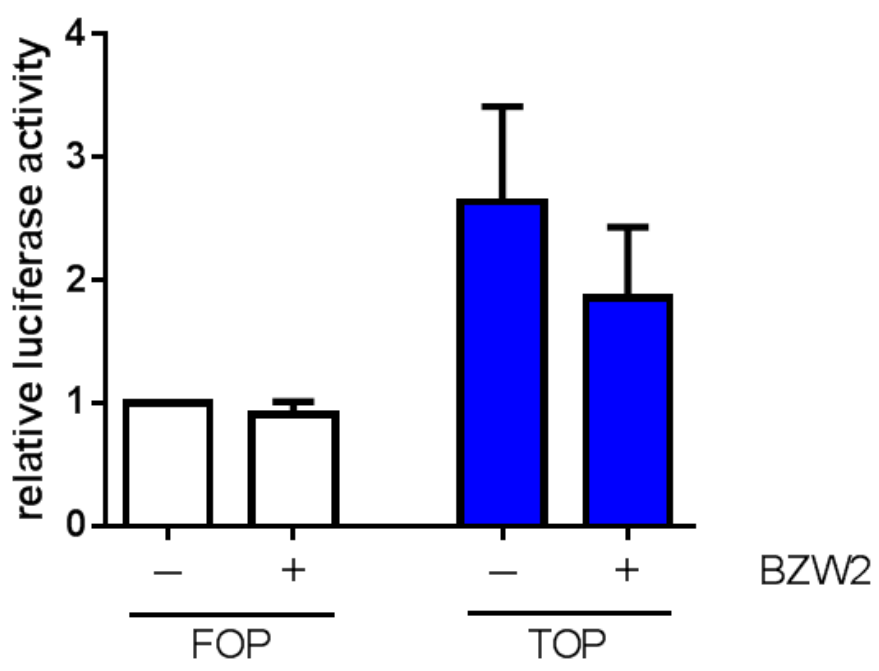

Figure 25: BZW2 role in the $W n t / \beta$-catenin signaling as a co-regulator.

A TOPflash plasmid includes luciferase gene driven by TK-promoter with 3 TCF/LEF consensus sequences. FOPflash plasmid (not shown) includes 3 mutated TCF/LEF consensus sequences and was used as a negative control for unspecific binding to the plasmid in all experiments. B A tendency to inhibition of Wnt/B-catenin signaling activity by BZW2 in HEK293 cells was detected by 
TOPflash/FOPflash reporter assay ( $n=4$ : triplicate of 4 independent experiments). FOP was used as a negative control.

\subsubsection{Influence of BZW2 on the $\mathrm{Wnt} / \mathrm{B}$-catenin signalling in vivo}

Since TOPflash/FOPflash reporter assay in HEK293 cells is a non-cardiac in vitro system, the putative BZW2 regulatory role on the $\mathrm{Wnt} / \beta$-catenin signaling was further investigated in BZW2 transgenic mouse model (a Bzw2 knock-in (KI) mouse model with a conditional potential named as first allele $B z w 2^{\text {tm1a }}$ knock-out (KO), UC DAVIS KOMP Repository Knockout mouse project) (Figure 26). The initial unmodified allele is predicted to generate a null allele through splicing to a $L a c Z$ trapping element contained in the targeting cassette. ${ }^{101}$ They consist of a $\mathrm{KI}$ cassette including the Bzw2 locus at exon 4, flanked by loxP sites (for Cre recombination recognition). The insert upstream from the floxed exon 4 (including $L a c Z$ cesette following by loxP and neomycin resistance cassette) is flanked by flippase (Flp) recognition target sites $(F R T)$. Consequently breading of these mice with constitutive Flp-recombinase mice would lead to a Cre-inducible KO mouse model (Figure 26).

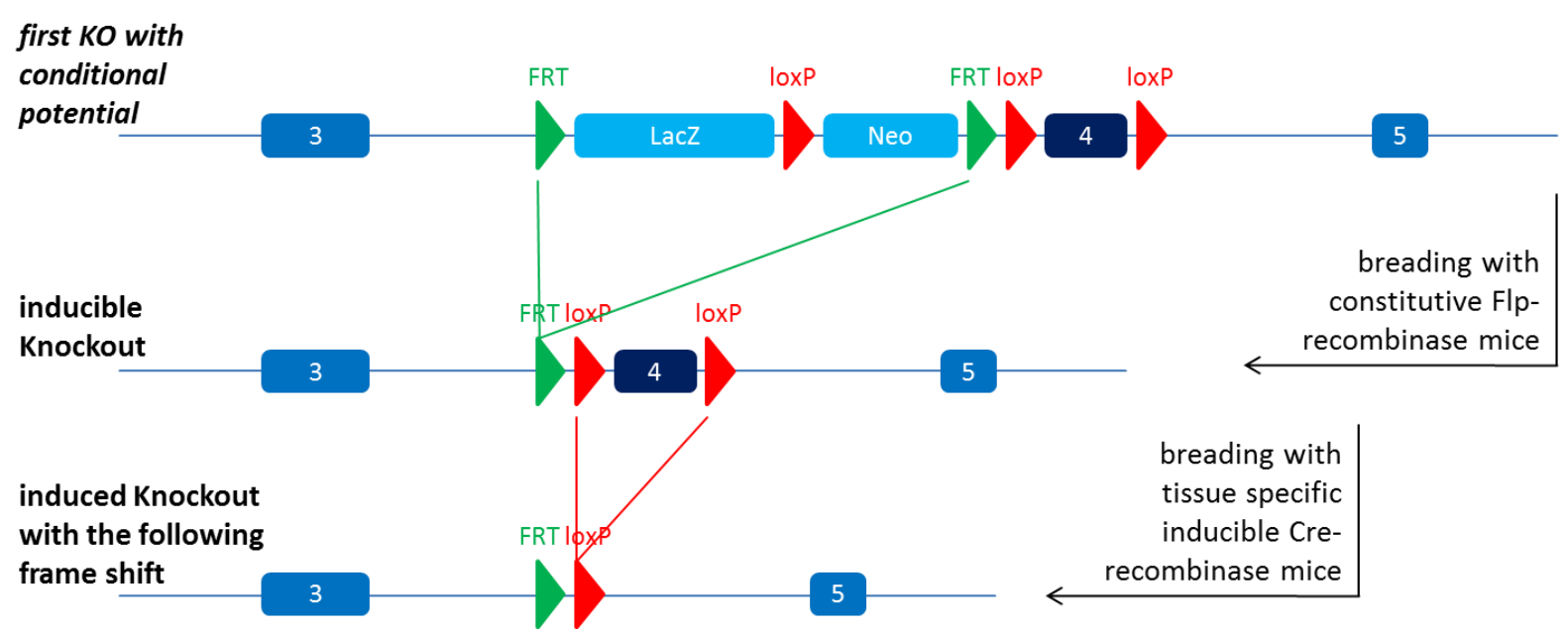

Figure 26: Bzw2 KI transgenic mouse model with a conditional potential.

The initial unmodified allele is predicted to generate a null allele through splicing to a LacZ trapping element contained in the targeting cassette ("first KO with conditional potential"). A knock-in (KI) cassette includes the Bzw2 locus at exon 4, flanked by loxP sites (for Cre recombination recognition). The insert upstream from the floxed exon 4 (including LacZ cesette following by loxP and neomycin resistance cassette) is flanked by flippase (Flp) recognition target sites ( $F R T)$. Consequently breading of these mice with constitutive Flp-recombinase mice would lead to a Cre-inducible KO mouse model. The following breading with tissue specific Cre-recombinase mice and induction of Cre-recombinase would lead to induced KO by exon 4 deletion with the following frame shift. 
UC DAVIS KOMPRepository Knock out mouse project.

Because of the time limit the $B z w 2^{\text {tm1a }}$ knock-out mice (in following named $B z w 2 \mathrm{KI}$ mice) were analyzed in this study. The insert upstream from exon 4 is approximately $11 \mathrm{~kb}$ long and consists of $\beta$-galactosidase (LacZ) and neomycin resistance cassettes, each including own polyadenylation sites which should avoid BZW2 translation. This is predicted to generate a null allele. ${ }^{101}$ To validate the model Bzw2 $\mathrm{KI}$ mice (wild type, heterozygous and homozygous) were analyzed for BZW2 expression. It was shown that already on the RNA level significant reduction of Bzw2 expression took place in heterozygous (HE) and homozygous $(\mathrm{HO})$ mice (Figure 27A). BZW2 protein is reduced in the HE and is completely absent in the $\mathrm{HO} \mathrm{Bzw2} \mathrm{KI}$ mice as observed via Western Blot by using a rabbit-anti-BZW2 antibody recognizing BZW2 protein region coding by exons 8-9 (Figure 27B).
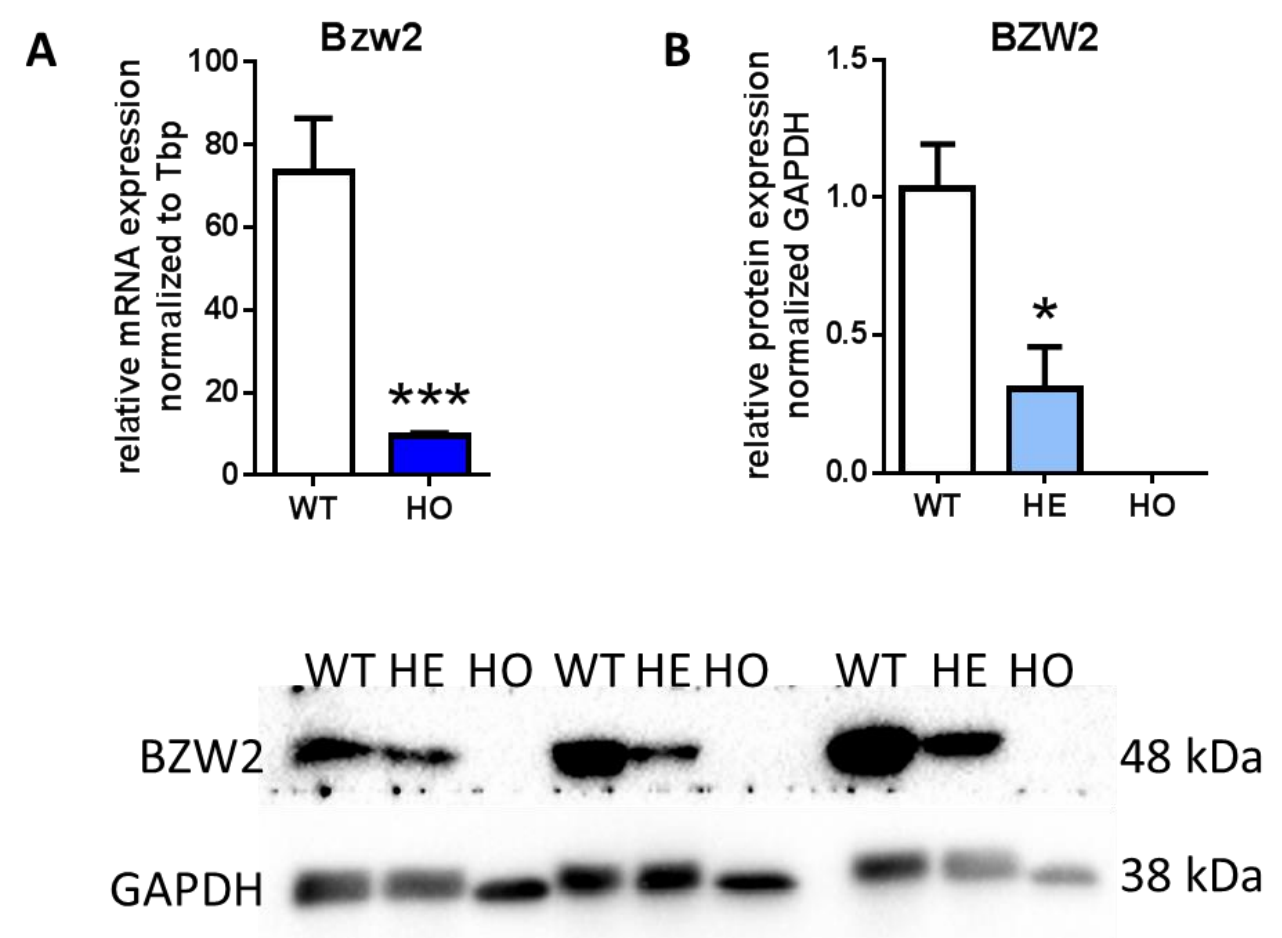

Figure 27: Validation of BZW2 expression in BzW2 KI mice.

Cardiac tissue of adult Bzw2 KI mice (heterozygous (HE) and homozygous (HO) mice) was analyzed for BZW2 expression compared to the wild type (WT) from the same mouse line. A Bzw2 mRNA normalized to Tbp expression is significantly reduced in heart tissue of $\mathrm{HO}$ mice ( $n=4 / W T$ \& $n=5 / H O$; Student's $t$-test, ${ }^{* * *} \mathrm{p}<0.001$ ). B BZW2 protein expression normalized to GAPDH is significantly decreased in $\mathrm{HE}$ mice and is absent in $\mathrm{HO}$ mice. The graph represents several Western blot analyses 
$\left(n=9 / W T \& n=3 / H E \& n=7 / H O\right.$, Student's $t$-test, $\left.{ }^{*} p<0.05\right)$, some of them performed with the help of Eric Schoger.

BZW2 protein expression in Bzw2 KI was validated using rabbit-anti-BZW2 antibody binding the protein region coding by exons $8-9$, which seems to be absent upon translation of the Bzw2 KI locus. However, the use of a rabbit-anti-BZW2 antibody (Q91VK1, designed and produced by Thermo scientific) binding the protein region coding by exon 3 (upstream of the insert) was able to show protein expression by immunohistochemistry analyses. Validation of the truncated BZW2 protein by Western blot was not possible, due to the antibody did not work for this analysis. Paraffin sections of adult Bzw2 KI mice (WT and $\mathrm{HO}$ ) were used for immunofluorescence analysis. Interestingly, expression of BZW2 was detected in $\mathrm{HO}$ Bzw2 KO mice (accuracy of the antibody was tested by several in vitro testing for cross reaction with BZW1, data not shown). This data suggest a truncated protein is generated in Bzw2 KI mice, whose cytosol/nucleus distribution remains to be investigated (Figure 28).

\section{BZW2 / DAPI}

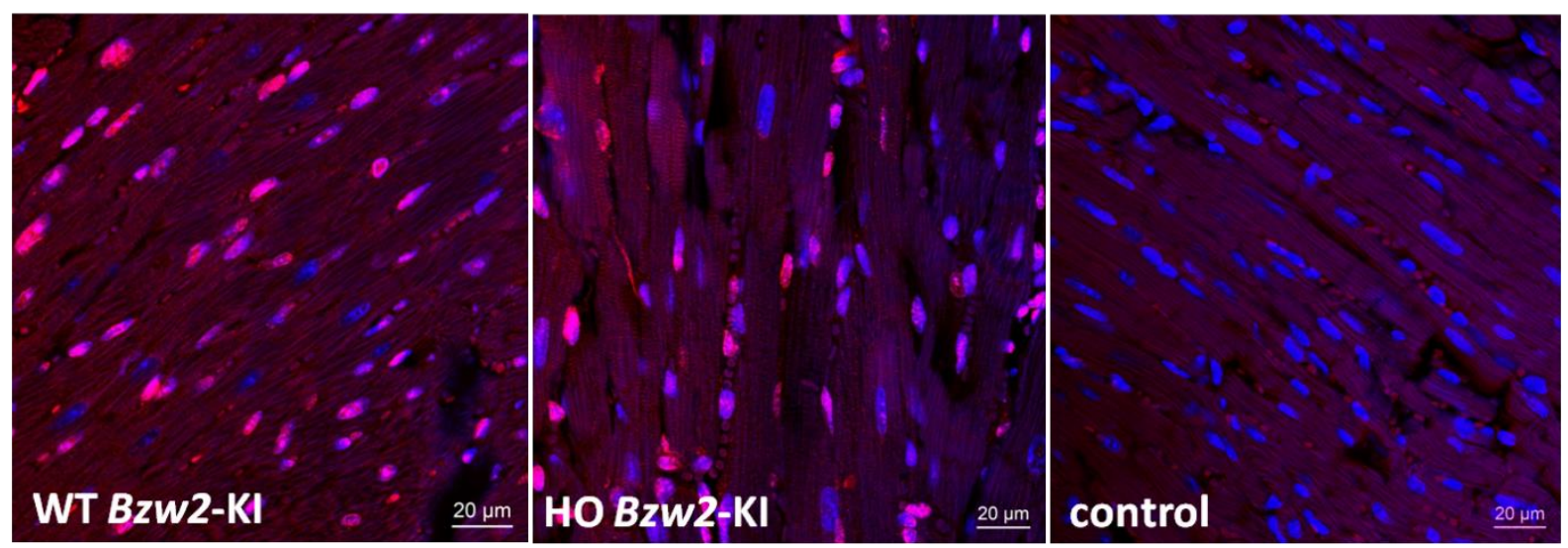

Figure 28: BZW2 truncated protein is expressed in the heart of homozygous Bzw2 KI mice.

Expression of truncated BZW2 protein in heart tissue of adult $\mathrm{HO}$ Bzw2 $\mathrm{KI}$ mice was analyzed compared to WT and antibody control. BZW2 was detected using rabbit-anti-BZW2 binding in the region coding by exon 3 (Q91VK1, designed and produced by Thermo scientific) \& anti-rabbit-Alexa Fluor 594 (red) antibodies. Nuclei staining was done by DAPI (blue). BZW2 truncated form was found in the nucleus. Confocal images were done from immunostained paraffin slides. Scale bar: $20 \mu \mathrm{m}$.

To investigate the effect of BZW2 on the $\mathrm{Wnt} / \beta$-catenin cascade, firstly $\beta$-catenin immunostaining was performed in paraffin section of adult Bzw2 KI mouse hearts. 
This analysis showed an increased expression of $\beta$-catenin in $\mathrm{HO} B z w 2 \mathrm{KI}$ mice compared to the wild type, which is apparently located at the membrane, although it is important to note that immunofluorescence detection of $\beta$-catenin in the nucleus in paraffin sections has been challenging.

\section{BZW2 / $\beta$-catenin / DAPI}
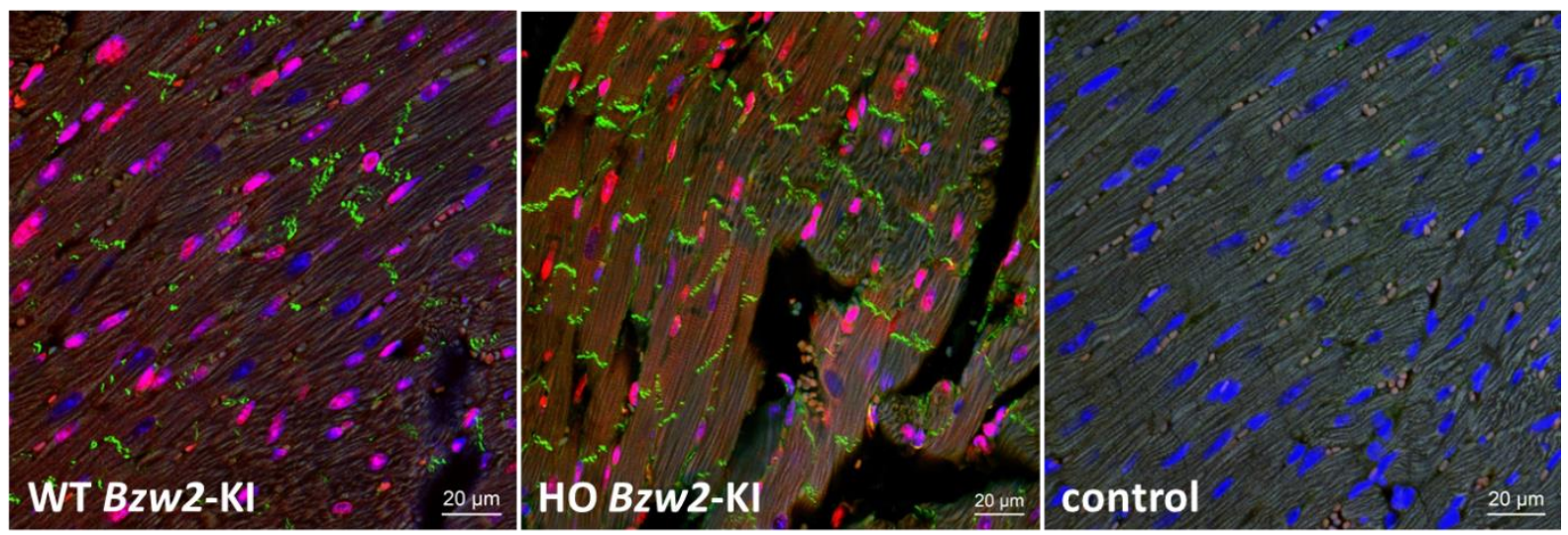

Figure 29: $\beta$-catenin is upregulated in the heart of homozygous $B z w 2 \mathrm{KI}$ mice.

Heart tissue of adult $\mathrm{HO} B z w 2 \mathrm{KI}$ mice was analyzed for $\beta$-catenin expression compared to WT and antibody control. $\beta$-catenin was detected using mouse-anti- $\beta$-catenin $\&$ anti-mouse-Alexa Fluor 488 (green) antibodies. BZW2 was detected by rabbit-anti-BZW2 (Q91VK1, Thermo scientific) \& antirabbit-Alexa Fluor 594 (red) antibodies. $\beta$-catenin was found upregulated and accumulated on the plasma membrane in heart tissue of $B z w 2 \mathrm{KI}$ mice. Confocal images were done from immunostained paraffin slides: Nuclei staining was done by DAPI (blue). Scale bar: $20 \mu \mathrm{m}$.

For further investigation RNA and protein from Bzw2 KI mice hearts were analyzed. In line with the immunofluorescence data, $\beta$-catenin was found to be significantly increased in the $\mathrm{HO}$ Bzw2 $\mathrm{KI}$ mice (Figure $30 \mathrm{~A}$ and $\mathrm{B}$ ). Interestingly, $\beta$-catenin expression was not changed in the HE mice, indicating that the complete absence of the protein (or part of it) is necessary for $\beta$-catenin dysregulation. To test if this regulatory effect is cardiac specific, RNA from different organs (heart, skeletal muscle, brain, spleen, liver, kidney and lung) of Bzw2 KI mice ( $\mathrm{HO}$ mice compared to the wild type) was analyzed for $\beta$-catenin expression. $\beta$-catenin was significantly upregulated in Bzw2 KO mice exclusively in the heart (Figure 30C). 
A

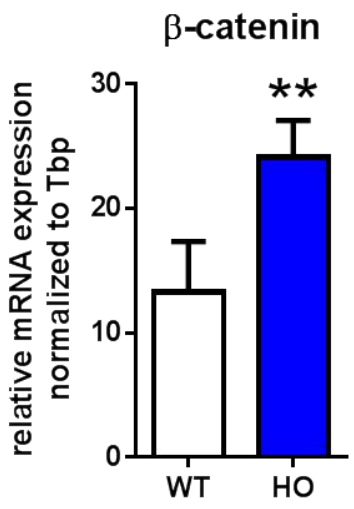

B

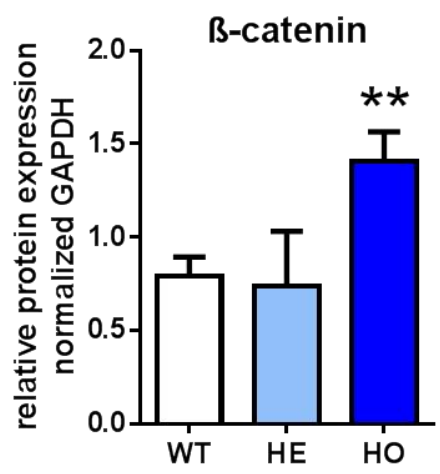

C

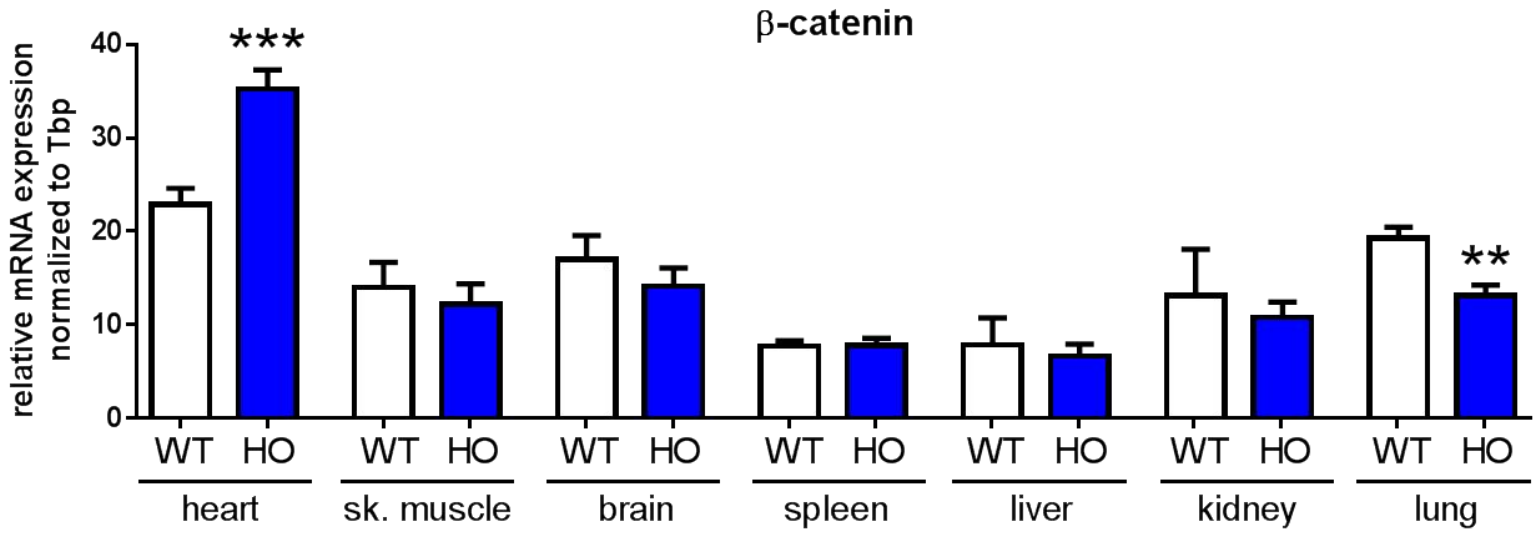

Figure 30: $\beta$-catenin expression analyses in Bzw2 KI mice.

Cardiac tissue of adult Bzw2 KI mice (heterozygous (HE) and homozygous (HO) mice) was analyzed for $\beta$-catenin expression compared to the wild type (WT) from the same mouse line. A $\beta$-catenin mRNA normalized to Tbp expression is significantly increased in heart tissue of $\mathrm{HO}$ mice ( $n=4 /$ WT \& $\mathrm{n}=5 / \mathrm{HO}$; Student's $t$-test, $\left.{ }^{* *} \mathrm{p}<0.01\right)$. B $\beta$-catenin protein expression normalized to GAPDH is unchanged in $\mathrm{HE}$ mice but is significantly increased in $\mathrm{HO}$ mice. The graph represents several Western blot analyses $\left(n=9 / W T\right.$ \& $n=3 / H E \& n=7 / H O$, Student's $t$-test, ${ }^{* *} p<0.01$ ), performed with the help of Eric Schoger. C $\beta$-catenin mRNA normalized to Tbp is significantly increased exclusively in heart tissue of $\mathrm{HO}$ mice compared to skeletal muscle, brain, spleen, liver, kidney and lung tissue ( $n=4 /$ WT heart \& HO kidney; $n=3 /$ HO lung; $n=5 /$ other groups; Student's $t$-test, ${ }^{* * *} p<0.001$ ).

These data together suggest that BZW2 deletion leads to cardiac specific upregulation of $\beta$-catenin expression, the key protein of the $\mathrm{Wnt} / \beta$-catenin signaling. 


\subsection{Investigation of BZW2 role in the normal heart homeostasis}

Next, the BZW2 role in the adult heart homeostasis in vivo was investigated. To test whether BZW2 reduction has an effect in heart function, HE BzW2 KI mice (described in 4.2.3.1., Page 67) were analyzed via echocardiography, a standard method based on a sonogram of the heart. Mice were anesthetized by $2 \%$ isoflurane inhalation and ventricular measurements were done with a Visual Sonics Vevo 2100 Imaging System equipped with a $45 \mathrm{MHz}$ MS-550D MicroScan transducer at the SFB 1002 echocardiography facility. First the mice were analyzed at baseline in the absence of any stimulus. Moreover, two groups were subjected to TAC, 12 weeks old HE mice and 8 weeks old $\mathrm{HO}$ mice with the respective age-matched-wild type mice from the same line used as a control.

Analysis of the geometry of the heart, as indicative of remodeling, showed that anterior wall thickness of the left ventricle in diastole (AWTh-d) was significantly increased in the 12 weeks old HE mice while the 8 weeks $\mathrm{HO}$ mice showed a nonsignificant increase (Figure 31A). Interestingly, this increase was primarily observed in female mice (Figure 31B). Moreover, anterior wall thickness in systole (AWTh-s) was significantly increased in females of the 12 weeks old $\mathrm{HE}$ and in the 8 weeks old $\mathrm{HO}$ (Figure 31C). 12 weeks old HE females showed an increased cardiac mass as indicated by increased heart weight relative to body weight (HW/BW), but no increase of this ratio was observed in 8 weeks old $\mathrm{HO}$ females (Figure 31D). Interestingly, the $\mathrm{HO}$ females seemed to be heavier than WT females, which can explain why despite a significant increased heart weight they had no changes in the heart weight relative to body weight (Figure 31E). Nevertheless, no significant functional changes were observed neither in 12 weeks HE nor in 8 weeks $\mathrm{HO}$ mice, as showed by fraction area shortening (FAS) and ejection fraction (EF) (Figure 31F). 

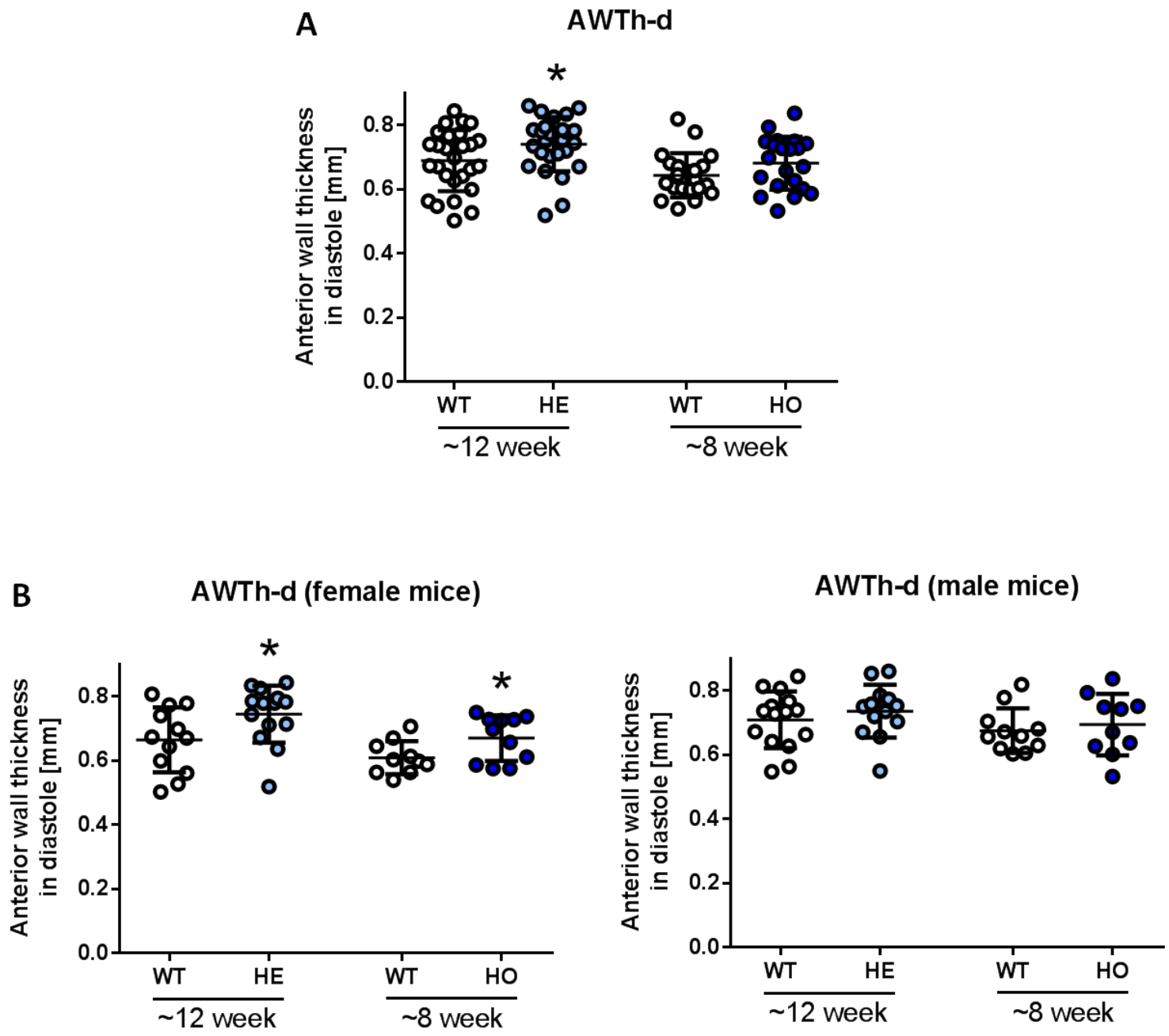

C AWTh-s (female mice)

AWTh-s
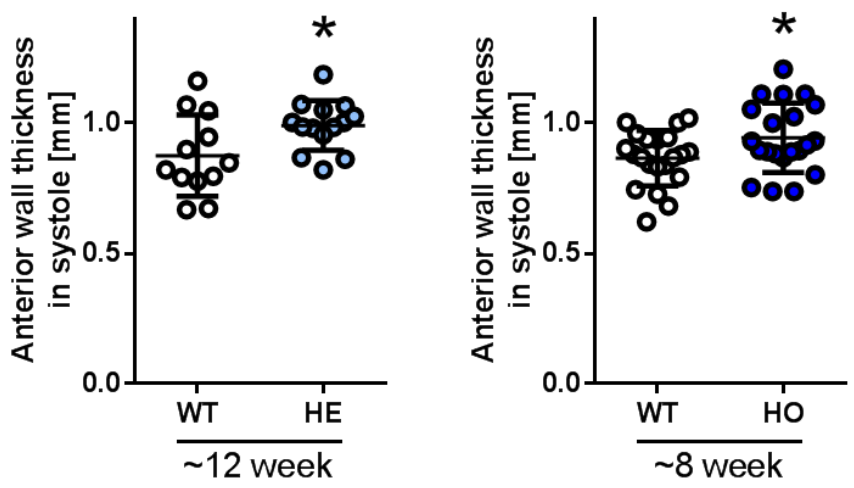


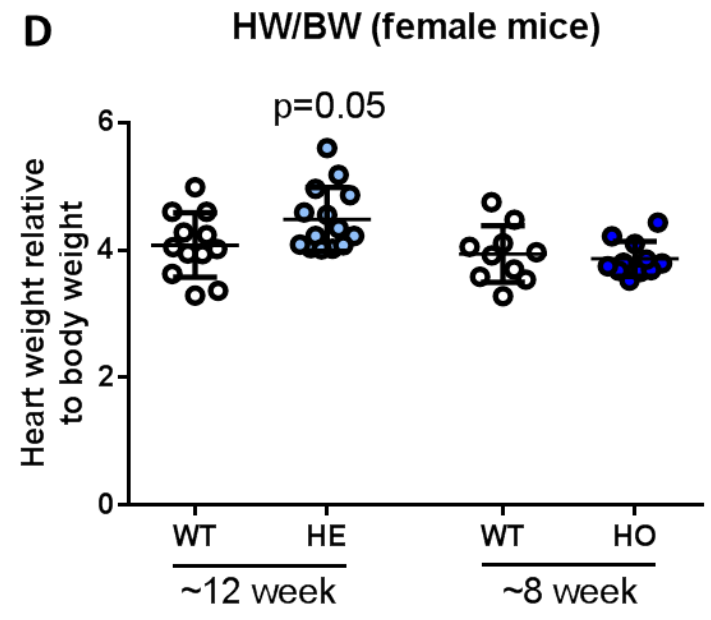

E

HW (female mice)

BW (female mice)
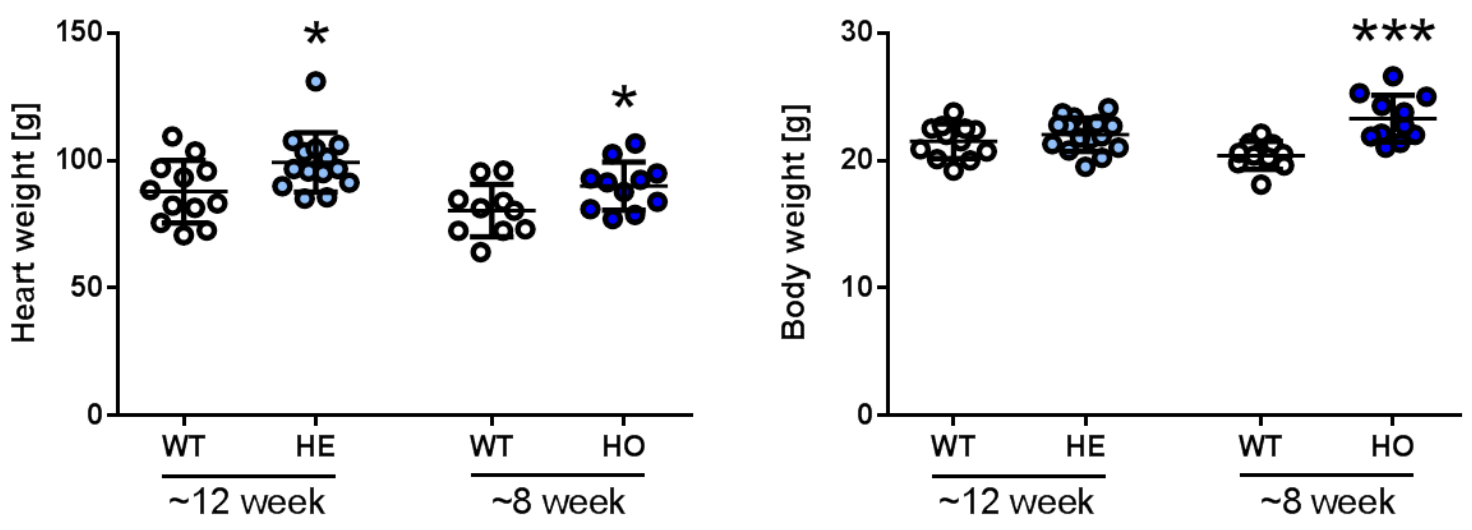

$\mathbf{F}$

FAS (female mice)

EF (female mice)
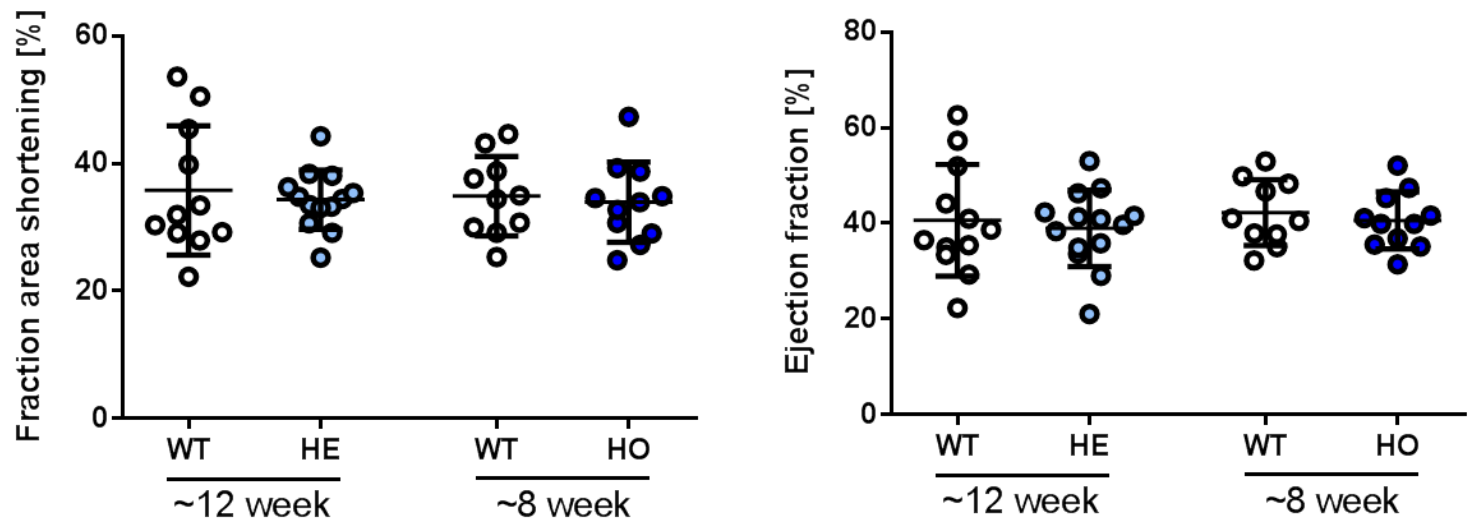

Figure 31: Echocardiography analysis of Bzw2 KI mice.

Cardiac functional phenotype of $B z w 2 \mathrm{KI}$ mice were analyzed by echocardiography with a $45 \mathrm{MHz}$ MS-550D MicroScan transducer. Heterozygous (HE) mice were analyzed in the age of approximately 12 weeks and homozygous $(\mathrm{HO})$ mice in the age of approximately 8 weeks, compared to the wild type (WT). Mice number: $n=27$ HE (27 WT); $n=21$ HO (21 WT); $n=14$ HE females (12 WT); $n=11$ HO 
females (10 WT); Student's $t$-test, ${ }^{*} p<0.05,{ }^{* * *} p<0.001$. A Anterior wall thickness of the left ventricle in diastole (AWTh-d). B AWTh-d, depend on mouse gender. C Anterior wall thickness of the left ventricle in systole (AWTh-s) of HO mice and HE females. D Heart weight relative to body weight (HW/BW) in female mice. $\mathbf{E}$ Heart weight $(\mathrm{HW})$ and body weight $(\mathrm{BW})$ in female mice. $\mathbf{F}$ Left ventricle internal diameter in diastole (LVID-d) in HO females. G Fraction area shortening (FAS, $n=13$ HE females (11 $\mathrm{WT})$ ) and ejection fraction (EF) in female mice.

To test if cardiac functional changes develop with aging, 47 weeks old HE mice were analyzed. Indeed, Bzw2 KI mice showed a significant decrease of the cardiac function demonstrated by fraction area shortening (FAS) and ejection fraction (EF) (Figure 32A). This was accompanied with a significant decrease in anterior wall thickness in systole (AWTh-s) and increased internal left ventricle area in systole (Area-s), which indicate dilation of the cardiac muscle in aged Bzw2 KI mice (Figure $32 \mathrm{~B})$. 
A

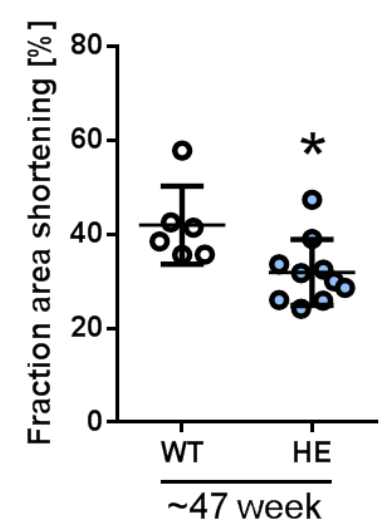

B

AWTh-s

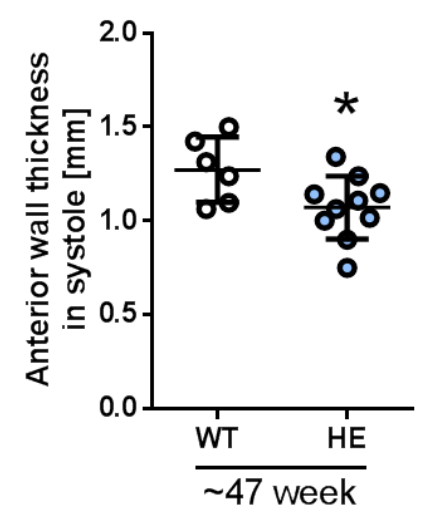

EF

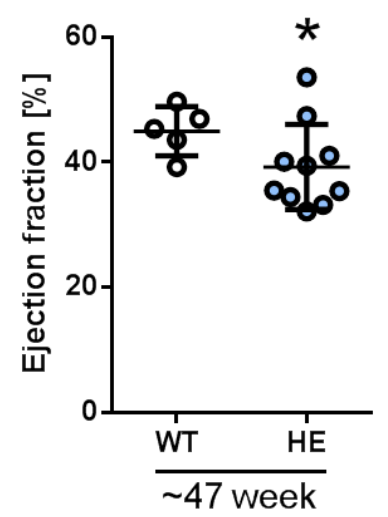

Area-s

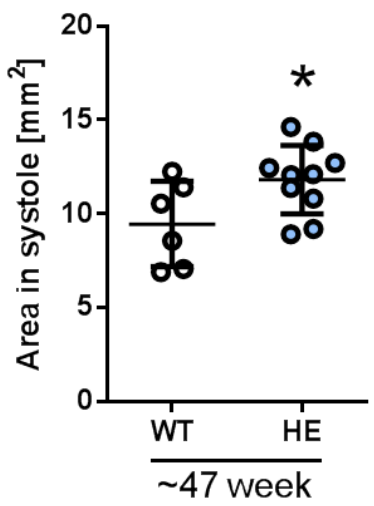

Figure 32: Echocardiography analysis in aged Bzw2 KI mice.

Cardiac characteristics of heterozygous Bzw2 KI mice (HE) in the age of approximately 47 weeks were analyzed by echocardiography, compared to the wild type (WT). Mice number: $n=10$ HE (5-6 WT); Student's $t$-test, ${ }^{*} p<0.05$. A Fraction area shortening (FAS) and ejection fraction (EF). B Anterior wall thickness of the left ventricle in systole (AWTh-s) and interior left ventricle area in systole (Area-s).

All together these data indicate that BZW2 loss and even a reduction results in hypertrophic remodeling with a concomitant development of decreased cardiac function in mice.

4.4. Investigation of BZW2 role in stress-induced cardiac remodelling

4.4.1. BZW2 expression in cardiac disease

Next, the role of BZW2 expression in cardiac diseases was analyzed. BZW2 was found to be upregulated in the heart tissue of mice with angiotensin (Ang) II -induced 
cardiac hypertrophy (Figure 33A) as well as in human hearts with dilated (DCM) and ischemic (ICM) cardiomyopathies (Figure 33B). This suggest that BZW2 is part of a developmental activated gene upon remodeling.

A
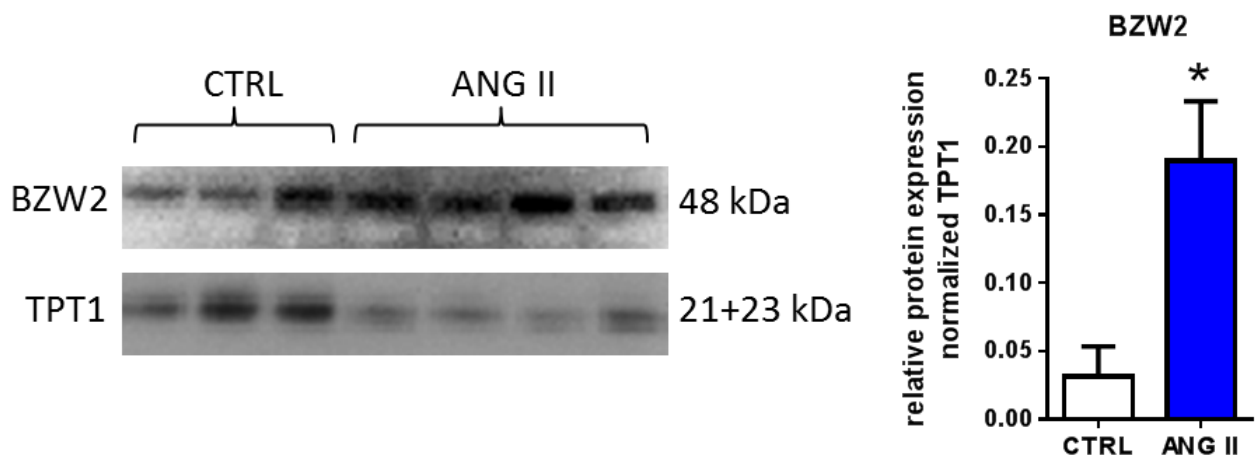

B

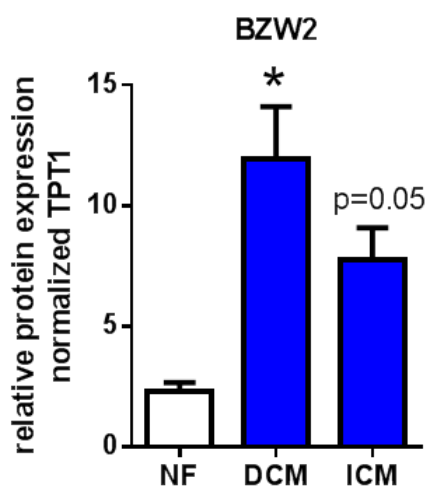

Figure 33: BZW2 expression in cardiac disease.

Western blot analyses showed that cardiac BZW2 expression normalized to TPT1 was upregulated in (A) angiotensin II (Ang II) treated mice $(n=3)$ in comparison to control animals (CTRL; $n=4$ ) (protein lysates kindly provided by A El-Armouche) as well as in (B) patients with dilated (DCM) ( $n=11)$ and ischemic (ICM) $(n=10)$ cardiomyopathy in comparison to non-failing human hearts (NF) ( $n=3)$ (tissue samples kindly provided by K Toischer / G Hasenfuss). Student's $t$-test, ${ }^{*} \mathrm{p}<0.05$.

\subsubsection{Transverse aortic constriction (TAC) in Bzw2 KI mice}

In the TAC model the constriction of the aorta is done in the area of the aortic arch between the brachiocephalic artery and the left common carotid artery (Methods, Figure 9, Page 49), leading to a pressure overload in the heart in systole. TAC initially leads to compensated hypertrophy of the heart. Over time the response to the chronic hemodynamic overload becomes maladaptive, resulting in cardiac dilatation and heart failure. ${ }^{102}$ This is an excellent well established model to study the process of progressive heart failure development in mice. 
HE Bzw2 KI mice were investigated compared to wild type age-matched mice. Sham operated mice were used as control for TAC. Heart geometry, size and function were analyzed by echocardiography 1-2 weeks before TAC operation (Pre), 2 and 4 weeks after TAC operation (Post 2 and Post 4 ) as well as by RNA analysis (5 weeks after TAC). As expected, TAC-induced cardiac hypertrophy and heart failure was developed as shown by increased anterior wall thickness and cardiac mass (Figure $34 \mathrm{~A})$ as well as decreased cardiac function demonstrated by fraction shortening and ejection fraction (Figure 34B) in wild type mice. Similar results were observed in HE $B z W 2 \mathrm{KI}$ mice, with the difference that 4 weeks after TAC they showed less of AWTh compared to the wild type. This was oberved in HE when compared to WT at the same time point but also when compared to HE Bzw2 KI at 2 weeks (Figure 34A). These data suggest a thinning of the wall maybe due to higher wall stress compared to WT mice. As shown in Figure 34B, cardiac function starts to decrease around 4 weeks post-TAC although this change is not significant. Due to the low mice survival rate no gender related study was possible. 

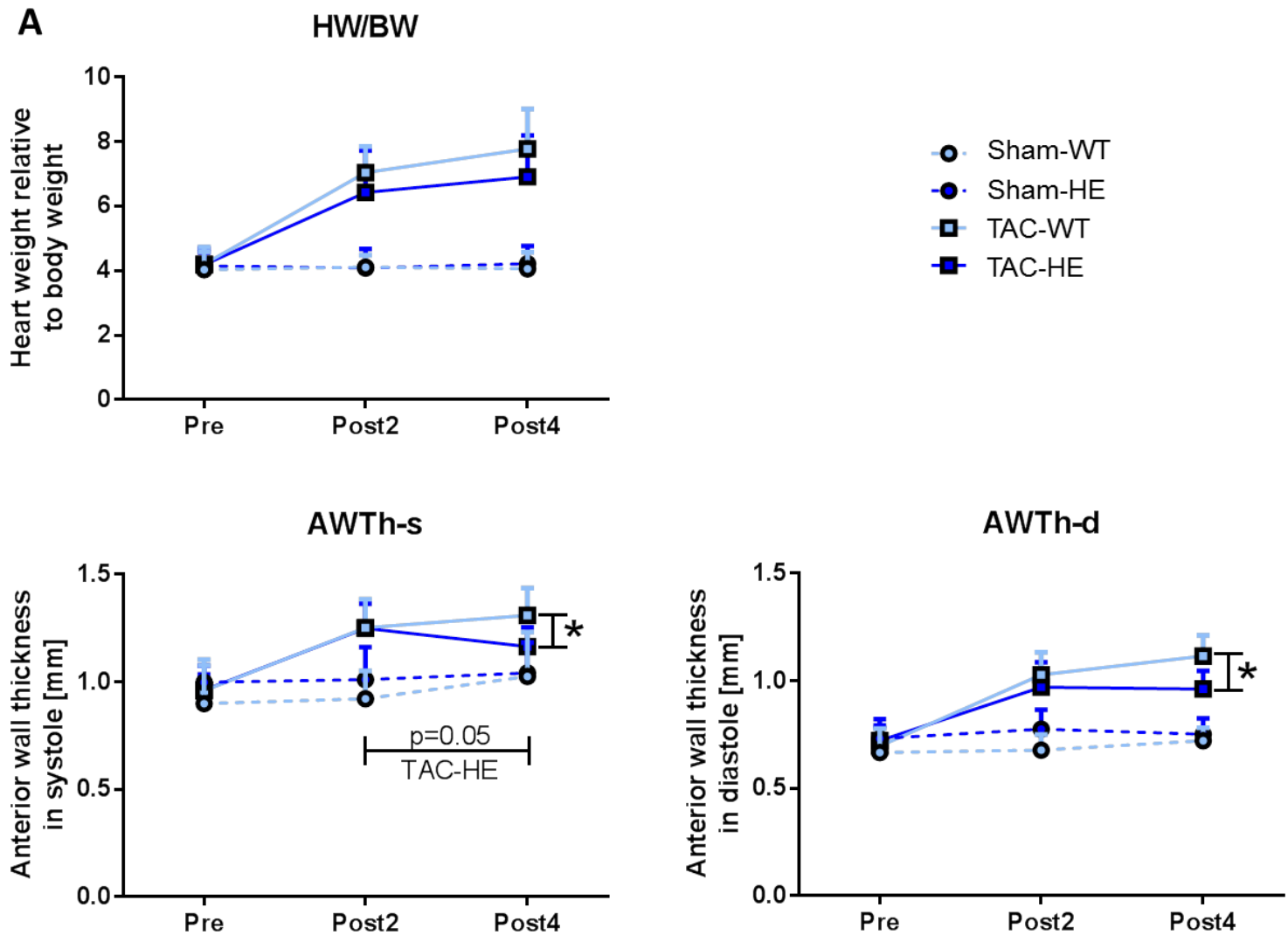

B

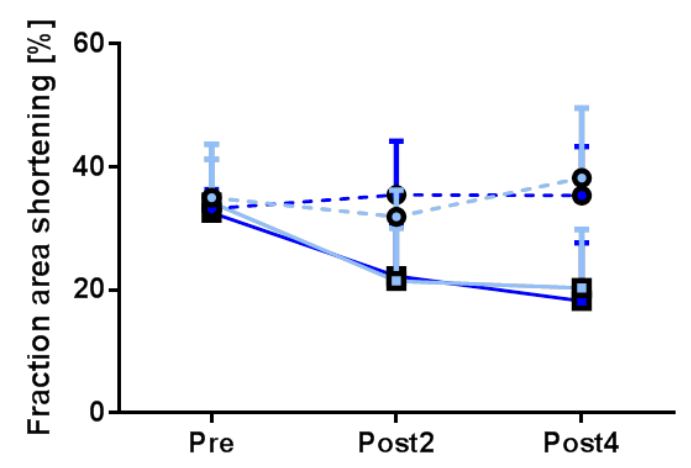

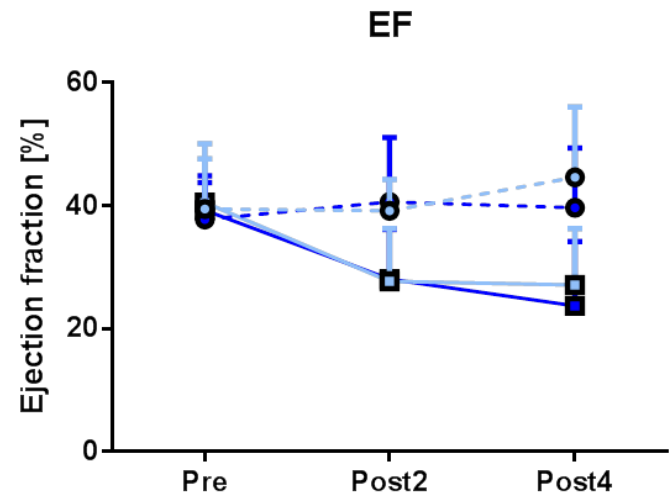

Figure 34: Echocardiography analysis in TAC operated Bzw2 KI mice.

Cardiac characteristics of heterozygous Bzw2 KI mice (HE) were analyzed by echocardiography, compared to the wild type (WT), before (Pre), 2 weeks after (Post2) and 4 weeks after (Post4) TAC operation. Sham operated mice were used as control. Mice number: $n=8-10$ in each Sham group; $n=18 /$ Pre, 12/Post2 \& 6/Post4 in TAC operated WT group; n=16/Pre, 14/Post2 \& 11/Post4 in TAC operated HE group; Student's $t$-test, ${ }^{*} p<0.05$. A Heart weight relative to body weight (HW/BW), anterior wall thickness of the left ventricle in systole (AWTh-s) and diastole (AWTh-d). B Fraction area shortening (FAS) and ejection fraction (EF).

Heart tissue was collected 5 weeks after TAC and used for gene expression analysis by qPCR. Atrial natriuretic peptide (ANP, encoded by Nppa) and brain natriuretic 
peptide (BNP, encoded by Nppb) are hormones of cardiac origin, which expression increases in accordance with the severity of the heart failure. ${ }^{103}$ Both hormones were slightly increased in TAC operated HE BzW2 KO mice compared to TAC- wild type (Figure 35).
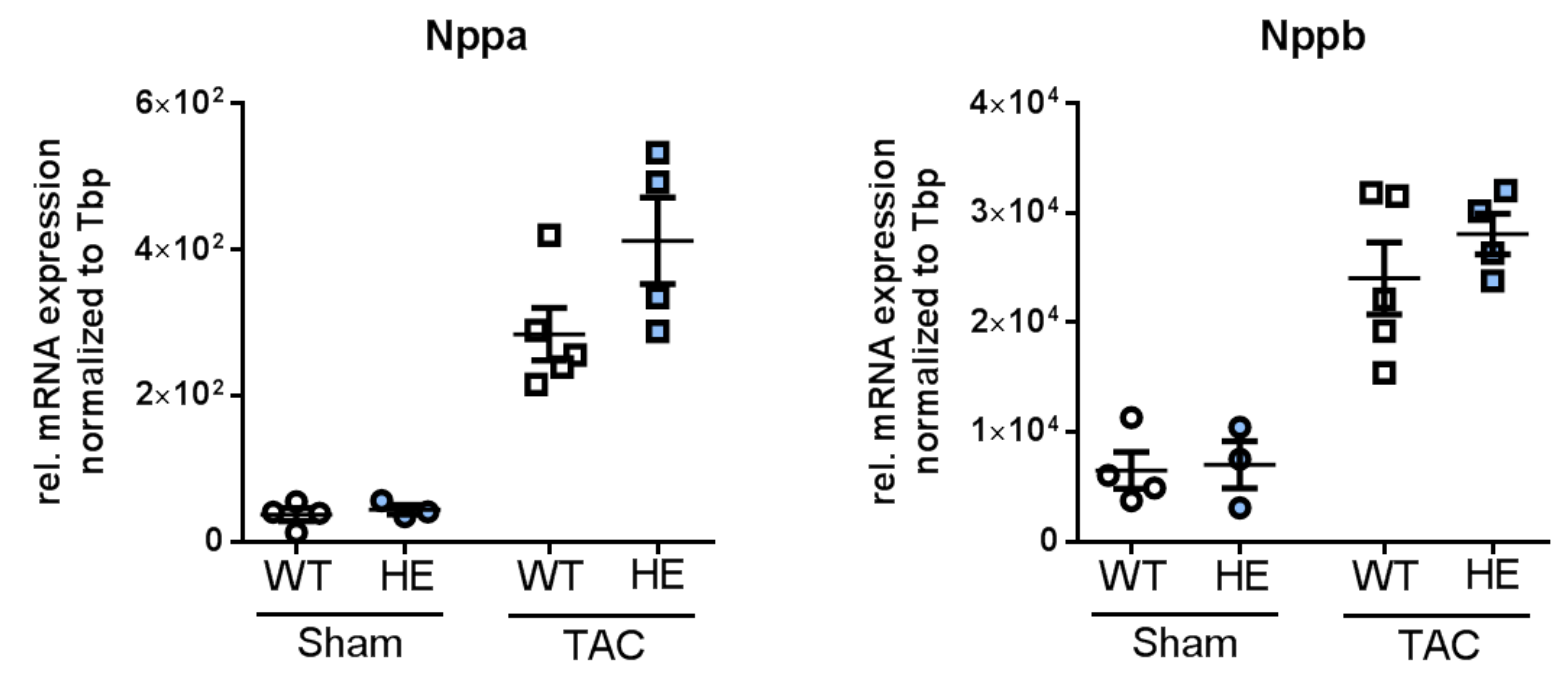

Figure 35: Hypertrophy marker in TAC operated Bzw2 KI mice.

Nppa and Nppb mRNA expression was analyzed in heterozygous Bzw2 KI mice (HE) compared to the wild type (WT) by qPCR, Sham operated mice were used as control. Expression was normalized to Tbp. Mice number: $n=4 /$ Sham-WT; $n=3 /$ Sham-HE; $n=5 / T A C-W T ; n=4 / T A C-H E$.

All data together suggest that BZW2 is important to maintain normal adult heart homeostasis and for the compensatory response to cardiac stress.

\subsection{Investigation of BZW2 role in in vitro cardiogenesis}

4.5.1. Generation of BZW2 gain-of-function in murine embryonic stem cells (ESCs)

We further investigate the specific role of BZW2 cardiac cell formation using and in vitor cardiogenesis model. To test the suitability of an in vitro model of cardiogenesis for studying the effect of BZW2 overexpression, BZW2 expression was investigated in murine embryonic stem cells (mESCs) in the process of cardiac differentiation. Similar to the expression observed in vivo, Bzw2 was highly expressed at day 0 of the differentiation and decreased continuously to day 16 (Figure 36). Important to note is that cardiomyocytes derived from stem cells are not fully mature showing 
fetal/neonatal characteristics ${ }^{104}$, which could explain the maintained lower level of Bzw2 expression in later stages in contrast to the increase observed from early neonatal to adult heart in mouse in vivo.

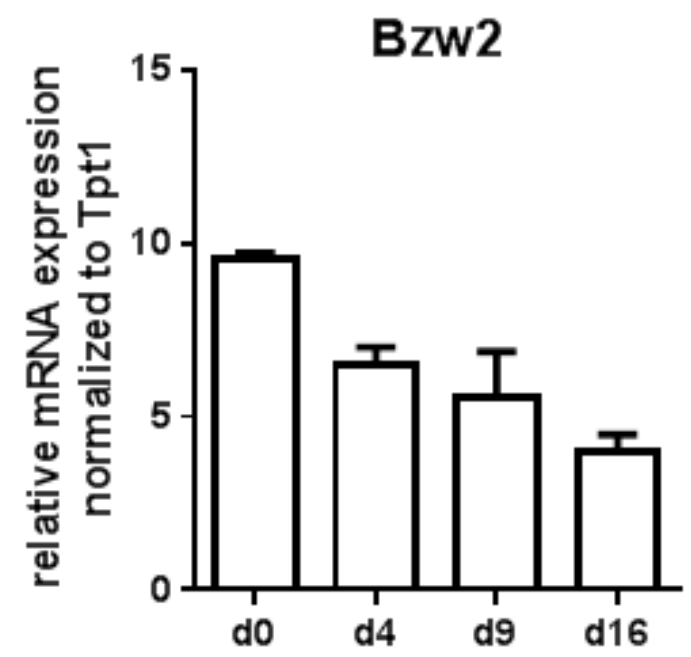

Figure 36: Analysis of Bzw2 expression in murine ESCs during differentiation to cardiomyocytes.

Bzw2 mRNA expression normalized to Tpt1 decreases during spontaneous cardiomyocytes differentiation from murine ESCs. Cells underwent several transitions: day (d) 0 - pluripotent cells; $d 4$ - mesodermal / cardiac mesodermal cells; d9 - cardiac progenitors / immature cardiomyocytes; d16 immature cardiomyocytes.

mESC lines overexpressing BZW2 were generated for cardiomyocytes differentiation experiment. A plasmid including murine Flag-Bzw2 transcript under $C M V$-promoter as well as puromycin resistance gene under SV40-promoter was transfected into ESCs expressing neomycin resistance gene as well as green fluorescence protein (GFP) gene under cardiac specific $\alpha$-Mhc-promoter for later selection and visualization of cardiomyocytes during differentiation. $1.5 \times 10^{6}$ cells were electroporated with $2 \mu \mathrm{g}$ linearized DNA and cultured for 2 days. After 12 days of puromycin selection 96 clones were picked, expended and snap frozen. 48 of them were collected for BZW2 expression analysis. Clones containing CMV-Flag-Bzw2 construct were identified via PCR (Figure 37) using specific primers detecting the insert DNA, which bind forward in $C M V$ promotor and reverse exactly between exons 3-4 of Bzw2 transcript. 


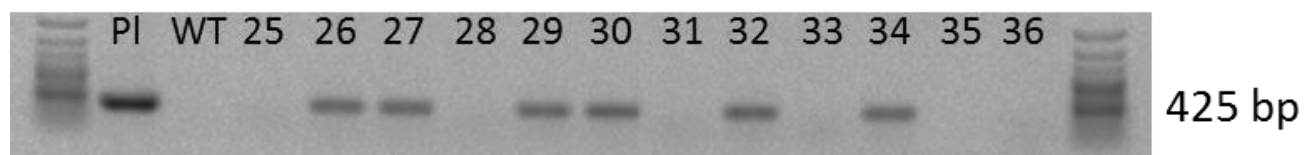

Figure 37: Validation of CMV-Flag-Bzw2 construct integration in genomic DNA of ESCs.

Integration of CMV-Flag-Bzw2 construct into DNA of ESCs was tested via PCR using specific primers and agarose gel electrophoresis. PI = plasmid as a positive control, WT = untransfected ESCs as a negative control.

The CMV-Flag-Bzw2 construct expression in selected clones was analyzed by mRNA and protein analyses (Figure 38). Two clones (\#15 and \#34) were chosen based on expression ratio of mRNA and protein analyses of the total BZW2 expression. BZW2 transgene expression as well as endogenous expression was combined as criteria (Figure 38). 
A

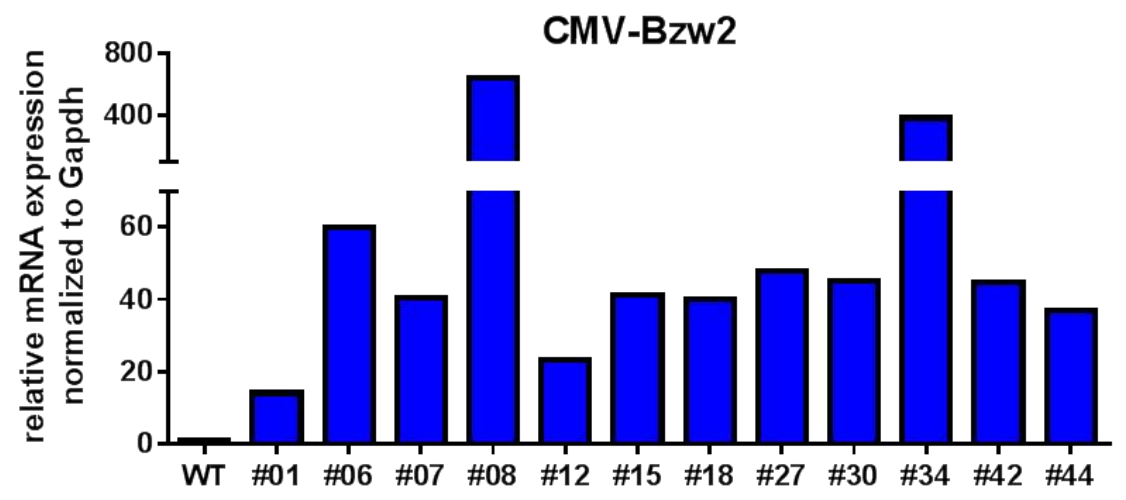

B

1. 2. 3.

1. 2. 3.

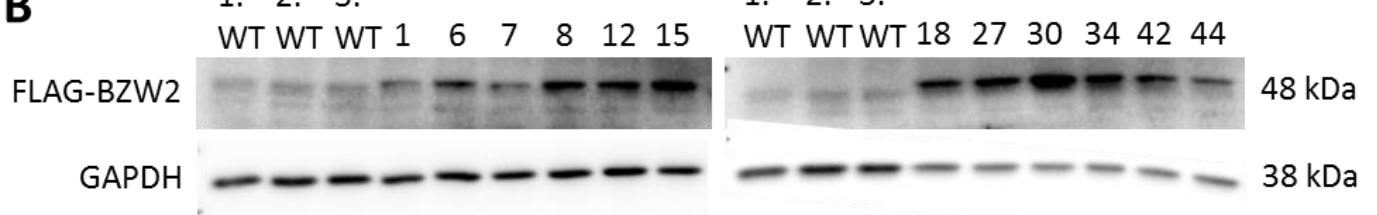

C

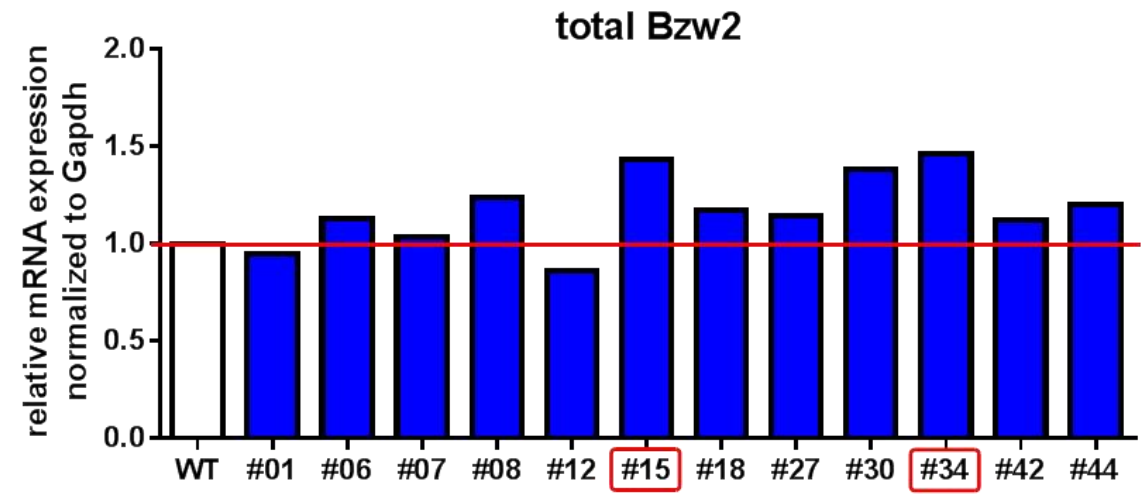

D

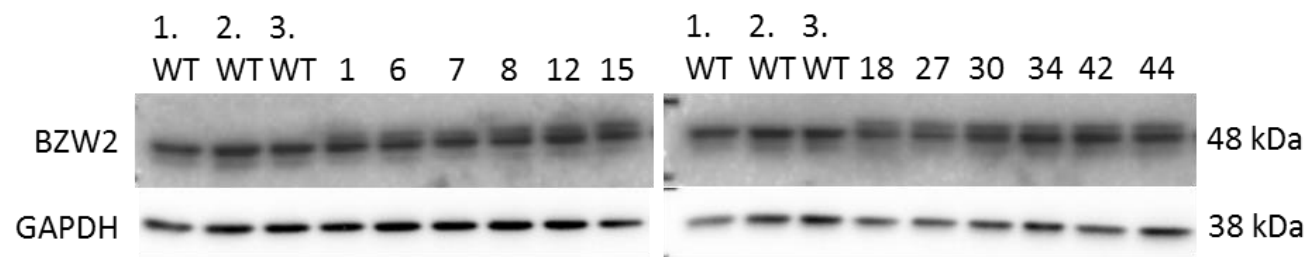

Figure 38: BZW2 expression analyses of ESC clones.

The transgene expression (A, B) as well as the total BZW2 (transgene and endogenous) expression (C, D) were tested via GPCR $(\mathbf{A}, \mathbf{C})$ and Western blot (B, D). The mean of the BZW2 expression normalized to GAPDH of the untransfected ESCs (WT) as a negative control $(n=3)$ was set to 1 and was used for normalization of clones. Clones \#15 and \#34 were chosen for following differentiation experiments.

4.5.2. BZW2 role in the ESCs differentiation to cardiomyocytes

The selecteed BZW2 overexpressing clones ESC-FLAG-BZW2\#15 and \#34 as well as untransfected ESCs as a negative control were used for differentiation to 
cardiomyocytes via embryoid body formation method as previously described. ${ }^{26}$ The strongest BZW2 gain-of-function was detected in clone \#15 (Figure 39A). Briefly, cells were collected at day 0 (pluripotent cells) in hanging drops in differentiation medium for embryoid bodies (EBs) formation. At day 3 (predominantly mesoderm) EBs were collected in medium and at day 5 (mesoderm / cardiac mesoderm) plated for further differentiation. From day 11 on (cardiac progenitors differentiation towards cardiomyocytes) cardiomyocytes were selected by neomycin (Figure 39B). To analyze the BZW2 role during differentiation samples from days 0, 4, 9 (cardiac progenitors / differentiating cardiomyocytes) and 16 (cardiomyocytes) were collected for expression analysis. Moreover EBs were measured at days 3 and 5 (Figure 39C) and GFP- and beating areas were visualized between day 7 and 16 .

A

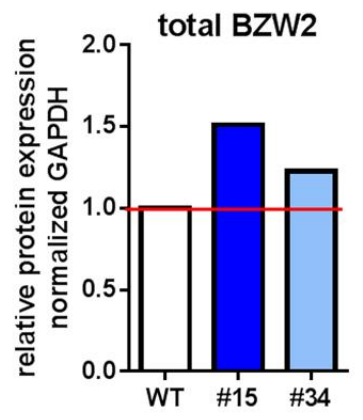

C

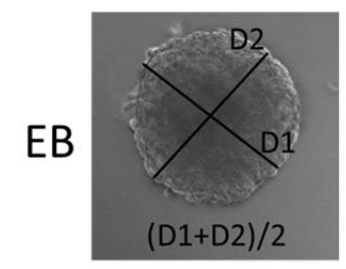

B Differentiation Experiment

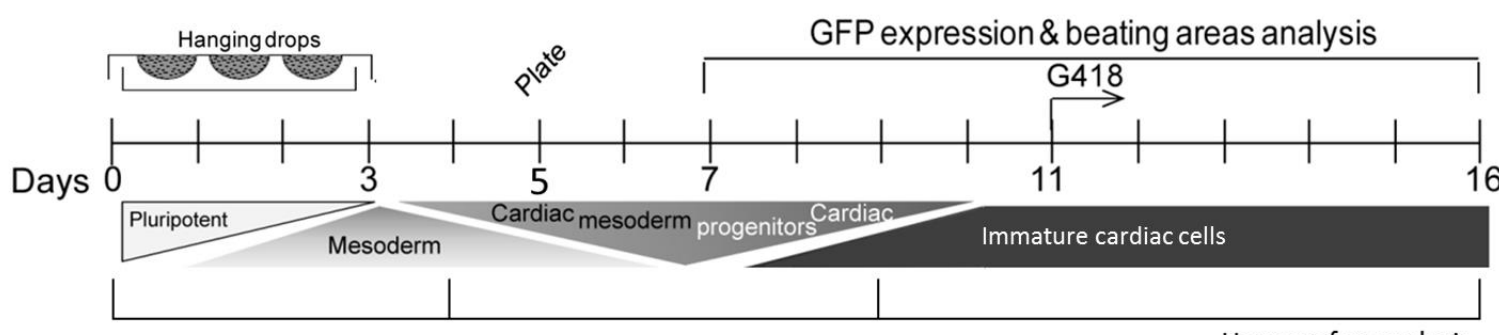

Harvest for analysis

Figure 39: Differentiation of BZW2 gain-of-function ESCs to cardiomyocytes.

A The highest total BZW2 expression normalized to GAPDH was observed in clone \#15 from chosen ESC lines showing via Western blot. WT $=$ untransfected cells. B The workflow of the differentiation experiments to cardiomyocytes (described above) shows cell type changes during differentiation. Modified from Renger A et al., 2013. ${ }^{26}$ C To detect EBs size as an evidence for differentiation capacity their perpendicular diameters (D) were summarized and divided by two.

The undifferentiated (d0) BZW2 overexpressing clones did not show any morphological apparent phenotype. During differentiation experiments towards 
cardiomyocytes EBs size was significantly decreased at day 3 as well as at day 5 inversely proportional to BZW2 expression (Figure 40).

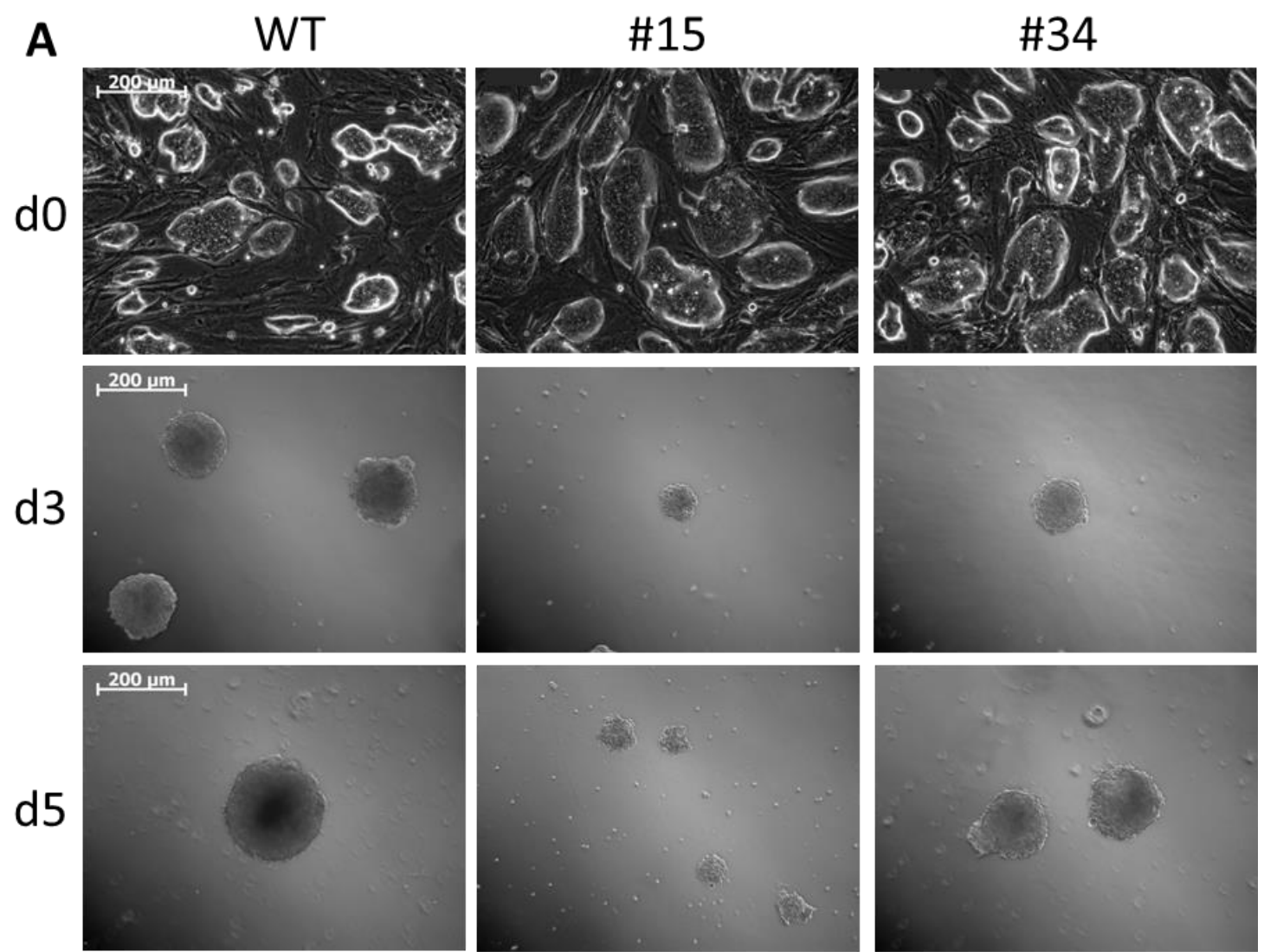

B

Embryoid body size at differentiation day $3 \& 5$

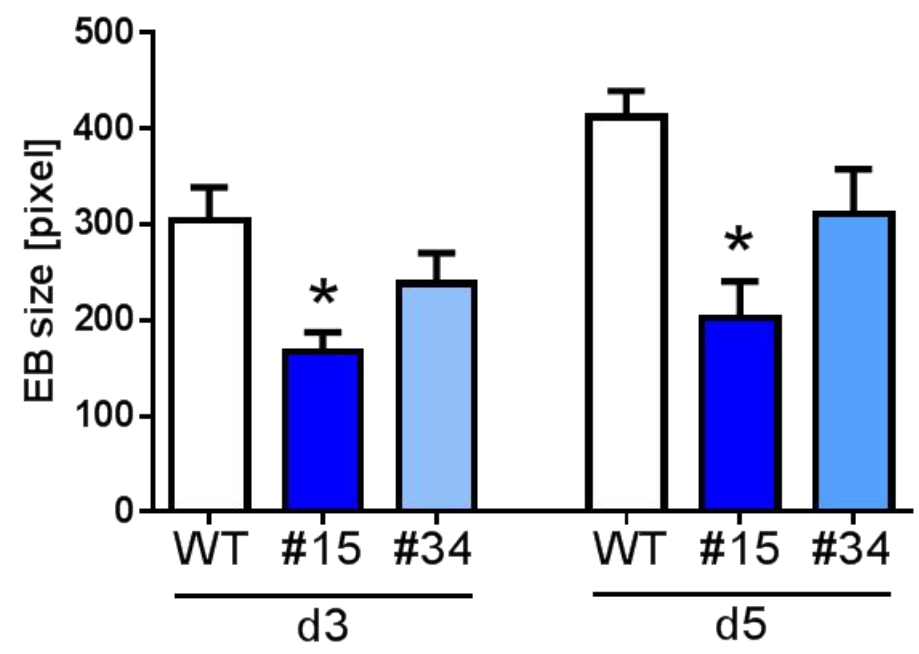

Figure 40: BZW2 role in early cardiac differentiation. 
A BZW2 overexpressing ESCs (clones \#15 \& \#34 versus control (WT)) were observed during differentiation. Whereas at day 0 BZW2 overexpressing clones did not show any morphological apparent phenotype, at days 3 and 5 formed embryoid bodies (EBs) were decreased in size compared to the WT (scale bar $200 \mu \mathrm{m}$ ). B Measured diameters of EBs at days 3 and 5 of differentiation are demonstrated in a graph (differentiation experiment number $n=4 /$ day $3 \& n=3 /$ day5; Student's $t$-test, $\left.{ }^{*} \mathrm{p}<0.05\right)$.

At the $16^{\text {th }}$ day of the differentiation control cells have formed extensive beating areas strongly expressing GFP. In contrast, first beating areas and very weak GFP signal started to appear in clone \#34 at this time point. Neither beating areas nor GFP fluorescence were detected in clone \#15 indicating inhibition of cardiomyocytes differentiation according to high BZW2 overexpression (Figure 41).
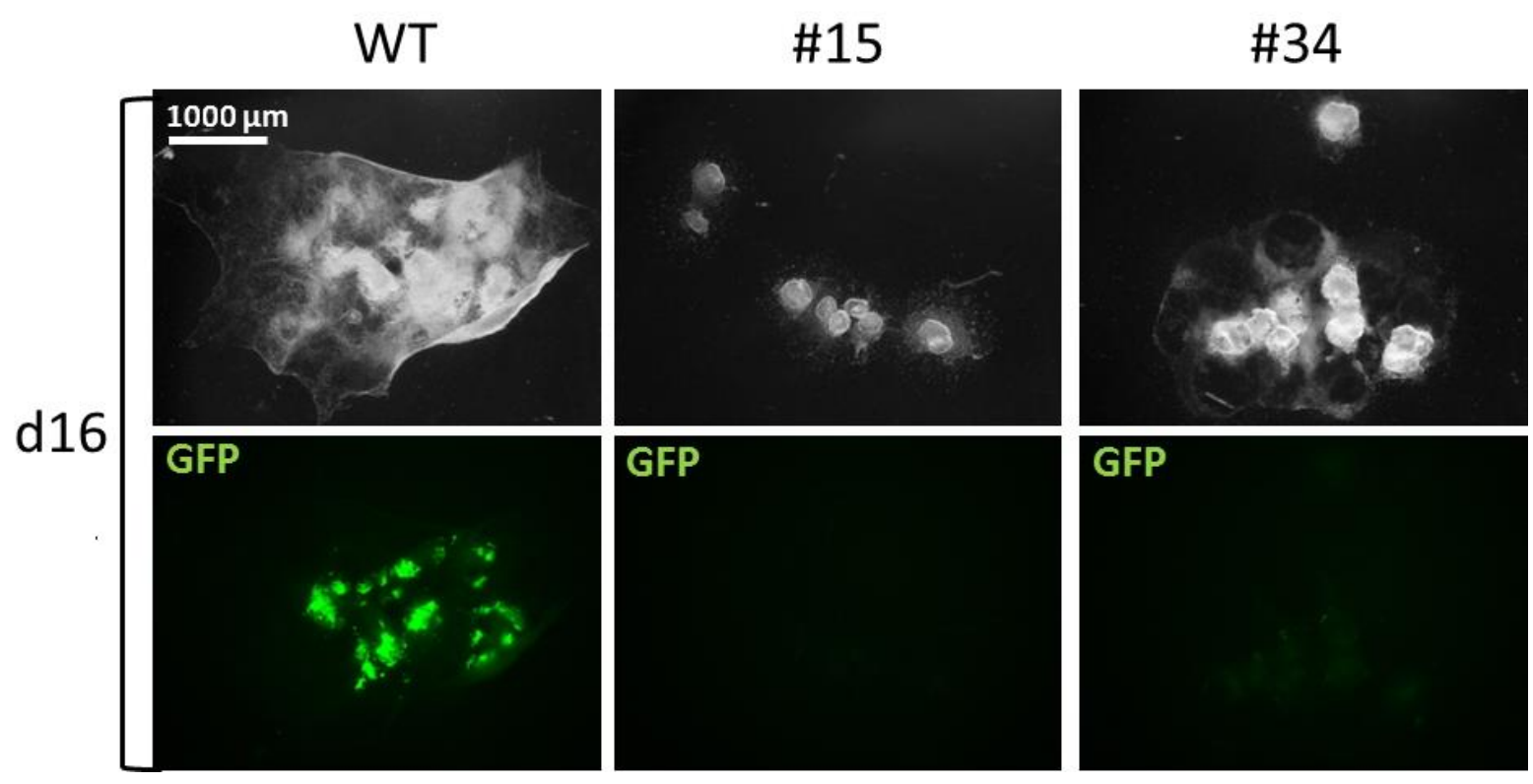

Figure 41: Differentiation efficiency of BZW2 overexpressing ESCs.

BZW2 overexpressing ESCs (clones \#15 \& \#34 versus control (WT)) were observed at differentiation day 16. Whereas control cells developed wide beating areas strongly expressing GFP, first beating areas and very weak GFP signal started to appear in clone \#34. Neither beating areas nor GFP fluorescence were detected in clone \#15 (scale bar $1000 \mu \mathrm{m}$ ).

To uncover the cause of reduced EBs formation under BZW2 upregulation, expression analyses were performed. Octamer binding transcription factor (Oct) 4 expression in undifferentiated cells $(\mathrm{d} 0)$ indicated that BZW2 overexpressing clones exhibited higher pluripotency potential compared to control at the starting point of the 
differentiation (Figure 42A). Proliferation capability in BZW2 overexpressing clones at day 0 did not differ from the control, as indicated by cyclin-D1 (Ccnd1) expression (Figure 42B). Interestingly, the cardiac mesodermal marker mesoderm posterior (Mesp) 1 was dramatically downregulated in BZW2 gain-of-function cells at the differentiation day 4 compared to the control (Figure 42C). This indicates cardiac mesodermal formation abrogation by BZW2 overexpression. Next, it was tested whether this inhibition takes place already at mesoderm induction. Indeed the panmesodermal marker brachyury (Bry) was significantly downregulated. This downregulation occurred already at d0 (Figure 42D). To distinguish whether the detrimental effect in cell specification was specific for mesoderm or a general effect, marker expression of other germ layers, endoderm and ectoderm, were tested. Interestingly, the endoderm marker SRY-related HNG-box (Sox) 17 was reduced in clone \#15 at d0 and increased at d4 (Figure 42E), whereas the late ectoderm marker bone morphogenetic protein (Bmp) 4 was upregulated in both gain-of-function clones at d0 and in clone \#15 at d4 (Figure 42F). These data indicate that EBs size reduction in BZW2-clones was caused by the inhibition of the mesoderm formation by favoring specification towards other cell fate. 
A

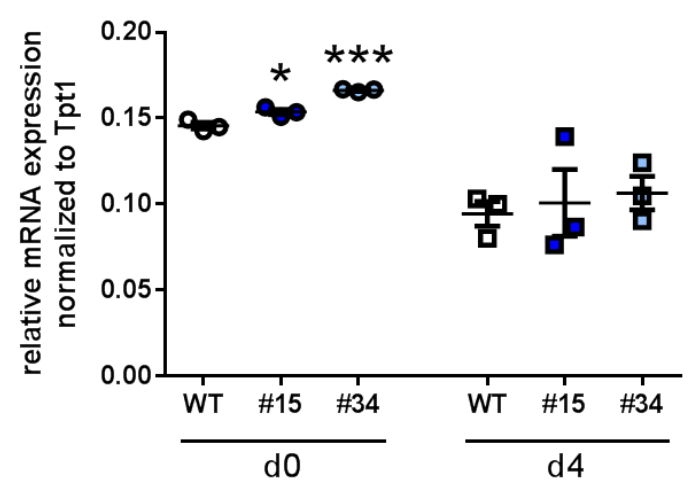

C

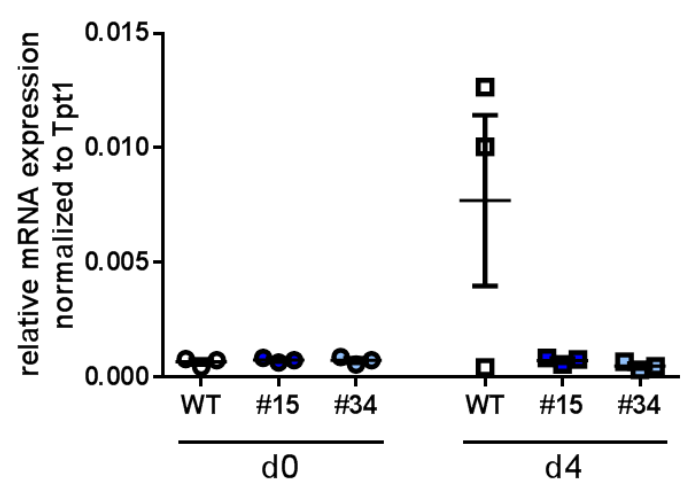

E

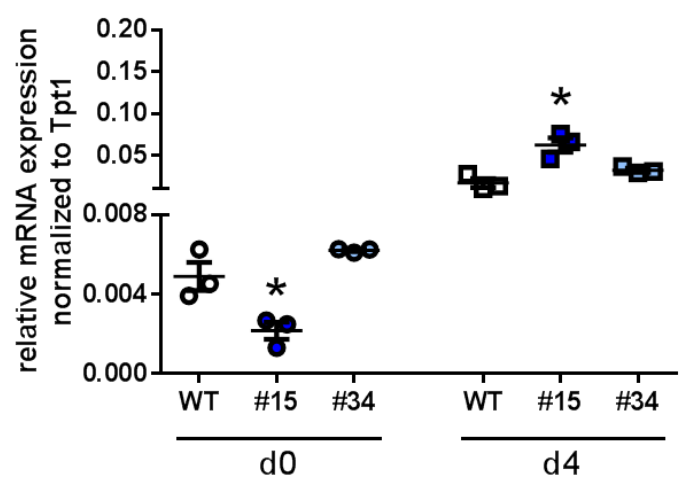

B

Ccnd1

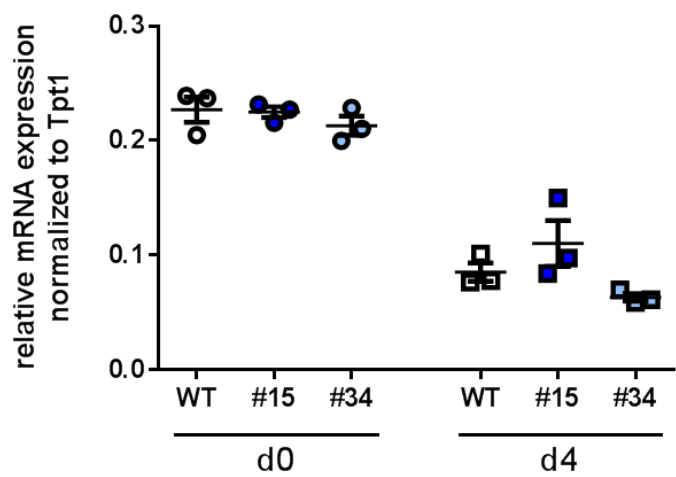

D

Bry

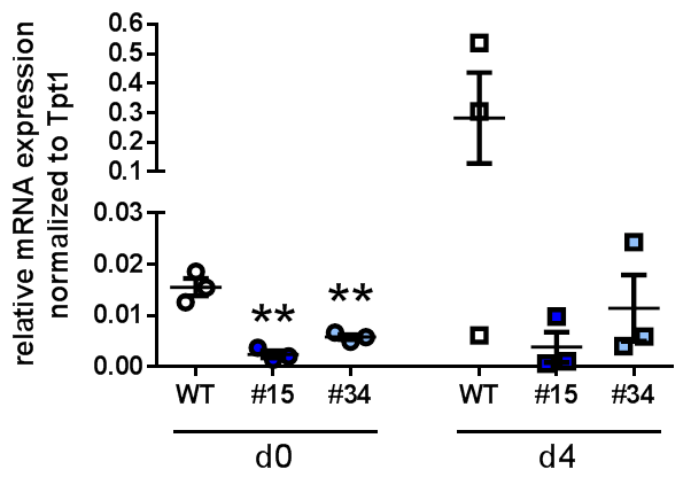

$\mathbf{F}$

Bmp4

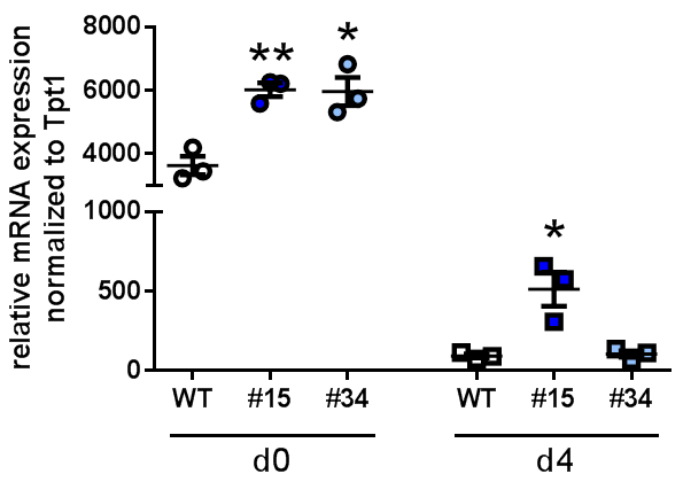

Figure 42: Expressing analysis of BZW2 overexpressing ESCs at differentiation days 0 and 4. BZW2 overexpressing ESCs (clones \#15 \& \#34 versus control (WT)) were analyzed at differentiation days 0 and 4 for mRNA expression via qPCR to look into reduced EBs formation in transgenic clones (normalized to Tpt1; differentiation experiment number $n=3 /$ group; Student's $t$-test, ${ }^{*} \mathrm{p}<0.05,{ }^{*} \mathrm{p}<0.01$, $\left.{ }^{* * *} \mathrm{p}<0.001\right)$. A Expression of Oct4 as a pluripotency marker. B Ccnd1 as a proliferation marker. C Mesp1 as a cardiac mesodermal marker. D Bry as a mesodermal marker. E Sox17 as an endodermal marker. $\mathbf{F}$ Bmp4 as an ectodermal marker. 
Next, the effect on the $W n t / \beta$-catenin signaling was tested. $\beta$-catenin as well as its target gene Tcf7l2 were upregulated at $d 4$ (Figure 43), which can be due to the increased endoderm population.

$\beta$-catenin

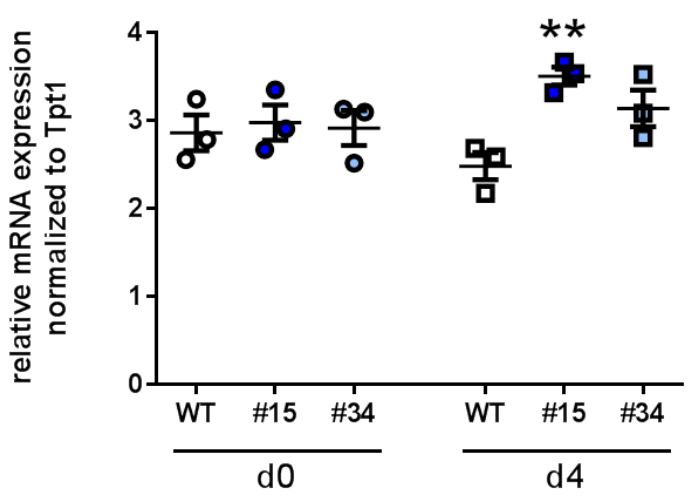

Tcf712

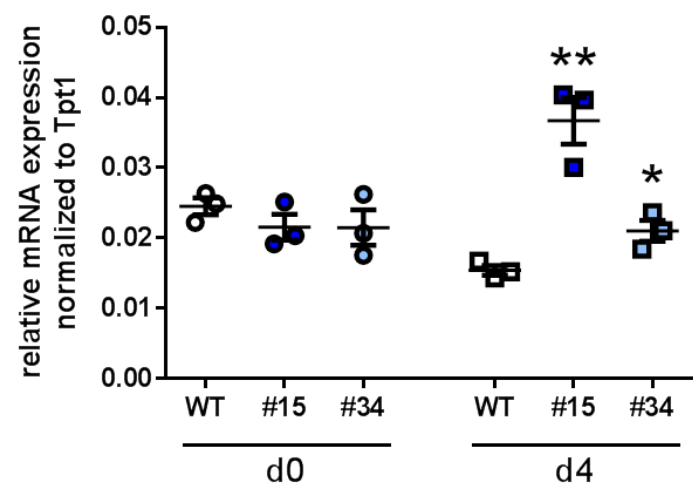

Figure 43: The Wnt/ $\beta$-catenin cascade in BZW2 overexpressing ESCs.

BZW2 overexpressing ESCs (clones \#15 \& \#34 versus control (WT)) were analyzed at differentiation days 0 and 4 for $W n t / \beta$-catenin signaling activity by mRNA expression analysis (normalized to Tpt1; differentiation experiment number $n=3$ /group; Student's $t$-test, ${ }^{*} p<0.05,{ }^{* *} p<0.01$ ). $\beta$-catenin was significantly increased in clone \#15 at day 4. Tcf7l2 expression was significantly increased in both clones at day 4 compared to control cells. 


\section{Discussion}

Wnt signaling is crucial for development in all species and especially in cardiogenesis it has a distinct time specific role. ${ }^{36}$ At the same time it is one of the pivotal signaling pathways regulating pathological and regenerative processes in many systems. ${ }^{69}$ Importantly, several studies have suggested the important role of the $\mathrm{Wnt} / \beta$-catenin signaling pathway in cardiovascular diseases. Components of the Wnt pathway at every level of regulation (such as membrane FZ, Wnt proteins, DVL-1, cytosolic $\beta$ catenin, Axin2) were found to be upregulated in hypertrophic and post-ischemic hearts in mice and rats as well in human hearts in end-stage heart failure ${ }^{70-74,105-107}$, while in the normal adult heart homeostasis the transcriptional activity of the pathway seems to be very $l_{0} w^{68}$. Studies in transgenic mouse lines showed that downregulation of the $\mathrm{Wnt} / \beta$-catenin signaling under pathological cardiac conditions lead to a significant improvement in cardiac function. Mice with cardiac specific $\beta$ catenin deletion indicated impaired hypertrophy development in TAC model ${ }^{80}$ and improved cardiac function after myocardial infarction ${ }^{77}$. Thus, the modulation of the Wnt/ $\beta$-catenin signaling is an attractive approach to maintain cardiac function under pathological conditions. However, the molecular mechanisms determining contextspecific regulation and responses of the ubiquitous $\mathrm{Wnt} / \beta$-catenin pathway in adult heart cells remain largely unknown. Previous work of the group described a binding of the factor KLF15 to $\beta$-catenin and TCF7L2 in the cell nucleus as well as an inhibition of the Wnt/ $\beta$-catenin transcriptional signaling by KLF15. ${ }^{78}$ This inhibition was found cardiac specific (Noack $C$ et al., unpublished) as increased activation of the Wnt/TCF transcription (due to the loss of inhibition) was observed in heart tissue in a mouse model with a global KLF15 functional deletion ${ }^{78}$. Since KLF15 is not predominantly expressed in the heart, the hypothesis was tested that cardiac specific co-factors were potentially required for this regulation. Screening a human cardiac library, BZW2 was identified as an interaction partner of $\beta$-catenin and KLF15 by yeast-2-hybrid screen (Renger A et al., unpublished). BZW2 was previously described to be highly expressed in the rat heart. ${ }^{82}$ The present study tested the hypothesis that BZW2 is a cardiac specific component of the Wnt/ $\beta$-catenin signaling and plays a role in cardiogenesis and adult heart homeostasis. 
5.1. BZW2 is associated with the $\mathrm{Wnt} / \beta$-catenin signalling components

In this study, an endogenous interaction between BZW2 and $\beta$-catenin was validated using murine heart tissue by co-immunoprecipitation and mass spectrometry analyses. Moreover, an interaction with KLF15 could be validated by coimmunoprecipitation by overexpressing experiments in HEK293 cells. These data indicate that BZW2 is able to bind both $\beta$-catenin and KLF15, both described components of the Wnt/ $\beta$-catenin pathways. BZW2 could be detected in both cell compartments, nucleus and cytosol. However, its abundance varied in different cell types. Overexpressed BZW2 protein was predominantly found in cytosol in HEK293 cells. Analyses of endogenous expression in heart tissue revealed a predominant BZW2 localization in the nucleus in comparison to cytosol. Previous reports showed the localization of BZW2 in cytosol of PC12 cells in overexpression assay. ${ }^{108}$ These indicate that BZW2 cell localization depends on the cell type and that can be associated to cell specific function of the protein. A predominantly cytosolic BZW2 localization is observed upon overexpression in HEK293 and PC12 cells with an embryonic origin and a nuclear localization is observed in adult heart tissue reflecting different functions of BZW2 in embryonic and adult cells. Moreover, cell specific posttranscriptional modifications of BZW2 may be required for its nuclear localization. In addition, overexpressed BZW2 (HEK293, PC12) could lack a complete endogenous activation for nuclear localization. Importance of endogenous activation for cell localization was demonstrated in a study using $\beta$-catenin stabilization in Kep1 cells (murine mammary epithelial cell line). In this system, upstream induced Wnt signaling led to upregulation of $\beta$-catenin, its recruitment to the plasma membrane and activation of target gene transcriptional activity, in contrast, overexpressed $\beta$-catenin was distributed in the cytosol and led to very low activation of target gene transcription. ${ }^{109}$

Since localization of KLF15 and $\beta$-catenin coincides in the nuclear compartment, the findings in this study suggest that BZW2 is a potential simultaneous nuclear partner of $\beta$-catenin and KLF15. An approach was taken, in which only the nuclear fraction of heart lysates was submitted to mass spectrometry, however, the stringent protocol needed for the nuclear fraction interfered with the detection of associated proteins by mass spectrometry in this cell fraction. 
5.2. Different BZW2 protein domains are responsible for a dynamic cellular localization

BZW2 possesses structural characteristics typical for transcription factors (acting in the nucleus) - putative ZIP and bZIP domains, as well as for translation initiation factors (acting in the cytosol) - W2 domain. In this study, the analysis of two truncated BZW2 forms demonstrated that the loss of the BZW2 N-terminus leads to significant reduced nuclear and increased cytosolic localizations in HEK293 cells. This may be explained by the fact that BZW2 N-terminus includes putative ZIP and bZIP domains, characteristic for DNA binding and that this fragment contains either a NLS or that the DNA binding domains are sequestering the protein attached to the chromatin and therefore leading to a shift of localization in the nucleus. Moreover, the BZW2 C-terminus includes a W2 domain, characteristic for protein-protein binding. The loss of the BZW2 C-terminus, although not significant, shifted the protein to a less cytosolic and more nuclear localization indicating that the W2 domain may be relevant for the cytosolic function and localization. A translational function of the W2 domain in BZW2 was already proposed based on W2 function in eukaryotic translation initiation factors ${ }^{86,110}$ in overexpressed HeLa cells. However, a role in translation remains to be confirmed in other cells and was out of the scope of this study.

5.3. Bzw2 is highly expressed during cardiogenesis and in the adult heart.

In line with reported mRNA expression data showing high expression of BZW2 in heart tissue ${ }^{82}$, BZW2 protein was found to be highly expressed in the adult heart and skeletal muscle tissue compared to other murine organs (brain, spleen, liver, kidney and lung) in this study. This finding is further support by the data shared from our collaboration partner (Personal communication, David Zhang, Pharmaceutical Division, Roche $A G$ ), showing the same finding in human tissue and strongly suggesting a conserved role for BZW2 in adult muscle tissue.

Expression analysis helps to infer the biological role of a gene product, therefore in this study a comprehensive expression analysis was performed for Bzw2 since no data were available. In the whole embryo before midgestation, Bzw2 was expressed strongly in somites, limbs, first and second branchial arches, midbrain/hindbrain, and 
dorsal root ganglia beside the heart. This pattern is similar to the $\alpha$-skeletal actin gene expression, indicating a potential similar role of both genes during embryogenesis. ${ }^{111}$ Furthermore, expression of Bzw2 specifically during murine cardiac development demonstrated a higher mRNA expression in early cardiac development (post coitum days 8.5-9.5), where differentiation and establishment of the different heart fields takes place ${ }^{112}$, as well as in the complete matured heart. Interestingly, Bzw2 expression was lower in late-embryonic (started at post coitum day 11.5) and in neonatal/early-postnatal (till last analyzed postnatal day 13) heart tissue, where maturation of the heart takes place ${ }^{112,113}$. In line with this finding, Bzw2 was highly expressed in undifferentiated adult cells as well as in cardiomyocytes of adult mouse heart (compared to cardiac fibroblasts). These data suggest a role of BZW2 in undifferentiated cells of the developing and adult heart, as well as in mature cardiomyocytes. However, the lack of BZW2 in HO mice, did not dramatically affect embryonic development (data not shown), but results in an incomplete penetrance of retarded development as analyzed in the Bachelor Thesis of Eric Schoger. ${ }^{114}$ These data indicate a possible compensatory role of proteins with similar structure. Further supporting this observation, high Bzw2 expression was detected in murine embryonic stem cells (ESCs) with subsequent decrease during spontaneous cardiac differentiation towards cardiomyocytes, which lead to the formation of neonatal-like cardiomyocytes rather than mature cells in vitro ${ }^{104}$. Together these data indicate a decrease of BZW2 expression in the process of the cardiomyocytes maturation whereas expression in terminally differentiated mature cardiomyocytes increases again. This suggests different functions in the process of final differentiation and in maintaining normal heart homoeostasis. Interestingly, high expression of BZW2 coincides with low Wnt activation in the process of cardiac differentiation but also in the adult normal heart. This suggests further a possible role of BZW2 in contributing to low activity of the Wnt cascade.

\subsection{BZW2 is a cardiac specific factor of the $\mathrm{Wnt} / \beta$-catenin signalling}

BZW2 role on the $\mathrm{Wnt} / \beta$-catenin signaling was investigated. Overexpression of BZW2 demonstrated mild inhibition of the Wnt-transcriptional-dependent luciferase activity, which was even less prominent upon increased TCF/LEF transcriptional activation by overexpression of $\beta$-catenin (data not shown). We hypothesize that BZW2 may act as a scaffold protein mediating the cardiac specific effect of KLF15- 
meditated Wnt cascade inhibition. BZW2 may be necessary for a complex formation without a significant effect on the transcription per se. Since HEK293 cells show a low mRNA expression of Klf15 as measured by relative qPCR quantification (Noack $C$ et al., unpublished), it may explain the non-significant effect on the $\mathrm{Wnt} / \beta$-catenin signaling by overexpressed BZW2 in this system. Other method for future analysis might be, to test if a KLF15 overexpression combined with a complete endogenous BZW2 deletion would still induce inhibitory effect on the $\mathrm{Wnt} / \mathrm{\beta}$-catenin signaling in HEK293 cells.

To investigate the effect of different deletion doses of BZW2 on Wnt/ $\beta$-catenin signaling as well as the effect on tissue development and homeostasis a Bzw2 knock-in (KI) model with a conditional potential, named as first allele Bzw2 ${ }^{\text {tm1a }}$ knockout (KO) was used. The initial unmodified allele is predicted to generate a null allele downstream of exon 3 through splicing to a $L a c Z$ trapping element contained in the targeting cassette. ${ }^{101}$ The model was validated by analyzing mRNA and protein expression. Using an antibody against the C-terminal W2 domain of BZW2 no protein was detected by Western blot analysis. Interestingly, a second antibody against $\mathrm{N}$ terminal protein region coding by exon 3 showed detection of BZW2 in the KI homozygous hearts. This indicates expression of a short BZW2 N-terminal fragment including ZIP domain coding by exon 3 in these mice. This would fit with a model, in which the protein is translated to a point in which the frame is altered between exon 3 and exon 4, resulting in a truncated protein product. Interestingly, under BZW2 deletion in both alleles $\beta$-catenin protein expression was found significantly upregulated in the adult cardiac tissue. $\beta$-catenin phosphorylation modifications leading to stabilization of the protein remains to be analyzed but analysis of $\beta$-catenin mRNA expression revealed that BZW2 deletion leads to de novo transcriptional synthesis of $\beta$-catenin. Furthermore, BZW2 dependent de novo synthesis of $\beta$ catenin was analyzed for its cardiac specificity in adult mice. Indeed, $\beta$-catenin mRNA was significantly upregulated exclusively in the heart compared to skeletal muscle, brain, spleen, liver, kidney and lung. One allele expression of BZW2 in heterozygous mice was sufficient to keep normal levels of $\beta$-catenin. These data indicate that BZW2 is necessary for the maintaining normal levels of $\beta$-catenin specifically in cardiac cells in line with the initial hypothesis that BZW2 may be a tissue specific cofactor in the Wnt cascade. 
Staining analysis demonstrated apparently prominent $\beta$-catenin expression visualized at cell membrane in heart tissue. Hendriksen $\mathrm{J}$ et al., 2008 demonstrated that $\beta$ catenin activation and recruitment at the plasma membrane generated a signalingcompetent form and is a transition effect upon Wnt stimulation, which is a more powerful activator of the cascade than overexpression of $\beta$-catenin. ${ }^{109}$ Moreover it is not yet identified, if the remaining N-terminal fragment of BZW2 is able to stabilize the nuclear inhibitory complex with $\beta$-catenin and KLF15. New questions have to be addressed, whether the remaining BZW2 peptide including the putative ZIP domain possess a regulatory function intervening with the Wnt cascade or whether BZW2 exert primarily a membrane associated regulation of the $\beta$-catenin or has further effect downstream the cascade together with other specific factors.

Bzw2 mRNA expression was found to be significantly upregulated exclusively in the heart tissue in the absence of KLF15, which resulted in Wnt transcriptional activation. In line with the data, $\beta$-catenin stabilized mice exhibited BZW2 protein upregulation in the heart, while no difference was observed in $\beta$-catenin downregulated mice. These data indicate a compensatory upregulation of BZW2 under $\beta$-catenin-dependent transcriptional activation. Several studies demonstrated negative regulatory effects by target Wnt genes like Axin $2^{115}, \mathrm{TCF}^{116}$ and $\mathrm{DKK} 1^{117}$. Moreover, a putative promoter of Bzw2 showed three consensus sequences of TCF/LEF binding sites. Testing this fragment in luciferase assay in HEK293 showed that the overexpression of the target gene TCF7L2 resulted in significant increase of luciferase activity indirect indicating that the $\mathrm{Wnt} / \beta$-catenin signaling positively regulates $B z W 2$ transcription. These capabilities could lead to tissue- and cell-specific BZW2 regulation.

All these data together suggest that BZW2 is involved in cardiac specific inhibition of the Wnt/B-catenin signaling by KLF15 in adulthood. Deletion of BZW2 leads to an increased de novo synthesis of $\beta$-catenin exclusively in the heart. Moreover BZW2 is tissue- and cell-specific regulated by the $W n t / \beta$-catenin signaling on the transcriptional level. 


\subsection{BZW2 is essential for cardiogenesis.}

Due to the pivotal role of the Wnt cascade in cardiogenesis, the role of BZW2 was investigated during this process in an in vitro model. Transgenic embryonic stem cell (ESC) lines with stable BZW2 upregulation were generated.

Undifferentiated cells of the BZW2 overexpression lines at the differentiation day 0 did not differ morphologically from wild type lines. Although BZW2 overexpression did not indicate decreased pluripotency, during the differentiation process the BZW2 overexpression led to smaller embryoid bodies (EBs) formation compared to the wild type cells at days 3 and 5. According to their BZW2 upregulation levels, ESC transgenic lines with higher BZW2 level showed stronger impairment of EBs formation. To underline the molecular mechanisms of cardiomyocytes impairment formation, cause for EB size reduction was analyzed by expression analyses. No $W n t / \beta$-catenin signaling changes were observed under BZW2 upregulation in undifferentiated cells, indicating initially a Wnt/ $\beta$-catenin signaling independent differentiation impairment. Furthermore, germ layers markers were differently expressed at the beginning of the differentiation protocol. While the ectodermal Bmp4 was significantly increased, the mesodermal Bry and endodermal Sox17 were significantly decreased, indicating that BZW2 inhibits mesoderm formation and leads ESCs into a more ectodermal fate. Moreover, at later differentiation day four (d4) in which cardiac specification occurs the cardiac mesoderm marker Mesp1 was significantly decreased in transgenic cells. Apart from this, at the same time point during cardiac specification, the $\mathrm{Wnt} / \beta$-catenin signaling was significantly upregulated in transgenic cells. Since downregulation of the $\mathrm{Wnt} / \beta$-catenin signaling is necessary for late cardiac specification ${ }^{112}$ these data indicate an interruption of cardiac specification of formed mesodermal cells under initial BZW2 upregulation. In line with this, at the end of the differentiation, no beating cardiomyocytes were detected around day 16 for BZW2 overexpressing cell lines, as normally expected. Similar to our data it was shown that inhibition of the Wnt/ $\beta$-catenin signaling by DKK1 treatment between $\mathrm{d} 0$ and $\mathrm{d} 4$ leads to significantly decreased expression of mesoand endodermal genes at $\mathrm{d} 0-\mathrm{d} 4$ and cardio-specific genes at $\mathrm{d} 6-8$ as well as significantly increased expression of neuroectoderm-associated genes at d6-8. ${ }^{54}$ If upregulation of the $\mathrm{Wnt} / \beta$-catenin signaling activity at $\mathrm{d} 4 \mathrm{is}$ based on a compensatory response to BZW2 upregulation is unclear. 
These data suggest that BZW2 upregulation disrupt mesoderm formation, and leads further to abrogation of spontaneous cardiac differentiation. Since mesoderm formation, an evolutionary conserved process, is the first step before cardiogenesis, tight regulation of BZW2 is essential for correct heart development.

5.6. BZW2 is important for normal homeostasis and stress-induced response in adult heart.

The BZW2 role in normal heart homeostasis was investigated using Bzw2 KI mice, described above. Echocardiography analyses revealed that mice of both genotypes ( $\mathrm{HE}$ and $\mathrm{HO}$ ) developed cardiac hypertrophy with consequent functional reduction in the aged mice (only aged HE investigated). This data are in line with a study demonstrating cardiac hypertrophy development following by dilated cardiomyopathy in inducible $\beta$-catenin stabilized mice under cardiac MIc2v promoter. Those mice exhibited a similar but dramatically stronger phenotype. ${ }^{81}$ Moreover, $\beta$-catenin membrane-associated accumulation, similar to $B z w 2 \mathrm{KI}$ mice, was demonstrated in mammalian hypertrophic cardiomyopatic hearts ${ }^{118}$ indicating the important role of $\beta$ catenin levels for maintaining normal heart structure and function. Moreover, our study introduces another level of regulation in which BZW2 is placed upstream of $\beta$ catenin to control this process.

BZW2 expression was found regulated upon cardiac remodeling. Angiotensin II induced cardiac hypertrophy in mice led to upregulated BZW2 protein expression in heart tissue as well as dilated (DCM) and ischemic (ICM) cardiomyopathy in human patients. This suggest that upon diseases condition, BZW2 is deregulated as part of a disease response, however the time specific regulation of BZW2 was not achieved in this study and is of relevance for concluding its role in the course of heart remodeling.

To investigate the effect of BZW2 variation in cardiac remodeling HE Bzw2 KI mice exhibiting BZW2 downregulation underwent TAC, a pressure overload induced hypertrophy model in the heart. Cardiac morphology and function were analyzed by echocardiography before, 2 week and 4 weeks after operation. Anterior wall thickness (AWTh), heart weight relative to body weight (HW/BW) and cardiac function demonstrated by fraction area shortening (FAS) and ejection fraction (EF) were used as parameters to compare cardiac geometry and functional performance 
after TAC. Two weeks after TAC all mice developed cardiac hypertrophy (controls and $\mathrm{HE}$ ), demonstrating by significantly increased AWTh and heart mass as well as showed decreased cardiac function (FAS, EF). Four weeks after TAC Bzw2 KI mice showed reduced AWTh in systole and remained stable in diastole compared to the wild type mice, where AWTh slightly increased. This suggests that reduced BZW2 leads to an earlier transition from cardiac hypertrophy to dilated myocardium under pressure overload-induced cardiac stress.

Altogether these data suggest that long term reduction of BZW2 results in hypertrophy development in aged mice and leads to an earlier development of cardiomyopathy in the stressed heart in young mice, indicating that tight doses of BZW2 are important to maintain normal cardiac homeostasis under stress conditions such an injury or the aged heart.

In conclusion, this study showed for the first time a comprehensive expression analysis of Bzw2 in embryonic development with a special focus on developing and mature heart tissue. These data suggest its relevance for processes of cardiogenesis and adult heart homeostasis. Indeed, it was shown that low levels of BZW2 are necessary for mesodermal formation and posterior cardiomyocytes development, which was impaired upon BZW2 overexpression. Concerning its role in the adult heart, the expression of BZW2 was shown to be necessary to maintain normal cardiac function and stress induced response, however its expression is apparently dispensable for embryonic development, may be due to compensatory genes. Moreover, BZW2 was shown to regulate the main component of the Wnt canonical cascade, $\beta$-catenin, in the adult heart.

It was demonstrated that BZW2 is a target of the activated Wnt pathway, which may function as a feedback regulator in vivo. Finally, this study also provides evidences for the role of different protein domains, BZW2 C-terminus including W2 domain is important for cytosolic localization, while N-terminus including putative ZIP and bZIP domains is important for nuclear localization.

Altogether, this thesis defines a novel component and a new level of regulation of the $W n t / \beta$-catenin pathways specifically in heart tissue. Given the ubiquitous expression and multiple functions of $\beta$-catenin, tissue specific modulation under pathological 
Discussion

conditions may provide new therapeutic approaches, these need further investigations. 


\section{Bibliography}

1. Bui AL, Horwich TB, Fonarow GC. Epidemiology and risk profile of heart failure. Nat Rev Cardiol.8(1):30-41.

2. STATISTISCHES JAHRBUCH 2006 Für die Bundesrepublik Deutschland. Statisches Bundesamt (Federal Statistical Office), Wiesbaden; 2006.

3. Yusuf S, Reddy S, Ounpuu S, Anand S. Global burden of cardiovascular diseases: part I: general considerations, the epidemiologic transition, risk factors, and impact of urbanization. Circulation. 2001;104(22):2746-2753.

4. Porrello ER, Olson EN. A neonatal blueprint for cardiac regeneration. Stem Cell Res. 2014;13(3 Pt B):556-570.

5. Dirkx E, da Costa Martins PA, De Windt LJ. Regulation of fetal gene expression in heart failure. Biochim Biophys Acta. 2013;1832(12):2414-2424.

6. Oka T, Xu J, Molkentin JD. Re-employment of developmental transcription factors in adult heart disease. Seminars in Cell \& Developmental Biology. 2007;18(1):117-131.

7. Frey N, Olson EN. Cardiac hypertrophy: the good, the bad, and the ugly. Annu Rev Physiol. 2003;65:45-79.

8. Friddle CJ, Koga T, Rubin EM, Bristow J. Expression profiling reveals distinct sets of genes altered during induction and regression of cardiac hypertrophy. Proc Natl Acad Sci U S A. 2000;97(12):6745-6750.

9. Akazawa H, Komuro I. Roles of cardiac transcription factors in cardiac hypertrophy. Circ Res. 2003;92(10):1079-1088.

10. Xie M, Burchfield JS, Hill JA. Pathological ventricular remodeling: therapies: part 2 of 2 . Circulation.128(9):1021-1030.

11. Mikhailov AT, Torrado M. The enigmatic role of the ankyrin repeat domain 1 gene in heart development and disease. The International journal of developmental biology. 2008;52(7):811-821.

12. Braun J, Dormann AJ. Klinikleitfaden Innere Medizin. 11 ed: Urban \& Fischer Verlag/Elsevier $\mathrm{GmbH} ; 2009$.

13. Zelarayan LC, Zafiriou MP, Zimmermann WH. Emerging Concepts in Myocardial Pharmacoregeneration. In: Steinhoff G, ed. Regenerative Medicine - From Protocol to Patient: Springer; 2012.

14. Qian L, Huang Y, Spencer Cl, Foley A, Vedantham V, Liu L, Conway SJ, Fu JD, Srivastava D. In vivo reprogramming of murine cardiac fibroblasts into induced cardiomyocytes. Nature.485(7400):593-598.

15. Jayawardena TM, Egemnazarov B, Finch EA, Zhang L, Payne JA, Pandya K, Zhang Z, Rosenberg $P$, Mirotsou M, Dzau VJ. MicroRNA-mediated in vitro and in vivo direct reprogramming of cardiac fibroblasts to cardiomyocytes. Circ Res.110(11):1465-1473.

16. Leor J, Gerecht S, Cohen S, Miller L, Holbova R, Ziskind A, Shachar M, Feinberg MS, Guetta E, Itskovitz-Eldor J. Human embryonic stem cell transplantation to repair the infarcted myocardium. Heart. 2007;93(10):1278-1284.

17. Doppler SA, Deutsch MA, Lange R, Krane M. Cardiac regeneration: current therapies-future concepts. J Thorac Dis.5(5):683-697.

18. Beltrami AP, Barlucchi L, Torella D, Baker M, Limana F, Chimenti S, Kasahara H, Rota M, Musso E, Urbanek K, Leri A, Kajstura J, Nadal-Ginard B, Anversa P. Adult cardiac stem cells are multipotent and support myocardial regeneration. Cell. 2003;114(6):763-776.

19. Hsieh PC, Segers VF, Davis ME, MacGillivray C, Gannon J, Molkentin JD, Robbins J, Lee RT. Evidence from a genetic fate-mapping study that stem cells refresh adult mammalian cardiomyocytes after injury. Nat Med. 2007;13(8):970-974. 
20. Bergmann O, Bhardwaj RD, Bernard S, Zdunek S, Barnabe-Heider F, Walsh S, Zupicich J, Alkass K, Buchholz BA, Druid H, Jovinge S, Frisen J. Evidence for cardiomyocyte renewal in humans. Science. 2009;324(5923):98-102.

21. Senyo SE, Steinhauser ML, Pizzimenti CL, Yang VK, Cai L, Wang M, Wu TD, Guerquin-Kern JL, Lechene CP, Lee RT. Mammalian heart renewal by pre-existing cardiomyocytes. Nature. 2013;493(7432):433-436.

22. Bergmann O, Zdunek S, Felker A, Salehpour M, Alkass $K$, Bernard $S$, Sjostrom SL, Szewczykowska M, Jackowska T, Dos Remedios C, Malm T, Andra M, Jashari R, Nyengaard JR, Possnert G, Jovinge S, Druid H, Frisen J. Dynamics of Cell Generation and Turnover in the Human Heart. Cell. 2015;161(7):1566-1575.

23. Bergmann $\mathrm{O}$, Zdunek $\mathrm{S}$, Felker $\mathrm{A}$, Salehpour $\mathrm{M}$, Alkass $\mathrm{K}$, Bernard $\mathrm{S}$, Sjostrom $\mathrm{SL}$, Szewczykowska M, Jackowska T, Dos Remedios C, Malm T, Andra M, Jashari R, Nyengaard JR, Possnert G, Jovinge S, Druid H, Frisen J. Dynamics of Cell Generation and Turnover in the Human Heart. Cell.161(7):1566-1575.

24. Porrello ER, Mahmoud AI, Simpson E, Hill JA, Richardson JA, Olson EN, Sadek HA. Transient regenerative potential of the neonatal mouse heart. Science. 2011;331(6020):1078-1080.

25. Alexander JM, Bruneau BG. Lessons for cardiac regeneration and repair through development. Trends Mol Med. 2010;16(9):426-434.

26. Renger A, Zafiriou MP, Noack C, Pavlova E, Becker A, Sharkova K, Bergmann MW, ElArmouche A, Zimmermann WH, Zelarayan LC. The four and a half LIM-domain 2 controls early cardiac cell commitment and expansion via regulating beta-catenin-dependent transcription. Stem Cells. 2013;31(5):928-940.

27. Auda-Boucher G, Bernard B, Fontaine-Perus J, Rouaud T, Mericksay M, Gardahaut MF. Staging of the commitment of murine cardiac cell progenitors. Dev Biol. 2000;225(1):214225.

28. Garcia-Martinez V, Schoenwolf GC. Primitive-streak origin of the cardiovascular system in avian embryos. Dev Biol. 1993;159(2):706-719.

29. Brand T. Heart development: molecular insights into cardiac specification and early morphogenesis. Dev Biol. 2003;258(1):1-19.

30. Moorman A, Webb S, Brown NA, Lamers W, Anderson RH. Development of the heart: (1) formation of the cardiac chambers and arterial trunks. Heart. 2003;89(7):806-814.

31. Brade $T$, Manner J, Kuhl M. The role of Wnt signalling in cardiac development and tissue remodelling in the mature heart. Cardiovasc Res. 2006;72(2):198-209.

32. Harvey RP. Patterning the vertebrate heart. Nat Rev Genet. 2002;3(7):544-556.

33. Kimelman D. Mesoderm induction: from caps to chips. Nat Rev Genet. 2006;7(5):360-372.

34. Noseda M, Peterkin T, Simoes FC, Patient R, Schneider MD. Cardiopoietic factors: extracellular signals for cardiac lineage commitment. Circ Res.108(1):129-152.

35. Showell C, Binder O, Conlon FL. T-box genes in early embryogenesis. Dev Dyn. 2004;229(1):201-218.

36. Gessert $S$, Kuhl M. The multiple phases and faces of wnt signaling during cardiac differentiation and development. Circ Res. 2010;107(2):186-199.

37. Bondue A, Blanpain C. Mesp1: a key regulator of cardiovascular lineage commitment. Circ Res. 2010;107(12):1414-1427.

38. Costello I, PimeisI IM, Drager S, Bikoff EK, Robertson EJ, Arnold SJ. The T-box transcription factor Eomesodermin acts upstream of Mesp1 to specify cardiac mesoderm during mouse gastrulation. Nat Cell Biol. 2011;13(9):1084-1091.

39. Abu-Issa R, Waldo K, Kirby ML. Heart fields: one, two or more? Dev Biol. 2004;272(2):281285.

40. Lough J, Sugi Y. Endoderm and heart development. Dev Dyn. 2000;217(4):327-342.

41. Schultheiss TM, Burch JB, Lassar AB. A role for bone morphogenetic proteins in the induction of cardiac myogenesis. Genes Dev. 1997;11(4):451-462. 
42. Reifers F, Walsh EC, Leger S, Stainier DY, Brand M. Induction and differentiation of the zebrafish heart requires fibroblast growth factor 8 (fgf8/acerebellar). Development. 2000;127(2):225-235.

43. Marvin MJ, Di Rocco G, Gardiner A, Bush SM, Lassar AB. Inhibition of Wnt activity induces heart formation from posterior mesoderm. Genes Dev. 2001;15(3):316-327.

44. Schneider VA, Mercola M. Wnt antagonism initiates cardiogenesis in Xenopus laevis. Genes Dev. 2001;15(3):304-315.

45. Tzahor E, Lassar AB. Wnt signals from the neural tube block ectopic cardiogenesis. Genes Dev. 2001;15(3):255-260.

46. Buckingham $\mathrm{M}$, Meilhac $\mathrm{S}$, Zaffran $\mathrm{S}$. Building the mammalian heart from two sources of myocardial cells. Nat Rev Genet. 2005;6(11):826-835.

47. Kubalak SW, Miller-Hance WC, O'Brien TX, Dyson E, Chien KR. Chamber specification of atrial myosin light chain-2 expression precedes septation during murine cardiogenesis. J Biol Chem. 1994;269(24):16961-16970.

48. Prall OW, Menon MK, Solloway MJ, Watanabe $Y$, Zaffran S, Bajolle F, Biben C, McBride JJ, Robertson BR, Chaulet $H$, Stennard FA, Wise N, Schaft D, Wolstein O, Furtado MB, Shiratori $\mathrm{H}$, Chien KR, Hamada H, Black BL, Saga Y, Robertson EJ, Buckingham ME, Harvey RP. An Nkx25/Bmp2/Smad1 negative feedback loop controls heart progenitor specification and proliferation. Cell. 2007;128(5):947-959.

49. Zaffran S, Kelly RG. New developments in the second heart field. Differentiation.84(1):17-24.

50. Tzahor E. Wnt/beta-catenin signaling and cardiogenesis: timing does matter. Dev Cell. 2007;13(1):10-13.

51. Cohen ED, Tian Y, Morrisey EE. Wnt signaling: an essential regulator of cardiovascular differentiation, morphogenesis and progenitor self-renewal. Development. 2008;135(5):789798.

52. Cai CL, Liang X, Shi Y, Chu PH, Pfaff SL, Chen J, Evans S. Isl1 identifies a cardiac progenitor population that proliferates prior to differentiation and contributes a majority of cells to the heart. Dev Cell. 2003;5(6):877-889.

53. Huelsken J, Vogel R, Brinkmann V, Erdmann B, Birchmeier C, Birchmeier W. Requirement for beta-catenin in anterior-posterior axis formation in mice. J Cell Biol. 2000;148(3):567-578.

54. Lindsley RC, Gill JG, Kyba M, Murphy TL, Murphy KM. Canonical Wnt signaling is required for development of embryonic stem cell-derived mesoderm. Development. 2006;133(19):37873796.

55. Yamaguchi TP, Takada S, Yoshikawa Y, Wu N, McMahon AP. T (Brachyury) is a direct target of Wnt3a during paraxial mesoderm specification. Genes Dev. 1999;13(24):3185-3190.

56. Vonica A, Gumbiner BM. Zygotic Wnt activity is required for Brachyury expression in the early Xenopus laevis embryo. Dev Biol. 2002;250(1):112-127.

57. Kwon C, Arnold J, Hsiao EC, Taketo MM, Conklin BR, Srivastava D. Canonical Wnt signaling is a positive regulator of mammalian cardiac progenitors. Proc Natl Acad Sci U S A. 2007;104(26):10894-10899.

58. Ueno S WG, Osugi T, Kohn AD, Golob JL, Pabon L, Reinecke H, Moon RT, Murry CE. Biphasic role for Wnt/beta-catenin signaling in cardiac specification in zebrafish and embryonic stem cells. Proc Natl Acad Sci U S A. 2007;104(23):9685-9690.

59. Naito AT, Shiojima I, Akazawa H, Hidaka K, Morisaki T, Kikuchi A, Komuro I. Developmental stage-specific biphasic roles of $\mathrm{Wnt} /$ \{beta\}-catenin signaling in cardiomyogenesis and hematopoiesis. Proc Natl Acad Sci U S A. 2006.

60. Qyang $Y$, Martin-Puig S, Chiravuri M, Chen S, Xu H, Bu L, Jiang X, Lin L, Granger A, Moretti A, Caron L, Wu X, Clarke J, Taketo MM, Laugwitz KL, Moon RT, Gruber P, Evans SM, Ding S, Chien KR. The renewal and differentiation of Is|1+ cardiovascular progenitors are controlled by a Wnt/beta-catenin pathway. Cell Stem Cell. 2007;1(2):165-179. 
61. Kwon C, Qian L, Cheng P, Nigam V, Arnold J, Srivastava D. A regulatory pathway involving Notch1/beta-catenin/Isl1 determines cardiac progenitor cell fate. Nat Cell Biol. 2009;11(8):951-957.

62. MacDonald $\mathrm{BT}$, Tamai $\mathrm{K}, \mathrm{He} \mathrm{X}$. Wnt/beta-catenin signaling: components, mechanisms, and diseases. Dev Cell. 2009;17(1):9-26.

63. Kimelman $\mathrm{D}, \mathrm{Xu} \mathrm{W}$. beta-catenin destruction complex: insights and questions from a structural perspective. Oncogene. 2006;25(57):7482-7491.

64. He X, Semenov M, Tamai K, Zeng X. LDL receptor-related proteins 5 and 6 in $\mathrm{Wnt} /$ betacatenin signaling: arrows point the way. Development. 2004;131(8):1663-1677.

65. Taelman VF, Dobrowolski R, Plouhinec JL, Fuentealba LC, Vorwald PP, Gumper I, Sabatini DD, De Robertis EM. Wnt signaling requires sequestration of glycogen synthase kinase 3 inside multivesicular endosomes. Cell.143(7):1136-1148.

66. Li VS, Ng SS, Boersema PJ, Low TY, Karthaus WR, Gerlach JP, Mohammed S, Heck AJ, Maurice MM, Mahmoudi T, Clevers $\mathrm{H}$. Wht signaling through inhibition of beta-catenin degradation in an intact Axin1 complex. Cell.149(6):1245-1256.

67. Dawson K, Aflaki M, Nattel S. Role of the Wnt-Frizzled system in cardiac pathophysiology: a rapidly developing, poorly understood area with enormous potential. J Physiol.591(Pt 6):1409-1432.

68. Cingolani $\mathrm{OH}$. Cardiac hypertrophy and the Wnt/Frizzled pathway. Hypertension. 2007;49(3):427-428.

69. Ozhan G, Weidinger G. Wnt/beta-catenin signaling in heart regeneration. Cell Regen (Lond).4(1):3.

70. Blankesteijn WM, Essers-Janssen YP, Ulrich MM, Smits JF. Increased expression of a homologue of drosophila tissue polarity gene "frizzled" in left ventricular hypertrophy in the rat, as identified by subtractive hybridization. J Mol Cell Cardiol. 1996;28(5):1187-1191.

71. Haq S, Michael A, Andreucci M, Bhattacharya K, Dotto P, Walters B, Woodgett J, Kilter H, Force T. Stabilization of beta-catenin by a Wnt-independent mechanism regulates cardiomyocyte growth. Proc Natl Acad Sci U S A. 2003;100(8):4610-4615.

72. Malekar P, Hagenmueller M, Anyanwu A, Buss S, Streit MR, Weiss CS, Wolf D, Riffel J, Bauer A, Katus HA, Hardt SE. Wnt signaling is critical for maladaptive cardiac hypertrophy and accelerates myocardial remodeling. Hypertension. 2010;55(4):939-945.

73. Chen L, Wu Q, Guo F, Xia B, Zuo J. Expression of Dishevelled-1 in wound healing after acute myocardial infarction: possible involvement in myofibroblast proliferation and migration. $J$ Cell Mol Med. 2004;8(2):257-264.

74. Oerlemans MI, Goumans MJ, van Middelaar B, Clevers H, Doevendans PA, Sluijter JP. Active Wnt signaling in response to cardiac injury. Basic Res Cardiol. 2010;105(5):631-641.

75. Hagenmueller $M$, Riffel JH, Bernhold E, Fan J, Zhang $M$, Ochs $M$, Steinbeisser $H$, Katus HA, Hardt SE. Dapper-1 Induces Myocardial Remodeling Through Activation of Canonical Wnt Signaling in Cardiomyocytes. Hypertension. 2013.

76. Ma B, Liu B, Cao W, Gao C, Qi Z, Ning Y, Chen YG. The Wnt Signaling Antagonist Dapper1 Accelerates Dishevelled2 Degradation via Promoting Its Ubiquitination and Aggregateinduced Autophagy. J Biol Chem.290(19):12346-12354.

77. Zelarayan LC, Noack C, Sekkali B, Kmecova J, Gehrke C, Renger A, Zafiriou MP, van der Nagel $\mathrm{R}$, Dietz R, de Windt $\mathrm{L}$, Balligand JL, Bergmann MW. Beta-Catenin downregulation attenuates ischemic cardiac remodeling through enhanced resident precursor cell differentiation. Proc Natl Acad Sci U S A. 2008;105(50):19762-19767.

78. Noack C, Zafiriou MP, Schaeffer HJ, Renger A, Pavlova E, Dietz R, Zimmermann WH, Bergmann MW, Zelarayan LC. Krueppel-like factor 15 regulates Wnt/beta-catenin transcription and controls cardiac progenitor cell fate in the postnatal heart. EMBO Mol Med.4(9):992-1007.

79. Baurand A, Zelarayan L, Betney R, Gehrke C, Dunger S, Noack C, Busjahn A, Huelsken J, Taketo MM, Birchmeier W, Dietz R, Bergmann MW. Beta-catenin downregulation is required for adaptive cardiac remodeling. Circ Res. 2007;100(9):1353-1362. 
80. Chen X, Shevtsov SP, Hsich E, Cui L, Haq S, Aronovitz M, Kerkela R, Molkentin JD, Liao R, Salomon RN, Patten R, Force T. The beta-catenin/T-cell factor/lymphocyte enhancer factor signaling pathway is required for normal and stress-induced cardiac hypertrophy. Mol Cell Biol. 2006;26(12):4462-4473.

81. Hirschy A, Croquelois A, Perriard E, Schoenauer R, Agarkova I, Hoerstrup SP, Taketo MM, Pedrazzini T, Perriard JC, Ehler E. Stabilised beta-catenin in postnatal ventricular myocardium leads to dilated cardiomyopathy and premature death. Basic Res Cardiol.105(5):597-608.

82. Nishinaka N, Hongo S, Zhou CJ, Shioda S, Takahashi R, Yamauchi Y, Ohashi T, Ohki T, Nakada $\mathrm{N}$, Takeda F, Takeda M. Identification of the novel developmentally regulated gene, Bdm2, which is highly expressed in fetal rat brain. Brain Res Dev Brain Res. 2000;120(1):57-64.

83. E ZG, Zhang YP, Zhou JH, Wang L. Mini review roles of the bZIP gene family in rice. Genet Mol Res.13(2):3025-3036.

84. Nijhawan A, Jain M, Tyagi AK, Khurana JP. Genomic survey and gene expression analysis of the basic leucine zipper transcription factor family in rice. Plant Physiol. 2008;146(2):333350 .

85. Landschulz WH, Johnson PF, McKnight SL. The leucine zipper: a hypothetical structure common to a new class of DNA binding proteins. Science. 1988;240(4860):1759-1764.

86. Singh $C R$, Watanabe $R$, Zhou $D$, Jennings $M D$, Fukao $A$, Lee $B$, Ikeda $Y$, Chiorini JA, Campbell SG, Ashe MP, Fujiwara T, Wek RC, Pavitt GD, Asano K. Mechanisms of translational regulation by a human elF5-mimic protein. Nucleic Acids Res. 2011;39(19):8314-8328.

87. Matsuguchi T, Chiba N, Bandow K, Kakimoto K, Masuda A, Ohnishi T. JNK activity is essential for Atf4 expression and late-stage osteoblast differentiation. J Bone Miner Res. 2009;24(3):398-410.

88. Wu CH, Sahoo D, Arvanitis C, Bradon N, Dill DL, Felsher DW. Combined analysis of murine and human microarrays and ChIP analysis reveals genes associated with the ability of MYC to maintain tumorigenesis. PLoS Genet. 2008;4(6):e1000090.

89. Koonin EV. Multidomain organization of eukaryotic guanine nucleotide exchange translation initiation factor elF-2B subunits revealed by analysis of conserved sequence motifs. Protein Sci. 1995;4(8):1608-1617.

90. Boesen T, Mohammad SS, Pavitt GD, Andersen GR. Structure of the catalytic fragment of translation initiation factor $2 \mathrm{~B}$ and identification of a critically important catalytic residue. $J$ Biol Chem. 2004;279(11):10584-10592.

91. Sohal DS, Nghiem M, Crackower MA, Witt SA, Kimball TR, Tymitz KM, Penninger JM, Molkentin JD. Temporally regulated and tissue-specific gene manipulations in the adult and embryonic heart using a tamoxifen-inducible Cre protein. Circ.Res. 2001;89(1):20-25.

92. Graham FL, Smiley J, Russell WC, Nairn R. Characteristics of a human cell line transformed by DNA from human adenovirus type 5. J Gen Virol. 1977;36(1):59-74.

93. Becker AM, Rubart M, Field LJ. Inducing Embryonic Stem Cells to Become Cardiomyocytes. In: Cohen IS, Gaudette GR, eds. Stem Cell Biology and Regenerative Medicine. 11 ed: Humana Press; 2011.

94. Jaspers $M H$, Nolde $K$, Behr $M$, Joo SH, Plessmann U, Nikolov $M$, Urlaub $H$, Schuh R. The claudin Megatrachea protein complex. J Biol Chem.287(44):36756-36765.

95. Nikolov M, Stutzer A, Mosch K, Krasauskas A, Soeroes S, Stark H, Urlaub H, Fischle W. Chromatin affinity purification and quantitative mass spectrometry defining the interactome of histone modification patterns. Mol Cell Proteomics.10(11):M110 005371.

96. Zafiriou MP, Noack C, Unsold B, Didie M, Pavlova E, Fischer HJ, Reichardt HM, Bergmann MW, El-Armouche A, Zimmermann WH, Zelarayan LC. Erythropoietin responsive cardiomyogenic cells contribute to heart repair post myocardial infarction. Stem Cells. 2014;32(9):2480-2491.

97. Pilbrow AP, Ellmers L, Black MA, Moravec CS, Sweet WE, Troughton RW, Richards AM, Frampton CM, Cameron VA. Genomic selection of reference genes for real-time PCR in human myocardium. BMC Med Genomics. 2008;1:64. 
98. Everaert BR, Boulet GA, Timmermans JP, Vrints CJ. Importance of suitable reference gene selection for quantitative real-time PCR: special reference to mouse myocardial infarction studies. PLoS One.6(8):e23793.

99. Haggart CR, Ames EG, Lee JK, Holmes JW. Effects of stretch and shortening on gene expression in intact myocardium. Physiol Genomics.46(2):57-65.

100. Zelarayan LC, Vendrell V, Alvarez Y, Dominguez-Frutos E, Theil T, Alonso MT, Maconochie M, Schimmang T. Differential requirements for FGF3, FGF8 and FGF10 during inner ear development. Dev Biol. 2007;308(2):379-391.

101. Skarnes WC, Rosen B, West AP, Koutsourakis $M$, Bushell $W$, lyer $V$, Mujica AO, Thomas $M$, Harrow J, Cox T, Jackson D, Severin J, Biggs P, Fu J, Nefedov M, de Jong PJ, Stewart AF, Bradley A. A conditional knockout resource for the genome-wide study of mouse gene function. Nature. 2011;474(7351):337-342.

102. deAlmeida AC, van Oort RJ, Wehrens XH. Transverse aortic constriction in mice. J Vis Exp. (38).

103. Yoshimura $M$, Yasue $H$, Ogawa $H$. Pathophysiological significance and clinical application of ANP and BNP in patients with heart failure. Can J Physiol Pharmacol. 2001;79(8):730-735.

104. Boheler KR, Czyz J, Tweedie D, Yang HT, Anisimov SV, Wobus AM. Differentiation of pluripotent embryonic stem cells into cardiomyocytes. Circ Res. 2002;91(3):189-201.

105. Aisagbonhi O, Rai M, Ryzhov S, Atria N, Feoktistov I, Hatzopoulos AK. Experimental myocardial infarction triggers canonical Wnt signaling and endothelial-to-mesenchymal transition. Dis Model Mech.4(4):469-483.

106. Duan J, Gherghe C, Liu D, Hamlett E, Srikantha L, Rodgers L, Regan JN, Rojas M, Willis M, Leask A, Majesky M, Deb A. Wnt1/betacatenin injury response activates the epicardium and cardiac fibroblasts to promote cardiac repair. EMBO J.31(2):429-442.

107. Haq S, Choukroun G, Lim H, Tymitz KM, del Monte F, Gwathmey J, Grazette L, Michael A, Hajjar R, Force T, Molkentin JD. Differential activation of signal transduction pathways in human hearts with hypertrophy versus advanced heart failure. Circulation. 2001;103(5):670677.

108. Takahashi R, Hongo S, In Ishinaka N, Ohashi T, Yamauchi Y, Ohki T, Nakada N, Takeda F, Takeda M. Molecular Properties and Developmental Expression of a Novel Protein, BDM2, in Rat Brain. Showa Univ J Med Sc. 2000;12(2):107-117.

109. Hendriksen J, Jansen M, Brown CM, van der Velde H, van Ham M, Galjart N, Offerhaus GJ, Fagotto F, Fornerod M. Plasma membrane recruitment of dephosphorylated beta-catenin upon activation of the Wnt pathway. J Cell Sci. 2008;121(Pt 11):1793-1802.

110. Dong Z, Liu Z, Cui P, Pincheira R, Yang Y, Liu J, Zhang JT. Role of elF3a in regulating cell cycle progression. Exp Cell Res. 2009;315(11):1889-1894.

111. Bertola LD, Ott EB, Griepsma S, Vonk FJ, Bagowski CP. Developmental expression of the alpha-skeletal actin gene. BMC Evol Biol. 2008;8:166.

112. Brade T, Pane LS, Moretti A, Chien KR, Laugwitz KL. Embryonic heart progenitors and cardiogenesis. Cold Spring Harb Perspect Med.3(10):a013847.

113. Li F, Wang X, Capasso JM, Gerdes AM. Rapid transition of cardiac myocytes from hyperplasia to hypertrophy during postnatal development. J Mol Cell Cardiol. 1996;28(8):1737-1746.

114. Schoger E. Characterization of Basic Leucine Zipper and W2 Domain-Containing Protein 2 (BZW2) Expression. Göttingen: Pharmacology, Georg-August-University; 2015.

115. Lustig B, Jerchow B, Sachs $M$, Weiler S, Pietsch $T$, Karsten $U$, van de Wetering $M$, Clevers $H$, Schlag PM, Birchmeier W, Behrens J. Negative feedback loop of Wnt signaling through upregulation of conductin/axin2 in colorectal and liver tumors. Mol Cell Biol. 2002;22(4):1184-1193.

116. Roose J, Huls G, van Beest M, Moerer P, van der Horn K, Goldschmeding R, Logtenberg T, Clevers $\mathrm{H}$. Synergy between tumor suppressor APC and the beta-catenin-Tcf4 target Tcf1. Science. 1999;285(5435):1923-1926. 
117. Niida A, Hiroko T, Kasai M, Furukawa Y, Nakamura Y, Suzuki Y, Sugano S, Akiyama T. DKK1, a negative regulator of Wnt signaling, is a target of the beta-catenin/TCF pathway. Oncogene. 2004;23(52):8520-8526.

118. Masuelli L, Bei R, Sacchetti P, Scappaticci I, Francalanci P, Albonici L, Coletti A, Palumbo C, Minieri M, Fiaccavento R, Carotenuto F, Fantini C, Carosella L, Modesti A, Di Nardo P. Betacatenin accumulates in intercalated disks of hypertrophic cardiomyopathic hearts. Cardiovasc Res. 2003;60(2):376-387. 


\section{Apendix}

BZW2 expressing plasmid pcDNA3.1 $1^{+}$-Flag-Bzw2-Neo includes Flag tagged murine Bzw2 transcript (mBzw2) under $C M V$ promoter as well as ampicillin $(A m p R)$ and neomycin resistance $(\mathrm{NeoR})$ genes. pUC ori: origin of replication. pcDNA3. $1^{+}$-FlagBzw2-Hygro plasmid includes hygromycin resistance gene instead of NeoR.

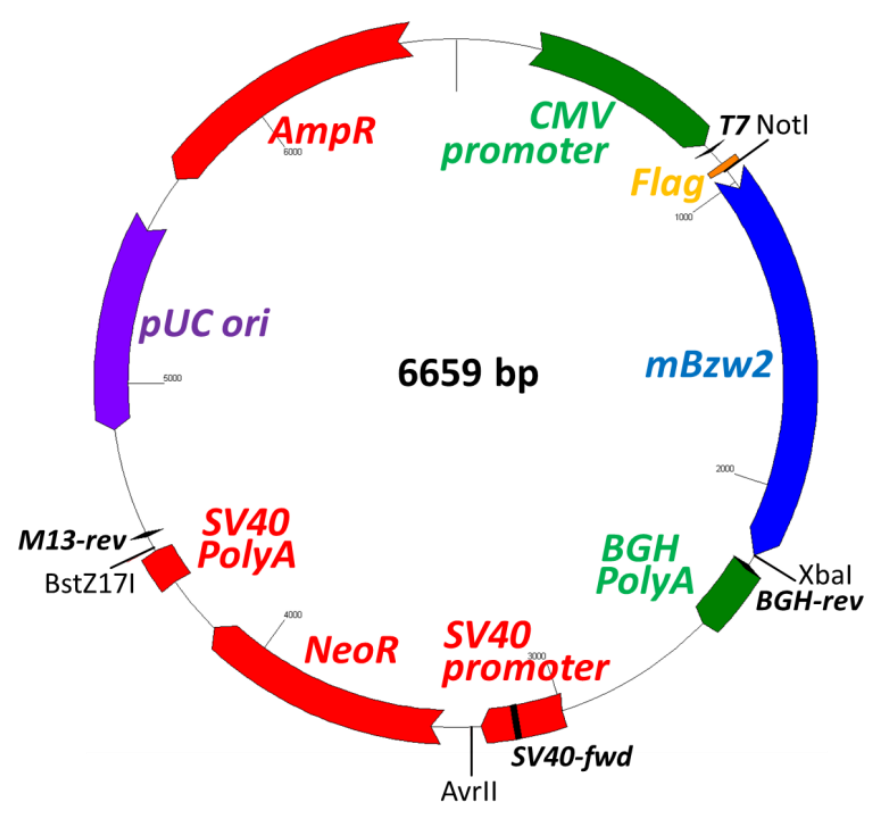

pcDNA3.1+-Flag-Bzw2-Neo

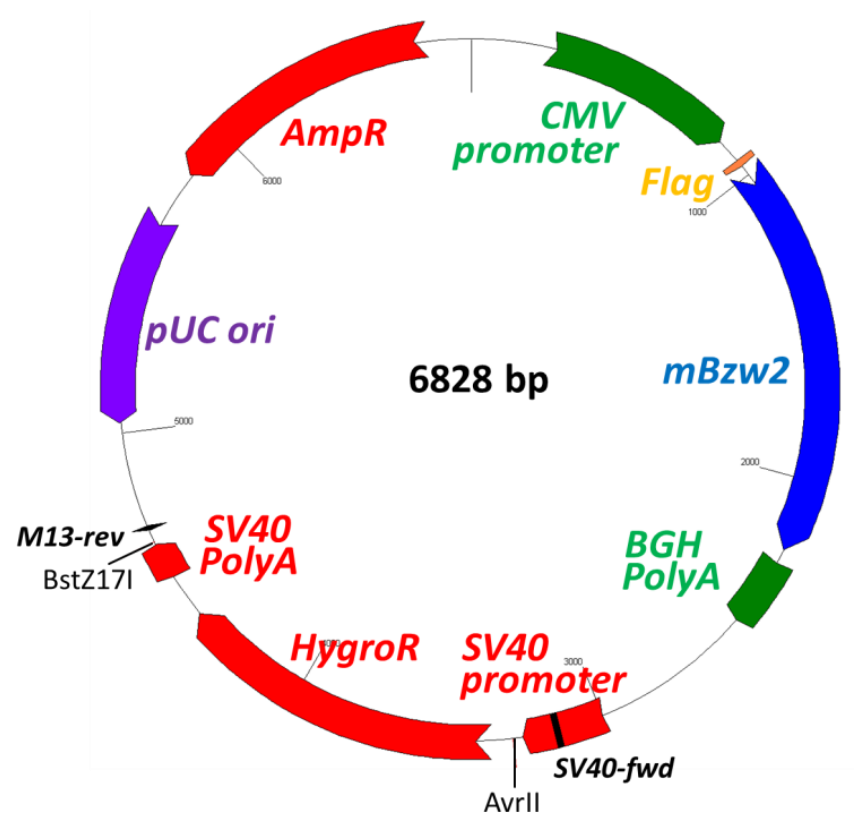

pcDNA3.1+-Flag-Bzw2-Hygro 
Both following modified BZW2 expressing plasmids includes puromycin resistance gene (PuroR). Furthermore, pcDNA3.1 $1^{+}$-Flag-Bzw2-Puro-Orange includes an orange fluorescent protein monomer gene (mOrange). IRES: internal ribosomal entry site.

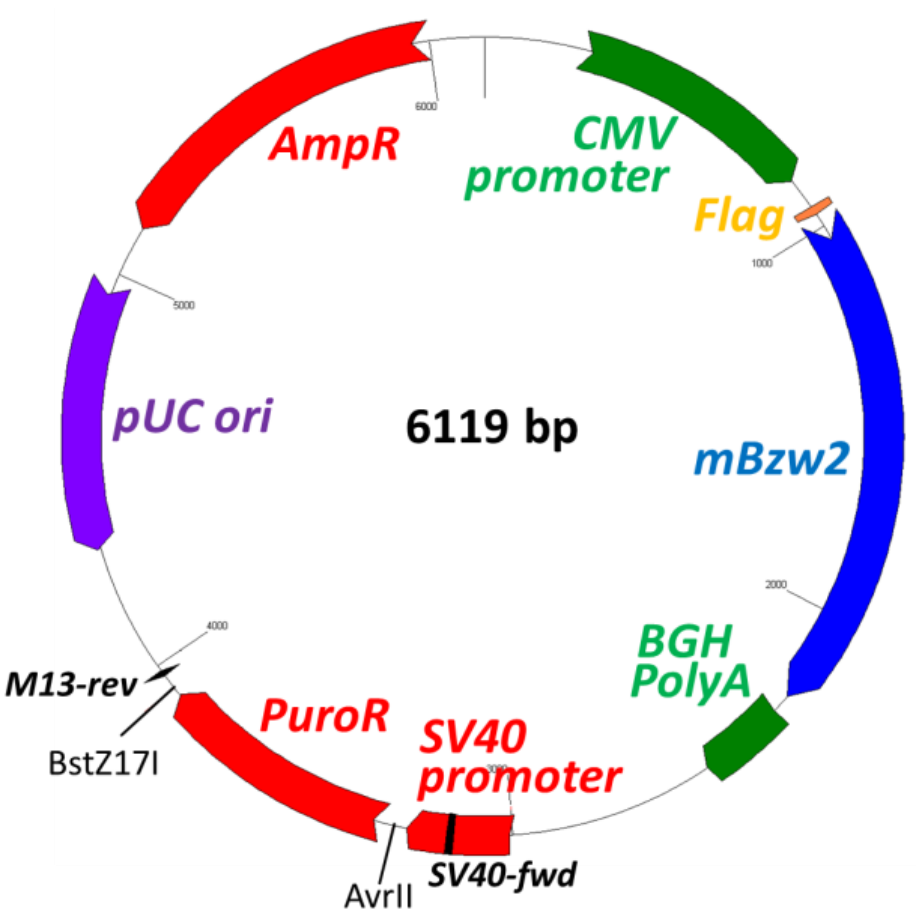

pcDNA3.1+-Flag-Bzw2-Puro

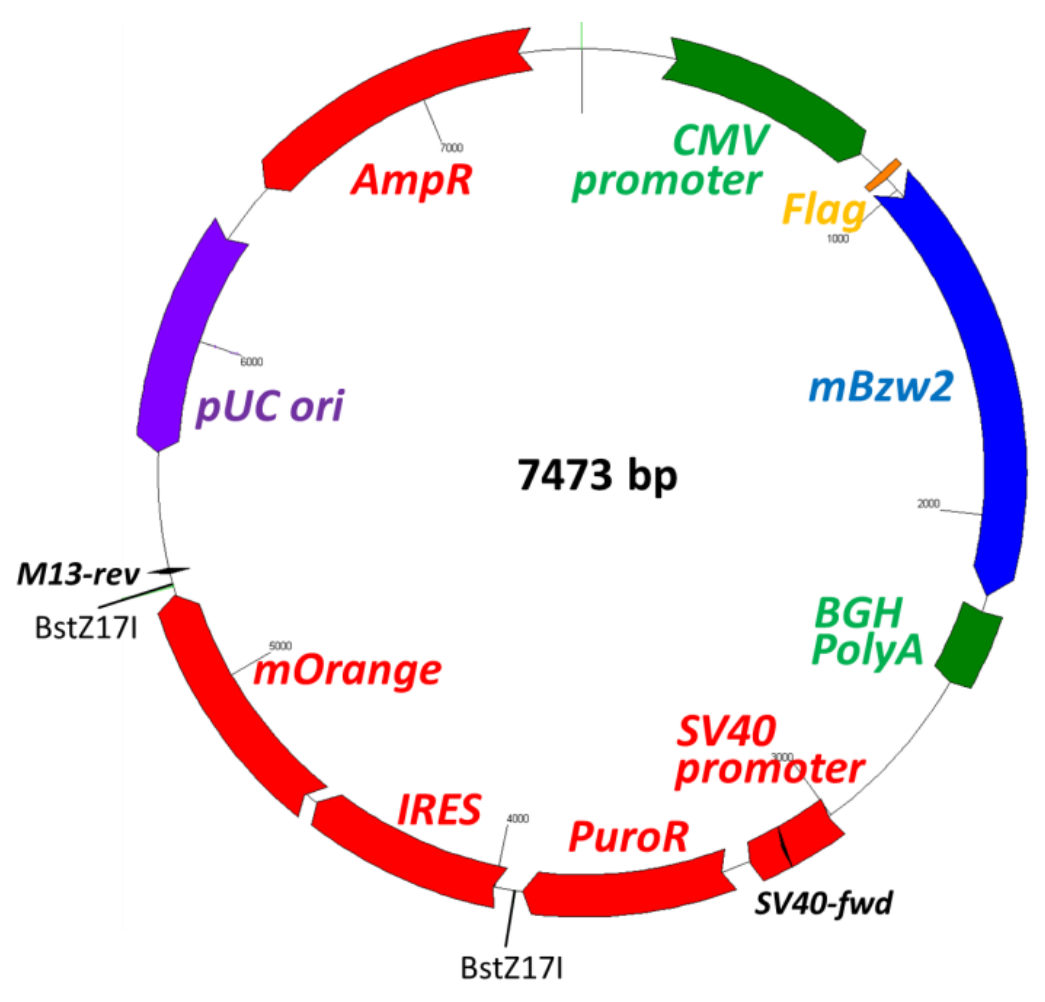

pcDNA3.1 $1^{+}$-Flag-Bzw2-Puro-Orange 
Two following plasmids are modified from pcDNA3.1 ${ }^{+}-$Flag-Bzw2-Neo (pcDNA3. $1^{+}-$ Flag-Bzw2-FL) and include Flag tagged truncated murine Bzw2 transcript forms. In $m B Z W 2-\Delta C$ the $C$ terminus is missing, in $m B z w 2-\Delta N$ the $\mathrm{N}$ terminus.

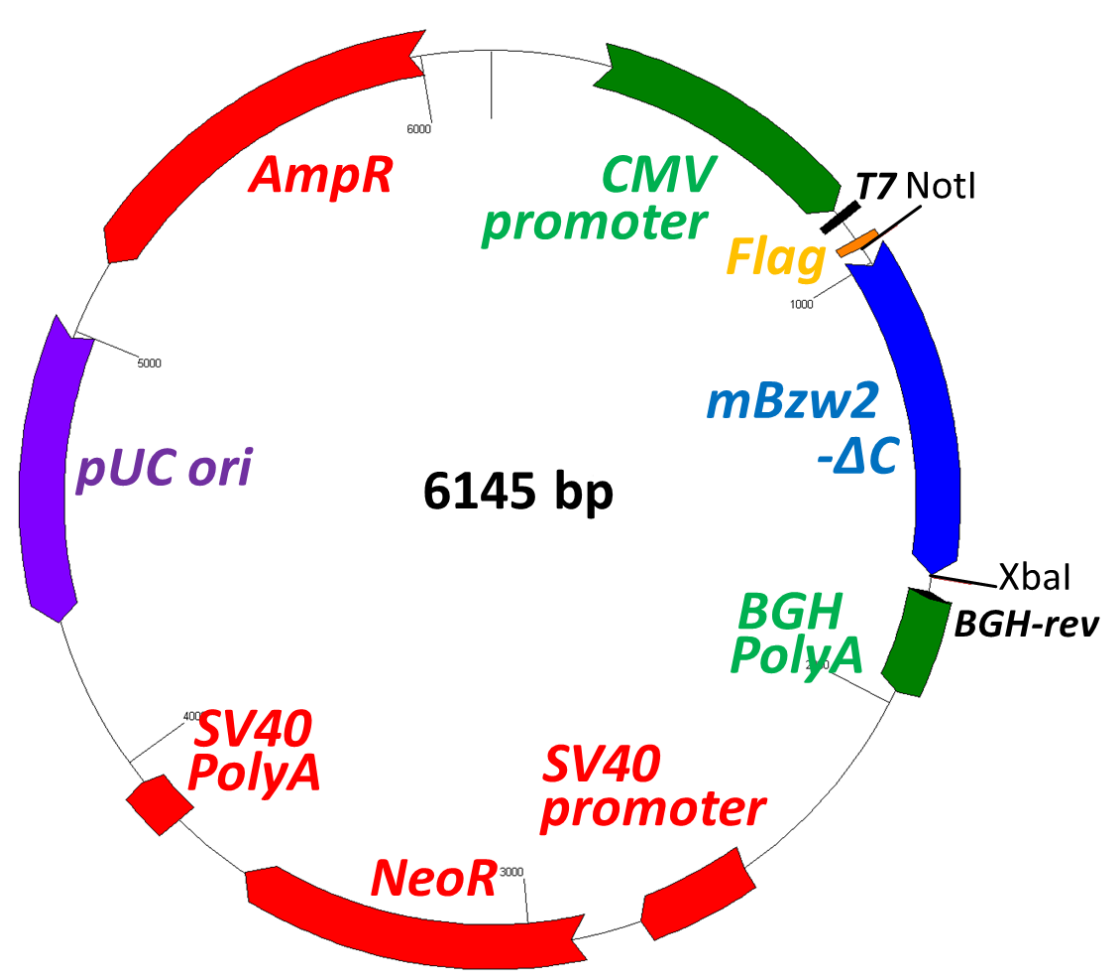

pcDNA3. $1^{+}-$Flag -Bzw2- $\Delta C$

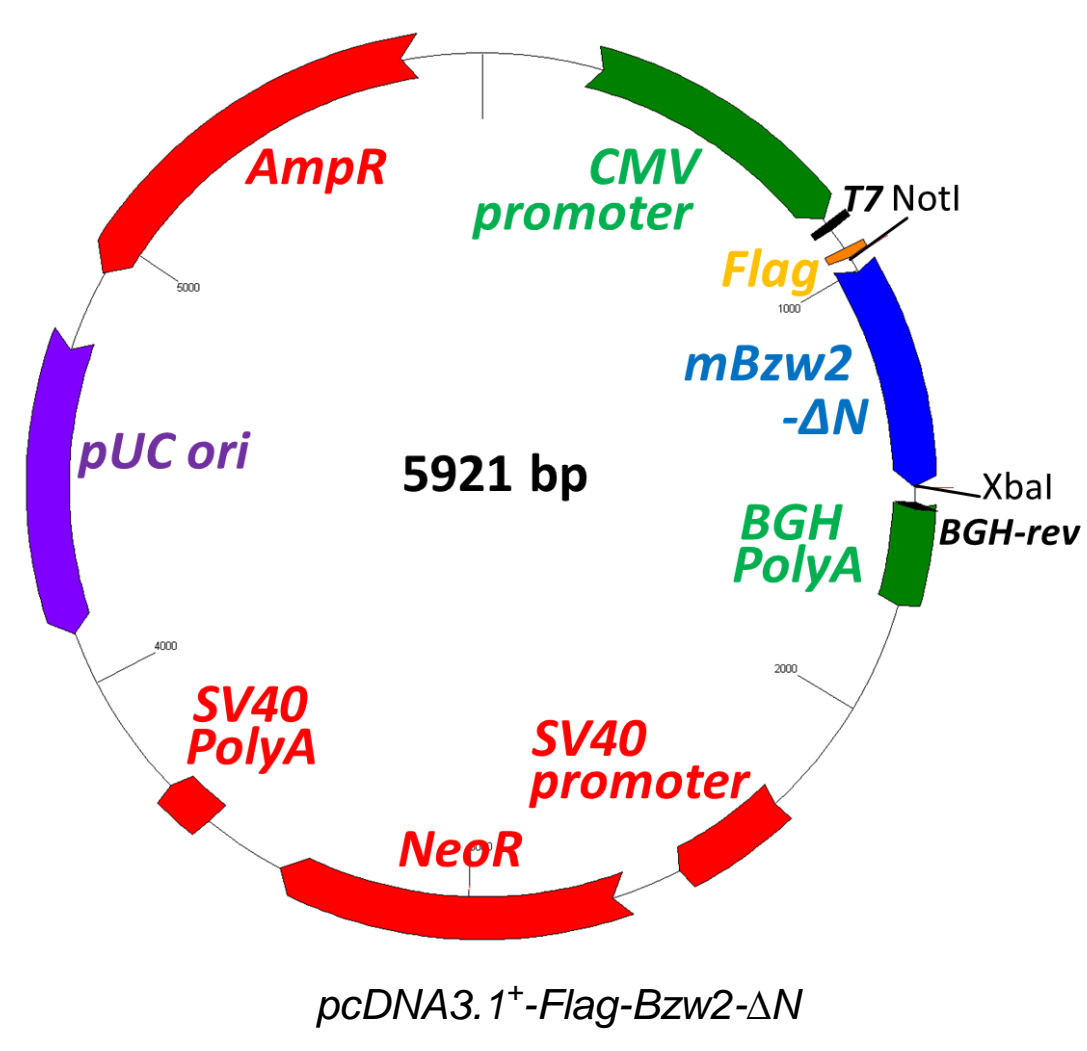

109 
Schematic view of the Bzw2 construct. $\triangle \mathrm{C}$ and $\Delta \mathrm{N}$ : truncated forms; ZIP, bZIP \& W2: protein domains; AB1: antibody (Q91VK1) for staining; AB2: antibody (HPA022813) for western blot; ex2-12: exons 2-12.

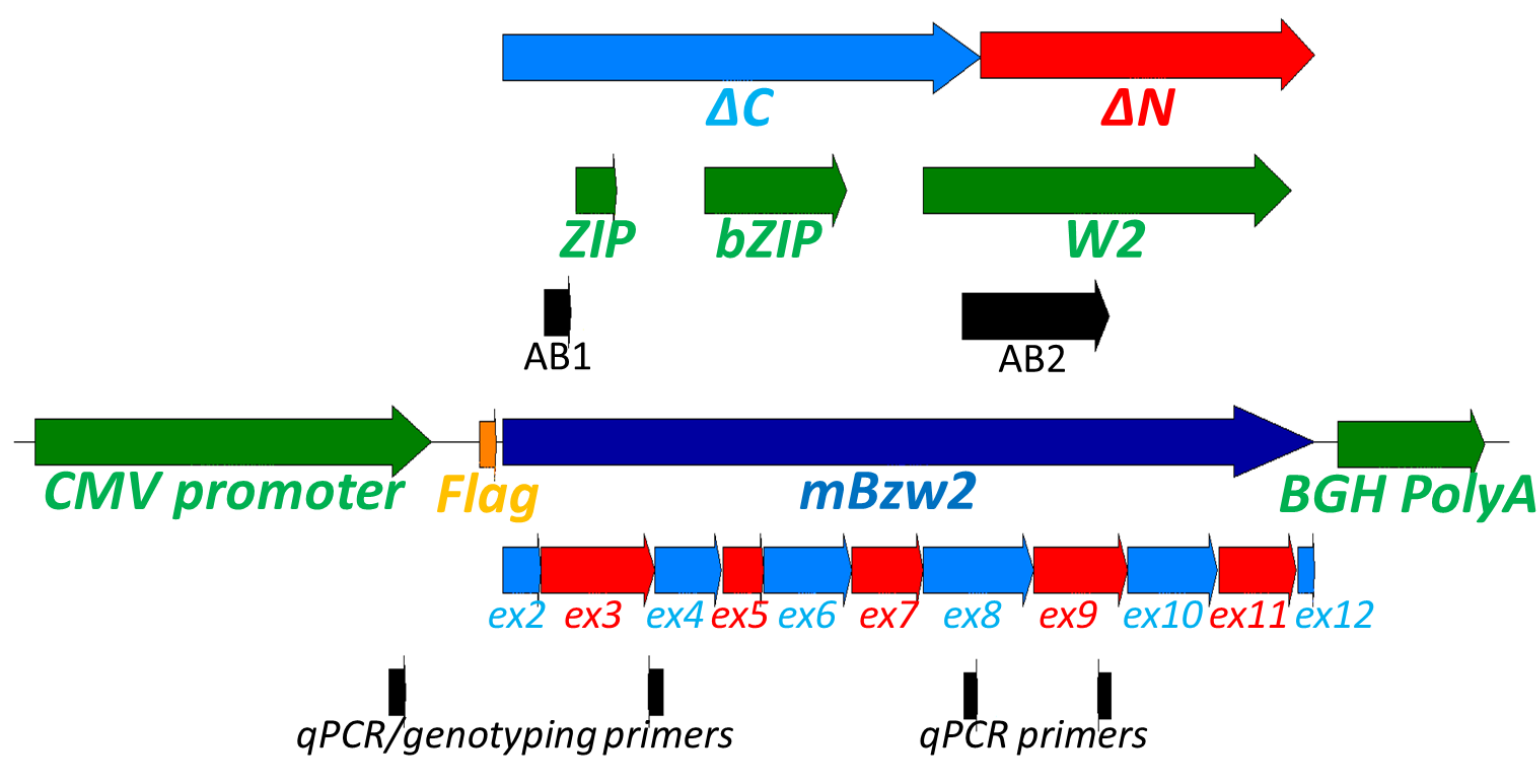




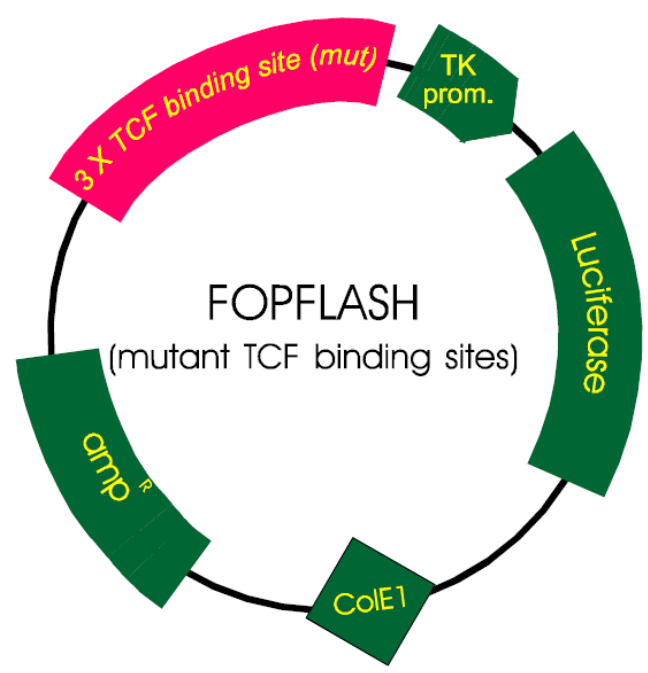

pFOPflash (Upstate)

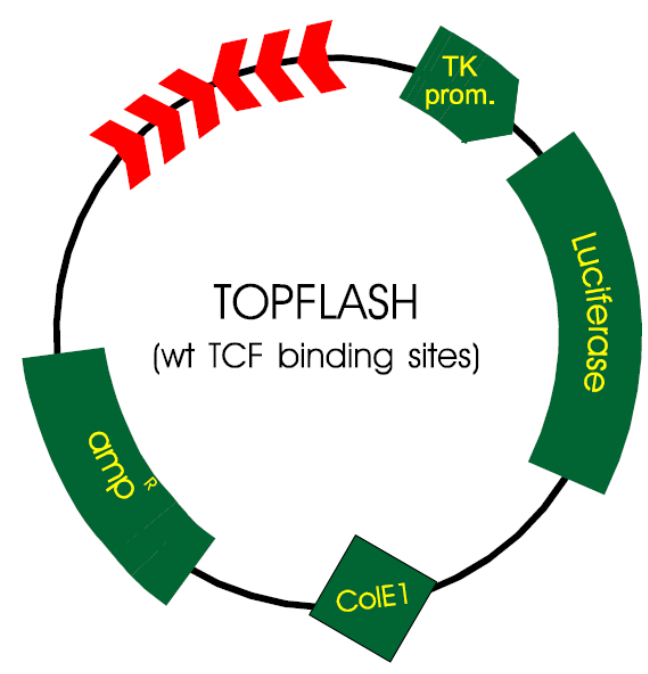

pTOPflash (Upstate)

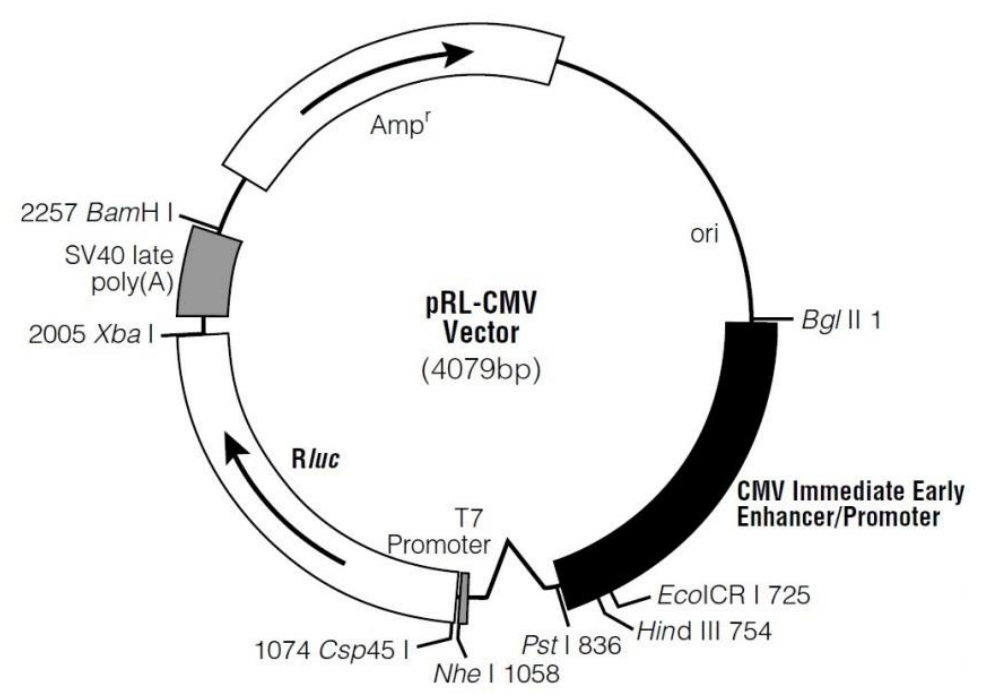

pRL-CMV (Promega) 


\begin{abstract}
$-1745 b p$
AACGGTACCTCTTTTCCAACCCAGTGTCCATCACGTGAAACAGGCGGTGCCACTGATGAAGGGTCTGATGTTGT AACTATTGGCACCTCTTAAGGACTTAGACTTACTCCTCATCTTCTCAGGCTGGCATCCTTATAT CTCAAAG CACTT CCTTTCACTAGATGAAGTTGTTAGAAACTCGGCGCCGGTGGCACAATCGACCGACTGTGTTTCTGCATCTGTTG हाTा TGCAGTTACTTाTACTTCGTCAGAGCGATTGGTGAGAAAGGAAATTGTGGTTTGGTTGGTTTGGT GGCTGTGGGGATGGAGCATGAGACCAAGATCGTGCCAGGCAAGTGTTCTACCACCAAGGAATAGCCCCAGCC CTAGGAAGGAACATTTATTCTGTGAAGTGACATATTTGTITTTCATATTCCTAATGACCCTTTTAAACTTCATGA AGTAATAATTGCTTGGGTAACCCCTTTTGTAATTTTTATTGATTCATTCATTTTGAGACAAGGTCTCACTTAGT TGCCAAGGCTGGCCTAGAACTTTTTTCTGTATCCCAAGCAGACTTAAACTGGAAATCCTCCTGCCTCAGCCTCCC AAGTAGCTGGGATTATAGGCCTGTGCCACCAAGATTAGCTTCAAGTCACACTTTITTAAATGGTAGATGATAAA TTCAGTAGCCTGTTTGAATAACATGTACTGTCTTACTTCGCCTCTATAACTTAAGCAGTCTAGGTATTTTTGGTAT ATATTCATGCCAACAGGTTATTCATTGTTAAAAGGTCCTAAAGAATACATTTTATGTATGAATATTTAATTTTTC TTACATATGAGAATCACATATTTACCCTCTTTTTAGGCAAGTAAGTTACACTTTACATTCTTTAATAGAATTITTA CCTATTGACAACTGAACATCATCCCATGTTAGCATAGCTGCTTACCAGGTAAGCATTTAAATGCTTATACGCTGC TTAATTITTAGGCCTTAAAAATGGTCCTAGATTITTAGGTCTTAGATCAATCAGATGACAATAAAATGACTGGTC CTGAAGACAGAAGGAGCAGAACACTAGTCAACACACACAGGAAGCAGGGGACATTTCTATCAGACAGGAAGT CCTCTGCAGAGGAGGCATGAGAGTATGCACAGAGAAAGGAACAGGATCAGCTGGGGGAGTCGACCTAGAAG AAGCCAGTATGTGGCCTCAGAAACTAGATTTCATCTTGTCTITTGGAGCAAAAAGCACAAGTCAGTGAGGTTG CAACGCAATGCATGATGGGGAAAATGGGGTCTTGACATAACTCCCATCATCAGAGCTAGAAGCAGAACCTGC GATACAGCAGAGTTAGATCTAATTCATCCTTTCCTGAGGCTGCCAATGTTCTATGCAGTGGCTAAGTTGTGATT TACGTAACTAAATGCGTGTGGAATGCTACAACTGTATTTCACATACATGTATGTTTGCCTTGGTGTGTGAGTGC AGCTGTAGGACAGCAGGGGGAAAGTAATTGTTAGACTGCACGGTATACACATGTAAGTATTCACAGATATTCA CCATATACTCCCCAAAAGTGTGGCATGAAGTCTAACTTCTGCCAACGTTGATGTGGGTGGTTGTTTCCCAA TIGCCAAAAGTGGTTCTTGGTAAACTTTCACATGTTGCCAGTCCAGTAGTGTAAAAGCCCTATTCCCACATGGTT GGGGTTGACCATGTACGCTAGCAAA
\end{abstract}

The putative Bzw2 promoter sequence (1745 bp upstream the Bzw2 start codon) which was cloned into pGL4.10 vector. Color code: three TCF/LEF putative consensus sequences (blue), Kpnl recognition site (light blue), Nhel recognition site (green). 